120 72

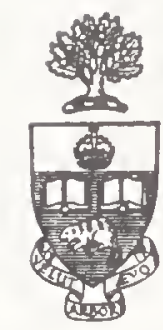

Library

of the

University of Toronto 


$$
-4 t_{\mathrm{con} / \mathrm{p}}
$$




$$
\frac{5}{2} \frac{67}{2} \quad(v-1-)
$$




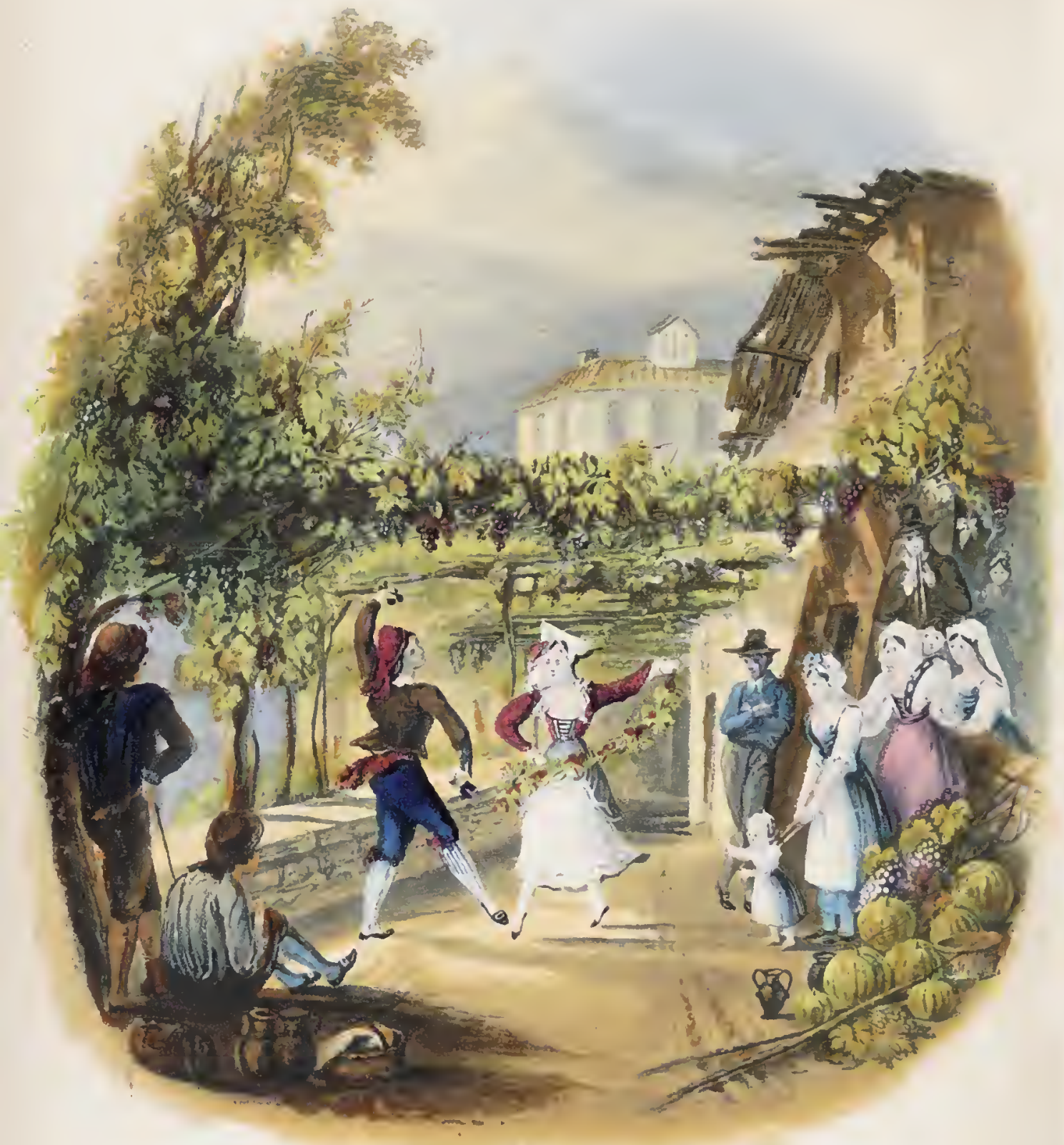




\section{AU'TMN.}

R(OBHRT MI'UIE.

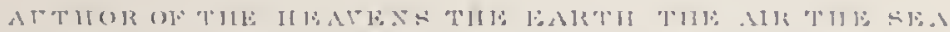

Nir.s.

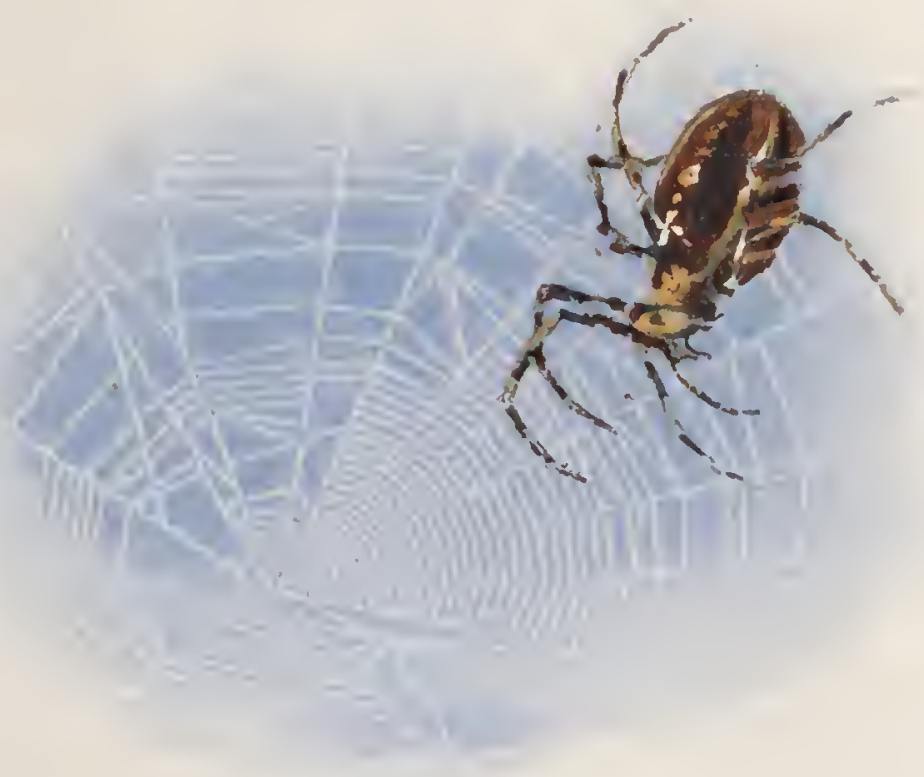

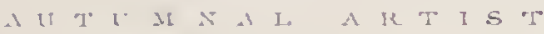

I. ( ) II) ( ) N

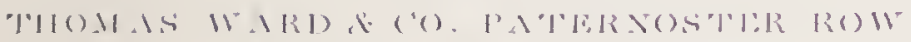


Digitized by the Internet Archive in 2018 with funding from University of Toronto

https://archive.org/details/autumnorcausesap00mudi 


\section{AU'TUMN ;}

OR,

THE CA USES, APPEARA NCES,

A N D EFFECTS

OF THE

SEASONAL DECAY AND DECOMPOSITION

OF NATURE.

BY R. M U D I E,

ATHOR OL "THE HEAVENS," "THE EARTH," ETC.

THHD THOUSAND.

LONDON :

TJOMAS WARD \& CO.

27, F-1TERNOSTER ROW. 
LONDON :

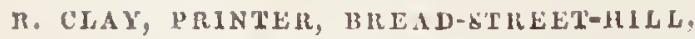
DOCTORS' COMMONS. 


\section{P REF A CE.}

IT is, perhaps, more difficult to define the time, and explain, in popular language, the phenomena of Antumn and their causes, than it is in the case of any other season of the varied year. This is, in part, owing to the indefinite occurrence of Autumnal action, but more so to its compound and very complicated nature.

The two great parts of the compound are these: First, Autumn takes up the new or successional race, (we speak of the vegetable kingdom, as the one which must abide the seasons, ) - and whether it consists in seed, in tuber, in bulb, or in any thing else, carries it onward to such maturity as that it shall be safe during the winter. Secondly, Autumn reduces to an elementary state, or prepares for reducing to that state, all that portion of the vegetable kingdom which has performed its function for the year, and is not to be stimulated into new action at any future time.

The first of these may be considered as a continuation of the summer-part of the regular course of the vegetative action of the year,-of that for which the spring is a preparation, and which by the act of summer is 
transferred from the present race to the succeeding one. Summer terminates with the simple elementary or primal act; and then this first, or conserving labour of the Autumn, is the nursing of the germ until it is so far matured as to be able to act for itself, as an independent being, when the proper stimuli are applied to it. This nursing is gxeatly promoted, and indeed chiefly performed by that portion of the summer heat which, so to speak, overlays the Autumn, and which, from there being less evaporation from plants than when they are in active growth, is not unfrequently more intense than during the summer, properly so called. It is more variable, however, upon the general principle, that whatever is easily heated, is cooled with equal ease. By these alternations of heat and cold in the Autumn, the seed or other germ is tempered for endurance as it is ripened; and when its action ceases, by its being fully ripe, it can bear more than in any other stage of its existence. It is in the surplus of this above what is necessary for the succession, that man finds the harvest of the year, and in that harvest many of the wild animals also partake. The parent plant, and the influences of the earth and the atmosphere, are the only agents necessary for the operation of ripening; and thus, though this is by far the more immediately important work of the season, in a practical point of view, the knowledge of no new agent is required in order to understand how it is performed. For this reason, and also from its being the view of the season which has been chiefly taken by writers-so as to leave little new to be said in the description of its phenomena-I have not 
treated it to much extent, or with any minuteness of detail.

With the other, or decomposing function, or action of Autumn, the case is very different. Those agencies which bring vegetation to the maturity of the year, have not in themselves any inherent power of operating its own decay. An animal does not die by the action of the living principle in it, neither does a plant or leaf wither by the action of growth. Death, in both cases, and in every case in which it can take place, is the opposite or antagonist of life; and that any power could be its own antagonist, would be a contradiction in terms. It is true, singular as the truth may appear to those who have not thought of it, that death ministers to life during the whole period of its continuance; and were it not for the resistance of this antagonist power, no kind of life could have its action brought up to such a degree as to be perceptible at all. What we call death is, therefore, as viewed in the general system of nature, a mere turning of the balance,-previously, life has preponderated, but now the scale of life kicks the beam, never again, in the case of the individual, to acquire the mastery.

In this view of it, and as applied to the display of life in material forms (which is the only true one), death is merely a phantom, - a general term : expressive of all agencies, and every agency, by which the functions of life in an individual plant or an individual animal are made permanently to cease. But those agencies, which constitute what we call death, are always distinct from and opposed to the principle of life, and neither 
plant nor animal can of its own living action terminate its own living existence, any more than it can of itself begin to exist. Opposite, indeed, as these two at first sight seem, they stand upon an equality; and, though the secondary agencies and the instruments by which they are brought about are very different, yet the primary agent in both cases is the same; and thus we can understand the force of the cxpression, "The issues of life and death are in the hand of the Almighty alone."

In the case of the annual death of nature with the season, and indeed in the death of all material beings, the withdrawal of the means of life is sufficient; and upon the summer vegetation, the diminishing of the action of moisture or of heat, or the disturbance of the balance of the two, is quite adequate to the purpose; and thus the Autumnal death of seasonal nature requires no new agent, and the explanation of it makes but little demand on the resources of philosophy.

But there is another function of Autumn to be performed; and that is the disposing of the part of seasonal nature which is dead; and this is a beginning, and as such, requires specific agents, varied according to the nature of that which is to be performed. The substance of all that dies, is organic; and as there is no more inherent power of self-destruction in organization than there is in life, agents for this purpose must be found. It is in these agents and their modes of action that the peculiar characteristics of Autumn lie, and they of course vary with the climates and characters of different places.

Agreeable with this view of the matter, the grand 
law of nature, attempted to be investigated andillustrated in this volume, is the law of Autumnal decay and decomposition; and I believe I may venture to say, that this law has never hitlerto been made the principal subject of a specific investigation, although it is one of the most important in the whole economy of nature,one, but for which, the spring showers would weep, and the summer breezes mourn, over a ruined earth, desosolate once and for ever.

In order to bring home the general principles to the reader, with as much of practical usefulness and of the function of artificial memory as possible, I have selected from the mighty multitude of the Autumnal host, those cuhorts, which always stand ready to invade the fields of the husbandman, when any thing is untoward in the state of his crops. I have laboured to explain the rusts, the smuts, the ergots, the mildews, the moulds, and all the other small but irresistible destroyers which may invade the staff of life in every stage of its progress, from the first rudiment of the ear, to the loaf set on the table. I have also endeavoured to point out some of the baneful effects of those little plants upon human life, not without hopes that my remarks, few and simple as they are will not be wholly useless to families.

Besides these, there are many classes of Autumnal agents, and modes and phenomena of Autumnal action, which would claim attention in a work fully explanatory of the season. Such a work, done justice to in all its parts, would, however, extend to many volumes. Some of them connect the Autumn with the winter, 
viii

PREFACE.

are wintry in their causes, and will be noticed in the volume on that season; while others must be omitted, as too abstruse in their nature, or too vague in the information we have of them, for being fit subjects for popular disquisition.

More I need hardly write by way of preface, the size of the book required the utmost condensation; and, for further particulars, the reader is most respectfully referred to its pages.

ROBERT MUDIE.

Grove Cottage, Chelsea, August, 1837. 


\section{ANALYSIS OF THE CONTENTS.}

\section{CHAPTER I.}

GENERAL DEPINITION AND OPERATIONS OF THE SEASON.

Great interest of Autumn...Co-operative power...Dangers of the crop...Surplus, and its consumers...Autumn, indefinite in timc... Two kinds of Autumnal action...Dispersion of sceds...The two parts of natural supplies...Illustration from the air in breathing... Matter never idle... Seasonal and periodical decay...The harvest of knowledge...Autumnal gloom... Oneness of nature in its successions...Autumnal agents.....................................pp. 1-33

\section{CHAPTER II.}

AUTUMN IN DIFFERENT LATITUDES.

Animals in Autumn...Autumnal conservation...Climatal Autumn... Equatorial regions...Regions of least Autumual action...Tropical animals and plants...Organic and inorganic action...Blunders of "the would-be wise"... Importance of the principle of lifc... Functions of the living membrane...Young and old leaves...Contrast of plains and mountains... Autumn on tropical mountains... Formation of glaciers... Relations of power and time...The best climates, and their changes in latitude... Autumn in various regions... Isothermal lines................................pp. 34-76

\section{CHAPTER III.}

AUTUMNAL DECOMPOSITIONS, AND THE AGENTS AND MEANS BY WHICH THEY ARE PERFORMED.

Tropical destroyers...Polar decompositions...Agents and action in different climates...Seasonal destroyers, and their modes of 
appearing...Race ministering to race... Energy of small life... Power of endurance and of muscular action in animals which lave no internal bones ... Plants and animals compared... Their resem. blances and distinctions... Idea of sensation...Structure of vertebrata...Joints, and their mechanism...the hand...Grand purpose in nature... Man .pp. $77-118$

\section{CHAPTER IV.}

THE ARMIES OF AUTUMN.

'College sophs"...Duty of an author...Functions of the Autumnal host...Vegetables properly Autumnal...Fungi, and their germs... Fungous growths...Gall insects...Fungous substances... Physiological mistakes, and their consequences...Fairy rings...Their appearances ... Their causes...Their duration ... "Marion," the dameschool keeper...Knowledge broad but not deep...Algæ...Confervæ ...Red snow... Showers of blood... Gory dew... Aërial plants...Plants in their simplest forms... Elementary states of animals and regetables...Reflections... Sea-weeds...Mosses................pp. 119-167

\section{CHAPTER V.}

SHORT NOTICES OF SOME PLANTS APPARENTLY AUTUMNAL-THE BISSIN正.

Office of the fungi... Of the byssinæ...Difference of these..." Peatmoss"... Luminous plants ... Superstitions ... Natural religion ... Plants in mines ... Plants in cellars ... Bead-moulds ... Nature of the byssinæ... Their proper offices... Importance of general views... Philosophic errors, and errors of fact... Seasons of the byssinæ... Our ignorance of them...Useful lesson ..................pp. 168-193

\section{CHAPTER VI.}

NOTES ON SOME OF THE MORE INTERESTING FUNGI.

Popular names of the fungi...Allusion to "fairies"...Blights, their numbers and fertility... They are nearly elemental... They are 
everywhere... In what they differ from the small byssi... Fungi on corn ... Rubigo ... Superstitions respecting blights ... Dust-blight... Smut in eorn...Causes of smut...Canker-brand...Vis medicutrix nalure...Poison of putridity...Grand purpose of the fungi... Growth of copses...........................................pp . 193-224

\section{CHAPTER VII.}

PRINCIPAL FUNGI BY WIICII GRAIN PLANTS ARE INFESTED.

linugi upon corn...Summer and winter ones...Particular advantages of Britain...Ergot of rye : a powerful medieine : a deadly poison : terrible disease produced by it...Supposed cases in England... Raphania...Cases in France...Cause and prevcution of ergot... The potato, and its advantages...Proper situations for it...Its native loeality...Analogy of animals and vegetables...The potato in Ireland...Contrast of grain and potatoes... Over culture of the potato p1). 225-255

\section{CHAPTER VIII.}

MISCELLANEOUS APPEARANCES IN AUTUMN.

Mildew on grain... May come at all stages... Its poisonous qualities... Cruel frauds by bakers, especially on the poor... The Hammersmith case...The bread poisonous, and not the fungus... Mildew on canvas... Rusty bacon a poison... Italian cheese... Charaeteristie fungi... Truffles...Phalli...Force of vegctation in fungi... Dry rots, with remarks on patent medicincs for bad timbcr...Proper vicw of the case... Concluding remarks on the season .p). 256-2Ss 


\section{ILLUSTRATIONS.}

No subject whatever can, by possibility, be chosen, so as to represent the general character of Autumn in all places and at all the times when Autumnal action occurs; and, therefore, we have selected one of the blithest of its scenes, as the subject of our frontispiece,-namely, the vintage under the sunny skies of Lombardy, in the vale of Aosta. The vignette is the large Garden Spider, Epeira diadema, which comes not till the Autumn; but, at that season, its labours are cqually curious and characteristic. In both subjects, we feel confident that our readers will agree with us that the execution improves as the seasors advance. 


\section{A UTUMN.}

\section{CHAPTER I.}

GENERAL DEFINITION AND OPERATIONS OF TLE

SEASON.

Even in the most simple and popular view of this season-the view of it which is taken by the most illiterate and least observant or reflective part of the community-it is one of the most interesting in the whole circle of the year. It is, by way of eminence, the harvest-the season of plenty, both to mau as a cultivator, and to all the children of wild nature. It is the time during which the produce of the ficlds and of the orchards is collected as a store, not only during the inactivity of the winter, but until the return of another Autumn brings a fresh supply. Not only this; but in the more productive parts of the country, where cultivation is carried on in an advantageous manner, it both leaves a surplus for the inhabitants of places less favoured by nature, or restricted by the arrangements of art from being the producers of their own food, and has a store in supplement, against years of scanty production, so that, with proper regulation, and ono 
district and one season reciprocating with another, there is a uniform supply of the essential necessaries of life, and mankind are left free to pursue their varions arts and occupations and studies, for the comfort and the improvement of the individual and the race, without being alarmed by any fear of want, and far less of suffering those periodical visitations of famine, which, in a less advanced state of the arts of cultivation, fell so severely upon the people, even of our own country, when their numbers were but a small fraction of what they are at present.

We shall not now enter into the particulars, or endeavour to describe how the inhabitants of different countries, and different districts of the same country, are engaged, according as their soils and chimates are adapted for, or their habits have been inured to, the culture of different kinds of vegetables; because these are matters of detail, and the common character of the season belongs to them all. They are joyous labours, as compared with the field labour of any other time of the year; because, in them, the reward of the labour of all the others is, upon the average, collected together, and the feeling which the whole inspires is thankfulness. Yes, there is a cause of thankfulness in the return which Autumn brings to the labour of the cultivator, which is not prompted by similar success in any other occupation of the human race. In every such occupation there is, nodonbt, a power, or rather a combination of powers, in nature, which works along with man, and which even guides him in his working; but, in very many human occmpations, and especially in such 
as are carried on within doors, this is not very striking, either in apparent amount or in time; and in most of these operations, if the materials of our work are the same, and used in the same manner and to the same extent, we can predict, with the utmost certainty of which human judgment is capable, that the results, in any number of cases, will be perfectly uniform. This is especially the"case in all mechanical trades; and thus the workman feels that the whole burden of the work is on his own shoulders, and the whole merit in the case of success, or of blame or disappointment in the case of failure, falls exclusively and undividedly upon him. In such occupations there is, therefore, something which tends to induce man to take more merit to himself than he is in justice entitled to, and to overlook that goodness of the Creator, which has so framed the materials as to fit them for the work, and so endowed man with wisdom and discernment, as that, by successive steps of improvement, he has been enabled to tum the properties of material substances so largely to his individual advantage.

In the case of the cultivator of the ground, whatever may be the subject or the object of his culture, the case is widely different. The auxiliary principles which cooperate in bringing about the results which he desires, or rather which he merely seconds, by applying the results of his observation, are most palpable, and they continue throughout the whole period of his cultivation, from the time that the seed is committed to the ground to that at which the liarvest is gathered in. These are so habitually conspicuous, that no man can be in the 
fields and overlook them; neither is it possible to aroid perceiving that they are of two kinds, and equally beneficial, - the actual performance of good, and the prevention of evil. That alternation of weather, which brings the crop to maturity, and but for which the seed corn might as well be cast upon the barren sands or to the idle winds, cannot be overlooked; and, although not quite so open to ordinary observation, the number of perils through which the crop comes, against scarcely one of which man can find a certain remedy, is certainly not less wondcrful. Take, for example, a grain of wheat-of that corn which to us is the most precions of all the earth's productions-and there is not one instant, from the time that it is committed to the soil, to that at which its produce is brought home, at which it is not exposed to some enemy, sufficiently powerful for effecting its destruction, and yet sufficiently concealed for entirely escaping human observation, until its existence is first shown by the irreparable mischief which it has committed. These destroyers all exist for benevolent purposes in the system of simple nature; and that they should be held suspended while man changes by cultivation the course of that nature, is a never-failing subject of admiration; and that the produce of the harvest should come safe through so many perils, against which the utmost vigilance of the husbandman cannot be the slightest protection to it, cannot fail to inspire him with a gratitude to Heaven, which those artists who arc comparatively little subjected to the uncontrollable contingencies of nature, can feel very faintly, if at all. 
If Autumn had nothing more than this to reeommend it, it would be well worthy of our most profound study, and our warmest regard; but the bounty of the great harvest of nature is not eonfined to man as a eultivator but is distributed throughout the whole of nature, in proportion to the neeessities of the numerous and varied members of the great family. It is the time espeeially, at which, while they eaeh seeure themselves, they afford a surplus for the rest, over and above this seeurity. There is not a weed in the fields, or a tree in the forests, which does not produee enough of the germs of life to eover the whole surfaee of the land with its own speeies, in the eourse of a very few years, if all those germs were to eome to maturity. This, however, is not the law of nature; for just as the individual race, whether plant or animal, is self-maintaining for its appointed time, even so is the whole system of organized nature, whether animal or regetable, self-maintaining, by the redundanee of one supplying the neessity of another. Henee, while this is the season during which, in seasonal eountries like Britain, vegetable life is in a great measure suspended, or in the progress of suspending, - when the future twig and flower are beginning to be mantled up in the liybernating bud-when the peremnial herb is retreating for safety to the rootand when the annual, and also the sueession in all the rest, is stored up in the seed,-it is the season at which the plants ean spare their surplus as food for the animated raees, not only without injury to themselves but with great advantage, by thimning them down to that number which is consistent with the due and B 3 
proper balance of the system. At the same time that Altumn brings a greater supply of food for every creature whose habit it is to remain active during the season, it diminishes the labour of the greater number; and the consequenee is, that they are all in better condition than at any other time of the year; and thus they are prepared both for enduring whatever of hardship they may be exposed to in the winter, and for resuming their labours with increased energy in the spring.

If the Autumn had no further reeommendations than those which could be amplified out of the few hints which have now been thrown out, and the details of which are so very pleasant in the books which treat of the phenomena and the labours of this season, it would be well worthy of a high place among the subjects which enter into the general edueation of all elasses of the people, or at least which ought so to enter, in order to ellable them to perform their various duties in society with pleasure and profit. These, however, are but a mere beginning of the various elements, which go to the formation of what may be eonsidered as the Autumn, in the proper sense of the term. The word Autumn, indeed, involves, perhaps, more than is involved in any other of the seasons; because it has a peeuliar mixed character, to which there is nothing corresponding in any of the rest, and more especially in the spring or the summer. Taking the vegetable kingdom as our guide,-and it is always the best one, because it is the most seasonal,-the more eonspicuous actions of the spring and summer are confined to one grand division of the kingdom only, and to one great 
purpose in that grand division; the annual addition to the growth, and the annual preparation for the continuance of the common plants and trees, which clothe and adorn the surface of the earth. To these purposes, it may with truth be said, that the whole action of the spring and summer tends; and tends as one continued chain of operation, displayed, upon the average, in the same individual, from beginning to end. But, when we turn our attention to the Autumn, as its action is displayed in the vegetable kingdom, we find that the state of things is very different; and that we have a compound operation, both parts of which have strong claims upon our notice.

As in the crisis of the other seasons, so in that of the Autumn, we must not content ourselves with the mere three months of the year as measured off in the calendar; neither must we take such latitudes as that of Britain, where the seasons are pretty regular in their times, as the standard whereby we are to judge. We must look at the globe, in all its varied latitudes and climates, and we must look at all its varied productions; and if we do this we shall find that at some place or other, or in the case of some one production, even when we confine ourselves to the phenogamous vegetation, it is always Autumn, just as in other places and in the case of other productions, it is always spring, or summer, or winter. Thus Autumn in the one hemisphere answers to spring in the other; and the time of either taken in any one hemisphere is summer or winter in the middle or equatorial latitudes, according to circumstances. If the country abounds in humidity, then it is summer under 
a vertical sun, and consequently the most luxuriant of all summers; whereas, if there is no humidity, it is the extreme burning sterility of a tropical winter. So also, even in our own country, there are various races of vegetables to which Autumn is rcally the spring or the summer; and there are some of the smaller animals to which it stands in the same relation.

Hence, if we are to have a correct notion of Autumn, one which will meet the whole case, we must take it as quite untrammelled by time, by geographical situation, or by any one class of the earth's productions; and look upon it as a certain stage in that progress of the works of nature which performs its round in the year or in a longer period, according to circumstances. But, in doing this, we must take some onc department of nature as a standard wherewith to compare the rest, so that our conchusions may be fixed and definite; and there is no standard more general and conspicuous, and therefore better suited to our purpose, than the phenogamous or flowering plants of seasonal countries, where the majority of them have onc state of activity up to the producing and perfecting of the flowers, and one state of subsiding toward a winter of repose, in the comrse of the year.

In treating of the activity of these plants, in our volumes on Sprisg and Summer, we endeavoured to show that, whether anmuals or percnnials, therc is a double action, the one part of which tends to the development or the increase of the individual, and the other to the continuation of the race; and that at whaterer tincs these may happen, the first is, properly speaking, 
a spring action, and the second a summer one. The spring action goes no farther than the development of the individual plant and the increase of its size; but this proper spring action may take place in spring, according to the calendar, in any other of the seasons, or all the year round. Thus the midsummer shoots on fruit-trees, and the aftermathe on hay grounds, are both spring actions; and in a lawn which is kept short by mowing, by pasturing sheep, or by any other means that prevent the plants from coming into flower, is really a spring action, over whatever portion of the year it may be extended.

In like manner the producing of flowers, of tubers, or of any other parts, out of which new plants are to be elaborated, is a summer action, whether it precede, or accompany, or follow, that spring action by which the individual plant is developed or its bulk augmented. But this summer action continues no longer than till the germ of the new plant is fecundated-lias become an independent being, capable of obeying, as such, the stimuli which may be applied to it, whether through the medium of the parent plant, or directly to itself, after the connexion with the parent plant has been dissolved.

Such are the limits of the spring and summer action on flowering plants, whether their stems be annual, as in herbaceous plants, or of several years' duration, and receiving ammal additions to the wood and the bark to their stens, as in trees; and whether the incipient germs of the succession plants exist as rudimental seeds, as rudimental bulbs or tubers, as simple multiplications 
of the roots, or as any or several of these according to their various modifications, which depend partly on the nature of the plant, and partly on that modification which every plant receives more or less from the soil and circumstance in which it vegetates.

This being the proper limit of the action of those two seasons of vegetation which precede the Autumn, at whatever time of the year, according to the calendar, their work may be accomplished, we are brought at once to the proper function of the Autumn, or at least to that stage in the progress of vegetation, at which the action up to the time when the plant passes into its winter's repose, or starts to a new regetation in cases where there is no hybernal pause, is Autumnal. It therefore only remains to consider what has to be done during this period or stage of natural action, what are the powers prepared for the doing of it, and what the modes of their operation.

The general principle is thus both an obvious and an easy one; and though the details are many and complicated, yet, when the principle is once understood, every reader can, with little difficulty, work them out for himself, in as far as may be necessary for his particular purposes, whether of general knowledge or of practical application. From what has been stated, it will readily be perceived that the grand autumnal action of nature resolves itself into two distinct parts, mamely, something to be done, and something to be undone; and it is necessary to have an accurate general notion of each of these before proceeding to the details of either. 
That which has to be done by the autumnal action, is the bringing forward of the seed or other germ, whatever it may be, and wherever situated upon the plant, from the instant of its fertilization until it has acquired that peculiar degree of maturity, by which it is enabled to preserve the life that it contains, independently of the plant which produced it, or of any other plant, until it shall be placed in circumstances that are favourable for its germination and growth as a plant. When it lias once been placed in those circumstances, and has begun to act in obedience to them, it must then run its course, without any other pause than those which belong to its race, and to the seasons of the place where it grows; but until it has begun so to act, the time during which it can retain its vitality uninjured is, in the case of a seed especially, indefinite, and, in many instances at least, very long,--longer, indeed, than any which we can positively number in years. There have been instances in which earth that had remained undisturbed in a mound many feet below the surface for nearly two thousand years, and from which every kind of seed was carefully excluded, after its exposure to the air and light, and the supply of humidity, produced an abundant crop of plants, evidently from seeds which had remained uninjured in the ground during that very long period; and there have been many instances in which weeds had been buried while in seed by deep ploughing, and which did not make their appearance during culture by a number of shallow ploughings, yet returned in all their abundance when a second deep ploughing had again 
brought the seeds so near to the surface as that they could be stimulated into activity by that action of the elements which puts the powers of vegetable life in motion.

We shall afterwards have occasion to notice very briefly the mode in which this part of the grand action of Autumn is performed; but the reader cannot fail to pereeive that it is one of the utmost importance in the economy of the vegetable world, and one without which the flowers would display their beauties in vain. The plants themselves are fixed to the earth; or every flowering plant which is not so fixed, is confined to the tree or other support upon which it is borne; so that if there were no means of distributing vegetables over the globe, except by plants in a state of actual growth, each wonld be chained to its locality; and whenever, by means of any of those contingencies of which examples are so frequent, any space should be dennded of its vegetation, there would be no alternative but for it to remain in that state for ever. There is no provision in nature for the transfer of a plant in the state of growth from one place to another, except in those few plants which grow floating in the water, and which cannot of course go farther than the water carries them ; but in the state of seed they are prepared to undertake journeys of any length, and the greater number of them are so formed that they can readily be transported by the winds and the waters; while not a few are winged for flight, and in all probability, countless myriads far too minute for any eye or any instrument are constantly floating in the most limpid water, and even in the most 
transparent atmospheric air, and are thus taken into the bodies of all animals and all larger plants, and exist in these ready to perform their functions whenever circumstances call them into activity. 'These last, however, do not belong to that class of the vegetable kingdom which has summer or flowering action so open to our observation, as that we can point out the different seasonal forms of its action. They do not belong to the ordinary vegetation wherewith the earth is clothed and ornamented at all times, and in which the succession of the seasons is so strongly marked. They rather form part of a vegetation which, though not necessarily Autumul in time according to the calendar, is yet essentially so in its use in the economy of nature: we mean the very curious race of the fungi, to which we shall have occasion to refer in a subsequent chapter of this volume. But independently of these, there is a wonderful power of distribution in the seeds of flowering plants; so much so, that if a new island is upheaved from the bottom of the sea, or formed by conflicting currents of water, no sooner does it become a fit receptacle for any species of plant, than that plant finds its way to it, - no doubt in the state of a seed, but by means and in a mode beyond our powers of explanation.

'The Autumnal rains occasion a pretty general distribution of the seeds of wild plants, although this is in great part from the higher to the lower grounds in the same country. Very many of these are conveyed by the water-courses into the rivers, and stranded upon the banks. These banks are not always fit receptacles for 
the secds and germs which are thus brought by the waters; but when the dry season comes, many of these stranded germs are wafted to distances from the banks of the rivers, where they find soils more congenial to their nature, and grow much more luxuriantly than in the more upland places upon which they are produced. There is a reciprocal advantage in this: the rich lowlands are more favourable for individual growth, and less so for flowering and the production of seeds, than the upland places; and the seed from the upland grows better in those low grounds. In severe climates, where the weather breaks in snow, and not in rain, there is a still greater preservation of the seeds of wild plants than in the rainy countries. In such places the dry weather continues up to the very day on the evening of which the snow begins to fall-for it usually begins in the evening, or rather during the night; --and the seeds, of whatever plant they may be, are perfectly secure under the snow, for the temperature there is never such as to hurt any ripened seed; and even bulbs and fleshy roots are much more safe under its protecting mantle than if they were exposed to the air at a much higher temperature than that which prevails over the surface. Then, when the snows melt, and the spring rains set in and swell the watercourses, the preserved seeds are borne down in great numbers; and it often happens in the high latitudes, that fields are formed and sown with the seeds of wild plants by these spring freshes, sometimes with a mass of ice below, which, protected by the deposited mud and sand and vegetation, may remain, not only for one 
season but for a number of years, unthawed under these curious lands. 'These buried masses of ice, with soil and vegetation over them, have often led to strange mistakes about the temperature of the interior of the earth in the high latitudes. Thus it has been said by many of the old describers, that if the soil in the vicinity of Hudson's Bay is dug into to the depth of a few feet, the interior of the earth is so cold that the ground is frozen. Now the great heat of the summer, as compared with the latitude, and the rapidity with which the sllow comes on in the Autumn, are such as to preserve a much greater winter heat in the ground there than there is in many places further to the south, having the winter more open, and the temperature of the air over the surface much higher. The sudden fall of the sllow, and the pertinacity with which it lies, prevent that radiation of the action of heat from the surface which would otherwise take place; and thus there is a very safe Autumnal preservation botl for the seeds and the roots of plants. Of the Autumnal action, as maturing and also as preserving the germs of flowering plants, we shall afterwards have occasion to speak more in detail; and therefore what we have stated must suffice for a general notice of what the Autumn has to do in the case of these vegetables.

The next part of the Autumnal action, as it refers to the same class of plants, is what it has to undo; and this is, perhaps, a more curious part of the subject than the former. Of course it lies wholly in the opposite direction, and is as much connected with the general destruction of vegetables as that which has been stated 
is with their general preparation. The seasonal growth of plants, whether as producing additions to the permanent volume of the individual plant, or as preparing for those seeds and germs which are to be matured by the preserving action of the Autumn, requires the use of many organs of a temporary character; and which, even in the most lasting of ordinary trees, are perfectly seasonal in their use, and, like the parts which produce the flowers and the seeds, are altogether incapable of performing their functions more than once. All the parts of vegetables which are thus destined to perform a single function, and have performed it, cease from that moment to be part of the living vegetable world. But the law in nature is general, that cvery thing which is without a use, and not in a state of preparation for a use, is really an incumbrance in the way; and the system of nature wonld be quite imperfect if there were not some means of removing those incumbrances, and transferring to a new use that portion of matter which had ceased to be valuable for its previous one.

We have illustrations of this law everywhere, in every growing and living thing to which we can turn our attention. Whatever is applied to the plant or the animal, in the way of food for the increase or the maintenance of the substance of its body, in the way of air for carrying on the functions of its system, or in the way of heat, light, or any other of those displays in nature which are known as action only and not as substance,-whatever is applied, naturally, to plant or animal in either of these ways, invariably consists of two portions, one of which may for distinction's sake 
be called cssential, and the othcr vehicular. The first of these may be taken as a convenient gencral name for the matter which goes wholly to the substance of the plant or the animal, either as new matter for an increase of growth, or as renovating matter to replace that which, laving already performed its function, is no longer fit for the support of life or growth; and which, were it to remain, would bc the same kind of incumbrance to the proper working of the individual, as that surplus of annual growth of which we are speaking is to the working of the gencral system of nature. In like manner the essential part of the heat, the light, or the other action, is that which is wholly transferred to or absorbed by the system of the plant or the animal, without being given out to, or becoming apparent in, anything else.

The vehicular part is that which conveys the other, simply as a means of conveyance, and which subdivides or dilutcs it to the exact degree which the condition of the plant or the animal requires. This vehicular portion is sometimes a separate ingredient determinable by our means of analysis, and sometimes it is not; though wc have reason to believe that, in every case, there is a natural distinction betwcen those two portions, if our analysis could be conducted with sufficient nicety for ascertaining it; and that when by any means more than enough of the essential portion is applied to any plant or animal, the system is thereby overworked and injured.

This fact of there being an essential and a vehicular portion in every kind of substance, and avery dcorrec c 3 
of stimulus which is applied or which can be applied in any one of the operations of nature, or to any one being possessed of growth or life, is one of the most extensive and most important facts in the whole economy of nature,-so much so, indeed, that it may be considered as the grand law, of which all the others are merely modifications. It is a law, indeed, which is not specifically recognised by the schoolmen, or set forth in the books which we are taught to look upon as authorities; but it is not on this account the less true or the less important. It is, indeed, the only law which enables us to apply one philosophy to the whole system, and make nature its own interpreter in all its parts.

The parts of nature are also so beautifully adapted to each other, and to the keeping of the materials and the powers of nature constantly in use, that that which is merely vehicular in the case of one being, is essential in that of another; and thus the very fact of growing and living in the one case, actually prepares the means of growth and life in the other; and if we follow out this principle of mutual assistance and dependence, we find that it is perfectly general, and so beautifully regulated as to keep up the whole system without any assistance.

This principle is one with which it behoves us to make ourselves thoroughly acquainted, not only because without it we can never understand the system of nature's working as it ought to be understood, but because the knowledge of it is essential to the preserving of a healthy state in our own bodies, in respect of food, of 
clothing, of exposure to the atmosphere, exposure to heat, exposure to damp, and every other case in which different degrees of that which is applied to the body call affect us in a different manner. It is the want of this knowledge which has, in every age, caused the medical profession,-or, to express it more correctly, the drugging trade-to be peopled with more abundant, more absurd, and more impudent, but still more successful and profitable quackery, than all other trades upon earth-the trade of public legislation for the benefit of quacks and impostors of another kind, perliaps, only excepted; - and the latter is but of nodern growth, and may be only of mushroom duration, while the drugging quack has existed from the beginning, and will continue until men acquire so much knowledge of their own bodies as part of the system of nature, as to enable them to do the best in every change of circumstances under which they may be placed. This is the grand practical purpose to which all our inquiries into natural causes and natural substances ought to be directed; and it deserves to be generally known and carefully inculcated, more especially upon the young, who are not yet bound to the chariot-wheels of custom, that there is no royal road to this species of knowledge; but that if they will not observe and think for themselves, they must be contented to remain for life in that helpless and pitiable condition in which they are defenceless to every species of imposture which can assail them on the subject.

We shall afterwards have occasion to mention one remarkable case of the provision of nature for supporting 
one class of beings upon that surplus which becomes an incumbrance to another class, when we go a little into the detail of means by which Autumn removes those materials which are left over when the purposes of summer and spring are accomplished; but still, as the principle is one which should always be ready, it may not be amiss to give one or two simple and familiar examples in further illustration of it.

The most general and familiar instance that can be given is that of the air which we breathe. There are always a few foreign substances mixed with this fluid; but, whatever these may be, their quantity, unless in the close vicinity of those substances that give them out in vapour, is so small that they have very little effect one way or another; and thus, when we speak in general terms of the air as applied to the lungs in breathing, we may leave those foreign substances out of the estimate. Now the air, in the average circumstances in which, in Britain, it enter's the lungs in breathing, contains two parts out of nine in weight (which is the proper measure of absolute substance) of oxygen, and the remaining seven parts of nitrogen; the first of which is the essential portion of the atmospheric fluid in breathing, and the second the vehicular portion. When the air is in the lungs, the nitrogen is wholly passive, except in so far as it may be expanded by the heat of the lungs, which in ordinary circumstances is greater than that of the air which is inhaled in breathing; and may thus assist in the expiration of the breath, after the oxygen-the essential part-lias done its work. But the oxygen takes up in the lungs 
as much carbon or eharcoal as converts it into earbonie acid gas, without any ehange of bulk exeept what it may reeeive from difference of temperature. In this process of breathing, 338 parts, by weight, of the oxygen of the lungs, take up from the blood 127 parts of earbon or eharcoal; whieh makes the eompound or acid heavier than oxygen in the proportion above stated, and more than one and a half times the weight of the same bulk of common air at the same degree of temperature. Thus, the carbonic acid which is the result of this operation, contains much more matter in the same bulk than it did when it entered the lungs in the state of oxygen. From this we would naturally infer that, as it takes a higher degree of the action of heat to keep any quantity of mattel expanded into a greater bulk, than it does to keep it in a smaller one, there should be a portion of the action of heat set free by the eonversion of this oxygen of the breath into carbonic acid in the lumgs. Such is found to be the fact; for while the action of heat which kecps the nitrogen in a state of gas remains the same, that of the earbonic aeid is eonsiderably less than that of the equal volume of oxygen from which it is formed; and thus it is probable, that while the breath removes the surplus ehareoal out of the system, a eertain action of heat is at the same time evolved by the process, which may stimulate the lungs, and at the same time protect their exeeedingly delicate structure from the temperature of the inhaled air, which is generally lower than that of the interior of the body. According to some of the earlier theorists,--who wrote before the 
doctrine of the different agents, agencies, or actions by which the operations of nature are carried on, were so well understood as they are now,-it was supposed that this was the only source of heat in the living body. 'This, however, is far from being the case ; for heat is an invariable concomitant of material action, in what manner soever that action may be carried on.

In the instance which has been mentioned, we have more than one illustration of the general principle. In the air we have the essential oxygen, diluted to the proper extent by the vehicular nitrogen; we have the carbon, which had become incumbrance and waste in the system, removed by means of the oxygen; and we have a new compound in the carbonic acid, which, being retainable in the atmosphere in a very small portion only, is precipitated to the earth, into the pores and openings of which it runs like water, and in all probability forms an extensive as well as an essential part of the food of plants.

The perspiration, which is at all times given off from the surface of the body in an insensible manner, is another instance of the discharge of a substance when it seems to be necessary to the healthy action of the system; and the stoppage of this by what we call "catching a cold," or by any other means, is so injurious, that we cannot fail in being convinced that the removal of that which has ceased to be useful, is as necessary to the proper working of every part of the system of nature, as the application of that of which the system stands in need. Thus the moment that this surphus or incumbrance is discharged from that to 
which it would be injurious if it were to remain, there is always a new use ready for it; and thus no part of the material of the creation is ever idle, though its combinations and forms are constantly changing as it passes from race to race.

Length of time, as we judge of it, is not a necessary element in this part of the system of nature. The period during which any identical portion of matter may be required to remain in the same production of nature is quite indefinite. It may be more brief than the smallest fraction of a moment of which our senses can take note, or our imagination can form a notion; or it may be days, months, years, ages, or periods so long that we cannot name them by any number. In all cases, however, of which we have any knowledge, whether the period be long or short, there is a growth of the individual, which is really a spring action,--and a fructification, which is really a summer action. After these, there is a maturing of the seeds or other germs, until they are independent of that by which they are produced; and then a transfer of the matter which has done its work, to some other race; and both of these are Autumnal actions-the two characteristic actions of that season, whether we consider it as a portion of the year, or of any shorter or longer period of time.

In the case of annual plants, we have of course only one annual Autumn, in which the maturing of the germs and the destruction of the old plant are both completed within the year. In shorter lived plants, there are, of course, as many Autumns in the year as there are successions of the plant; and in some species, 
in those places which are favourable to their rapid growth, this may amount to five or six, or eren more. None of these Autumns of the plant, whether there is one or there are more than one in the course of the year, is absolutely confined to the Autumn according to the calendar. They vary in their times even in wild nature, and man can vary them still farther by artificial means. Thus, if we were to take our Autumn according to the months, we should have a very garbled and uninstructive notion of the real function of the Autumn.

In plants of peremnial duration, the case is still more complicated. Such plants in seasonal countries, - the common deciduous trees of our forests, for instance,have a double period, a period for the season, and another period for the tree, longer or shorter according to its duration. In those cases the destruction of the seasonal Autumn is, generally speaking, accompanied by an antummal perfecting of germs; but the destruction of the long Autumn of the tree is a final destruction, not necessarily accompanied by any means of providing a successor; and it is by the action of this kind of Autumnal destruction, that the characteristic vegetation of large tracts of country is often changed-of which there are many instances in the British islands; and the greater part of them consist of the removal of trees, and the substitution of surface regetation, or of peat bogs in their stead; and then, when another and more mysterious wheel, in the curious and in many instances inexplicable revolutions of our globe, comes round, the lofty plants, with the entombment of more humble ones 
by which they were at the first lidden from the air and the sun, are converted into beds of coal. Thus, if we follow out the study of the Autumn in a proper manner, it leads us to all the revolutions that have taken place in the surface of our planet; and in this way a plant of which we can, in a few months, see the beginning, the perfection, and the decay, becomes to us an epitome of the system of growing nature in its widest extent and through its most prolonged duration.

This is the grand advantage which studying the productions of nature in their connexion, and the events and occurrences of nature in their succession, has over the mere observation of the individual substance and the passing moment; and it is this which gives to the law of the seasons so high a value above all the beauties of the seasons taken in their individual character. It is this also which makes the principles of seasonal action thicken upon us as the year advances; and the Autumn to become the harvest of knowledge, as well as of the fruits of the earth. Nor can we help admiring that bountiful and beautiful wisdom, which has laid the elements of instruction most abundantly, in the grand season of plenty and of gratitude.

There is something fresh and delightful, and peculiarly fitted for giving buoyancy to the spirits, in the opening of the spring, and something lovely in the bloom of the summer; but in them we behold only the progress of one generation as it were, in which each plant (we speak of plants only, and of flowering plants especially,) works chiefly for itself,--first for the increase of its substance by leaf and stem, and then for its 
adorning, by the symmetrical form, the radiant beauty and the delightful fragrance of the flower. It is true that the great act of nature, the most important one in the whole revolution of the seasonal period, whether that extends to a year, or more, or less, is accomplished in the summer, and is the grand work and purpose of that season; but, like all beginnings in nature, it is a matter of inference, not of observation; and therefore, by all mankind for many ages, and by the majority of mankind in every age, it has been, and is, unheeded.

But the want of knowledge of this act of the summer, has a most unhappy effect upon the feelings which we have in respect of the Autumn. It is impossible, indeed, that we can pass unheeded the plenty which the Autumn brings us. But the reflections to which this is calculated to give rise are few, and they are also narrow and selfish. For as the amnual harvest which we obtain from the earth is viewed by us as resulting from that in which we have a right of property, a merit in labour, or both united, we are apt to forget the part which nature has in the productiveness of the year, and look upon the whole produce as the return of our own capital and our own skill, just as we do in any mechanical work or mercantile speculation. That this is the true state of the case, is proved by the habitually prorerbial fact, that the cultivators of the ground, for what purpose soever they may cultivate, are always complaining of the weather, as the grand enemy by which all their labours are frustrated, and all their products diminished. They are nowise at fault themselves, but "the weary weather" never will be obedient to their 
dictates. What with rain, what with drought, what with heat, what with cold, each thrusting itself forward at the time when its opposite would lrave been by far the more benefieial, the crop which they get is always "below a fair average;" and what they do get is gotten in spite of the weatler, and not by means of its cooperation. It is in vain that the fable of the farmer,-into whose hands Jupiter gave the management of the weather, and who, by having rain and drought, and sunshine and snow, when and where lie wished, brought his land into a state of such utter sterility that he was fain to plead more earnestly than ever that so dangerous a power might be taken out of his hands, - has stood on the record against them from remote antiquity; for the majority contend stubbornly that all the merit is their own, and that all the blame falls upon the weather, which, notwithstanding all the examples which have been set before it, and all the experience it must have had, "will not understand and obey the rules of good husbandry."

But if the season is thus blamed-and any one who ehooses to colleet the evidenee may find that it is very generally so blamed-in so far as it is concerned in that portion of the produce of the year in the producing of which the labour of man also bears a part, how much more fell and fatal must it seem in those cases where, without the interposing hand of human skill, it works for dissolution only, and without any saved remnant or any useful result which the eyes of eommon observation can discover!

In its very beginning, it takes the growing world,- 
we say the growing world as that which must abide the season, and is therefore most expressive of it,-it takes the growing world in the very fulness of its beauty, shrivelling the petals of the flowers, and casting them to the dust, alike unseemly to the eye and ungratifying to the smell. And this is only the mere beginning, or rather the signal to begin; for it takes place when all the rest of nature is in the full vigour of its activity. But yet a little, and the trees are stripped of every leaf; the herbage is consumed from the pastures; the winds awaken, the clouds congregate, and the rains come down, scourging the earth to the bare rock; while the swollen streams roll the fat of the land onward to the sea; and then, as if to make the work of desolation doubly sure, the cold mantle of the snow is cast upon the land, and the waters are bound in fetters of ice.

This is the visible progress of the Autumn, which the people of seasonal climates witness every year, and which displays itself with more force and fleetness, in proportion as the climate is more seasonal; and thus the Autumn is emphatically termed "the fall" of the year, and spoken of in gloomy terms as a season prominently fatal to luman life. There is no doubt that this is the general impression among the majority of those inliabitants of the country whose thoughts extend beyond the mere event of the hour; and there is as little doubt that, from the close analogy that there is between this decline of the year and the decline of liuman life, gloom and despondency are produced, and the mind shrinks fron thonght upon the most important 
of all subjects, because of the horror which it fails not to inspire in the unrenewed heart.

It is in vain that recourse is had to the delincations of those occupations and scenes which are usually supposed to take off the gloor. of this season,- - the reapings, the vintages, the harvest-homes, the huntings, and all the other characteristics of the rural Autumm. These are, like "merry music when the heart is sad," an opiate for the time; but, like other opiates, they leave the mind enfeebled and the anguish deepened when their very momentary influence is over; and this is the reason why it is of so much importance to have clear and comprehensive views of the Autumn,--views much more comprehensive than can be obtained from observing and studying the plenomena of the season in any one country or chimate.

We must also make ourselves acquainted with both the means and the mode of action of each of the parts of the double function of the season,- the perfecting and preserving of all that is essentially necessary for the spring and summer of the coming year; and reducing to the condition in which it shall be most useful for future growth, all the vehicular portion where function ceases with the year, and which requires to be decomposed before it can again run the same course.

Hitherto, this has been viewed cliefly in the case of flowering plants; and we shall still continue to view it through them, because there it is most conspicuous and most perfect. Flowering plants have not, as animals have, the power of subsisting directly upon organized substances as food; they do not take into their system

$$
\text { 1) } 3
$$


solid food of any kind; or at least if they do, it is in a state of atomic division, or nearly so; and as it is taken in along with water, we are not able to draw the line with any precision between the essential and the vehicular parts of the food of these plants, or to trace any function in them at all analogous to that of assimilation in animals. But when we contrast the average appearance of flowering plants in a country whose seasons are strongly marked, at the two periods of their greatest development and their greatest nudity, we cannot fail to observe, that as much must be done in order to reduce them to the last of these states as is done to bring them up to the first. It is true that trees and shrubs accumulate an addition to the substance of the individual, which is not lost in the reversal brought about by the autumual action. But this has a limit; and a greater Autumn is at work in reducing the matter of the most long-lived tree, and often goes on in the central parts for years, or even for centuries, before the external or living part of the tree yields to final decay. It is probable that, taken upon the average, this gradual decay of the solid parts not only keeps pace with, but in most instances exceeds the anmual increase of solid matter in trees; for, except in a few spots, and they are but few as compared with the whole surface of the land, almost every country gives evidence, in the remains which are buried in the earth, of having been more thickly wooded at some former period than it is at the present day. But this belongs to the progressive history of the earth, rather than to the seasonal history of the year; and therefore we are 
not required to go into the details of it, though it is necessary to keep the general principle in mind, becanse it explains various matters which otherwise would appear anomalous in the annual Autumn. Indeed, in all our examinations of naturc, and more especially in those which have reference to succession in time, we must bear in mind that the system of nature, in all its days, and years, and ages, is one; and we can never have a proper understanding of even the most bricf period of this succession, though narrowed to the most limited, to the smallest extent in space, if we vicw it apart from that natural sucecsion, in which all its appearances arc effects of what went before, and become in their turn causes of what follows after. It is this which forms the great difficulty as well as the great charm of the study of nature in any one of its departments, in any one of its individual productions, or in any onc momentary state of that production. The charm consists in the microscopic animaleuli and the majestic array of a planetary system bringing us alike near to that part of the study where it rises above all human philosophy, and leads us captive in bonds of delighted veneration to the adoration of nature's God.

Hitherto, we have considered only or chiefly the flowering plants as an index to the proper function of the Autumu; and we have done so because they are at once the most easily obscrved and the most striking. But we need hardly remind the reader, that the scason tells upon the wholc of nature, thongl differently on the different parts; and that the immediate agencies by which these Autumnal changes are brought about, vary 
with the different classes. In all of them, however, there is an Autumnal action, upon rather than of the individuals themselves. If in the course of the season they cease to be possessed of vegetable or animal life, then we may consider them as entirely passive, or given up to the common laws of matter; but if the life is not extinguished, we can consider them only as being modified, and of this modification the varieties are almost innumerable. In the animal kingdom, the slightest seasonal influence upon the actual condition of the creature, may be considered as taking place in those birds which summer in the cold latitudes, and perform Autumnal migrations into warmer ones; and the extreme limit in the other direction may be taken in those invertebrated animals which are consigned to the egg, and those reptiles which become so completely dormant in the cold wcather that they may be broken in pieces without the slightest signs of motion or sensation. In the vegetable kingdom, the pines, and the other evergreens, which carry their foliage through the utmost severity of the winter, in the most polar situations in which a plant will grow, are to be regarded as those which are the least affected by the Autumnal agency; while those plants which remain during the winter in the state of seeds only, are obviously those upon which the influence of the season of decay is the most complete.

But in all these instances, it is only what may be considered a seasonal modification of continued or transmitted life; and this depends in a very great measure upon the astronomical and meteorological influences of 
the season, and does not demand a reference to those special terrestrial agents which must be regarded as the appropriate armies of Autumn, in preparing the productions of the earth for the action of a new spring and summer; and it is in those of them which are more especially its own, that we are to seek the proper character; of the season.

This is not done in the ordinary books which treat of the Autumn, and therefore they present us with little else than a number of phenomena, which have no apparent comnexion except that they follow each other in a certain order of time; and a list of this kind, how long soever it may be, and how finely and forcibly soever the several parts of it may be delineated, cannot be so generalized as to form any part of that vital description of knowledge which contains in itself the principle of its own extension. We must, therefore, take our range somewhat wider than this; and if we shall fail in producing the effect which we wish, our failure will be where few or none have hitherto attempted. 


\section{CHAPTER II.}

\section{AUTUMN IN DIFFERENT LATITUDES.}

In the phenomena of nature in different latitudes, and the extent of its action there, Autumn is as much diversified as any of the other seasons; and as its action may everywhere be regarded as consisting, in great part, of a reversal of the action of spring and summer, it follows as matter of course that it should also be the reverse of that action in its power. In our volume on Sunner, we endeavoured to explain the nature of the surpius of summer action, which is the power left at the disposal of man, as available for the purposes of artificial cultivation. In as far as the Autumn prepares and preserves the seeds, the frnits, and the tubers, and other root or stem accumulations of matter for the succession of plants, man reaps in the Autumn a harvest proportionate to the advantage which he takes of the surplus of summer power. In cultivated countries the domestic animals, which bear their share in the labour along with man, and contribute largely to the amelioration of the soil, have also their share in the abundance of Autımn. Many of the wild animals partake along with them, and the numbers 
of these increase as cultivation advances. In wild nature also-where there is no labour of man except in the destruction of that which nature produces spontaneously and unassisted by him-the wild animals have their share in this abundance of the season ; and those which are the most numerous and have the largest share, gradually fade away in their numbers as the dominion of man becomes move fully established. But in every case, whether of wild nature or of the highest degree of human cultivation, there is a strengthening of those wild animals which are to winter in activity, which is not equalled at any other season of the year; and this is wisely done, inasmuch as it prepares them, not merely for enduring the hardships of the winter, but for performing those labours to which their economy calls them when spring again renews the year. There is a great deal of beautiful manifestation of design in the several adaptations of the creatures in this way; for the waste of the system not only diminishes in the extreme severity of the winter, when food is difficult to be obtained, but in the fulness of the abundance of Autumn, when the most nutritious food is obtained with the least labour, both by the vegetable feeders, and by the carnivori which feed upon them. The mammalia and the birds, which are the classes of animals most open to common observation, and therefore most useful for illustration upon all general points, have, generally speaking, two labours to perform previous to the Autumn, although both the one and the other are in some cases carried into the Autumnal months as these stand noted in the calendar. The first operation, and the most important 
one in the progressive cconomy of nature, is the producing and the rearing of their young for the year; and the second, which is more exchusively for the individual, is the renewal of their clothing-the production of new hair or fur in mammalia, and new feathers in birds, secreted by those organs of the skin which nature has provided for the purpose, and which work with the utmost nicety and perfection in proportion to the necessity that there is for them; so that every animal is clothed for the winter in proportion to the degree of winter severity which it has to endure. The performance of those parts of their annual economy, calls forth powcrs in the animals which are not required in their ordinary cvery-day labour of finding their food and attending to their safety; and as it is a law of the whole system of nature, that every power, whether animal or anything else, continues for some time after it lias accomplished its purpose, those very powers of the animals whose working had to a considerable extent exhansted their systems, remains to work during the Autumn for the recovery of their tone. What we thus see in the individual animal is a sort of epitome of what takes place in the year itself, as applicable to the whole of nature; for in so far as Autumn is the season which matures and conserves all that is to work in the succeeding spring and summer, a surplus of what may be called summer action is carried forward into the Autumnal months for the performance of this part of the Autumnal action of the year. This portion may naturally be supposed to be the reverse, in regard to latitude, of the proper action of the Autumn, that is to 
be smallest where the real Autumnal action is greatest, and the reverse; but still it is necessary to bear it constantly in mind, otherwise we shall be in danger of falling into error in our estimate of the more characteristic action and use of the Autumn. 'This being understood, we may proceed to take a rapid glance at the characters of Autumn in the different latitudes, or, to speak more correctly, in the different climates; considering these as dependent upon local circumstances, such as elevation, soil, and exposure to the sun and the atmosphere, and to the effect of surrounding surfaces, as well as to mere distance from the equator.

This view of the Autumn involves what may be considered as the astronomical cause of the season, though it is not wholly confined to that cause; and in the former volumes of this series on the Seasons, as well as in those on the Heavens, Earth, Air, and Sea, we have had occasion so frequently to allude to this as dependent on the motions of the earth, that repetition in this place is quite umnecessary. We may, therefore, hold it as understood, that the astronomical Autumn in each hemisphere, is that portion of the earth's revolution during which the sun apparently declines from the tropic in that hemisphere, toward the tropic in the opposite one; but that it does not begin until the time of the tropic is past, longer or shorter according to circumstances, and also more marked in its character, according to the latitude, the elevation above the mean surface, and those other particulars which tend to vary the seasonal appearances and productions of different regions of the globe. 
In the more faroured spots under the equator, nearly on the level of the sea, where there is at all times a sufficient supply of moisture to accord with that maximum stimulus of heat which constantly occurs in such places, there is no perceptible difference of seasons, and consequently no marked Antumn or Autumnal action ; for if there is any pause in the flowering and fruiting, of the vegetables, it is occasioned not by the ordinary astronomical causes of diversity of seasons, but by the reciprocal action of the hemispheres upon each other, or those of land and sca, occasioning atmospheric cmrrents, in consequence of which drought and rain alternatc with each other. But in the tropical districts of extreme fertility, to which we allude, the alternation is not that of growth and scorching, as it is in the more arid places of the same latitudes: it is an alternation of flood and marsh-of water stagnating to the depth of a good many feet at one season of the year, with rich muddy soil at another, but so sliaded from the sum by lofty trees, and twining parasitical plants of most luxu iant growth and extremc bcauty, as never in the least to suffer from the torrefying infuncnce of the solar beams. The comparative cquality of day and night throughout the year, contributes to this uniformity of the seasons; and though such places are the most favcurable on the surface of the earth for their own rich and peculiar vegetation, they are particularly unhealthy for man, and for those animals which are especially raluable to man in a state of civilisation. Rice, and some of the plants which produce the farinaceous substances known by the names of arrow-root, 
fapioca, and others, grow luxuriantly; but the culture of them is fatal to Europeans, and unhealthy even to the native population of these countries. Ground animals which graze the herbage, there are none, and there is no herbage for their support; consequently the larger carnivora which prey chiefly upon such animals are found on the margins of those districts rather than in them. The mammalia, which are at home there, belong chiefly to the pachydematous, or thick-skinned animals, - as for instance, the hippopotanus, in the river: or the stagnant water, though breathing air like a land animal, and gnawing twigs and aqnatic plants for its food; then the rhinoceros, not actually in the water, but among the reeds and giant grasses, in its immediate vicinity; and afterwards the elephaut, in the rich forests, which we would call between the wet and the dry; and next to the elephant there succeeds the wild hog, still partial to the water, and closing the list of the living pachydermata of the rich and humid places of the warm latitudes; to which the buffalo succeeds, and the series continues in the rmminant animals, until these again mingle with the wild asses on the margin of the desert, which are again pachydermata, though very different in many of their characters from those which occur in the tropical waters or their immediate vicinity.

In this respect, however, there are great diversities in the different continents or quarters of the world which are intersected by the equator. The hippopotamus occurs only in Africa; and the rhinoceros and elephant in that quarter of the world and in Sonthern 
Asia, and there are speeifie differences between both as oeeurring in the two quarters. In the corresponding latitndes of Sonth America, there are no mammalia of large size, though sueh as do oceur belong also to the paehydermata: these are the tapir, bearing some slight resemblanee to the rhinoceros, but without any lorny appendage to the nose, and the peeary, which has some eharacter in eommon with the hog. The tapirs of Anerica are about the size of asses, and there is a species in the A siatie isles a little larger: the pecearies are small animals, about half the dimensions of the wild hogs of Europe, and they are peeuliar to the warm forests of the Ameriean continent.

Such are the ground mammalia of the more fertile portions of the tropieal zone of the world, where there is hardly any difference of seasons, and Autumnal action and Autumnal agents are unknown. They are associated with the largest and most powerful of the reptiles, - the eroeodiles and alligators among the sauria or those of the lizard tribe, and the pythons in the East, and boas in the West, among the serpents whieh are possessed of great meehanieal strength, but lave no poison fangs.

At a ligher elevation above the surface of the ground, we find the quadrumana or four-handed animals, in vast numbers, and in great variety of size and form, though all in so far resembling each other in that type whieh is so often, but so improperly, regarded as a sort of earicature of the human body. 'There is no caricature in the ease; these animals are adapted for living habitually and for finding their food in trees; 
and their hands, of which they always have four, and sometimes the tail answers as a fifth one, are merely grasping instruments, and not instruments of all work, like the human hand. Higher still in the giant-growth of those tropical forests, there is another, and a very peeuliar raee of mammalia, the sloth, eonfined as living animals entirely to South Ameriea. They live more exclusively in the elevated parts of the trees than even the apes, monkeys, and other foul-handed aninals ; and in their mode of life they resemble the common ground manmalia, reversed in their positions. 'They move about among the twigs, hanging by the feet with the baek undermost, and browse the leaves over them; they also repose in this posture, which is with them the posture of rest; and when they are compelled to deseend to the ground, they are out of their place in nature, and eomparatively helpless.

The mammalia and reptiles which we have noticed, remain in their perennial forests, with little or 110 ehange of seasons, and without ever migrating into any other parts. In addition to these, there are many tree birds, of the zygodactylie, or yoke-footed order, that is, the elimbers, which have two toes to the front, and other two to the rear; which have the feet well adapted for aetion among the twigs, but which are very awkward upon the ground. The short-tailed and thickbodied parrots, the toneans, and many other genera, have these charaeters; and they remain as constantly in the forests, and are as little seasonal in their habits, as the mammalia and the reptiles which have been deseribed as inhabiting the same plaees at all seasons. In 
their colours, these birds" form a remarkable contrast to the mammalia of the tropical forests, for they arc as gay as these are dingy. 'Their bright colours and the adroitness of their motions among the branches are, however, their chief attractions; for their voices are harsh and screamy, and they are in general mischievous in their habits. It should seem, indeed, that both the mammalia and the birds of these rich forests assist in breaking down the trees which they inhabit; for when they are kept in confinement, they are very much given to gnaw and pull in pieces every thing that comes in their way.

In those places which may be considered as laving the minimum of seasonal action, and sonvetimes 110 perceptible seasonal action at all, the particular agents of the Autumn are not required, and they accordingly have no place. Thus we may take these places as the first beginning from which seasonal differences become apparent as we ascend in latitude and also in height above the mean level of the sea. Before, however, we attend to the gradation and the use there is for Autumm either way, it may not be improper to notice what may be termed the fall of the year, in places in the same latitudes, but differing in their physical characters from those hrumid olles which we have described. In them there is a season of anmual vegetation, and a season in which that vegetation disappears, the spring of the vegetation coming on with the seasonal rains, at what time soever of the year those rains may occur, and the Autumn commencing when the heat and dronght have become so powerful as to begin to wither the annual 
stems and the annual leaves. In those places, both the conservation of the preserved plants, and the extinetion of those plants or parts of plants which have performed their offices in nature and are no longer required, are brought about by the influence of the sun and the atmosphere without any special Autumnal agents to perform the decomposition. This, by the way, is one of the reasons why the exposed surface in sueh plaees is so apt to tum into desert. The intense heat of the sull evaporates all the evaporisable parts of the decaying plants ; and what remains is dust before the wind, or seum upon the waters when the rains come; and thus both these agencies tend to transfer it into the rich and marshy places where such exist, or into the courses of the rivers where there are no woods and marshes to entangle it as in a net-work, and in the latter case it goes to form banks in the sea, or cleep and extensive alluvial deposits in the lowest estuaries of the rivers. It is owing to this that the dry and the humid lands within the tropies, or in places having tropieal climates, form so striking a contrast with each other, as compared with similar places in the temperate latitudes. The quantity of soil which is formed in the lower valleys of some of the great rivers in the warm latitudes, is perfeetly astonishing as compared with any deposit of the same kind which occurs in the temperate ones. 'The lower valley of the Ganges is a remarkable instance of this, where the entire extent appears to have been gradually gained from the sea to a depth of several hundred feet. In the valleys of some of the American rivers, the alluvial deposit is one of im- 
mense depth. The most perfect skeleton of the megatherium, (a luge animal of the sloth funily, of which we have not the smallest traditionary notice in the living state, which is now in the cabinet at Madrid,) was found in the alluvial soil on the banks of one of the affluents of La Plata, near Buenos Ayres, at the depth of a hundred feet below the present surface, where it had evidently not been buried by any violent eonrulsion of nature, but by the slow progress of the annual deposit during the rains. The lower valley of the Mississippi, toward the Gulf of Mexico, lias not been much explored, and it is a turbulent river, and constantly changing its channel; but the quantity of matter which it has aecumulated through a long extent of the valley is very great. The Mississippi is not within the tropies, and the regions from which some of its waters eome are very seasonal; but the seasons toward its eonfluence with the Gulf of Mexieo partake not a little of the tropical eharacter.

In some of those tropical countries there are double seasons in the course of the year, as the apparent shifting of the cahn action, both nortlwward and southward, brings rain, and the setting in of rain in the warm latitudes is always a spring time for the vegetation, at what time soever of the year it may happen. But still, at whatever times the rains oeeur, and whether the intervening periods of drought be longer or shorter, there is never any thing that we ean call a specific action of Autumm. The decomposition of that seasonal part of the vegetation which has performed its work, is always effeeted by the means which have been stated. 
Even in the case of the decomposition of the solid wood of the tropical trees, in what we have called the "long Autumn," to distinguish it from the Autumn of the year, the destroyers which are employed in supplement to the decomposing powers of the sun and the atmosphere, have never a summer character. They are insects which enter the trees in countless myriads, and reduce the whole of the interior to dust; but which, of course, do not change them into any other vegetable substance more easily decomposed, so as to be available as a pabulum for new vegetables of the same kind. Thus, in whatever light we view the tropical countries, we are unable to find in them any thing that we can call an Autumnal action; and it follows that, in these countries, there is really no Autumn.

Setting out from the low-lying countries within the tropics, where the seasons are blended, and where there is no definite Autumn, there are two directions in which we may proceed, if we wish to trace the differences of seasons. The first of these is met with as wo ascend in elevation; and the second as the latitude increases. Immediately under the equator, the differences of seasons are not very great at any elevation, though they do become a little more conspicuous as we ascend the mountains; but when we pass to some distance from the equator, the seasons upon elevated places become different from what they are in low situations. In the latter, the prevailing action of the whole year is summer action, and the modifications of wet and dry, without much reference to change of 
temperature, farther than the secondary influence of evaporation in producing cold, which, however, is often greatcr than one would suppose. Within the tropics, snow never falls on the low grounds, or at moderatc elevations; but there arc frosts on the hills, and hailstorms which sometimes descend into the plains and do great damage to the more tender crops. From this cause the cultivation of indigo in the valley of the Ganges, which is now onc of the staple articles of Indian farming, and of which between nine and ten millions of pounds arc anmually sent to Britain from the lowcr vallcy of the Ganges alonc, is rendered a liazardous crop, though when no casualty occurs it is a very profitable one.

In all those tropical comntries of which we have been speaking, the decomposition of the ycar is effected without any particular Autumnal agency, and the conserving part being against lieat and drought, and not against cold, is provided for by the peculiar structure of the plants themselves. Plants there arc so numcrous, and so varied in their structure and habits, that the whole space to which we are restricted for the Autumnal characters of all latitudes and climates, would not suffice for half of them. But we may statc that, in general, the epidermis of such plants is so formed that it is very decidedly a non-conductor of heat; so that, though the ardour of a vertical sun beats, day after day, upon the plant, standing upon parched earth or heated sand, the internal part of the plant remains as cold as if it were growing in Lapland. This is partly occasioned by the smooth surface of the epidermis, which 
reflects away the heat, and partly from the little evaporation that goes oul at the surface. There is a curious property in those plants which remain in leaf abiding the utmost fervour of the tropical sun. The means by which it acts, and the mode of its action, have not been explained, and perhaps they are not explainable on the principles of science as at present known. But the fact of its operation is well known; and it is certain that plants which are clad in this tropical armour, can endure vicissitudes of the atmosphere which would speedily be fatal to those which are natives of climates the most inhospitable in respect of cold. The chief peculiarity in the action of such plants is their great power of absorbing moisture, and the small tendency which they liave to give it out. The absorbent power does not reside in the roots, or in any specific organs; for the plants continue not merely to live but to grow, though the earth, as far as their roots extend, is as dry as dust. The moisture which thus sustains their life and growth is not derived from the soil; for water-melons, which are not named from any reference to their growing in or near water, but from the cooling nature of the juice of their fruit, which is as refreshing as a fountain in the desert, grow to the weight of fifty or sixty pounds each fruit, upon sand, in which there is no water till a depth of two hundred feet or upwards is attained, and where not a drop of rain falls to aid them in their growth.

Such plants are circumstanced in a manner in which no plant of our temperate climate could subsist for even a week, and yet they grow most luxuriantly there, and 
come to even greater maturity than they would in humid grounds, or exposed to those regular showers, which are so essential to the growth of our vegetation. That they must absorb a great deal of water, or of the elements of water, is certain, from the succulent nature of their leaves, for the plants of the hot and dry deserts are internally the most succulent of all plants; and we have an approximation in the house-leeks and several other plants of our own climates, which grow upon house-tops, old walls, and other places, where they have little soil, and very limited means of deriving a supply of humidity by spongelets or absorbing organs upon the epidermis. It is obvious, therefore, that those plants of the desert must receive that moisture which not only preserves their existence, but in many of the species supports a vigorous growth, and under circumstances which we would consider the most unfavourable, by absorption through the epidermis, close and poreless as that epidermis seems to our inspection. 'The process of absorption by a living subject, whether a plant or an animal, is, however, one the mode of which is very obscure. It is doubtful whether, even in the case of ordinary nourishment or growth, the new matter ever passes in substance into the body of the plant or the animal. On the other hand, the probability (for there is no positive certainty) is, that the absorbed matter, when it passes into the system of the plant or the animal, so as to become part of that systemto be changed from dead matter to living, is always in an atomic state, that is, divided into parts so small that neither they nor the passages through which they entcr, 
can possibly be discovered by any microscope. The matters which are given out by the living animal or plant, are dead matters when they are given out; and thus they are given out by pores or openings of some dimensions, how small soever those dimensions may be.

This is a very important matter, and one the knowledge of which is indispensable to a proper understanding of the working both of plants and of animals, and their adaptation to different climates and different seasons; and it is a matter which can, perhaps, be more advantageously studied in the plants of the desert, which are to all appearance deserted there by the ordinary assistants of vegetation, or at least by what we consider as such, and thrown entirely upon their own resources; for in them we can contemplate the single subject and its adaptations much better, than when it is confounded with a number of others which we regard as auxiliary, and contributing-we camut tell how much-to the result which we observe; and yet we nerer can understand as we ought how a plant or an animal is affected by the action of Autumn, or of ally other season, unless we have some notion of the function of an absorbing or assimilating surface.

We are apt to be misled by an error which is very prevalent upon such subjects as this, and which the generality of the printed books tend more to confirm than to correct. We are apt to look upon the action of a living vegetable or animal as being mechanical, or chemical, or a compound of the two; whereas, the very slightest consideration of the case might satisfy any one that the real principle, the operating power, both 
in vegetable and in animal action, is not only different from every kind of mechanical or chemical principle, but in direct opposition to them,- - that the plant or the animal maintains its place in nature as a distinct being, only so long as it can act effectively in opposition to the laws of dead matter, whether we regard those laws as chemical or as mechanical, according to the ordinary distinction made by the schoolmen, though it must be confessed that that distinction is by no means clear to the comprehension of ordinary readers, and the boundary is by no means well defined even by the said schoolmen themselves; inasmuch as that all chemical action passes into mechanical action when carried to a certain extent, - of which we have an everyday example in the steam-engine, which furnishes, by chemical agency, the most energetic and at the same time the most manageable power which we possess, and of which we have still more energetic though less manageable instances, in the explosion of gunpowder, and also frequently attended with the most direful consequences, in the blowing up of the boilers of steamengines by an excess of heat and a deficient supply of water, resolving the steam into its constituent gases, oxygen and hydrogen, the expansive force of which at the instant of their separation is greater than any mechanical resistance that we can name. There are also instances of an opposite kind, in which substances are melted, or burned, or otherwise have their chemical constitution changed by rapid motion, and other mechanical means, such, for instance, as the hammering of a rod of iron until it becomes red hot. 
These mechanical and chemical actions, and also the passing of the one into the other, we cam understand; and the knowledge which we obtain of them from our own cxperiments is exceedingly useful, as applicd to explain the phenomena and the action of all those parts of nature which are not commected with life, either animal or vegetable. But when we comc to consider the relation between action in dcad matter, and any of those actions of life, we find ourselves beset by difficulties which we camnot overcome; because the transition of any portion of matter from the dead to the living, or from the living to the dead, whether the living state be that of animal or of vegetable, is a mystery beyond the limits of our ordinary philosophy. Some have indeed stumbled upon what they supposed to be the steps of the transition hcre, or at lcast a vague sort of approximation to them, and we have had, and have at the present day, men seated in profcssorial chairs, authorized and appointed for the instruction of thc young and the ignorant, and guarded against public inquiry by "Doctorial and other dubbings," who, in violence of logic and common sense, and outraging even the shadow of philosophy, speak of "organic matter waiting to be organized," and so docile withal in its nature, that it is more plastic than Hamlet's cloud, which, in the opinion of the old courtier, was in the consecutive moments of his speaking, "backcd like an ouzel-and very like a whale;" for this plastic matter is, it secms, quite ready for sea or for land, for plant or for animal, and, just as the waves set or the winds 
blow, it may become a sea-weed or a lichen, a lettuce or a lion.

As long as doctrines of this extraordinary nature are maintained by those who are actually prepared and appointed for the teaching of others, so long must we expect that much both of ignorance and error will abound in society; and, therefore, despite the doctors, it behoves every man who loves the truth, and who has any opportunity, how apparently slight soever, of maintaining the truth, to expose such absurdities, by whomsoever they may be abetted, because the more high and honourable the party is in station or repute, the more he is a real pest in the way of knowledge.

This is not a mere error in the philosophy of matter, such as that of mistaking one substance or species of material action for another; for it strikes directly and inmediately at that fundamental doctrine of all religion and all morality, the creation of the world by a being of infinite wisdom and power, and of every living creature after its kind, as is expressly declared in the sacred vohme. It is worthy of remark that, in the account of creation given in the first chapter of the book of Genesis, though those portions which could not easily be explained to human beings, and are not essential to any important point of human belief, are very lightly passed over, the specific creation of the individual kinds of plants and of animals is clearly and expressly set forth as an emanation of the Deity himself: "God said, Let the earth bring forth grass, the herb yiclding seed, the fruit-tree yielding fruit, "fter his lind;" and 
again, "Let the earth" bring" forth the living creature after his kind, cattle, and creeping thing, and beast of the carth after his lind ;" and in order to guard against chis very mistake, this supposition that there is or can be, in the mere matter of the carth, of itself, and without the germ or emanation of life, originally from the Crcator, and subsequently transmitted from gencration to gencration, a power of originating any one animal or plant, even the most simple and the most microscopic, it is added: "Gro MADE the beast of the earth after his kind, and cattle after their kind, and evcry thing that crecpeth upon the carth aftcr lis kind."

It would be irrelevant to our purpose to enter into the philology of these most important passages. We may, however, mention that the word translated "grass" obviously does not meall the gramina, or grasses in our modern sense of the word; for these are included among the "herbs yielding seed," and are, in fact, the most important of all seeding plants, as they form the bread-corn of every nation on the earth. The word seems rather to denote those humbler vegetables, the lichens and others, which have no visible seeds; for they are they which immediatcly clothe the surface-the earliest vegetation upon new lands, and they merit the distinctive epithet of contrast with "herbs bcaring seed."

The introduction of this principle of life, as an element of action in all the displays of nature, whether seasonal or not, occasions a difficulty which does not occur in any part of matter that comes wholly within the laws of chemical and mechanical causes; and in the study of this principle, or of its results, which are, in 
fact, all of it that we can study, we do not derive the least assistance from any or all of their principles. When a plant or an animal overcomes a mechanical resistance, we are in the habit of saying that it does so by mechanical means; and when it overcomes a chemical resistance, we say in like manner, that it does so by chemical means; but our observation and expression do not, in any case, reacl the origin of the action, or the manmer in which the first and esssential part of it takes place. In what we call the mechanical structure, both of plants and of animals, we find, in the organs by which these actions are performed, instances of contrivance and adaptation so perfect and beautiful, that our choicest art not only falls far short of them, but differs from them in kind as well as in degree; and when we endeavour to understand and to describe that which pnts the animal machine in motion, we are left entirely without any one relation or analogy that will connect it witl our mechanics; and when we have simply stated that it is "the action of life," we lave reaclied the utmost bound of our philosopliy, and any thing fiurther that we attempt to say, is not explaining, but, as is emphatically expressed, "darkening counsel by words without knowledge."

If we have recourse to chemistry, and resolve the animal or the vegetable with the utmost nicety of our analysis, into the different substances of which its body is composed, we are still not a jot nearer the principle of life than when we look upon it in the living state, and the performance of its functions. Indeed, we are not so near; for in the living plant or animal, we see all of 
life that can be seen; and before we can bring our chemistry to bear on it, it has ceased to be a living thing, and so our analysis of it tells us nothing more of the nature or the functions of life, than the analysis of a mineral dug from the deepest mine.

In all the phenomena of the animal and vegetable world, and more especially in the autumnal phenomena of the latter, the principle of life is a most important element; and the reason why it is more important to a right understanding of the action of Autumn than of that of any other season, arises from the fact, that in the Autumn, both parts of the action of life, or the action upon life, are concerned,-the conservation of that which is necessary for the following spring, and the decomposition of that which is to be in future useful only as matter.

We have already mentioned that the external ageney against which the tropical vegetation his to be protected, npon the low grounds, in the Autumm, is an excess of dry heat. At great elevations in those latitudes, and in the high latitndes, the external action against which the vegetables have to be preserved, is the very opposite of this--extreme humidity, or extreme cold, according to the local circumstances. Now, as these are obviously the reverse of each other, the means by which plants are protected must also be quite different; and we must take this into our consideration, if we wish to understand the differences of preparation which the plants of different climates undergo in the Autumn. The decomposition of the parts which had done their office, is a distinct matter. We have alrearly said that, 
in tropical countries, the influence of the elementsthe powerful influence of the sun, the atmospheric air, and the heavy rains, are sufficient to effect all that part of it which more peculiarly belongs to the year, without the calling in of any, or at least of many of those agents which we shall afterwards have more particularly to notice as the autumnal army-the specific and appropriate decomposers of organic matter in temperate and polar latitudes.

Viewing, as we must, the action of life as a matter, with the intimate nature of which we can never become acquainted, we must at once admit that there is in a living membrane, a power of which no analysis of dead matter, even although the subject is the very membrane whose living action we wish to ascertain, can give us even the slightest knowledge, so far as we can judge of it; the action of life is an action of surfaces only, and in this it agrees with electricity, and with various other kinds or modifications of action, which also refer only to surfaces, and are not varied in their intensity by increase or diminution of the thickness of that which presents the surface. In this view, which, though shadowy, is the clearest that we can obtain upon so nice and difficult a subject, it should seem, that while the membrane is alive, the two surfaces of it perform different functions with regard to the very same substance. The one, for instance, absorbs matter probably divided to the primary atom, as we have frequently had occasion to state; and the other secretes, or gives out matter, derived from the absorbed elements, but totally changed in its compositions and properties. This, how- 
ever, contines only so long as the membrane is alive; for the moment that life eeases, it beeomes passive to all external ageneies which are strong enough to act upon it, and transmits whatever is eapable of passing through it with equal ease both ways, unless, in so far as can be easily explained by the text, the eolour, or some other property of its two surfaees, be eonsidered simply as matter. A fruit remaining on the tree affords a familiar, and, at the same time, an appropriate illustration of this. As long as the said fruit continues in vigorous life, the epidermis or membrane, with which it is invested, eontimues smooth and expanded; and there is no doubt, that besides what may come from the tree through the pediele or stalk, it absorbs matter from the atmosphere, which matter it assimilates and appropriates to the purposes of its eontents; but the moment that the fruit dies, this action of the epidermis eeases, it shrivels, and the substance of the fruit diminishes without being taken baek again into the tree by means of the pedunele. When the fruit attains its full maturity, this action of the epidermis ceases, and as it has then passed into a state of autmmual preservation, the separation of the mature fruit from the tree is not attended with that shrivelling whieh is almost invariably displayed in an immature one. In leaves, and more especially deeiduous leaves, whieh are adapted for aetion in the spring and summer only, this difference between the living membrane and the dead is even more conspicuous. Leaves, when in the full vigour of their growth, become flaceid and wither mueh sooner, and also shrivel up to a much smaller and more brittle volume than leaves 
which have passed the vigonr of their growth, and are subsided into ripeness. Not only this, but they are much more affected by differences of external action upon them, when in the living state, for the most vigorously-growing leaves and plants are the first to droop in a hot and drying day; and, indeed, the leaves even of the very same species of plant are so different in this respect, when grown in humid and in dry atmospheres, that we can readily understand why these should be great in different climates.

But the power of the living vegetable in resisting heat, is as obvious as in resisting evaporation; for as long as the leaf, the fruit or any other portion, which is annual, or otherwise seasonal, remains in rigorous action, it preserves a wonderful uniformity of temperature, even under the most varying state of the air, and of the heat and light of the sun. But as soon as its proper action ceases, it approximates dead matter in the readiness with which it is lieated and cooled. A very striking and satisfactory instance of this may be observed in the old and the new leaves of laurels, hollies, acubas, and the other evergreen shrubs which are common in almost every garden. The young leaves of these are, in the healthy state of the plants, very considerably advanced, before the old leaves begin to show much change of colour or other evidence of decay; but if, when the sun beats warm upon them, the finger is applied, the young leaves will feel cold, and the old ones warm; and as the season advances, and the old ones come nearer to that stage in which they are to heal off from the plant, this difference will be found to 
liave increased. But though the old leaf is thus evidently much more obedient to the alternations of heat and cold than the young leaf, it is by no means so liable to be injured by the extremes of their action. The heat warms it sensibly to the touch, but does not make it droop, and the cold is also felt in it, but the returning heat does not wither it as it withers the young leaf. In these plants, we have the action of spring in the young leaf, and that of Autumn in the old, brought together, and thus we can compare them more easily than we can compare the effect of the two seasons upon plants at their respective times in the calendar. The leaves of those evergreens also give us at least a close approximation to the vegetation of tropical countries; for the Autumn of their leaves is really a tropical Autumn, as it is produced by the heat of summer. It is of no consequence of what latitude or region of the globe those evergrcens may be natives; for they follow the same law in all climates, from the equator to Lapland, and some of them are the last plants we meet with in that inhospitable region. They also resemble the tropical plants in their flowering and fruiting, the flowers and the fruit being produced upon the shoots of the year, along witl the young leaves, though the fruit does not, generally speaking, ripen until the next season, and sooner or later in that season, according as the leaves are slied. We have examples of this in the holly, the pine, and the juniper, and there are gradations in various other plants. These plants grow at higher clevations above the level of the sea, as we approach the equator; and thus we have a regeta- 
tion, which is uniform in its seasons, along the whole quadrant, as far as vegetation extends, - so that there is an Autumn produced by the hot season in some plants of every latitude, only in the cold latitudes, and the lofty situations of the warm ones, two seasons are required to prodnce this action; while in the seasonal plants of warmer latitudes and places, a single year, or even a shorter period in the case of some of them, suffices for the rmming of the whole comrse.

These facts, and they are facts which any one may verify by observation, show very clearly that it is quite impossible to understand the results of antumnal action in any one latitude without some knowledge of the same in every latitude; and this is the reason why we have endeavomred to explain, in as far as it is explainable, the action of the sun and atmosphere upon vegetables, in connexion chiefly with the vegetation of the tropics. Having done so, we shall take a rapid glance at the general action of the season, or rather the effects of that action in latitudes and at elerations above the surface, where the characters of the warmer places within the tropics, and the seasonal displays of their vegetation, in so far as it lias snch displays, are departed from.

Taking then the low-lying and rich portion of the equatorial lands as that where there is the minimm of seasonal action, and where that action depends in a great measure upon the presence or the absence of humidity, as the minimum or beginning of scasonal diversity, there are two directions in which we can follow the series of increasing differences,-we may follow it in elevation up to the mountain-top, where 
vegetation ceases, becausc the temperaturc, cxcept under the immediate influence of the sun's prescnce, is below the frcezing point all the year round; and wc may also follow it in latitude, until, from similar causes, vegetation again ceases, only the causes of its cessation arc distributed in very different portions of timc.

Upon the summit of the intertropical monntain, the rays of the sun beat with great rehemenec during every day of the year; and dming crery night the temperature of the air sinks considerably below the freczing point. It must be understood, lowever, that independently of the greatcr rarity of the atmospherc, and of the small radiation of heat from a surfacc covcred with snow, as compared with that from a surface not so covered, and especially from the surface of the naked earth in a warm latitude, or at a warm scason, the daily influence of the sun is inferior to the oppositc influence. That this must be the case will be at once understood when we consider the successive elevations of the sun during the time it is above the horizon. The average time that it is so during the twenty-four hours, is twelve hours. Immediately under the cquator it never varies from this, and for several degrees on each side of the equator the seasonal deviations from this are so small that they arc not worth taking into the account. 'The small addition to the sun's appearance above the horizon arising from the refraction of the atmosphere, may also be omitted in the general estimate; and thus we may say, that in these latitudes the sun rises at six and sets at six all the year round, $o r$, in other words, that there are twclve hours of the 
presence of the sum alternately with twelve homrs of its absence. Now, during the quadrant of the sun's apparent daily path, which extends from sumrise till the luminary is on the meridian at noon, the sun has the same gradations of elevation above the horizon as it has on the quadrant of the earth's meridian, from the pole to the equator, at the equinox; and during the quadrant from noon till sumset, it has the same succession of elevations irr a reversed order. Thus, at sumrise and sunset, the influence of the sun is a minimum, and its momentary effect is no greater than on the poles at the time of the equinoxes; and it gradually increases to its maximum at mid-day, and diminishes in a similar manner to the time of sunset. Some portion of the morning elapses, therefore, before the sun's influence upon the surface of the earth is equal to that of the winter sun in those high latitudes, where snow lies unthawed for several months of the year. Thus, a considerable portion of the day must be spent before there is any thawing of the night's frost, upon a lofty mountain within the tropics; while, in consequence of the time required for producing an effect, the hottest period of the day will be about two or three o'clock, and the freezing temperature will be again arrived at a few hours after sunset. Thus, though the rays of the perpendicular sun have just as much heating power upon those mountain tops as they have upon the low grounds in the same latitudes, the effect which they produce upon the surface is rery small; and as dependent upon the sun only, there is but little melting of the snow during the day, or accu- 
mulation of ice during the night; and this being the case, there is very little seasonal change of vegetation, in the highest situations under the equator where vegetation grows. 'The snow upon the lofty mountains there may be said to be permanent at the same level, except in so far as it is affeeted by the seasonal shiftings of the atmosphere from hemisphere to hemisphere, which bring alternate rain and drought, the first of which tends to produce eold, and the seeond heat. Therefore, let us take what altitude we will, there is really very little seasonal aetion immediately under the equator, except in so far as the latter part of the rainy season brings frost there, which is not the case on the lower grounds. In eonsequence of this tendency of the rains to bring frost, the vegetation in very lofty places must have an antumnal defence something similar to that in the high latitudes; but as this depends not upon the general action of the sun, but upon the rains, which set in at different times of the year at difierent places, it does not admit of reference to one specific time, or even of general explanation. There is another mountain phenomenon resulting from seasonal action, which does not oceur in these equatorial situations, namely, the formation of glaeiers, or fields of iee, lower down than the mountain snows. Those glaciers, though permanent in their larger masses, or probably diminishing in some places and increasing in others, owing to local circumstances which eannot be explained upon general principles, are spring formations. The heating of the earth does not keep pace with the solar influence; and thus while the sun aequires so mueh power during 
the day as to melt a certain portion of the snow, and send the water down the slope, the water so sent is frozen during the night; and if the situation is favourable for its accumulating, its mass soon becomes such as to resist the power of the summer sun. The warmer parts of the temperate zones are the situations in which those glaciers are chiefly to be met with, and the most remarkable ones are found in the Alps. There are none upon any of the British mountains, because none of these mountains are of sufficient height for having their summits clad with snow the whole summer round, thongh several of those in Scotland retain snowy patches. In such high latitndes as the Grampians, the year is considerably advanced, and the day much longer than the night before the snows on lofty summits give way, mless to the inflnence of atmospheric currents; and thus there is not a sufficient return of cold during the night to convert into ice the snow which has been melted dmring the day. On the northeast sides of some of the mountains, which have lofty precipices there of a horse-shoe form, there are slight approximations to glaciers, or rather, perhaps, we should say indications of the mode in which those vast fields of ice are formed; for in a few of those peculiar momntains, there are small lakes at the bottonns of the precipices, the water of which remains in a state of ice all the year round, though a stream is discharged from it dming the summer. The reason is obvious: those precipices facing the north-east are turned away from the most powerful action of the sum; and, therefore, in the early part of the year the cold of the night in 
them predominates over the heat of the day; and while the snow melts away from the upper part of the preeipice, the eold thereby produced, and the shading of the bottom from the direet rays of the sun, oeeasion a freezing temperature there.

As we proceed farther to the north there is still less tendeney to the formation of glaciers than there is in the Seottish mountains; because, before the mountain snows there yield to the influence of the season, the season is mueh further advaneed, and the day is mueh longer in proportion to the night.

This aetion of the spring, or the summer, as it happens, in the elevated regions of the several latitudes, is neeessary to a right understanding of the autumnal aetion. In every thing which is completely seasonal the Autumn is just the converse of spring; and as spring has to eontend with an aceumulation of winter cold, greater in proportion as the winter is more severe, so autumn has to contend with an aecumulation of summer heat, greater in proportion as the summer is warmer as compared with the winter. Both these eircumstanees tend to inerease the violenee, and to shorten the duration of the partieular seasons to whieh they refer. This is a very general law of nature, and one of whieh you onght never to lose sight. Mechanics in estimating the effeet of compound machines, are well aware of the invariable truth of the maxim, that "What is gained in power is lost in time, and what is gained in time is lost in power," the product of these two being the expression for the work done; and, therefore, as the one increases the other 
must diminish. But in this case the numerical values of the two, in order to produce the same result, are not always the same. The result is a maximum, or the most advantageous possible when the two are equal; and in proportion as they become unequal the effect diminishes. Any one may understand the general principle of this by taking two numbers whose sums shall in all cases be the same, and which shall be equal to each other in one case and unequal in every other. Say the numbers 4 and 4 , whose sum is 8 , and the unequal divisions of that sum in whole numbers are 3 and 5,2 and 6 , and 1 and 7 . The products are respectively, 16, 15, 12, and 7 , the first being the product of the equal numbers, and the others diminishing until the product in the case of the greatest inequality, that is when one of the numbers is 1 , the product is one less than the sum of the numbers.

We cannot, however, apply this rule arithmetically to all cases, or, indeed, with perfect accuracy to any case of natural action; because there is one of the clements-and the most important one-the natural principle or active power, which camnot be reduced to an arithmetical expression. The time can always be so reduced, and we can judge in a general way of the increase or the diminution of the power, but we cannot apply our arithmetic so as positively to say that it is twice or one-lialf, or any other definite proportion in one case of what it is in another. We are unable to do this even in those cases to which we apply measuring instruments, and read the degrees of their rariation arithmetically, - as for instance, when we cstimate heat 
by a thermometer, humidity by a hygrometer, light by a photometer, and so on in other cases, the names of the instruments merely expressing that they are measures of the agencies which we compare by means of them. But in these cases it is not the active power that we measure, it is the effect of that power upon the measuring instrument, and upon that instrument only. Thus, in the case of heat, the degrees shown on the seale of the thermometer are nothing more than the degrees of the expansion of the mercury, the spirit of wine, or whatever other fluid the instrument happens to contain; and all that we can infer from it is, that when the degree of expansion in two cases is the same, the action of heat to which the instrument is exposed is also the same in both. This is a relative standard which serves very well for comparing degrees of heat, though it gives us no information of the absolute heat in any one degree. The common thermometers, which consist of fluid enclosed in a glass ball, with a stem to it closed at the opposite end and containing no air, show heat by the expansion of their contents. But there are others intended for measuring, or estimating much higher temperatures than those instruments can bear; and they are called pyrometers, or fire-measurers. Some of them are composed of earthy matters which can bear a very strong heat without being meited, but which contraet, owing in great part to the giving out of water, with which they are intimately incorporated. They are, generally speaking, formed of clay; and as they do not expand again when cooled, an equal contraction of two pieces exactly agreeing with each other in form. 
and size, is presumed to indicate an equal degree of heat in the two cases. We say "presumed;" for even in this simple case there is a-little uncertainty, upon the very principle of gaining in time and losing in power, which we are endeavouring to illustrate, and in consequence of this it is at least lighly probable that long exposure to an inferior action of heat will produce the same effect as a more brief exposure to a higher one. In order to be perfectly accurate in our comparison we must, therefore, take equal times into our consideration, otherwise we shall be in danger of underrating the power which acts during the short time, and overrating that which acts during the long. Equal expansions, or equal contractions of the same instrument, or of instruments exactly similar taking place in exactly equal periods of time, are, therefore, the grounds upon which we infer equal actions of lieat, and the same rule applies to every other kind of action which we can estimate by its effect upon an instrument.

The principle which we have now attempted to explain is one of essential importance in forming an accurate judgment of the seasonal action, autumnal or otherwise, in the different latitudes. In temperate climates, say about the middle of the quadrant, or fortyfive degrees of latitude, in the nortliem hemisphere, which is the most seasonal one, or a few degrees more or less, according to the local circumstances, the seasons are gradual in their action; and spring and Autumn are so extended in their duration, that each of them occupies in favourable situations not mucl elevated above the mean surface more than a fourth part 
of the year. Here; therefore, whether we regard the grand causes of seasonal action as working for the spring, or working for the Autumn, there is a considerable gain in time, and consequently a loss of power could be borne, and the same eftect produced as if the time were more brief, and the energy of the power greater. But the solar influence upon every latitude is in proportion to that latitude-local causes being the same, whether the spring and the Autumm are of longer duration or of shorter. Hence, the power which, in consequence of the longer time, cond be dispensed with to produce the same result, is not withheld, but is a surplus power, an additional advantage, which those latitudes possess over both the tropical and the polat ones. It is quite true that the monentary action there is never brought up to the same intensity which it has upon the low grounds near the equator, or even to that of the short summer of the high latitudes, where the night is either very short, or sunless or sunlight throughout; and thus there are degrees of obedience to this action in the vegetation and also in the seasonal animals, at both extremes of the quadrant, which do not, and which cannot take place in the middle latitudes. But notwithstanding these, the niddle latitudes have advantages over both the extremes, not only in the longex duration of their spring and their Autumn, but in the absolute quantity of the working power of nature during both these seasons. 'There is no better' ilhustration of the truth of what has been said of the superiority of those climates, not only in the mildness of their seasons, but in their excess of beneficial yearly 
action above what theory would assign them, and even the observed average temperature, than that they have in all ages been the regions in which the human mind has had its greatest and its most beneficial development, and where the human hand has been most advantageously turned to every description of useful labour. If we look at the history either of ancient or of modern times, we find that this has been permanently the case. Neither the people of the tropical countries nor those of the polar ones, have ever become civilized of themselves, and far less have they distributed civilisation over any other parts of the earth, though there are instances in which hordes emigrating from the north in a state of great barbarity, have improved after a long residence in the middle latitudes. We have no instance of any considerable movement of the human race from tropical climates into temperate ones; and it does not appear that the contrary movement has had any beneficial effects either upon the physical constitution, or the intellectual, or moral character.

It is worthy of remark, too, that the whole of what may be called the great events of the history of mankind, have taken place, or at least had their origin, in these middle latitudes. Egypt was, no doubt, gorgeous and savage in grandeur, and possessed 'considerable, thongh comparatively useless, learning, in very early times, and that Upper Egypt reaches the tropic, and is partly within it; but Egypt, though nearly a tropical country in situation, is a remarkably seasonal one; and in the extreme south of it, the winter nights 
on the rocky liills are intensely cold, while, at particular times of the year, there are heavy showers of hail, or rather of pieces of ice. But we cannot judge, with any degree of accuracy, of the former climates of different latitudes, or of the nature of their seasons, from what we observe at the present time. Even now, the winter is often intensely cold, upon the elevated grounds in the southern parts of Greece, in Calabria, in Sicily, and in the Isles of the Levant,-every where, indeed, under the exposure to the uninterrupted winds which sweep from the Pole across Russia, the Black Sea, and so on to the Mediterraneall; and this influence is felt to a very considerable distance up the valley of the Nile, and was, no doubt, more extended and more powerful before so much of the adjacent country was converted into deserts-for those deserts, as they become lieated during the day, deflect the cold air from the valley, and disperse it upward through the atmosphere. It would be foreign to our purpose, as well as incompatible with our limits, to trace the progress of human improvement, or to show how much it has been dependent upon that average species of climate, and protracted duration of the spring and Autumn, which is the most advantageous. But any one who chooses to advert to the history, will find the voice of all ages in favour of it.

There is, however, a single circumstance, which we may mention, as tending to show how the progressive changes of climate, and those of the centre of civilisation (so to express it), have proceeded together.

Of India, we cannot speak with any thing like certainty; but we lave no reason to believe that there 
ever was any very high degree of civilisation there. At all events, whatever it may have been in itself, it never, by the effort of its own population, produced any decided effect upon the rest of the world; and so we may leave it out of the estimate. Doing this, and taking the range from Persia to the Atlantic, we find the centre of the most early civilisation about the parallel of thirty degrees north latitude; that is, passing through Egypt and Babylon. After a time it was farther to the north, and Tyre and Carthage were the chief seats of art and enterprise. At a period still later, the parallel of forty was the average line; and at the present time it has passed the middle of the quadrant, and may be reckoned somewhere about the parallel of fifty. We do not know the state of the parts remote from this general parallel, in the earlier periods of their history, or eren during the greater part of it, as the average line of our information is that of civilisation and enterprise. But there is every reason to belicve that the northern countries were then much more covered with woods and marshes, and that the seasons were more severe, and the country altogether much less fitted for agriculture, or for the support of the more nseful domestic animals, than in modern times; while the woods and marshes prevented that interconse, without which there can be little or no hmman improvement.

It is an agreeable proof of the mity and perfection of the system of nature thus to discover that man, who, in his bodily structure, is the most universal of all terrestrial beings, and who, by his mental contrivance and resource, can subsist under far greater clianges 
than any of the rest, so far obeys the law, thiat he succeeds best in those latitudes, where the general action is most mild, and at the same time most favourable.

The latitudes to which we allude are those in which the polar and the equatorial actions are most nearly equal to each other. Whatever the season is, whether spring or Autumn, the one of these two actions may always be considered as the producing power, and the other as the resistance by means of which that power is enabled to bring up the effort to the useful degree; and from their being thus in the even balance, a very little increase in either of them causes the other to give way. It is this which makes both the spring and the Autumn so prolonged and so gradual; and enables the skilful cultivator to extend seed-time and harvest, in one or another of the plants which he cultivates, over a very great portion of the year. But, although this balance of the polar and the equatorial actions enables man to select his crops and his seasons, and adapt them to each other from experience : yet, in wild nature, the seasons of those climates follow in nearly the same succession year after year.

In the more extreme latitudes of the quadrant, the state of things is of course different. At the confines of those parts which have a decidedly tropical character, the seasons are consequently mixed, or rather there are double seasons in the course of the year,-a tropical winter in the warm months, and a polar winter in the cold ones; but both of these are much less decided in their character, than where either species of winter arrives singly. Each of these winters is preceded by 
its own Autumn; and both winter and Autumn tell upon one part of vegetation from the drought, and upon another from the rain or snow. Generally speaking, the Autumn of the lierbage precedes the drought, and so also does that of many of the bulbous-rooted plants; and the Autumn of the timber trees precedes the cold and humid winter. With us, the Autumn of the hay-fields falls in the summer, the Autumn of the orchard and the forest agrees with the Autumn of the Calendar, and the Autumn of the corn-fields is intermediate between the two. In regions further to the south, the harvest of the grasses is over, and they are overtaken and parched by the hot and dry winteras we have termed it from its effects-before the time that our field grasses come into flower. In such places the harvest of the grain plants falls about the time of our hay liarvest; and still farther to the south, it occurs, in some of the kinds of grain, as early as our spring.

As we proceed northward into higher latitudes, the dry winter, or pause of nature in the hot months, which occasions the double seasons, becomes less and less apparent, until it at last vanishes altogether, and the seasons are single in the year, as respects that part of the vegetable kingdom from which we have drawn our principal illustrations. Still farther to the north, the winter encroaches on both the spring and the Autumn, and continues to do so till both these seasons are nearly obliterated; and after this it continues to encroach both ways upon the summer, till that is at last wholly or nearly obliterated, and the polar winter holds dominion over the year. 
As this tendency toward winter increases, the character of the native vegetation changes, and the cultivated plants are fewer in number, and their periods of harvest are changed. In mortherly places, wheat does not ripen, unless it is sown in the Autumn of the preceding year; and then it suffers in winter, unless in places which are well sheltered, or where the snow covers it until the spring fairly sets in. The cultivated plants have, lowever, been collected from very different climates; and as no culture can wholly change the climatal nature of a plant, we cannot take them as perfect indices to the seasons in any one latitude. If, however, the reader has attended carefully to the scope of this chapter, he will be able to form a general notion of the office which Autumn has to perform to the seasonal vegetation of the different latitudes and climates of the quadrant; and thus he will be in so far prepared for entering upon the consideration of the mode in which the work of the Autumn is performed, and the agents and means which are employed in the performance of it.

It is necessary, however, to bear in mind that, when we speak of the seasons as having certain characters, and the Autumn as laving certain operations to perform, in any particular latitude, we are not to be understood as saying, that the state of these things is the same all round the parallel, even where the height above the mean level is the same; or that all places which have their antumnal action the same, have necessarily the same latitude. There are so many local causes that affect the characters both of places and of seasons, that before we can speak with precision of any 
one, we must be in possession of its particular case from actual observation continued through a series of years, among which we must include the changes that have taken place, whether in the course of nature or by the operations of art. To do this, even for one place, is incompatible with the nature of a short sketch; and thus we must content ourselves with the broad outlines of the principles.

We cannot lay down a rule even for the temperatures; for the isothermal lines, or lines of equal mean. annual temperature, never lie nearly on parallels of latitude, but trend northward in some places, and southward in others; and they are not the same in any two consecutive years. Even if we could depend on the mean temperatures, which we cannot, they are no guides to the seasonal variations; for, of two places with the same average temperature for the year, one very often has the seasons mild, and passing gradually into each other, while another has them in extreme contrast, and with violent weather at the changes. Upper Cinada and middle Europe form a case in point; for in Europe the seasons are mild, and in Canada, with the same temperature on the average of the year, it is hotter than India in summer, and colder than Lapland in winter: and, as the Autumns of such places. have different labours to perform, they must be furnished with different powers for the performance, in terms of that general and beantiful law of nature, according to which every agent is fitted for the performance of its work, in that inestimable manner which is in itself an' ample demonstration of the being and a ttributes of God. 
CHAPTER III.

AUTUMNAL DECOMPOSITIONS, AND THF AGENTS AND MEANS BY WHICH THEY ARE l'ERFORMED.

$W_{E}$ take the decomposing action of the Autumn, which is exerted in bringing the old regetation of the year to the dust, in precedence of its ripening or preserving influence; because it is more decidedly an Autumnal action, and not, like the other, performed by the plants themselves, and as such, really the perfection of the Summer action; and we shall consider it not only as it refers to the decomposition of that which has been produced within the year, but as referring to that of organized vegetable matter generally. We might also, without much impropriety, have included the decomposition of animal matter, for that is an action of the same kind; but it is not so strictly seasonal as that of vegetable matter.

It has been mentioned, that in tropical climates, the action of the elements is sufficient to effect all the seasonal decomposition of vegetables, with much assistance from special agents; and that the decomposition of the more solid and durable parts, when it does not yield II : 
to the great changes of temperature and humidity, which are the elemental means of decomposition, are reduced to dust by the direct labours of vast myriads of insects, -insects, whose numbers are so great, that the broods of the season might sufince to reduce to powder the most ample forest on the face of the globe. Their labours are, however, restrained to the need there is for them by their very nature; for though no vegetable substance is proof against the action of their little jaws, they do not assail the living timber of trees, or injure any of the parts in which the vital action is carried on. Dead wood is that upon which they feed; and when a tree is dead in the interior, which is a condition to which the greater part of exogenous trees have a tendency to come, and a greater tendency in warm climates than in cold, these insects will sometimes excavate into a system of tubes, without any external appearance of the depredations they have committed. In Australia, where the forest trees appear to have a particular proneness to internal dying, these insects often attack painted posts near the houses of the settlers,-or the posts and other timbers of the houses themselves,-and eat them away to the thin portion which is impregnated by the paint, before the owners have any conception that they are in the least injured. They generally enter the trees at the lower part, and they come in secret, and often under the mask of a covered way, which they construct as they advance; and which they carry on, not only from tree to tree, but partly up the trunk, if the portion next the ground is not quite suited to their purpose. Some of these creatures are not only blind, but so 
impatient of the action of light on their bodies, that they are never seen in the open air during the day. Still they make their corered way as directly toward the tree which is to furnish then with food, as if they were not only provided with eyes, but had actually made a previous survey of the place, with all the science and sagacity of experienced engineers.

The numbers and the action of these little creatures are alike astonishing; and they show very forcibly, that we must not estimate power in the works of nature, upon the same principles as in those of man. They also present another subject for our consideration, which must be very perplexing to those who advocate the possession by animals of reason and purpose, similar in kind, and differing in degree only from those possessed by man. We have said "suited to their purpose," when speaking of their making their attacks only on those trees which are internally dead; and we liave done so in order that we might thence take occasion to point out why, of themselves, they can possibly liave no purpose, but merely answer that purpose in the economy of nature, for which they were designed by the Author of nature. We can imagine no purpose of theirs, by whicl they are guided to the tree, either by previous experience, or by present sensation; and we might say, with quite as much philosophic trutl, that an egg is hatched, or a seed germinates, of its own forethought purpose. That they are organized, and otherwise fitted for the performance of a certain part in nature, and perform it, is true; and when we have said this of them, as of any other race of animals, we have 
exhausted all that we can rationally say about the matter. They do this by the law that God has given to their nature; and nothing that man can plan or execute, can at all come up to the perfection and certainty with which that law works, without the slightest knowledge of any kind on their part.

The labour which these wood-destroying insects perform, belongs to the class of Autumnal labours, because they consume the waste of vegetation; but they are called into being by the stimulus of Summer action, and are found only in countries which have the hot and dry, or tropical winter. They do not, therefore, belong to the class of Autumnal agents, as we understand that class in temperate climates; for they may be considered as one of the means by which the ardour of the elements performs its work.

As long as the tropical energy continues so powerful as to occasion a double season by the ardour of the summer, both the preserving and the decomposing which are effected by the Autumnal working, as the heat and drought become intense, are of the same character as those under the tropics, where the only winters are parching ones. But when we advance to such a distance from the equator, as that there is a winter's pause arising from cold, the preceding decomposition is an Autumnal one, in our ordinary sense of the word, and the proper Autumnal agents are employed for carrying it into effect; though, up to the lighest latitude at which there is a flowering vegetation, with leaves that are shed, or stems and leares that die down in the season, there is still a remnant of the tropical 
action, so that the decomposition is not wholly effected by the Autumual agents.

Here, a question may not unnaturally present itself to the mind of the reader,-and it is a question worthy of some consideration :- "Why should agents be required in performing the labours of an Antumn, which is to be followed by a cold winter, or winter arising from a deficiency of temperature; and not in the case of a warm and dry winter, or one which arises from deficiency of humidity?"

The answer to this question is easily seen : There is a' deficiency of action as the cold sets in, for cold is not action, but its opposite; and there is an excess of action when the sun parches the earth, and withers the vegetation. 'The excess of solar action in this latter case, is applied to the decomposition of the surphus vegetation, in as far as that is decomposable by heat, which of course reaches all the parts of it which can be turned in to vapour by the temperature; while, with the declining heat of a temperate or a high latitude, there is no surplus of this kind, after the weather begins to be a little cool, and humidity increases on the surface of the earth, which is generally the case under these circumstances. 'Thus, we can easily see that something in the way of decomposition is produced by the action of the sun in the tropical Autumn, which cannot be so produced in the temperate one, and especially in that of the colder latitudes.

But we have not yet stated the whole of the difference. Those parts of plants which are products of the season, and require to be turned into materials for new plants. 
when the proper labour of the season is accomplished, are mostly cellular, or consist of an accumulation of little vesicles or compartments, separated from each other by thin partitions, and containing fluids of some kind or other. Now, in a tropical country, after the walls and partitions of these cells have lost the tenacity and flexibility of life, and also the resistance to lieating, which the living membrane possesses, the whole struc-ture becomes heated, the fluids expand, and the cellular membranes of tissues are rent in pieces by the force of the expansion. In the cold Autumn, again, there is not sufficient solar action for performing this disintegration of the cellular tissue, and therefore, other agencies are required for the purpose of reducing it. Maceration in water effects some decomposition of the unnecessary parts of vegetables in the Autumn of temperate climates; but still the effect of this, in destroying the cellular structure, is comparatively slow. It is true, that the deciduous leaves in temperate climates are destructible by less powerful means than the leaves of tropical plants. The latter have to endure a much greater action of heat, and greater and more frequent changes of temperature, during the period of their activity on the trees, than the former. They are, of course, proportionally strengthened in their structure and texture, so as to enable them to endure this increased severity of vicissitudes. Accordingly, great part of them are strong enough to endure all the seasons of the year, in the same manner as the matured leaves of our evergreens are equally proof against the summer's heat and the winter's cold, until the period of their usefulness 
is run; while thcre are few deciduous leaves capable of enduring much alternation of frost and warm sumshinc. There is, however, a difference betwecn those evergreen leaves of the tropics, and the leaves of our evergreens; for, as we have alrcady remarked, thc young leaves of the latter are equally liable to injury from frosty nights and sunny days, as those leaves which fall in the Autumn.

In the tropical countries, the leaves and stems of that herbaceous vegetation which dies down in the parching season, are reduced to powder by the disruption of their cells, and very speedily disappear; whereas, in the cold latitudes, they in great part remain proof not only against the Autumn, but against the winter. There is some advantagc in this, for these withered stems form a sort of protecting mantle to the crowns of the roots, during those trying times, when winter is struggling with Autumn, before the snows, and again, during the struggle of spring and winter, before the night-frosts altogether cease, and the good weather sets in. Thus, when we speak of Autumnal decomposition as taking place, either in one commtry or in another, we must always be understood to speak with limitation, and not as if the whole of the vegetable structures, which have no future living function to pcrform, were decomposed to an equal extent, and with cqual rapidity. Some resist both the Autumn and the winter, to fall in the ensuing spring or summer; and some remain upon one kind of surface, while they are dissolved upon another; so that here, as in all cases of nature, wc must observe the characters and habits of the several specics, before 
we can venture to say how far they come within the operation of the general principles, or, to speak more correctly, the prevailing ones.

With these allowances we can, however, have a tolerably clear notion of the mode of acting and the agencies in the different climates. As compared with the whole mass of vegetation, there is much more to be done on the low grounds of the middle latitudes, than on any other places of the globe. The trees there are almost exclusively deciduous; very many of the small plants are annuals; and most of the herbaceous peremnials die down and wait in their roots, till they are stimulated by the returning energy of the new season. In consequence of this, there is much of the matter of vegetation thrown off unfit for vegetable purposes, and the greater part of it in a state of nature is but ill adapted for the support of vegetable-feeding animals of whatever kind; and therefore nothing is left, but either that it should remain as unseemly and injurious waste, or that it should be decomposed. For it to remain in the first of these states, would be contrary to the whole system of nature's economy, the fundamental principle of which is that nothing shall lie waste; and therefore the means of decomposition are prepared.

It is in accordance with the perfection of design which r'uns through the whole, that this matter, which is ammually decomposed, so as to prepare it as a natural manure for the fields, should be greatest in those latitudes where we have endeavoured to show that the whole system of nature works to the greatest advantage, and most beneficially for man. As we recede 
from this middle latitude, whether toward the equator or toward the pole, we find this quantity of matter prepared by annual decomposition to become less and less. Both ways, more of the trees are evergreens. In the direction of the equator, a greater and greater portion yields to the decomposition of the dry season as we advance farther and farther into regions of a decidedly tropical character. In the direction toward the pole, the numbers and also the size of the herbaceotis flowering plants continue to diminish; but, as the decomposing power of the elements also diminishes, in at least an equal proportion, the proper agents of the Autumn are not the less required.

Before we proceed to the more particular consideration of these agents, there is yet another general view of the decomposing operations of the Autumn, as contrasted with those of the spring and the summer, which it is essential to take correctly, and to bear carefully in mind. At every season of the year, from the first moment of the bud or the germ, or even of the rootlet, which is anterior to both of these in its seasonal action, at least in many plants, there is always a destroyer ready; and if, for the general well-being of the whole, of which we are very incompetent judges, the action of this destroyer should be required, it is never slow in the performance of its work, and the cases are few indeed in which human agency can prevent its operation. Of these destroyers, which attend on the vegetable tribes during the whole season of their growth, a few are vegetable; but by far the greater number are animal,namely, various species of insects, chiefly in the larva 
state, but some of them also when full grown, as in the case of the aphides, and various others.

As is the case everywhere in nature, the destroying agents of the spring and summer, or those of the season of growtl, are, upon their confines, blended with those of the Autumn, in the reduction of the yearly growth which has performed its office, back to the state of an inorganic material for future use. So that we cannot, in the case of every individual of them, say that this belongs to the spring or the summer, and that belongs to the Autumn. But this does not arise from any want of natural distinction between the two; it arises from the imperfection of our powers of observing, which cannot follow nature into any of the more nice and delicate parts of its working. It is the same in the nicer distinctions of regetables and animals, and even of inorganic matter, or matter which takes its peculiar form without any organization. There are many substances on the confines, which show so few of the common characters, either of animals or of regetables, that they have been equally claimed by witers on the two kingdoms, as falling within their proper doninion. It has been, in some of the more obscure instances, the same with both of these and the mineral kingdom. But, in every case where finer instruments and'more accurate methods of observation have enabled the investigation to be carried a little farther, the proper place of the substance in the system has been clearly ascertained.

Now, if there have been these difficulties in the case of substances which can be examined in their separate 
state as existences, how much more must it be the case with agencies, which are and can be known in their effects only? But still, in every case, it is only when we carry the matter to the extreme limit that there is any difficulty. In those every-day matters, which are in reality the only important ones, and in which alone the great body of the people can take any interest, there are none of these sources of mistake. Plain people may not be able to define in set phraseology what they mean by an animal, a vegetable, or a mineral; but they never commit the slightest mistake with regard to any one of these with which they may happen to be practically concerned. It is exactly the same with the distinction between the action of spring and summer, and that of Autumn. They may not be able to state, in logical terms, how these are to be distinguished from each other; but they can at once refer the one to the season of growth, and the other to that of decay.

As to that which may call the destroyer into action, the case is by no means so clear; because it is very probable that, at whatever season it may take place, there is a particular state of that which is destroyed, which brings the destroyer, and, in many instances, rouses it into life. The appearance of insects in such numbers as to be decidedly hostile to vegetation in the season of its growth, is so much more conspicuous in seasons and situations when and where there are obviously checks to its growth, than under the opposite circumstances, as to leave no doubt that a diseased state of the plant always precedes, and we may almost say occasions, the depredation. Any one who chooses to observe the 
state of vegetation in an inconstant spring or early summer, where it meets with repeated checks, and in another season of uniform progress, will find the difference in the insect ravages in very exact proportion to that of the states of the weather. It is not the extreme changes, however, that bring on the attacks of the insect destroyers. When a temperature below that of freezing alternates with warm sumshine, the destruction of the early leaves is accomplished without the aid of insects; and it appears that these extremes are unfavourable for their development. Hence, in valleys among lofty llountains, where the spring alternations come with severity when they do come, regetation suffers much less from insects than it does upon low: plains, where the alternations in the early season are more mild. The retentive clays are the soils upon which there is the greatest derastation in this way; and accordingly it often happens that, to the northward of London, the hedges and gardens are clean stripped to the last leaf, and nothing but the oid silken tents of the caterpillars left in their stead, while there is liardly one leaf injured where the subsoil is gravel. Where aphis or coccus makes its appearance at a more advanced period of the season, it always appears first upon the least vigorons trees or parts of trees; and the. same may be said of every other insect, to whatever plant or part of a plant its ravages may be more immediately directed.

But althongh those spring and summer destroyers may thus be regarded as always making their appear-. ance consequent upon some diseased state or action of. 
that which they attack, yet they always act upon vegetation in its growing state, or its progress toward maturity, and not after it has performed its sensonal function, and requires to be renoved in the ordinary course of the healthful action of the system; while those dissolving agents which are really Autumnal in their character, never begin their operations until the function of that upon which they exert their encrgy has been performed, or, at all events, until it has been rendered unfit for the performance of that function. There are, however, as we might expect from the fact that the seasons overlay each other in point of time, some which stand so intermediate between the summer and the Autumn, that it is not easy to pronounce with certainty to which of the two they in strictness belong. This is especially the case with some of the parasitical plants, which commit the most serious ravages upon the crops of cultivated grain ; but, as those crops are wholly in an artificial state, and we know not exactly what their habits are in wild nature, or to what encmies they are subject there, we camnot assign these parasites their proper places in the natural order of the seasons.

There is one distinction which deserves especially to be kept in mind, notwithstanding the apparent anomaly in the case just mentioned, and in some others. The spring and summer destroyers, or, as they may be more correctly designated, regulators of vegetation in its progress toward maturity, are, with very few exceptions, and those chiefly referable to plants in an artificial state, animal; and the greater number of them are insects in the progressive stages of their growth, 
and before they come to their state of full and final development. The Autumnal ones, on the other hand, are chiefly vegetable, and in great part peculiar to that season, not making their appearance till it arrives, and ceasing to appear when it is over. Even in these matters, however, it is impossible to speak in perfectly general terms; because places which are so sheltered as not to feel the great natural variations of the sun's influence and the atmosphere in the different seasons, cannot be affected to the same extent, or even in the same manner, as places which are fully exposed to those influences. Whenever the causes of these exceptions exist, we must make allowance for the exceptions themselves; and thus our general reasonings regarding the phenomena of the seasons in any latitude or place; must always have reference to free exposure to seasonal action there.

There is one particular in which the spring and summer regulators, and the Autumnal reducers or decomposers of regetation, agree with each other ; and it is one in which both of them differ greatly from the more permanent tribes, both of animals and of vegetables. Certain years produce or develop them,-or, as we say, bring them in great numbers, - while in other years they are comparatively few. Now we have every reason to believe that the individuals are just as prolific in those' years when they are many, as in other years when they are of rare occurrence. Hence we must conclude that the numbers of eggs on other germs, must be in proportion to those of the parent animals or plants by which they are produced. In consequence of this we 
would naturally conclude, that after one year of great abundance of those enemies of vegetation, whether animal or vegetable, we should have a greater abundance the following year, and so on progressively. So far, however, is this from being the case, that their occurrence in great numbers for two consecutive years is exceedingly rare; and if there is more than an average production any one year, there is generally less in the year following. The actual development of those animals and plants has, therefore, no relation to the number of germs that are produced and fit for development; but appears to depend wholly on the circumstances by which they are called into activity. It thus appears that their office in the system of nature is a secondary one. They come not for themselves, so to speak, but for the benefit which they render to a more important part of nature; and when they have done their duty they.disappear, and do not again return until their presence is required. They also come in exactly the requisite numbers; and although, in seasons when they are more than usually abundant, they appear, for the time, to lay waste the whole of the vegetation, yet it is in general found that the improvement in future years more than compensates for their temporary depredations.

In this subservience of what we may regard as the inferior parts of the creation to those which are superior, we see the beginning of a chain of relations, which, when we follow it out, is fraught with instruction of the most delightful kind, and which is a sharp reproof to us when we limit our notice to the mere 
individuals in their insulated states, or merely in their individual functions as having reference to themselves, how curious or how wonderful soever these may be. To examine the individuals, and to collect and keep them as objects of study, is so far from being wrong, that the omission of it is a criminal neglect of those opportunities, which, as rational beings, it is our duty to improve. But this is but a small, and, comparatively, an unimportant part of the subject; and the working is far more instructive than the mere works.

Of that working, the grand lesson to us is not so much in that which the parts perform, each for itself, as in that which they perform for each other. In this we can trace a very beautiful gradation. The humbler tribes minister to those that are next above them; and these again to others, in a long-continued series; and, whether it is plant or animal, we invariably find that the higher it is in the scale of organization, its servants are the more numerous. Take, for instance, the humbler kinds of vegetation, - the lichens and mosses on our cold and elevated mountains, - and contrast them with the more valuable plants which we cultivate. The watchers which nature has set over the former are very few; and even the influence of the seasons upon them is comparatively limited. They creep on in a sort of perennial dulness; and many of them keep constantly dying at one part and growing at another. But if we turn our attention to the plants on a farm, in an orchard or garden, or even to the trees of a forest, planted by the hand of nature, we find them peopled, and watched, and regulated, and served by innumerable hosts; which 
hosts are always more numerous and raried in proportion as that to whieh they minister is more valnable in its nature and more energetie in its growtl.

In every department of living nature, whether vegetable or animal, we ean trace this ministering of race to raee; and in both departments we find, without exception, that the more eompletely developed any one raec is, the more numerons are those that attend upon it. It is true that there is, in all eases, a reeiprocity, and the raee which ministers subsists either direetly or indirectly upon the other; but still, that whieh is the more highly developed, is the more continual in its duration, either in the individual or in the succession; while the others are more seasonal, and come only at sueh times and in such numbers as they are wanted. Thus, in the mammalia, whieh stand at the head of the irrational series, there is 110 pause in the suecession, no preservation of the germ, even for the shortest period of time, apart from the parent animal. In the period required for their development, there is great variety in the different orders and genera; but there are no means by whieh a host of mammalia eould be called into being to meet any momentary contingeney. The birds, and the oviparons reptiles and fishes, have some pause in' the germ, and may be transported from plaee to place in that state; but the eggs of all of them are masses of considerable size, and of compound strueture; and they are liable to suffer, both from meclianical eontingeneies and from ehanges of temperature, even within a moderate range. They are subject to destruction by these casualties, much in the order that we have mentioned: 
them-first, the birds, then the reptiles, and lastly, the fishes,-although there are considerable differences among the members of each class. 'Their prolific powers, taken upon the average, also increase, as their organization becomes lower; and under favourable circumstances, many more of their germs come to maturity, than when the circumstances are unfaromable. But still they all require some considerable time for their full development; and therefore, no part of any one of them could be produced to meet any momentary contingency in the state of the inferior classes,-as for instance, if any check given to vegetation in the growing season shall multiply the caterpillars greatly beyond their average numbers, there are no means by which the caterpillar-eating birds can be increased in the same proportion, so as to save the vegetables from the ravages of these temporary swarms. This would, in fact, be defeating the purpose of nature; for it is not the birds, but the vegetables, which require the additional insect supply, and it comes for ultimate good to them, however it may seem to work for evil at the time.

If we follow the cliain of being still further downwards, we find at every step a fresh confirmation of the general principle, that the less perfect the development, the more is the race obedient to contingencies; and that it is not only more obedient to them, but better fitted for yielding this obedience. The germs of its life are more abundant, more portable, more generally distributed, and more indestructible; and when we approach the limit of observation, we are umable to say where the 
germs may not be, or against what agency or length of time they may not be proof. Those very minute, but most numerous of all the children of nature, often make their appearance, we know not whence, how, or by what agency; but they do come, and we can have no doubt that in them the law of succession is as perfect to the race, as it is in the most fully developed and important of the mammalia; for, though many of them appear to be immediately stimulated into activity by particular states of substances, which have neither animal nor vegetable life in themselves, yet they act in opposition to these substances, and not in concert with them. Their quantity of matter is so exceedingly small, that they interfere much less with the laws of inorganic matter, than the larger plants and animals do; but in so far as our eyes or our instruments can examine them, their organization is as perfect, and as wonderful, as that of the very largest species.

It does not appear, indeed, that quantity of matter has any thing to do, as an element, in animal or vegetable life; but that, on the contrary, it is an incumbrance; and that, in proportion as it is increased, a larger portion of the action of the life must be expended in carrying it about, or in protecting it from the common laws of matter. The proof of this may be taken upon any one of the more conspicuous actions which can be compared in animals. Compare the leap of a common flea with the spring of the lion or the tiger, or the bound of any one of the mammalia. 'The march of an ant over rough gravel, or the clods of a border, is as great in comparison to its volume, as if a dray-horse 
were to cross indiscriminately over London in a straight line; and the distance over which it can travel among such obstacles, is as much in proportion to its bulk, as it would be to the horse to do forty or fifty miles of this sort of steeple-chase in the course of, not one day only, but of many days in succession. Observe a small beetle, or even a caterpillar, moving with ease substances equal to several hundred times its own weight; and see if any vertebrated animal, even the very strongest, could perform a similar feat. There is no doubt, that the invertebrated animals which have been mentioned, have an advantage over vertebrated ones in mere force of motion, in consequence of their muscles being internal of the supporting crust, while those of the vertebrata are external of the bones of the skeleton.

But although the internal muscles of the invertebrated animal have thus a considerable advantage over the external ones of the vertebrated, both in power of action and capacity of endurance, the whole difference between them does not depend upon that, for much is also owing to the much smaller weight of matter which the action of those muscles has to put in motion; and the advantage of this comparatively small quantity of matter is especially conspicuous, in what the little aninual can bear without being in the least injured. If size were an element of endurance, then the fall of an insect from a branch of a tree to the gravel-walk below, would be, to it, fully more than a fall from the top of St. Paul's, upon a heap of angular masses of granite in the street below, wonld be to a man; and yet the insect is not in the least hurt, - not nearly so much as a man would be, 
by merely slipping and falling on the smooth pavement. Considering its small quantity of matter, a little insect could not, in falling from any height whatever through the atmosphere, acquire such a momentum as seriously to injure itself, even though it were possessed of an internal skeleton, against which the external soft parts might be bruised, or which might be fractured by the fall. Thus, whatever view we take of it, the small quantity of matter with which the principle of life in the insect is loaded gives it a wonderful advantage in respect of the accidents which it can bear uninjured, and also of the labour which it can undergo without being in the least fatigned.

This, however, is only a part of the advantage which it possesses over a vertebrated animal. The firm covering, whether approaching-more nearly to the nature of leather, or to that of horn, with which it is enveloped, protects all the internal or working parts both from the influence of the atmosphere, and from blows; and the muscles, being shielded in cases, and proceeding in straight lines from their origin to their insertion, and through the centre of motion in the bending of a joint, or in the moving of any of the parts of the body, at all times work to the greatest advantage; whereas, the external muscles of an animal which has internal bones always work to a disadvantage, and sometimes the portion of labour which is lost in bringing the muscle into play is much greater than that which is available for the purposes of motion. Thus, while the invertebrated animal is secure against casualties, it is enabled, at all times, to devote the entire force of the muscles to 
the producing of the particular motion or effort to which it may happen to be impelled by the instinct of its nature. We are apt to refer to the wings of eagles as organs of mighty power in the way of flight, and to admire the beautifully smooth motion of a kite, as it glides down the wind, or the graceful floating of a kestrel, as it leans on the viewless air. And among vertebrated flyers, we are ready to admit that these are splendid and beautiful motions, and the mechanism by which they are performed is one of the finest studies in the whole circle of the mechanical arts, and, we will add, one of the most useful to those whose profession it is to ascertain how, under particular circumstances, the greatest effect may be obtained with the least possible expenditure of power, which is, or ought to be the grand point with every practical machinist. But splendid, graceful, and easily performed as those motions are, they sink into absolute insignificance when compared with those of the winged insects. Even "the shardborne beetle, with his drowsy hum, that rings night's yawning peal," as the Arch-poet of nature most truly and graphically expresses it, has more power of wing than all the eagles which ever breasted the tempest athwart the mountain-top. Ascending from the earth, in which he has a power of burrowing downwards, as great in comparison as if a man were to work his way down to a field of coal by mere bodily exertion, without tool, or the removal of any part of the rubbisl, and shouldering aside clods and pebbles many times his own weight, he elevates his shards-his wing-covers, or elytra,-unfolds the filmy expanses of his wings, and 
winnows the air with them, until the energy produees the humming sound; and any one against whom such a beetle has impinged, when "wheeling his droning flight," can tell with what impetus he eleaves the air. This, too, is one of the most sluggish-winged of all the inseet race; but any one can observe instanees, as, for example, the common fly and the gnat, or the bee, for swift motion of the wing; the diumal lepidoptera, or butterflies, for smooth and easy gliding; and the iridescent gleaming of the dragon-fly, as it starts from place to place by the margin of the brook, as if it were an embodied rainbow dancing in joy before the majesty of its parent sum.

These, and thousands of others, woo our attention at almost every spot where the foot can fall; and they arc all so interesting, so curious, so redolent of the most sublime--the most God-like philosophy, that the willing student has no choiee but that of giving the preference to the new one during the time of its novelty. When we say, "God-like" philosoplyy in this case, we use the word neither irreverently nor unadvisedly; for the sehool of nature is God's own university for the instruction of all his creatures in the philosophy of nature, and though the lessons can be appreciated by us only in the humble and limited eondition of earthly students, the lessons themselves are lessolis from Heaven. Our present allusion to the subject is neeessarily incidental, and we eamnot enlarge upon it; but every reader who studies his owl best enjoyment will take especial eare that the philosophy of inseet life is to him no negleeted portion of the mighty volume of terrestrial nature. 
We have gone into the illustration of the higher orders of organized being, as requiring service, and of the lower ones, as being fitted to serve, upon the case of the animals, rather than upon that of the vegetables, because the more numerons functions of the animals render them better adapted for popular description; and we have taken the broad distinction between the two great divisions of animals which have internal skeletons, and animals which have not, because that is at once the most comprehensive and the most obvious to which reference can be made; and also, because it leads to certain other conclusions, without which the contrast would not be so complete as to warrant the deduction which we mean to draw from it, and which has been anticipated in the assumption, that the one race are qualified more for being served, and the other more for serving.

But although we have thus taken the animal kingdom as the chief subject for our illustration, it must not be supposed that the vegetable kinglom is unavailing for this purpose. As the actions of plants are more limited and less diversified than those of animals, we may naturally suppose that the lines of demarcation between them are not so clearly drawn. But still, if we take the two great provinces of the regetable kingdom, the plants which are vascular in their structure, and those which are cellular--that is, those which consist of elongated tubes or canals more or less mixed with cells, and those which consist of cells only, we have a division bearing no inconsiderable resemblance to that of the animal kingdom,-the vascular plant answering to the vertebiated animal, and the cellular: 
plant to the invertebrated one; and the first being more especially the served, and the second the servant. We shall have occasion to enter somewhat at length into this subject, or at least part of it, in another chapter, inasmuch as a portion of it is more immediately belonging to and characteristic of the Autumn; and consequently we may now pass it with a single remark, in which the principle of the distinction may be seen. Take any majestic tree, an oak, for instance, among exogenous trees, or those which grow at the surface, and a palm, as among the most stately of those which are endogenous, or grow at the centre, and how long soever either of these giants and glories of the forest may endure the common action of the seasons in climates and under circumstances which are favourable to them; yet, let either the one or the other be once completely dried in the whole of its substance, and let it remain in that state for only a very short time, and giant as it is, and long as may be the period of its natural endurance under circumstances favourable to it, there is no more return for it to the living and growing world; and it is a useless thing until the agents of the long Autumn bring it to the dust and make it fit for being the mere matter of some new race of plants. But if, in contrast with this, we take some of the more minute of the cellular plants which to our common observation seem nothing else but stains on the surfaces of stones and other solid substances, we find that they can be dried, and remain so for a long, and, probably, an indefinite period of time, and are again revived whenever moisture is supplied to them. Of the strength of the action к 3 
of those very minute and simple, we shall in the mean sime say nothing farther than that they are as remarkable in this respect as they are in their tenacity of life muler changes which are fatal to all plants of more complicated structure, more raried functions, more imposing appearance, and more ornamental to the surface of the earth in wild nature, as well as more valuabie to man in the arts of life.

But, notwithstanding the greater capacity of endurance, and of overcoming as well as abiding mechanical resistances, which the invertebrated animals and the cellular plants possess, we must not suppose that they have, upon the whole, a higher function in nature. Viewed with reference to the part which they perform in the system, none of them is higher than another, for whey are all equally perfect-all the very best adapted to their several purposes; and, therefore, the estimate which we take of their relative values is founded npon their usefulness to man. In the particulars of this estimate we are necessarily often in the wrong, because our knowiedge of uses is very limited and imperfect; but we shall see that the foundation of this estimate is the true one, and the only one which shows purpose and design in the whole system.

Let us again revert to the animals as the most appropriate subject for illustrating the principle; and we shall at once perceive that the two grand divisions are organized upon parts of the system which have very different functions. All the systems of the invertebrated animals are contained within the general crust or firm integument in which they are cased; and the vital 
funetions, or those that work for the noirishment of the individual, or the continuation of the race, are those to which all the others are subordinate. They are creatures whieh lave little or 110 resouree in themselves; and while no animal proeeeds by reasoning from experience, as man does, it is very doubtful whether, in very many instances, they proeeed upon what we may call the momentary stimulus of sensation. Their aetions are often exceedingly curious, so mueh so that we are apt to be carried away by the very seductive vanity of taking ourselves as the standard, and so plaee them at the very top of the series in point of what we call "animal sagacity." Sagacity-sagacitas, from sagire, "to have quiek pereeption" (Sagire, sentire acutà est),--always involves the idea of something to be pereeived; and even if we concede to an animal the most aeute and perfect senses with which material organs ean be endowed, they ean perceive nothing but that which affeets them at the time. No eye ean, to-day, see the sun of yesterday or of to-morrow; and to revert to the past, or anticipate the futme, is the provinee of mind, not of matter. Finite mind eould not, indeed, accomplish that which, when we are led into temptation by this very seduetive and very general error, we impute to the sagaeity of these animals. We never hear enough of the marvellous seienee of the bee, which, in the formation of her eells, gets the maximum of aecommodation in the minimum of spaee, and the maximmm of strength from the minimum of materials; or of the wonderful sagacity of other insects, not only in placing. their eggs in sitnations where the the young shall have 
food, but in placing them in the bodies of other insects; and, as the small one feeds upon the internal parts of the large, making it avoid the vital portions, until it makes its last meal, after which the skin of the one upon which it has fed becomes a place of refuge to it during the time that it is in the crysalid, or dormant state.

These, and countless other cases have been adduced as proofs of the sagacity of the invertebrated races of animals, and they are no doubt all exceedingly wonderful. But, we would ask the special wonderer at those small and insulated parts of the great system of nature, to name any one production, or any one action or phenomenon in the whole range, which is not wonderful. The especial wonder of the whole is that the system of nature should exist, and that we should be endowed with the faculties of perceiving and enjoying it; and surely we will not gire our sagacity credit, either for creating the system, or acquiring our powers of discermment, whether in the observation of present subjects by means of the senses, or in that mental power which supplies us with the vinculum uniting the past with the present, and making the two an experimental guide for the future. This last part of the perception (and it is the only one in which we can be said to have design or purpose, in the limited sense in which that can be predicated of us) is not obtainable by the exercise of our mere bodily senses, how acute soever we may suppose them to be; and if we were to suppose that, as mere corporeal organs, or rather as functions of such organs, they were sharpened, in some other animals, to tenfold, or ten thousind fold the acuteness 
they have in man, that would not give them the slightest tendency to connect the sensation of one moment with the sensation of another. In human beings we find that the acuteness of the senses is not only not in proportion to the intellectual acquirement and power, but that it seems to have a tendency to follow the very opposite ratio. Savage nations, low in the intellectual scale, and having none of the enlightenment of science, or the advantage of art as founded upon science, are proverbial for the extreme sharpness of all their bodily senses. When the natives of America werc first visited by Europeans, they could sec the foot-print of an enemy, hear a sound, or scent an object, under circumstances where the most enlightened Europcan found no impression upon any one sense; but even those among them who had made the greatest progress towards civilisation (we cannot say progress in it), had no name for a number greater than three, and consequently no distinct idea of such a number itself.

Among mankind, therefore, the devclopment of the sense's as bodily, and that of the mind as intellectual, follow opposite laws; and it is a kindly provision of Heaven, to man in a state of privation and destitution, that the senses should be sharpened to him under circumstances which prevent much intcllectual development. But even in these cases man is not destitute of mind, how little soever it may be improved by cultivation; and, therefore, in the very lowest condition in which we can suppose him to be,-unless, indeed, under that singular modification of disease, temporary or permanent, which destroys the connexion between sensa- 
tion and thought, is still upon a much higher level than the most fully developed of the other animals; and, therefore, even in those states in which man may with propriety be said to have no sagacity, he is still higher than they are.

This brings us to the grand distinction, not only between man and all mere animals, but between the two grand divisions of these the invertebrated animal stands lowest, inasmuch as the organs of sense are much less developed in them than in the vertebrated races, and in not a few of them the existence of any sense, except mere sensibility to atmospheric changes, is extremely doubtful. We must therefore discard entirely all notions of the superior sagacity of such animals, and view them in their proper place in the system, namely, that in which they are more under the influences of the circumstances in which they are placed than any other animals whatever. This agrees with the observed facts, and also with what we have stated as being the principal office of such animals in the economy of nature, which is indeed only an inference from the facts. They come in their requisite numbers when circumstances require their presence, and when they are no longer necessary they disappear, but wait in the rudimental state ready to obey a new call, though never coming till that call is made. Their coming and their going thus depend upon causes entirely external of themselves; and in whatever way they perform their functions, that is a portion of the very constitution of their nature from which they cannot depart, and which, instead of being the result of sagreity, cannot, in many instances, be 
looked upon as in any way resulting from sensation. That we are not able to say what it is owing to, is no argument, as ignorance can ncver be made the foundation of reasoning; and the same plea for sagacity to a bee in the structure of its cell, upon principles of the most refined mathematical nicety, might, with equal propriety, be applied to the form which any organ of an animal, or even a vegetable, assumes; for if we understood the use of the organ rightly, the organ itself is always the very best adapted for that use, that can be imagined. We have gone somewhat at length into this question, because it is one upon which erroncous opinions are very generally advanecd, and have a vcry mischievous tendency; and, therefore, no opportunity of laying a sure foundation for the truth ought to be omitted. There is one little matter which we may still repeat in illustration of what we have said of the natural place of the invertebrated animals. They are better adapted for external contingencies-that is, states of things, in the bringing about of which themselves have no part-than the other animals; and it is the general law of nature, that every production or class of productions is, upon the whole, though not perhaps always in the individual instance, placed in that situation for which it is best adapted.

When we turn our attention to the vertebrated races, we find, that though in their four grand classes they may be said to inhabit four distinct localities in nature, - namely, the birds in the air, the mammalia on the surface of the earth, the reptiles in the mud and sludge, and the fishes in the water,-yet, as there is one general 
plan of organization among tinem, there is one general purpose, (though both plan and purpose are greatly diversified,) not only in the four classes which have been cnumerated, but in the different members of each class.

In all of them there arc two distinct systems; the one external of the bones, though more or less included within partial protections of bony substance,-and the other, in its more important parts, internal of the bones. It is this latter system which stamps the grand distinguishing character upon all the vertebrata. The vertebral column consists of a skull, in which the brain is lodged, without any otler organ along with it; and a back-bone, consisting of vertebra, or jointed pieces, varying in number and form in the different races, and containing, safcly protected on its inner side, toward the great cavity of the body, the dorsal cord or continuation of the substance of the brain. In all the invertebrated ones, the bony parts which support the brain and dorsal cord are wanting; and, generally speaking, the parts answering to the contents of these bones, are but imperfectly developed, and follow the direction of the alimentary canal.

Upon comparing the powers of sensation and the development of the brain, and its rertebral or spinal continuation in difierent animals, we find that there is a constant corrcspondence between them; so that though we cammot say the relation is exactly the same in every particular case, yct morc acute and perfect sensation so constantly accompanies a nrore perfectly developed brain, that we consider that organ as the grand part of 
the strmetnre, mpon which the sensation depends. In using the word "sensation" we must, however, exercise a little caution, for mere sensibility to atmospheric clianges, or other external circumstances, is not synonymons with that sensation which has a developed brain as its centre, but in many respects the very opposite. If the words may be used, the sensibility to the ordinary physieal state of things may be ealled passive sensation, while that which has its centre in a brain is active. The objects which affeet the two are also quite different, and refer not to the physieal nature of objeets, but to particular states of them. Sensation of this active kind is still only momentary, or active during the presence of its object; but it has much more to do in the eonduet of the animal, than any of those which can be ealled aetive sensations, or referred to a partienlar organ in those animals whieh have not a developed brain, a skull, and a backbone; and, therefore, as the animals are, so to speak, more under the control of their own sensal pereeptions and less under that of external cirelmstanees than the invertebrated animals, they require a differently modified organization, and requiring it they possess it.

The first objeet which is obviously attended to in the structure of the vertebrated animals (and it is most conspicuons in those that have the brain most filly developed), is the securing of that organ and its spinal continuation against injury from jolting and concussion when the animal moves. Sueh animals never have the bones of the anterior extremities articulated or jointed on the spinal column, but merely embedded in the solt. 
or fleshy parts which are united to the processes, or projecting pieces of the vertebræ. 'Thus, whatever jar the fore legs, the hands, or the wings, as it may be, meet with in the performance of their motions, is never communicated to the important part of the animal farther than through the medium of the soft parts, which break the shock, - as the jolt of a carriage upon the wheels is broken by the springs; the other vital parts being suspended from the spinal column, by the ribs, which are not, in the more typical animals, articulated upon it, but merely attached by flexible cartilage, are equally secure against injury from concussion. Concussion from the action of the posterior extremities is not so liable to be injurious; but even this is guarded against by there being some cartilaginous unions, more or less flexible, between the spine and the first articulation of these extremities. Thus the organs of motion are left free to the performance of their offices, without any risk of injury under ordinary circumstances, either to the system of sensation, or to that of motion; but as the first of these is the most important one in the economy of the animals, it has the most complete protection.

In all the moving parts of the vertebrated animals, the muscles, or organs of motion, are external of the bones which they move; and thus they never can pass through the centre of motion, and much of their mere power is lost by the situations in which they have to be placed with reference to the parts which they move. The muscles which raise and depress the wing of a bird in flying, offer a familiar instance of this. 
Both sets have their origin, or fulcrum of motion, on the stermum, or breast-bone of the bird; and thus, if they were both inserted in the same manner on the humerus, or shoulder bone of the wing, they would both pull in the same direetion. But the muscle which depresses the wing is inserted on the under side of the humerus, farther from the body than the eentre of motion in the bone, and that which raises the wing is inserted on a proeess nearer the body than that centre. Henee, although both museles in their eontraction pull in the same direction, the depressor pulls the liumerus down, and the elevator pulls it up. Of these muscles, the depressor acts the most direetly, and lias the advantage in the lever; and, eonsequently, besides being the larger and more powerful musele of the two, it acts with less waste of its energy. But as the elevator aets on a shorter lever, its aetion is more rapid, though less powerful. This is a great advantage to the bird in its flight, as a rapid elevation of the wing and a powerful downward stroke, are exactly what are wanted.

There is not one joint in any of the vertebrated animals whielı does not furnish a most pleasant and useful lesson in meehanies; but we eannot enter farther into the details.

There are, however, various advantages in the action of joints with external muscles, which render them far more eommodious than those whieh liave the muscles internal. Witl the internal museles, passing through the eentre of motion of the two parts which are jointed together, there never ean be motion by the 
flexure of a single line passing through the joint; and this is the only kind of motion which admits of being turned into any direction. We have examples of it in all those joints of vertebrated animals: a round head of bone works in a socket, and which are thence called ball-and-socket joints. From this, which is the universal joint, there may be all varieties, down to a simple hinge-joint, which has motion in one plane only. With internal muscles there cannot possibly be any joint, consisting of one hard surface working directly upon another, except a motion on two points, one of which is situated at each side of the openings in the two pieces, through which the internal muscles pass from the one to the other. If the articulated substance is very hard, a joint of this kind is exceedingly firm and accurate; but it has motion in one plane only, from which it cannot deviate, and thus all the variety of which it admits is merely a greater or a less degree of flexure. The joints of a crab's claw are very perfect examples of this, and they work without the slightest shake. If, however, the least twisting motion, or deviation from motion in the one plane, be required, a joint with internal muscles can have no stability; because the only way that even this limited change of motion can be obtained, is by uniting the ends of the two pieces by means of a ling of flexible matter, which shall "give" in the requisite direction, and to the extent which is necessary. 'The joints of the walking legs of a crab, and also the proximal ones of the pincer claws, are of this kind; and so are the proxinal joints of the legs of insects which have 
motion in more planes than one; and therefore all such animals appear very feeblc and lumbering on their legs, as compared with vertcbrated animals. If steady motion in any number of planes is requircd, there must be as many separate joints as therc are planes; and thus, in order to have even a very inferior command of its limbs, an invertebratcd animal must have many more jointed pieces in them than a vertebrated one. The human arm and hand are capable of more varied motions, both in the positions of the arm and the actions of the hand, than any otlier piece of animal mechanism; for, to say nothing of the different movements of the parts of the hand itself, the point of the finger can, without any motion of the shoulder, divide space, not only down to the two thousand five hundredth part of an incli in every direction, but absolutely to an indefinite extent beyond this-an extent which cannot be stated in numbers, as the finger can glide with equal smoothness througlout the whole, without any perceptible starting from one point to another. It is true that the hand is the extreme instance, because it has to obey the eye, the wish, the thought, and the feeling, in every manual operation in the arts, some of which, as in the touch of an instrument by a first-rate musician, are so exquisitely delicate, that, instead of being described, they cannot be appreciated, or even felt by one who is not possessed of equal dexterity, and equal feeling of the art.

But the human hand stands alone among the mechanical structures of animals, inasmuch as it is the L 3 
servant of a mueh higher power than any which is found in them. It has to minister to mind-to an intellectual prineiple which is in its nature pérfectly untrammeled by any thing material; and eonsequently it eannot enter into any estimate of the relative perfections of the others.

It is, however, the ultimate point to which all the remarks which we have made on the gradations of nature tend; and we must eome to it, and even to the intellectual principle of which it is the servant, before we ean rightly understand or duly appreeiate the truly wonderful system of ereation, or reverence aright that wisdom, power, and goodness, by which it has been made, and is sustained.

But when we confine ourselves to the vertebrated animals, we find in them an adaptation of the parts for varied aetions, and an accommodation of organs to senses, of which there are no traees, or at least very faint ones, among the invertebrated tribes. Thus the proper organs of the alloeated senses, - the eye, the ear, the nostril, and the tongue,-have their own distinet organs of motion as well as their susceptibility to sensal impressions. We ourselves ean fix the eye, bend the ear, or extend the nostril, so as to eateh through any of them an impression, or a suceession of impressions, which would pass unknown if it were not for the power which we have, of ealling the organ to the performanee of its duty.

In as far as we ean judge from similarity of the general strueture, the nere animal power of sense in the vertebrated animals, the mammalia especially, 
must have some resemblance to our owll; but of course they can have none of those intelleetual impressions which, in us, follow so immediately after the sensal perceptions, that we eannot say with precision where the one ends and the other begins. As sensation is their highest endowment, and indeed the most elaborate and elevated power-the farthest removed from the mere properties of dead matter, and the greatest departure from the laws of that matter, so the gratifieations of the senses must be the highest enjoyments of these animals; and as they, in their very nature, stand the most in opposition to the laws of matter, their produetion and the maintenance of their being must demand the greatest effort. This is the reason why, in them, the germs of life never can bear to remain apart in a dormant state, ready to be called into action by the operation of external causes; and for this reason, again, they cannot work to the contingeneies of the system, but must be the served, and not the servers, in nature's eeonomy.

Taking them as a elass, the mammalia, in this respect, stand higher than any of the other classes even of vertebrated animals; but when we take the orders and genera of whieh the elass is eomposed, we camnot arrange them in the order of precedeney, and say in what way one order is, upon the whole, superior or inferior to another. Eaeh has its proper place, and its proper locality, from the whale in the oeean to the chamois on the mountain roek; eaeh is the forcmost of material beings in its own proper place; and while none of then are the servants of any other race, 
we cannot say that any of them are the servants of others.

'Thus from the very lowest stage of animal life, we can follow the chain upwards to this the highest one; and in the vegetable kingdom it is the same. But when we come to the highest, they all appear to be objectless and detached. There is no dependency, and no reciprocity of use, between a fox and a sheep, or between an oak and a beech. Many of the mammalia, no doubt, eat the flesh of others: wolves eat sheep, and lions and tigers prey indiscriminately on very many of the animals of the desert and the jungle. But still we cannot say, that the ultimate purpose of nature is accomplished when those carnivorous animals are fed,-that the purpose for which sheep exist is simply that they may be eaten by wolves, - that the purpose for which wolves exist is to eat sheep, or that the more formidable beasts of prey were made for no other purpose than that they might rend and devour the other animals of the wild woods, or that these other animals have no other purpose than that of being rent and devoured by those powerful carnivora. The system of growing and living nature is all too mighty in its extent, and too wonderful in all its parts, for admitting us to believe, even for one moment, that the climax of the whole of it is, that a lion shall be fed in the wild woods of Africa, or a tiger in the jungles by the Ganges.

This would be but a sorry conclusion to so long and so splendid a series; and yet, if we look no farther than mere matter, in the utmost perfection of organizing 
and endowment in sensation which it can possibly possess or receive, this is the only conchusion at which we can arrive. And if we come only thus prepared, and proceed thus far, the cui bono? will stand up like a lion in our path, and demand of us, "Wherefore all this display of wisdom, of power, and of goodness, which bears the indelible and unconcealable impress of divinity upon its every step, if the ultimatum to be reached is nothing more than the feeding of a ravenous beast in the wilderness?"

Nay, with such views we find that the system breaks down with us before we arrive even at this conclusion; for if sensation, which we must regard as the highest merely animal endowment, is actually to be taken as such, the lion is vastly behind very many of the other mammalia, and the reputed king of the beasts is a cruel, a stupid, and, unless when goaded on by necessity, a crouching and cowardly tyrant.

Even if we include man, and view him as wholly made of the same clay with the rest, the question remains as stubborn, and as urgent for an answer as ever; for of what avail is it that man should be born, and toil and fret for three score and ten tedious years in this world, and then go to mingle for ever and wholly with the clods of the valley. Assuredly this does not remove the doubt, or clear up the difficulty; and the chalice of annihilation is in nowise sweetened by being presented to our own lips.

There is but one way, but that way is straight, open, easy, and sure; the purpose of Almighty God in the fulfilment of his own pleasure toward a rational, 
immortal, and accountable creature, according to the revelation of his own word. All this creation is for him-for instruction and for use; and it is so rich, so varied, so completely inexliaustible, that, notwithstanding all that has been known, and all that has been done, unnumbered ages yet run their course, with increasing knowledge, and multiply enjoyments, and yet the bounty of the Creator in that world which he has given us as our heritage in life, may be as fertile in new knowledge and fresh enjoyment as ever. And that it is given to us, not as food is given to an animal, or holes to foxes, or nests to the birds of the air, but given to us as intellectual and as moral creatures, for self-instruction and self-government, is proved by the fact, that no enjoyment of the world will remain ever fresh, and ever acceptable to the mind, save the enjoyment of the knowledge of it. A little more ambition, and hollour is degradation; a little more avarice, and wealth is poverty: but knowledge is of heaven, and the freshness of immortality plays around it with a radiance which no reverse can cloud, and death itself cannot extinguish. 


\section{CHAPTER IV.}

THE ARMIES OF AUTUMN.

To muster the whole array which Autumn brings forward for effecting the restoration of nature, and of vegetable nature, and the substances necessary for its support, especially and more conspicuously than all else, to that condition which is requisite for reposing with safety during the winter, and starting with due energy and advantage in the spring, would be equally long and laborious, - a labour which no single individual of the human race could possibly accomplish, which could not be done with proper unity and effect by the joint exertions of any number, and which, even though it were done, could not be perused with due attention during the period of an ordinary life, by even the most voracious and insatiable devourer of books. In passing, we may observe that there is a curious correspondence between the literary glutton and the gastronomic: both are, in their several ways, thin and cadaverous; and as the man who gorges himself to intemperance with food, is deficient in health and strength, so the intemperate reader is invariably sadly wanting in thought and 
reflection; and in proportion as he indulges to excess, he actually brings himself nearer not only to the condition of absolute ignorance, but to the incapacity of receiving instruction. This seems paradoxical at first sight; but it is nevertheless true, and a very little consideration will suffice to show that it cannot but be true. We make this statement with great deference, and with every desire to do honour to those seats of learning, which kept the lamp glimmering during the ages of ignorance, after inordinate huxury had quenched it in the monastic cell; but we cannot have been mistaken in the invariable feeling, that "college sophs," who live in and upon the library, are more guiltless of thought of all kinds than any other set of the human race. We do not blame the institutions for this; for almost all of them number among their resident members the uoblest ornaments of the human race; but these are invariably men who shun the ever opened book, and the emanations of whose minds go fresh, free and original, to the contemplation of material nature, of man, and of the revelations of God whether in his works or in his word. If such is the case with those who have had the advantage of the technical rudiments of science, how much more pitiful must be the condition of those inordinate ard indiscriminate readers who launch npon the ocean of books withont having even the guidance of such glimmering stars as technical "courses," in which there is scarcely one appeal to reality, or one loophole through which the system of nature and its workings can be seeu from the dungeon of most profound but most unusable erudition. 
But we mention this only in passing, though it may serve, if not as an excuse, yet as a sort of "saying," why we have not attempted an impossibility, and also why the attempt would not have been desirable, even though the impossibility of the case had been removed. The duty of an author is not to furnish thoughts, but means, or rather opportunities, of thinking; for a communicated thought is not a thought at all to the person receiving it. It is a mere story, and as such, a sensible reader will not receive it as truth without carefully weighing the evidence, the labour of which is many times greater than if the party were to think for himself. This is the real secret why inordinate readers are most deficient thinkers; and it also shows the force of the apliorism of the wise man, that " a great book is a great evil."

We have this, however, to guide us, with regard to the armies of Altumn, that they are in every case perfectly regulated, both in numbers and in strength, to that which they are appointed to accomplish; and thus they always succeed, and their success is always attended with advantages. What they are, how they work, and when they work, are, however, matters of very variable and indefinite character. It is the action done, and not the time or the agent, that determines it to be Autumnal; and the result of that action, in so far as it is bronght about by those agents which we have called the armies of Autumu, is always the reduction to an elementary state, or a state in which it is material and not a work, of something which has performed a seasonal, or periodical purpose, in 
some portion of time longer or shorter, and which is never again to perform that purpose, until it has passed through a succession of changes, which are often very protracted in their occurrence, and generally beyond the range of our observation. In the case of vegetables, even those which are the longest lived, the same individual parts never have a second summer action; and in animals, though the same parts continue to act during the whole time that the animal is in the same state of development, yet the matter of which those parts are composed, is continually changing, so that we cannot say positively that any one particle of material substance can sustain the action of animal life beyond the lapse of a single and indivisible instant of time. Now all passages from organized and living being, back to the state of dead or inorganic matter, in what beings, what manner, what times, or .what periods they may be accomplished, are essentially and properly Autumnal actions, and the agents by which they are brought about are included in the armies of Auturnil.

Those armies, in whatever manner they may carry on their operations, arc all either animals or vegetables; and as they come only at the times when, and in the places where, they are specially wanted, and retire when their labour is accomplished, they belong to that grand division, whether of the one kingdom or the other, which we have described as serving, not as being served. The decomposing power of the atmosphere, and that which is produced by the chemical action of the componcnt parts of a substance upon each other, do not 
come within the class of Autumnal agents, or form any part of the armies of the season. The instant that the action of life ceases in the whole, or in any part of an animal or a vegetable, the substance thereof is under the physical laws of matter, and of course obedient to them. It will be borne in mind, from what we have stated, that, in the tropical countries, the action of the elements, together with that of the component parts of the substances themselves, is sufficient not only to reduce to dust, but actually to dissipate so as that it is not easily found afterwards, all that part of the production of vegetable growth which is strictly seasonal; and that the auxiliaries to these powers in the slow decomposition of more permanent matters, are chiefly animals. But as the difference of season increases, and the annual destruction or decomposition becomes greater, the decomposing power of the elements becomes less, and hence the proper Autumnal agents are called into existence, and the proportion which they bear to the whole, increases with the latitude and difference of seasons, until the utmost limit is arrived at.

As the spring and summer destroyers, or rather regulators, of vegetation are chiefly animal, and as the Autumn is in its more important character the reverse of these seasons, we may take it for granted that the proper armies of Autumn should be vegetables, and actual observation shows us such is the fact. They are not the only agents which are most active in the Autumn, but they are the most conspicuous; and we cannot distinctly state that there is any large and distinet class, though there are a few genera and species of 
animals which come into activity, only, or chiefly, in the Autumn; and there are Autumnal clianges in many animals. Such animals as merely undergo an Autumnal change from their habits at other seasons of the year, cannot, of course, be classed among the armies of Autumn; and the animals which, in such climates as that of Britain, come into activity at this season only, will be better described in separate notices, and thus the section of the Autumnal host which most prominently demands our notice here, are the Autumnal vegetables.

Those vegetables are, generally speaking, the FungI, a very peculiar race, simple and cellular in their structure, generally soft, tender, and perishable in their consistency, wonderfully rapid in their growth, almost equally so in their decay, often of extreme minuteness in their size, and possessing powers of reproduction, which are altogetlıer astonishing, and quite unequalled even in the case of fishes or insects, or even the niost productive of the flowering plants, though among these there are instances to be found of such fertility, as more than five millions produced by a single mother in the course of a single year. The germs of all the fungi are very small, and those of the more minute ones are quite invisible to the naked eye, or even by the help of glasses of no ordinary magnifying power: they are thus anong the minutest things of which we have any idea of having separate existence. Small as they are, however, each one is the depository of a distinct and specific life, far less liable to be injured than a germ of larger volume, and perfectly ready to come into action 
whenever circumstances demand its appearance. The extreme minuteness of the germs, or sporidia, of many of these fungi, renders it necessary that we should speak with great caution respecting their numbers; but according to the estimates made by those who have examined them with the greatest attention, and the assistance of the best instruments, we are led to conclude that in some species there are ten millions of germs in a single cell; and that more than fifty millions, not of germs but absolutely of cells, are produced in the course of a single minute. It is, therefore, no exaggeration to say that a single fungus is capable of producing in one hour a greater number of germs of being, than are produced by the whole warm-blooded animals upon the face of the earth, in the course of an entire year. Wherever there is great power in nature, there is always an equally great use or necessity for that powerupon the obvious principle that nature, or in other words the Author of nature, does nothing in vain. Consequently when we find that plants, which are strictly Autumnal in their appearance, their characters, and their functions, have this extraordinary prolific power above all other growing or living creatures, it impresses us with much more exalted notions of the importance of Autumn in the economy of nature, than when we look upon it merely as the season at which mankind gather in the fruits of the earth, and hunt the beasts of the field.

The fungi get their name from the cellular or spongy texture of their substance, which never consists of firm or lengthened fibres; and as they appear above the 
surface of the earth, they have no distinction of stem, leaf, and flower, like ordinary plants. They do not even resemble these in their chemical composition, for many of them contain the same component parts as animals, and resemble animal substances not a little both in taste and in smell. Mushroom ketcliup, for instance, when of the best quality, is, with the exception of the spices used to flavour it, composed entirely of certain species of fungi; and a ketchup can be made, and is understood often to be made, from bullock's liver, which so nearly resembles the other, that it is not easily detected, either by the taste of the epicure, or the analysis of the chemist.

Even among cellular plants, the fungi form a most peculiar province; and though they are not flowering plants, in the common acceptation of the term, the parts of them which are most conspicuous above ground, or external of the substances upon which they grow, are a kind of flowers; that is, they are parts whose chief office is the production of germs, which are called spores, or sporules, and which bear the same relation to the fungi which seeds do to common plants. As is the case with plants themselves, these are, however, much more simple in their structure than seeds. The greater number of them are inconceivably small, and, therefore, difficult to be examined; and the examination of them is subject to all the imperfections, which are inseparable from examinations carried on by means of glasses of ligh magnifying power; but there is no perceptible distinction of germ and cotyledon, or seed lobe of any kind, and the spore or sporule appears to be 
equally instinct with the vegetable life with which it is charged throughout the whole of its volume,

This is a very curions property of those germs; and when we have seen a little more of the functions which these curious plants perform in the grand system of nature's economy, we shall find that the wisdom of the Creator is as wonderfully displayed upon this, which, to our comprehension, seems the very verge of nothingness, as it is in the most magnificent production of the earth, the earth itself, the solar systcm, or even the nuniver'se.

In consequence of their extreme minuteness (and many of them are so exceedingly small that they are dispersed through the atmosphere, not like smoke merely, but like invisible vapour), these germs appear to be proof against almost every description of mechanical injury. How it may stand with them in regard to chemical decomposition is not so easily ascertained, although it is highly probable that, against the ordinary clremical actions which take place in nature, they are very powerfully guarded, by that simplicity and minuteness which present so little that can be acted upon. In many cases metallic salts, and other caustic substances, destroy the developed fungi, and prevent future growth on the same spot. But from this we camnot infer the destruction of the germs, by even the most active of those substances; for in the case of every vegetablc, the destruction of the growing plant is one thing, and that of the germ another and much more difficult one.

The fungi themselves show, perhaps, the most remarkable instance of this; and both tendencies adapt 
them tor the performance of those Autumnal labours for which they are immediately, and, to common observation, spontaneously called into existence and action, at the particular times, and in the particular places and numbers, which are required. The rapidity of growth and brevity of duration in a mushroom are quite proverbial, though they do not apply in their full force to the esculent mushrooms, properly so called; but still, the whole even of these, in their ordinary exposures in wild nature, are completely gone in the course of the season; and they come one knows not whence, and go one knows not whither; for the whole of the race melt away, and there is not a wreck or memorial of them to be found. Some of the species, especially those which grow upon matter which is warm with putrefaction, attain a considerable size, and yet their duration is limited to a few hours; and they yield to we know not what, without the attack of any destroying enemy, or any considerable change in the state of the atmosphere. Upon the rest of vegetation around them, the most observant eye cannot mark the slightest change either for the better or the worse; but in the morning, a considerable breadth of surface shall be spotted with these more evanescent of the fungi; and if their office is accomplished without a succession of crops, not a trace of them may remain when the sun has gained its meridian height.

This power of growth and rapidity of decay place vegetable life in a very extraordinary light; and when we consider that the thousands-in all probability the millions of offspring, which this evanescent thing has 
committed to the keeping of nature, are, in their own minuteness, hidden from every foe, and thus far more safe than the acorn, the eocoa-nut, or any other more mailed and fortified fruit, we are taught, to the nitter confounding of all our plilosophy, that the causes by which great actions are performed in the eeonomy of nature, set at nought the line and the balance, and rise immeasurably above all our powers of calculation.

We ean easily see, however, that this perfect readiness to come when the state of things renders them necessary, and to yield without effort, or without demanding the labour of any other productions of labour, when their work is aceomplished, are precisely those properties which espeeially fit them for being the armies of Autunm, in the deeomposition of those vegetable substances which have performed their functions as portions of organic nature, and ready to be turned into simple materials or clements for new combinations.

But though Autumn is their appropriate season, and their numbers increase according as the elimate is more seasonal and the Autumn more brief, yet they are not eonfined to the Autumnal montlis, neither is the deeomposition which they effeet that of vegetable substances only. It may be in any plaee-in tlie fields, or in human habitations, or at any one season of the year, and it may be any part, external or intemal, of an organized substance, animal or vegetable,-only let destruction be required, from the state of the substance and for the well-being of the general system of nature, and the fungus is instantly there in any number that may be necessary, and in numbers and individual power, 
exactly appropriated to the work they have to perform. Is there disease of any of the membranes which line the seed-cells of an apple, in the rind of which there is no visible perforation? - a mould comes in myriads upon the diseased spot. Is there any animal or vegetable substance whatever that begins to putrefy under circumstances where the ordinary action of the elements, or the labour of insects, is incapable of reducing with that rapidity which is required?-then it is speedily covered with its appropriate fungus, although the same species of fungus may never have previously appeared in the same part of the country, and may never so appear again. Have the beams of a dwelling, or the timbers of a ship been constructed of materials injudiciously selected or prepared, or unskilfully placed, so as to want that wholesome ventilation, which is essential to the durability of almost every kind of timber, and there is the very first dawning of incipient disease?- - there, the various fungi, indiscriminately called dry rots, marshal their hosts, and bring destruction in the most fearful and often the most fatal manner.

These are but a few out of innumerable instances, and one or other of which must have been noticed by every reader; but we shall not swell the catalogue, as we shall have occasion to advert to some of these, and a few others somewhat more in detail, in consequence of their interest in a practical point of view. In some of these the fungus does not come upon the plant or portion of the plant, till after its seasonal labours are at an end, and it is no longer useful in the growing world. They come upon it in early stages of its growth, and 
their effect, to ordinary observation, is to lessen the quantity and deteriorate the quality of the harvestand not merely to perform the apparently kindly office of preparing the waste for again running its course in the living circle.

Hence, it has sometimes been said that fungi occasionally assail living plants or living parts of plants, and even living parts of animals, as well as those which are in a state of incipient decay. This is a very nice point; and one upon which it is necessary to speak with great caution; but the analogy is strongly against the fact of any fungus attacking either an animal substance or a vegetable one, while that substance is under the healthy and vigorous action of the life of that to which it belongs, or indeed under the action of that life at all. That the parts attacked by the fungus may extend their own unwholesome condition, and the fungus along with it to other parts, is highly probable, for canker in a tree, and gangrene in an animal, have a similar power of extension. It also may, and often does happen, that the fungus shall produce a sort of increased action, and the plant which is attacked shall, for a time at least, appear to grow more vigorously than a sound plant; but even this does not show that the fungus lives upon, far less that it is originally called into action by the healthy growing matter of the plant. Of this we have also an analogy in the bodies of animals, as well as in those of plants, when there is no fungus in the case. Ill-conditioned wounds, and other sores, often have their inveteracy greatly increased by those growths which are sometimes called "proud flesh," and which are said 
to be of a fungous texture ; and those branched enlargements which sometimes grow in the nasal and other passages, and prove exceedingly troublesome diseases ; and yet they are produced by diseased action of the systems alone. There are also innumerable fungous productions upon plants, some of them arising from the irritation of insects, and some from disease in the plants themselves. The gall-nuts, as they are called, which are formed on the leaves of the oak, the willow, and many other trees, often attain considerable size; but they are not the growth of fungi, neither are they in any way productions of the insect as part of its own system, nor are they indeed animal matters, or matters having the sliglitest approximation to animal composition in any sense of the term. They are purely vegetable matter, the product of the plant itself; and if that plant contains any remarkable regetable principle-as, for instance, gallic acid in the oak,-that principle is always more highly concentrated than in the healthy parts of the plant; which is the reason, by the way, that the galls of the oak answer so much better for making black ink along with iron than a much larger quantity of the wood or any other part of the tree, and also why galls formed in warm climates are much better for producing black colour than galls formed in cold climates.

Excrescences of this kind are formed on very many plants, and all of them enclose first the eggs and then the larvæ of small four-winged flies, which are called the Cynipida or family of gall-flies. Some of them are very singular in their appearance, and none are more 
so than the Bedegnars, which are formed on the twigs of rose-trees, and especially on those of wild roses. These are often equally singular and beautiful, representing a thick tuft of slender vegetable fibres, often measuring two inches in diameter, and of a delicate green or pink colour. Any one not aware of the fact would naturally suppose that these are parasitical vegetables, growing on the rose-tree, instead of results of diseased action in the tree, brought on by the puncture of an insect not nearly the tenth part of an incl in its longest dimension. These, and many other fungous appearances upon plants and also upon animals, which are occasioned either by diseases, the real causes of which are not very often perfectly known by us, or by the operations of insects, and also various diseased formations upon animals, have at times been confounded with the fungi. These are produced upon the living substance certainly; but they are also produced by diseased action of the life of that substance; and although the beginning of the diseased action may be the puncture of an insect, or any other injury, mechanical or chemical, the agent in that operation does not, and cannot, elaborate one particle of the unnatural production.

Thus, in no one of these fungous appearances is there the least shadow of proof that any fingus grows upon that which is alive; nor is there any clear proof of this in any one case to which reference can be made. Indeed, that a fungus should so grow, is so contrary to the proper character and appointed function of this department of the vegetable kingdom, and so contrary 
to the general analogy of nature, that before it could be received as a general trutl, very numerous and conclusive proofs would be necessary.

It will be borne in mind that the proper function of the fungi is the final decomposition of organic matter, or the reducing of it to such a state as that, generally speaking, it shall pass to the general store of inorganic matter, without the assistance of any specific destroyer. Other than this, we know of no general class or division of beings, which thus come into existence and activity, obviously for the service of the system, and not for the multiplying and continuing of their own kind, which are the evident purposes for which all the rest work. No doubt very many of the animals live upon vegetables, indeed all of them that do not live upon animal matter; but it is not clearly made out that any one vegetable lives directly upon the substance of anotlier vegetable or of an animal, until that substance has been disorganized and decomposed. That any one of them should so live is contrary to the general physiology of vegetables, as none of them have any system or any organ by which disorganization call be performed, or matter taken into their structure, in mass, as food is taken into the stomach of animals.

There has always been, on the part of some at least of the propounders of opinions of these matters, a disposition to deny, or at all events to overlook, this grand physiological distinction between animals and vegetables, and hence those averments (to give them their gentlest name) which liave been made in very recent times, about vegetables giving out to the soil a certain 
refuse of their food, something in the same manner as is done by animals, which refuse renders the soil unfit for the healtly support of the same kind of vegetables, and hence the advantage of a rotation of crops in farming. But the case here, besides being at violence with all that lias been clearly ascertained in vegetable physiology, is not even true to that loose analogy with animals from which it is attempted to be drawn. Supposc (which is a mere unproved supposition, that a plant does draw from the soil a certain specific aliment, it ueeds no conjurer to tell us that the rejected discharge by the plant, if any such there were, would not be fit for being returned to it again, as a pabulum, either in what we have called the essential or the vehicular part. If such were the case, either witl plant or with animal, it would show an imperfection in the working of nature capable of being detected by human ingenuity; and this is so perfectly contrary to all that we know of the system, and all that we believe of its Author, that no liuman being, of ordinary understanding and reflection, can possibly entertain it for a moment. If the ejected substance is immediately fit for the purposes of nutrition, then both the ejection and the reception of it would be labours without an object, and thus a direct variance, an indirect violation of all that we know of the system and economy of nature. But that that which is ejected should be injurious in the preparation of the proper food of that by which it is ejected, whetler plant or animal, is not only not proved, but the whole experience we liave, which of coursc applies to animals only, goes to establisli tlic opposite as a general truth. 
Even in the case of some of the fungi, and of flowering plants, we have a very clear and satisfactory instance of this kind in those fungi which formed what are ealled fairy rings upon dry commons, and which in the days of ignorance were supposed to be trodden down by the imaginary elves, after which they are named, in theix midnight danees during the summer months. We are not so well versed in fairy lore as to be able to say what was supposed to become of those light-footed gentry during the inclement season, whether they migrated like birds, or hybernated like toads; but we believe their nocturnal dancings were suspended during the cold season; and it so liappens that the rings or cireles upon the sward, whieh were supposed to be trodden down by their twinkling feet, are covered with much more luxuriant grass during the Autumn, the winter, and the spring, than the rest of the sward upon which they are marked. This fact in natural history is embodied by the great poet of nature in his allusion to the fairies; and there is far more of the essence of genuine philosophy in it than in many treatises which are laboriously composed, with the express intention of being profoundly philosophical. He says,

\footnotetext{
"the demi-puppets that

By moonshine did the green sour ringlets make, Whereof the ewe not bites; and those whose pastime Was to make the midnight mushrooms."
}

These fairy rings, which at one time caused a good deal of speculation among the observers of nature and inquirers into natural eauses, afford one very pleasant 
means of explaining the functions of some of the fungi, and the relations between them and some of the flowering plants, more especially the grasses. They occur only upon dry and warm places, which are covered by a short and kindly sward. If the surface is level, they are perfectly circular; but upon au uneven surface they move less rapidly up hill than in any other direction. Some are a mere spot, without any opening in the centre, and others are a good many feet, or yards, in diameter. The spots open in the second year of their appearance to the extent of from half a foot to a foot, which is about the breadth of the ring, and also the rate at which it expands in all directions in the course of the year. We had daily opportunities of noticing them for more than twelve years in a place where they were numerous, and where their progress was interrupted, both by obstacles and by their interference with each other. One advanced to a foot-path, where for a season or two it was interrupted; but a segment at length made its appearance on the opposite side of the path, where it gradually advanced, but as a segment of a smaller circle than the portion which remained on the other side. In another instance two met; and at first they seemed to have bent each other inwards to a cliord, where they came in contact. This chord soon parted, however; and the result was a figure composed of the greater part of two circles. Each of the points of junction appeared, however, to march with more celerity than the rest of the circumferences; so that in time it became a sort of oval; and by the time that we 
ceased to have the opportunity of observing it, it lad become nearly circular. Some advanced upon marshy spots, and others toward the rocky pavements or the shingly beaches. The situation was near the sea, and when they came to the shore the part was obliterated, and the circle gradually became an arcli. There were other interruptions, such as the meeting of three; but we never observed one formed within the circumference of another, or two coming in contact, without the obliteration of both when they met.

Electricity, and various other means, have been resorted to on purpose to explain these rings. Electricity is, however, a very suspicious means of explaining any phenomenon, except such as we actually see produced by lightning; and though in all probability some casualty happening to the grass gave origin to these lings, there is no doubt that they were continued by the fungi, afterwards to be noticed. Every cause by which the grass was burnt up did not, however, produce them; for upon the same ground there were often burnt-up patches, which produced no fungi, and led to the formation of no fairy rings. What was the difference of cause in the burning ip of the spots was not ascertained, and is probably not ascertainable; but whenever the fungi came upon a burnt-up spot at the same time as upon the rings, then those spots were sure to be ultimately converted into rings. In this part of the matter there is certainly something which we are unable to understand, and of course to explain; for though the burning up of the grass and the appearance of the fungus are both connected with the fairy 
ring, yet neither the one nor the other appears to be in any way the cause of its first formation. One of the fungi that make their appearance on the rings is the common field, or esculent mushroom, Ayaricus campestris; but so far from a ring being the consequence of that mushroom wherever it appears, there is not one ring for many thousands of mushrooms. We cammot, therefore, in any way, look upon the mushroom as the primary cause of the ring, but rather must consider the burnt-up spot, from which the ring begins, as the disposing cause to the appearance of the mushroom.

Of this there is a very obvious confirmation in the well-known fact, that fungi grow much more readily in places where vegetables have been burned by ordinary fires than they do upon ground of the same description, where no combustion has taken place. 'This is the case, not only with those fungi which rise (in their blossoms) above the surface, but also in those that remain below ground in all their stages, as the Morel, for instance. This fungus is a favourite in most countries, and it is particularly so in Germany, where the peasants collect it in great quantities, as a regular and profitable article of trade. Observation taught them that morels were to be found more abundantly in places where there had been fires, and that they could be found there at times when there were none any where else: therefore they were in the habit of burning the weeds in patches, as a means of cultivating morels. But the fires which they kindled often extended so as to be most mischievous and dangerous? 
and they were in consequenee prohibited under severe penalties. 'This faet, whieh is established by practical experienee, without the slightest referenee to any theory, not only eonfirms the truth of the origin of the fairy ring being an affeetion of the herbage antecedent to the appearance of the fungi, but it throws considerable light on the general funetion of these plants, and may be borne in mind till we eome to the suminary statement of that function.

And here, before we returu to the particular eonsideration of the rings, it may be both useful and gratifying to remark how beautifully one part of the system of nature sheds light upon other parts, when we pursue the inquiry without the bias of any theory, and with due allusion to the general relations. We have already remarked that the fungi are speeially constituted for yielding an immediate and perfeet obedience to eircumstances, by the universal distribution and the indestructible nature of their germs, as well as by the great rapidity with whieh these germs are developed, whenever they are neeessary, or, which is the same in faet, when circumstanees are favourable to their development. Their adaptation to their purpose, of which the general view is clear, notwithstanding the obseurity of the details, is one of the most striking instanees of perfeetion of design which we meet with in the whole range of material nature. The absolute number is not known, as the fungi of many parts of the world have hardly been notieed, and the knowledge of them is imperfect every where; but we are within the limits when we say that the speeies 
consists of many thousands, and the average of germs to a species of many hundred millions. Here, then, is an army outnumbering millions of times withont number all the armies that man ever brought into the field, always ready at a moment, and every member instinct with powers for the full and perfect discharge of its duty. The design shown in the adaptation of any organ to its office, or of any animal or plant to its place in nature, is beautiful; but they are small in comparison with this gigantic adaptation. And, mighty as the muster is, the wonder stops not here; for the whole of this Autumnal host act in accordance with the beams of the sun, and the motion of the earth in its orbit. In this we find one of the links of that golden chain,-that chain made without hands, and inscrutable by every created power save mind, by which the heavens and the earth are, without material connexion, bound together in perfect and perpetual liamony. But the subject addresses itself as powerfully to our gratitude as it does to our admiration. It is wonderful that sucl adaptations should be; and it is delightful that we-" children of the dist," and "crushed before the moth," as we are in the mere body, and the temporal life and possessions, and all their pomp and pretence-are mentally so endowed by an all-bountiful God, as that we can understand and appreciate these things, and that this, the most refined and exalted of all our pleasures, should remain with us unimpaired and unshaken by all the vicissitudes of life, to which, as bcings of finite perception and capacity, we are of necessity subjected. Nor does it 
stop here; for the feeling of immortality is strong in the thought; and as no power in nature is given in vain, "three score and ten years" in a world of contingency-certainly not "a world of woe" to the wise, let life or fortune change as they may-cannot "trammel up the consequences" of these glorious glimpses of the attributes of Him who is from eternity to eternity. He, who has so ordained that the mushroom, "which springeth up in a night," and the sun of the molning beats upon it, and it is gone, never appears but to perform its appointed work, has not, contrary to the law of every other portion of his works, made man in vain-given him a spirit meet for immortality, without the immortality along with it. It is not-it cannot be: the whole of creation stands witness to the contrary.

But we must return to the consideration of the fairy rings; and they who have not felt how forcibly the proper contemplation of any one portion of nature leads to the relations of all nature, and the comnexion of lature with nature's God, may perhaps wonder why " the green sour ringlets of which the ewe not bites," should lead us to the revolution of the earth in its orbit, and the more mighty zone of the mind's eternal duration. Yet there is one little consideration which may be satisfactory to them in this matter, and instructive in other respects. In the ages of ignorance the formation of those rings was attributed to supernatural agency. Now, however erroneous this may have been, and howevel absurd, in the judgment of reason, the fancied agent in this, or in any other case, 
may appear, there is a witnessing for the truth involved in it; and wherever ignorance calls in the aid of supernatural influence, philosophy, guided by the light of revelation, will find the impress of divinity peculiarly strong. And such must be the case; for the mytho$\operatorname{logy}$, whatever it is, is really the effect of the benighted mind groping for that God which it feels but cannot see, for want of the only light whereby the true God can be revealed.

Whenever a mushroom crop appears upon the burntup spot,-and they are, generally speaking, agaricaca, or fungi of the mushroom family, of some species or other, and mostly esculent, or at all events harmless ones, as they grow upon dry and kindly places,-they disappear with the Autumnal rains, and their disappearance is followed by a more rank and vigorous vegetation than there is on the surrounding surface. This continues till March, or till later in the season, according to the nature of the place, and the character of the year; and while it continues in the full vigour of its greenness, it is avoided by cattle, and especially by sheep, and stands a luxuriant spot in the middle of a closely-nibbled surface. But the fact of this rankness of vegetation having been preceded by a crop of fungi, has really no more to do with the ewe's abstaining from biting than the fairies have; for any one may observe, that all rank spots, from whatever cause they may be produced, are avoided in the same manner. Nor is it difficult to ascertain why the cattle and sheep should prefer the herbage around to these rank spots; for one has only to taste the grass on the two. 
That upon the spot merits the character of "sour;" for there is an acerbity about it, while the finer and more fertile grass on the rest of the surface, ripened as it is by the summer action, has a saccharine taste, and contains much more nutritious matter than that which is rank in growth. This, by the way, runs very generally throughout nature; for we find that the insects do not begin their attacks until there is a partial stop, or, at all events, weakening of the vegetation; and at whatever stage of the annual progress of the plant these attacks are made, they are always made on the youngest part, because that is the most susceptible, and consequently the most liable to temporary checks from partial changes of the weather. The conduct of the aphides, on what plant soever they appear, is a proof of this.

In the following summer, the spot upon which the rank grass appeared after the mushrooms, diminishes in its vigour, though it remains for some time of a darker green than the rest of the surface; and as long as it does so the sheep prefer the less vigorous part of the pasture. But in the course of the warm and dry weather it subsides into the same tint as the rest.

But before this takes place, there is a change of appearance in the margin around the spot. Earlier or later, according to the degree of warmth and drought, the grass upon a ring round the spot becomes pale and sickly, and in the extreme heat it withers away, and leaves the surface as if it liad been scorched. In the later period of the drought, this sterile circle is the only visible part; and after the midsummer rains it 
becomes covered with fungi, which often form a complete ring, varying, as we said of the rings in general, from half a foot to a foot in breadth. The Autumnal rains put an end to the fungi ; and after this the grass again appears in the Autumn, the winter, or the spring, according to circumstances. The ring thus begun, shows a rank and dark green vegetation in the early part of the season, the same as was shown by the spot; and as the season advances, this ring is surrounded by one of parched surface; that is, succeeder by fungi, and the fungi, again, in proper time, by rank and dark green vegetation. The same succession is repeated year after year, and the ring enlarges, until it meets with interruption in one or other of the ways that have been stated.

That this is the progress of the ring, we have observed in very many instances; and we believe that there is no established case of a ring, or arch of a ring, laving been formed on the first instance. They all proceed from centres; and if any portion of the circumference shall become obliterated, it is in consequence of unfavourable ground being reached.

The absolute duration and the specific use in nature of these rings, are as much involved in obscurity as their original cause. In those which we watched during the period before alluded to, there were differences of appearance in years of different character; but we do not feel warranted in saying that there was any indication of increased vigour or of decline in their action. From the curvature of fragments in some places a diameter of 500 or 600 yards may be inferred, which at 
an increase of sixteen inches on the radius in the course of each year, would indicate a duration of, about, from 500 to 700 ycars; but the data are too vague for allowing this to be positively asserted. 'Those which we observed as entire circles were of much smaller dimensions, but no note had been taken of the date of their origin or of their progressive history.

The use is even more obscure. That they do answer some purpose in the economy of nature must be taken for granted, for if they did not answer a purpose they would not have a place. This may be held as a general truth in every part of nature; but whether we shall or shall not have any knowledge of the use, and whether the use that we conjecture in these abstruse cases is or is not the right one, are very different matters. If we were to give an opinion upon the matter, we should be inclined to say that the surface over which the ring has passed, is rather more vigorous in its vegetation, and more kindly and free from the admixtme of mosses, than that over which no ring has made its progress. This, however, is a mere opinion, and not a truth which rests upon any thing like evidence.

'The progressive extension of the ring admits of far more satisfactory information. When the fungi have once occupied the surface, thcy have performed the whole of thcir work in the scason, so that the surface upon which they liave grown does not require their growth, and thus is unfit for calling them into action. But the ground external of the ring, as long as it remains of a certain character, of the nature of which we have no knowledge further than that it must neithcr be 
too arid nor too humid, still requires them, and of course it is fit for their reeption. These faets are proved by the annual inerease of the ring in diameter. The fungi of course shed their spores or germs in the same abundanee toward every side of the place where they grow, and of course the same number of them fall inwards as outwards. Indeed we may suppose that the numbers which fall are equal and distributed to equal distances upon every incl of the place where the fungus grows. But they do not grow within the ring; and thus we must conclude that the ground there has, in consequence of having produced one crop of fungi, become unfit for the production of another. What the change is we have no means of aseertaining; but there is no way of accounting for the fact of the increase of the ring, but by supposing that the same ground cannot produce a crop of the same fungus in two consecutive years. How long it may retain this incapacity is a point which we eannot decide; because one year would explain the fact of the fungi never retreating inwards, or that of both rings becoming obliterated where two meet: and as the progress outwards is only from half a foot to a foot in the course of each season, we eannot suppose that the dispersion of the germs in any direction is to a greater distanee.

But, whatever the distance may be, it is obvious that there must be something favourable to the growth of the fungi in the state of the ground outside, and something unfavourable to it in that inside,-inasmuch as the progress is always the one way and never the other; though in what the difference may consist, is a point which we eamnot, in the present state of our knowledge, 
determine. After the ring is once begun, there appears to be something in the spores of the fungi which conduces to the burning up of the next ring, though what it is we camnot tell, as the very same fungi, when they grow in their ordinary detached manner, do not occasion any burning up of the grass in the drought of the cnsuing season. On the other hand, the work which the fungi perform must tend to make the ground more fit for the growth, not of a new vegetation, but of the very same plants, the grasses at least, that were there before the ring passed over it; but what specific action is performed there are no means of ascertaining. Where we have examined them, the grasses and the flowering plants generally, seemed to be the same within the fairy ring as without; and thongh we are inclined to think so, we cannot positively state that there was any diminution of the small mosses and the ground lichens within the ring. 'The general conclusion, though it is not one of the most satisfactory nature, is that there is much of the philosophy of the fungi to be learned from these fairy rings, but that we must have much more information than we at present possess, before we can turn that pliilosophy to use.

The three hypotheses of the action of under-ground larva, the mixing of the droppings of horses with the. soil, and electricity, which have been mentioned as the primary causes of fairy rings, are all equally unsatisfactory. We have seen the grass destroyed by larvæ over very considerable surfaces, without the least appearance of fungi; we have seen fairy rings in places where there could not possibly be any droppings of a 
horse, while we never saw a ring originate from any substance of the kind. Fungi no doubt make their appearance there if the substance is in a humid place or after rain; but they are of a much more evanescent nature than those which appear on fairy rings. Then, as for the electricity, it is so well suited for being appealed to by those who find it necessary to say something, and yet do not know what to say, that it always calls to our recollection the case of a very virtuous but very ignorant old woman who was the keeper of a dame school. One of her duties, and indeed the chief one, was the most praiseworthy task, or pleasure rather, of teaching the children of the peasants to read the Bible; and as far as ordinary words, and a very pious and by no means unappropriate commentary, considering the nature of her audience, were concerned, Marion was not unqualified; but the proper names were sad posers to her. By some means, however, she had learned the sound of the word Naphthalim, which she used for every proper name illat came in her way; and the repetition of this word in some of the genealogical chapters, as for instance, "Naphthalim" ninety times over in the first thirty-four lines of the tenth chapter of Nehemial, had a most monotonous effect, though it was as solemnly received by the whole school, and probably was just as useful to children of tender age, as if Marion, instead of rendering the second verse "Naphthalim, Naphthalim, Naphthalim," had pronounced it, "Seraiah, Azariall, Jeremiah." Marion's well-meant blunder (for it was well meant,) lay in the desire of reading the Bible "all throngh," without any regard to her own capacity or 03 
that of her scholars. It is much the same with those philosophers-and others, who will needs read the book of nature "all through ;" and Electricity has often been, and in some instances is still, a most convenient "Naphthalim." In the case of those who are utterly ignorant, such a subterfuge may perhaps do just as well as that of Marion did with the infants, and it may even afford some little amusement to those who are better skilled in the matter. But, at a time like the present, when knowledge is what is most appropriately styled "diffused," that is, spread over a great breadth of the public with most lamentable disproportion in depth, the mischief done by the dissemination of a false or inadequate cause for any one phenomenon is incalculable; and both the original propounder of such an error, and the wretched compiler who lumps books together, for the sheer lucre of his hireling fee, and haply under the sanction of some literary appellation profanely bought for money, who aids in circulating cheaply the falsehood which cost him nothing - save the peculation,- - deserve to be held up to the most reproving obloquy of the friends of true knowledge and of man; and he who has the opportunity of doing this and neglects it, from indolence, from false delicacy, or from any other motive, is no friend of cither in deed, whatever he may be in desire.

Whenever the cause cannot be assigned upon principles which are clear in themselves, and consistent with all the great laws of science as established by wellgrounded experienee, the candid plan is to confess the truth at once, and point out in the most eareful mamer, and with direct reference to all the established truths 
that bear upon it, where the difficulty lies; because this misleads nobody, and it shows where the subject should be taken up by future inquirers. The case of the fairy rings is a good illustration of this, and the fact of its being so is one of the reasons why we have dwelt upon it to a considerable length. We know from direct observation, that when the fungi make their appearance uponsa burnt-up surface, the result is a fairy ring, which extends in future years, and the limit of whose extension we do not know. It is also obvious, that, in this particular mode of their action, the fungi do not depart from that Autumnal character which is so peculiar to them, inasmuch as they do not spring up until after the death of the other vegetation. It is clear therefore that there is something to be decomposed which requires their action; but it is not easy to say whether that something is more immediately in the refuse of the plants which have been burnt up, or in the soil or surface, independently of that refise, to which latter the action of the sun and air is admitted by the burning up of the herbage, so as to prepare it for the action of the fungi. We mentioned the case of morels growing abundantly after fires in the German forests; and any one who has been in the habit of observing in this country, must have often seen that after a shower has fallen upon a spot where vegetables have been consumed, as for instance upon that where a gipsy fire has been, that there was a growth of fungi upon the margins. The same happens in the case of the droppings of animals, and of many substances prone to ferment and putrefy; but in no one of these instances is 
there the least tendency to the formation of a fairy ring. 'The fungi, whether of a more short-lived or a more permanent description, vanish when they have run their course, and no succession of them has any tendency to spread over the neighbouring surface in future years as happens in the case of the fairy ring.

This lets us see where the difficulty of the subject lies. We can observe the burning up of the lerbage, the succession of the fungi, their disalpearance, the increased verdure for a season, and sometimes longer, of the space which they occupied, and that these follow each other as the ring extends; but of the original cause of the decay of grass on the central spot, or of that on the successive rings, we are entirely ignorant. We cannot suppose that the fungi are primary agents in the matter, and that their incipient growth causes the grass to wither; because that would be contrary to their very nature, and lead us completely astray upon a subject whereon information of a more perfect and connected kind than any which we at present possess, is lighly desirable, as well for the practice of the cultivator as for the inquirer after natural truth.

We have been thus minute in the mention of these rings, because there is much to be learned from the study of them, and because they are found in places the visiting of which is highly conducive not only to the mere liealth of the body, but to the tuning of it to that ready obedience to the impulses of the mind, which makes observation something higher and more worthy of a rational and immortal being, than the mere sensual exercise of the bodily organs, how pleasant soever that 
exercise may be for the moment. 'They are never' found upon humid meadows, in the shade of woods, or upon rank and shaded places of any kind. The grassy down, and the open common, when not too high and bleak, and especially where stretching onward to the sea, are the situations in which these phcnomena are to be looked for; and perhaps there are no spots on the surface of the earth, the visiting of which is better calculated to give health to the body and expand the mind in those trains of thought, the progress whereof is toward immortality.

In the remarks which we have made, and which are necessarily of a desultory cast, both from the nature and from the novelty of the subject, we have endeavoured to show that, as the appropriate armies of Autumn, the fungi appear to disorganize those organic substances which have ceased to be useful, and which do not yield to the common action of the elements, or are not disintegrated by small animals. In doing this we have endeavoured to point out the limit of their functions, namely, that they never make their appearance or assail any organized body, or portion of such body, so long as it is in the healthy exercise of its own proper life, however appearances might lead partial and careless observers, or those who do not take the general principle along with them, to come to an opposite conclusion. In this view of them, which we are fully convinced is the right onc, we find that the use and action of those plants are illustrations of their nature. 'They are passive, never invading the rest of the world as a host, but abiding their time and yielding 
the most implicit obedience to circumstances. Even those which come upon plants early in the season, and destroy that produce which a healthy plant would yield, form no exception to the general nature and functions of this Autumnal army.

That which we are to consider as being Autumnal action in the decomposition of organized beings or their parts, and especially of plants, which are the principal subjects of our present inquiry, or expatiation (if any one think the former word too assuming), is not confined to time of the year, or to period of the life of the vegetable. It is true that in countries which are strictly seasonal, and in the case of plants which have rum what we may call their full course in a state of uninterrupted health, we look for the fungus only in the Autumn; and where the annual course lias been perfectly regular, the fungus does not appear to be essentially necessary. In fact it seems to be a general law of nature that there shall be some deranged state, some departure from the ordinary course, in order to render the fungus necessary. The condition in which it makes its attack is that which, in ordinary langnage, is not inappropriately termed "dead and alive,"-that is, no longer fit for living action, and yet not ripened for what may be called the maturity which passes naturally into death. We shall have occasion to revert to this in a subsequent chapter, when we come to speak in some little detail of blights and dry-rots; but it is necessary to keep the principle in mind, in every inquiry respecting the action of Autumn.

If there were no contingency, that is, no departure 
from perfeet uniformity, in the weather, day after day, and in the seasons, year after year, then the labours of the fungi might be wholly dispensed with, and the rest of nature might go on without their interference. But the daily and yearly variations are neeessary parts of the aetion of so extended and eomplieated a system; and it is in them that the eompensations are to be found which secure the preservation of the whole. To unreflecting minds this may seem an imperfeetion; but it is in reality the very highest perfeetion that can be imagined, and one of the strongest proofs that the system of nature is the production of infinite wisdom.

If it were not for this balanee, this means by which every state involves in itself the power of produeing its opposite, just in the same manner as the reeession of a planet from the sun toward its aphelion involves the return again to the sun in perihelion, and this return involves the recession. Thus, all the parts of the system, while they work each apparently for itself, work mutually for each other; and though many of the parts are above the reach of our knowledge, we can feel and admire the beauty and the harmonious working of the whole.

In the vegetable kingdom especially, the fungi are the only agents whieh perform what we ean properly eall an Autumnal labour in the decomposition of the organic strueture of other vegetables; and, at whatever time, or in whatever manner they may perform their offices, we have no reason to believe that they ever eome into activity, until they are called to do so by ineipient death on the plants, or parts of plants, upon 
which they make their appearance. 'There are, however, some plants belonging to another department of the vegetable kingdom, which, like the fungi, are cellnlar in their structure, and, in the common meaning of the word, flowerless, which are apt to be confounded with the fungi, both in nature and in function; and thus it may be as well to point ont in what the distinction consists.

The plants which are most liable to be confonnded with the fungi, are a few of the mosses which grow upon the surface of plants, and especially the lichens, which are more frequently found in the same situations. Of the mosses we shall hare occasion to speak at some length in our volume on WINTER; and therefore we need not mention them farther at present than to say that the decomposition of other regetables, living, dying, or dead, is no part of their office in nature.

The same may be said of the lichens, which are plants of a very climatal nature, thongh they have no specific seasonal office, or, at all events, not an Autumnal one. The word lichen, literally means that which has a rough surface, something resembling the papille with which the tongne is covered; and when the plants are large enongh for displaying it, they certainly have this character. They belong to a larger division of the vegetable kingdom, which have been called Algce, or Algares, and popularly flags, though in common language, the term "flag" is not applied to the whole of them, neither do they include all plants to which the name of flags has been giren. 
These Algce are more general in their habitats than any other of the grand divisions of the vegetable kingdom; but although this causes a great deal of variety in their external appearances, they still have some very important characters in common, and it is impossible to have an accurate understanding of the rest of the regetable kingdom, or indeed of the working of natnre, especially its seasonal working, without some knowledge of them, if it were only for the purpose of drawing lines of distinction.

The Alge occupy three very distinct localities, and their organization and habits are of course adapted to these. The first are the Fuci, or sea-iveeds, which are distributed over the ocean in every part of the world. They follow the general law of land regetation, in being most numerous and most luxuriant in the tropical latitudes. As is the case with that element which they inhabit, the fuci have not much of a seasonal character, and in our latitudes they belong to the winter vegetation more than to any other, and consequently do not come within the scope of the present volume.

The second division chiefly inhabit the fresh waters, or have the principal times of their appearance or growth when the earth or the air are hmmid. 'They are known under the general name of Conferva, because the greater number of them are formed in jointed pieces; but some of them (to which we shall have occasion to advert, in order to prevent them from being confounded with the fungi, with which they have no function in common,) are among the most simple of all vegetables, and can hardly be said to be organized, 
though they are living productions, and the principle of life in them seems to be remarkably tenacious. They are very decidedly seasonal plants; and they are most abundant in those countries in which the seasons are most marked. In the sunny lands of the equatorial latitudes, though in respect of animal life and of vegetable life in some others of the grand divisions of the kingdom, "the waters bring forth abundantly," yet the confervæ are less plentiful in them than in the high latitudes. The rivers and tanks of India, and of tropical climates generally, are much more free from this sort of vegetation than the pools and streams of Lapland. In our own country, the waters of the cold uplands abound much more in confervæ than the rivers of the warm valleys and the plains; and the tracing of a river from the sources of its feeders on the most elevated places, to the first locality of sea-weed in its estuary, affords a tolerable view of the climatal distribution of those confervæ which inhabit the running waters. In the rills which distil immediately from the snow, they are not very abundant; neither are they in the dark waters which find their way from the more elevated peat-bogs; but in those places where the seasonal springs "well out," and the seasonal pools settle, they are very luxuriant. While the water remains, they are green and vigorous; but when the drought comes and the water is evaporated, they become white, dry, and matted into a substance resembling coarse pasteboard, broken into patches, which cover the whole extent upon which the water has been stagnant. When the wet again sets in, they become green, and put out 
a new vegetation, which is repeated, in situations favourable to them, until the beds of the waters are, to a very considerable cxtent, filled up.

Some of the plants of this section or order of the Alge, may be regarded as standing on the extreme verge of vegetation, in respect both of the simplicity of their structure, and of the circumstances under which they vegetate-sucl vegetating as it may be called. The Nostocs, so called because, after vanishing we know not whither, they return we know not whence or how, are the most remarkable in both respects. They make their appearance when the atmosphere, or the place, or both are humid; and in the drought they disappear to our obscrvation, though we cannot say that they are entirely gone. They come upon all sorts of surfaces, - upon rocks, upon the leaves of plants, upon the waters, and even upon the snow, with which they are mingled in its fall; and such as are so probably grow, or, at all events, have their rudiments floating in the air. These last are called "red snow," "showers of blood," or "gory dew," according as they are accompanied by a frozen shower, a shower which is unfrozen, or unaccompanied by any shower in either state. In the case of the snow, there is little doubt that they fall along with it; but in the absence of frost it is probable that the humidity merely excites them on the surface. On damp and shaded spots, some of the family are pretty permanent, and hence, in the ages of superstition, they were regarded as blood which had been foully shed, crying from the earth for vengeance against the perpetrators of decds of cruelty; and the 
supposed showers stained with blood, especially those of snow and hail, were regarded as omens of the most fearful character. Some of the species grow in the interior of gloomy caves in wild and lonely places, and others on the damp walls of the dungeons of old castles, or in the crypts of ruined abbeys; and though they are very simple things, being nothing more than vegetable jelly with the mere rudiments of organization in it, they have led to the formation and the belief of most direful stories.

Such as have no sanguineous hue, have got names of quite another kind, being called "flowers of heaven," "fallen stars," "quenched ignes fatui," and various other things, with no one of which they have the least connexion. These names have been given to such as appear upon the ground or upon plants; and those that appear upon the waters are frequently called "scums." Of both there are probably some that descend in their rndimental state along with the showers, as it is in moist places and during showery weather that they make their appearance. Some of them occasionally mantle the pools with a complete covering, which however is of a very evanescent nature, and is brushed away by the wing of the first dry wind.

Many of them are Autummal in their seasonal appearance, but they come at the beginning; and the fact of their being observed at the times when ignes fatui, shooting stars, and other luminous matters are most frequently seen, no doubt led to the erroneous opinion that they are the remains of such meteors after their light las burned out. 
Simple as these plants are, wo can nevertheless trace a shadowy sort of resemblanee between them and the more complex, or, as we call them, the "ligher orders" of vegetalules. It may, at first sight, seem a little arrogant, on our part, to make distinetions of higher and lower, where all is perfect, and where the proto-coccus in the polar snow-shower is just as well adapted to its purpose as the most stately tree in the equatorial forest. But sueh is not the faet, our eomparison being merely that of the different degrees of vegetable aetion, and in this respect we find not only the difference specified, but a very strong proof of our most rational theory of vegetable life, namely, that in proportion as vegetable action is less vigorous, it is less easily destroyed. The simple plants of whieh we are speaking have little distinction of parts, and those parts are very minute; but they can grow safely on the snow, and ride seeure upon the snow-cloud, even in those latitudes where is falls in an almost impalpable powder.

Plants of this order may be said to eonsist of only two parts, a thallus, and threads and vesicles. Thallus literally means that from or in which there is sprouting, and, in the general sense, any green or growing expansion whatsoever; but we apply it to that part of the simpler plants, whieh answers to root and stem, or root, stem, and leaf, compounded in a single organ.

In like manner, when there is a part growing upon a thallus or root, and combining the eharaeters of stem and leaf, we eall it a frond, as in a fern or a sea-weed; when these two parts are distinct, we come to the leaf (phyllum); and when we have the final state in the P 3 
vegetable development, we have a flower-leaf (petalum) which means an expansion as well as the others, but dues not necessarily involve the idea of greenmess.

Thus the thallus in those very simple vegetables is the "plant;" and the filaments or vesicles, or both, are the parts of fructification, or those which answer to the flowers of those plants which are of more conplicated structure. The spores, or sporidia, are the seeds (that which is sown) which are in some instances enclosed in a sporidium, and in others naked in or upon the thallus. A thallus is thus the very simplest plant of which we can have any notion; and, as the seeds of all plants are more simple structures than the plants themselves, the sporidr of such plants are the very simplest forms in which vegetable life exists, and for this reason they are the least destructible-the least subject to decomposition. Some of these plants appear in various fluidsas for instance in fermented liquors; and it is probable that the most minute animalculi are supplied with vegetable food by others so minute that our most powerful magnifiers cannot detect them. This however is the extreme limit of both kingdoms of the vegetable world, and thus it is not the proper field for popular speculation. Some species which admit of being examined, and which consist of vesicles which part and form separate plants, appear to have such limited power of vegetable action, that they are not able wholly to resist the common laws of the matter of which they are composed; and accordingly their vesicles are, in part, filled with crystals.

But though, in these cases, we have an action of dead 
matter and an action of living matter, or rather a law of dead matter and one of living nuatter, embodied within the same volume, and that a very small one, we must be careful not to confound them, or to imagine that the one can, in any way, be converted into the other, so as that crystallization can change to vegetable life, or vegetable life to crystallization. The magnitude of the subject is not an element of the distinction, neither is the proximity of the dead state and the living. It has, we believe, been ascertained by careful and satisfactory experiments, that if an atom of carbon and an atom of water are intimately combined, the compound is a jelly soluble in water, and possessing the chemical properties of the general material of which, making allowance for their particular products, the tissues of vegetables are composed. But that does not make it a vegetable or part of a vegetable, any more than the grinding of flour or the baking of a loaf of bread makes that loaf of bread part of the body of a man. We know that the matter of the loaf goes to the nourishing of the body; and we can follow it as food to a certain extent in the system, and find it as an animal fluid in another; but there is a mystery between, which we cannot understand, nor can we say positively at what stage of the process the food becomes part of the living body. The case of the minute conferva is not easier than this one; and thus though we do know that a certain compound of charcoal, or carbon, and water, may form a jelly similar to that of vegetables, we are not acquainted with any chemical process by which the said jelly can be made a regetable. All that we have arrived at is, that the matcrials of 
nature are fit for the purposes of nature, a truth which stands in need of no philosophic investigation. Herc therefore in the very simplest case to which we can have recourse, we find nature as faithful a witness for its author, as in the most complicated of all possible cases. So far as they are at all understandable, all the cases are indeed equally simple; and the only difference is in the number of steps in the investigation, which is merely a question of time and labour, and not one of understanding, one way or another. The difficulty is the same in them all; and other than a distinct creation of every species, it admits of no variation. Introduce this, and the whole of nature is simple, beautiful, and perfect; reject this, and it becomes any thing that any body chooses to fancy,-and all are in the wrong.

We have been drawn on to such a length with this order of the algæ, that we can spare no room for treating of the lichens. Another occasion will occur, however, and our present object is not to treat positively of this class of plants, but to show that they ought not to be inchuded among the armies of Autumn; but that though some of them have slight external resemblances, their natures are different, and their functions diametrically opposite.

The whole class of the alga, whether their habitat be the sea, the fresh waters, or the air, are less seasonal than any other class in the vegetable kingdom; and in so far as they are seasonal they are a winter vegetation rather than any thing else. They are not scavengers in any sense of the word. They are producers, not destroyers; and they have the merit of working in 
places and under circumstances where other workers there are none.

Some, as we have remarked, float on the waters, and others ride on the winds and the clouds; but the greatcr part have fixed localities, rocks and stones in the sea, the banks and beds of the fresh waters, the surfaces of rocks, the bark of trees, the summits of mountains, places where there is no food even for a moss, are among the situations to which the algæ give the benefit of thcir labours.

But upon what surface or substance soever, any one plant of the class may have its locality, it draws no part of its nourishment from that substance; and the lichens which cover the pole of an aged tree, are no more nourished by the substance of that tree than the lichens which cover the face of a rock are fed upon the substance of that rock. It is true that they do not come upon the smooth bark of young and vigorously growing trees in such numbers, or so readily as they do upon trees of fecble growth or upon dry wood; but it is the greater security of the resting-place which favours them, and in all cases their function is not directly to turn that upon which they grow into soil, but to collect soil upon it. That they have an indirect tendency to stunt the growth of those trees on which they are abundant, and in some instances to decompose the rocks on which they grow, is true; but the injury to the tree is occasioned by the exclusion of the air, and also by the soaking of the water and the cold produced by evaporation. To rocks and stones they afford protection from the influence of the air, and this in part explains the meaning of the 
common saying, that "a rolling stone gathers no moss," for it is worn away both by the friction of the motion, and by the influence of the atmosphere. Mountain rocks are no doubt, generally speaking, of firmer texture than those in lower and more sheltered situations; but they have much more severe vicissitudes of the weather to encounter, which in great part corresponds to their firmer texture; and thus they owe much of their safety to the lichens.

A direct proof of this may be seen in any old tower which has long stood the weather, unexposed to smoke, which is unfavourable to the growth of lichens. The stone of which the tower is built may be all from the same quarry, but still it will be found that, while the parts near the foundation are rarely time-worn, especially toward the south-west, the marks of the chisel are fresh upon those near the top, more especially on the north-east side, where the lichens are always most abundant. It is the same with the fuci and the conferve; for the rocks and channels that are covered with them, are not nearly so much worn as those that are bare.

The mosses have a different form and function from the alga; but, like them, they are no direct destroyers or preyers upon the substance of other plants. Thus they do not form part of the Autumnal host, but belong to the winter vegetation in their general character and the greater part of their numbers. 'Their presenec is no doubt unfavourable to the growth of many plants, and the soil which they form is of a peculiar character; but they are accumulators of soil; and the antiseptic or 
preserving powcr of those accumulations is clearly established by the perfect state in which both animal and vegetable remains are found after having becn buried in peat-bogs for hundreds of years. We must, however, refer to our volume on Winter for some notice of the office of those vegetable conscrvatives in the grand system of nature. Linnacus, whose fancies often cmbody far more knowledge than other people's facts, called the alga, Vernaculi, or homc-born slaves, and the mosses or Musci, Servi, or drudges; and both names arc well descriptive of thcir leading labits; for the algæ do not wander far, that is, thcir sporre arc not conveyed to any very great distance; and the mosses, if supplied with sufficient humidity, drudge on in their growth all the year round.

The Fungi-the appropriate troops of Autumn, in the performance of its field-labours-have bcen already stated to be the very reverse of all this. They wander cvery wherc, according as their presence and labours are required; the greater number are of very bricf duration; and though some of them spread very fist, and contiuue for a considerable time in their successions, there is not one that has a second season of growth in the individual plant. For this reason Limueus bestowed upon them the name of Nomades, or wanderers. 


\section{CHAPTER V.}

SHORT NOTICES OF SOME PLANTS APPARENTLY AUTUMNALDTIE BISSINA.

We have alveady described the fungi as the appropriate armies of the Autumn, in the conquest over that part of uature, and more especially of vegetable nature, which has performed the whole of the function for which it was called into existence, and thus is of no more use in the organic world, until it shall have beeu reduced to the condition of merely elementary matter. This they do by decomposition, and not by mere disiutegration-by chemical solution of the substance, and not by merely tearing it asunder; and they either convert it into their own very perishable substances, or they so destroy its organic structure, that it becomes an incoherent powder when dry, and a plastic dough when wet. At whatever time of the year, or stage of the growth of a plant or part of a plant, this is performed, it is always an Autummal action, and the work of an Autumnal agent; and it is in the following out of this into its details, that we obtain a proper view of the characteristic labour of Autumu in preparing materials 
for a new action of life. That either the fungus itself, or the vegetable or other matter which it disintegrates, is instantly fit for being the food of any one species of plant, we do not mean to assert. The food of plants is a very obscure matter; and he would be a very bold theorist who ventured to say that any one substance which can be examined separately, is the fond of any one species of plant. Considered in their relation to the rest of the vegetable kingdom, the fungi are not, in any sense of the word, the nurses of the new vegetation, they are merely the destroyers of the old; and before the new comes into operation, they have ceased to exist. Their business in nature is to deliver up to the store of inorganic matter, and to the dominion of the laws by which that matter is governed, the substance of what has previously organized, but which the action of those laws is of itself insufficient to reduce in the requisite time without the assistance of the fungi.

This is the final and appropriate action of these plants, though we cannot fix the stage at which it begins, nor take up the history of the decomposed matter the moment that the fungus has done with it, or trace it to any new structure into which it may enter. We have stated it as a matter of probability, and as being in perfect analogy with the whole system of nature, that the appearance of the fungus should be always preceded by a diseased state of that upon which it appears. Indeed, if vigorous liealth in a plant is not sufficient to protect it from the ravages of the fungi, it would be very difficult to assign any reason why the fungi have not, ere now, extirpated every other 
raee of plants from the face of the earth. At the other end of the sueession we are met by another and a more insurmountable diffieulty; for, as plants lave no visible or probable means of assimilating food, as animals have, we eannot see how that which is prepared by the fungus ean be in substance applied directly to any other plant.

Henee we must use no small degree of eare upon this subjeet; and, in looking at the eause of the appearance of fungi, either generally with the season, or more loeally at any season, we are upon the only tenable ground when we suppose that the state of the plant, or part of a plant, or other substanee upon whieh a fungus appears, is the disposing eause which ealls the germ of that fungus into activity. It is obvious that this disposing eause may vary. It may be what we call natural deeay, or the plant's being no longer able to contend against the common laws of matter; and we know that when this is the case, there are many instances in which the action of those laws is quite eompetent to the effecting of the deeomposition, without the assistance of any fungus. It may also be a ehange in the physieal circumstances of the situation whieh renders them too much for the faculty of resistance in the plant, of whieh we have many instances, whether they be or be not accompanied, or rather followed by fungi, by inseets, or by any other destroycrs. It may also result. from the action of other plants of a parasitical nature, whieh, in an indirect and secondary manner, weaken. the aetion of that upon which they grow, or even meehanieally divide its substance. These are the chief 
classes of the means by which a plant may be reduced to such a state that fingi may grow npon it; but each of them evidently admits of variation in so many ways, that it would be impossible within our limits to cnter into the details.

What we said generally of those lichens which grow on the bark of trees, having a secondary tendency to produce a diseased action in tlose trees, will, of course, apply here; and so well docs it apply to some families of the lichens, that they liave not unfrequently becn classed among the fungi, some of which they appear to resemble both in their external characters, and thcir apparent uses in nature. When we scrutinize them closely, the difference in their natures and functions become plain enough; but as they are not completely so to popular observation, we shall briefly notice some of the leading ones. Tllose to which we principally allude are the Byssine, or Bysso-lichens, so called, because they are, in the more characteristic specics, composed of fine fibres like those of flax, cotton, or wool. Some of them perform operations which tend to prepare plants for the attacks of the fungi, though only by attracting damp, or by mechanical division.

Some of these plants are very curious, and a few are scarcely less brief in their duration than the fungi, and like those they have their germs very generally distributed, and so very minute, that there are few places from which they are excluded. But they appear in situations where no fingi do or can appear, and they agree with the lichens in deriving their nomishment from the medium in which they grow, and not from the sub- 
stances upon which they are found. Many of them occur on the leaves of plants, and in or under the bark of trees; but they also occur where there is no animal or vegetable matter to be decomposed,- - as on the walls of mines, in ink, and in various other situations, where no one would expect to meet with a single specimen of the fungi. They are also rather permanent in their duration if the circumstances continue favourable to them; and as they do not appear in any way to consume the quantity of matter of that upon which they are situated, their disappearance, when they do disappear, is measured by a change in the state of the atmosphere or other medium in which they exist. As they are dependent on the state of the atmosphere, they must be in so far seasonal; but they are more generally found in close and damp places where there is little atmospheric change in the course of the year. In such places they are perennial plants, having little seasonal change; and thus they cannot be admitted among the army of the Autumn, properly so called. They are fibrous in their texture.

They form a sort of series, from a resemblance to the Terrucarince, or wart lichens; but we cannot say that the termination of the series (in so far as the termination of so obscure a series can be said to be observed,) makes any nearer, or, indeed, so near, an approximation to the character and office of the fungi, as those at the other end of the series which have the most resemblance to the last of the more typical lichens. They lead us out of the vegetable kingdom, or at all events to the extreme linit of vegetation, and leare us not a little in doubt. 
what sort of productions we have to deal with. We find them at greater depths under the surface of the earth than any other vegetables; and they are also understood, in some of the final races, to vegetate in the air. Both of these are understood to emit light under peculiar circumstances; and it may be possible that some of the luminous meteors which are seen in the air, are in some way or other occasioned by these filmy vegetables. In all of them, indeed, we find so close a connexion with the state of the atmosphere, as to leave little doubt that they are dependent upon that element.

There are two distinct forms, or types, of them; and many varieties of each. The first get the name of Rhizomorphacea, or root-formed_-"root-moss"-in some of the more common species. They are small plants, which creep along in thread-like thalli, with short lateral branches, sometimes single and sometimes double; and these are the fruit, or receptacles of the spores or germs. They are an obscurely inhabiting race; and althongh, as we have said, they derive their nourishment wholly, or chiefly, from the air, they share the free atmosphere and the beams of the sun. They are found under the dead bark of trees, especially pine-trees, in dark cellars, among sawdust, and on the interior surfaces of mines; and the darker the place is, their growth appears to be the more vigorous. Those which are found upon trees, appear to have their chief office in stripping of the bark, which they do with much rapidity; but they merely loosen it from the wood without decomposing the substanee of either. Their labour, however, admits the damp of the air and the Q 3 
rain to the wood, by which means the albuminous or cxternal layers begin to decay, and then the fungi make their appearance and perform tle work of decomposition, generally attacking the barkless stem, at the air-line, or the place between the carth and the atmosphere, and so felling it as certainly, though not so speedily, as the axe of the woodman.

Many of the plants are what is called phosphorescent, that is, they give out light, though whether the light which they give out has or has not any connexion with the substance called phosphorus, is a point which has not been ascertained. Those which grow in mines have this property in the highest degree; but it is not confined to them, for it is also found upon those which grow under the bark of decaying firs and other trees. In lonely situations, in some parts of the country, thcy sometimes occasion no small alarm to those who go under cloud of night, to pilfer sticks in woods, especially fir woods of small and stunted growth, where the trees are in progress of decay. When they break down the decaying stems, the bark separates, and gleams of a pale bluish, and to them very alarming light, are given out. Also when they tread off the loosened bark with their fcet, or detacl it with their hands, they find that the same suspicions lights attach to themselves, and many of the rustics living in the neighbourhood of such woods, are scared from committing depredations on the same, by those luminous appearances, which they not unnatirally suppose to bc of supernatural origin. We are 130 friends to superstition in any form that it may possibly assumc; but we have the experience of direct observa- 
tion to convince us that the superstitious terrors of the rustics in some of the remote and simple provinces of the country, operate to no inconsiderable extent in restraining them from the commission of many of the minor, and even of the major crimes of the night, against which the equally or probably more grossly ignorant populace of other places, have no defence save the fear of human punishment. That we may not be misunderstood, we repeat again that we are no friends to superstition, in any form, or to any degree that it may exist; but really, from what we have witnessed and carefully examined in the witnessing, of the totally uneducated, where those superstitions existed, and where they did not, we feel not only inclined but compelled to come to the conclusion, that a very heavy and indeed criminal responsibility lies upon those who go about to destroy the superstitions of ignorant persons, without substituting something better in their stead.

This is a point of no small importance, and as it is contrary to the dogmas of the moder'n improvers of mankind by human legislation aud other human means alone, it may not be amiss to devote a single paragraph to the farther consideration of it, the more especially that it involves no weak argument, for both the truth and the necessity of a light from Heaven to lead and guide men in the true path of their duty as rational and social beings, to say nothing of their higher hope of their being heirs of immortality.

If any one doubts the truth of this, let him test his suspicions by the evidence of unprejudiced experience; and if he himself is not more deeply imbued with pre- 
judice than the parties to whom we allude we feel perfectly convinced that the very first ray of the light of this observation will clear away his suspicion, and establish him in the truth.

Compare the state of rude nations, as they are described in the writings of their most able and impartial observers, or those who in our own country in the present day, are in a state of ignorance in different places and under different circumstances, and you will invariably find that those who are the least free from superstition are invariably the lowest, both in the intellectual scale, and in the moral. In what we are in the habit of calling the savage nations, there are always some glimmerings of civilisation and some displays of the social affections among those who have a system of superstitions; and the more elaborate and complicated that system may be, how absurd soever it may appear to those who have the light of inspiration to illuminate their paths, the intellectual and the moral and social condition of the people are not only the higher, but the people themselves are more easily brought to the perception of the truth, and to obedience to it as a system, than those who have no mental system of superstition or mythology, and thus are entirely under the guidance of their merely animal appetites and passions.

We are disposed to include, and indeed we must include, in the category of the ignorant, or if you will of the savage, all nations which have been, and which are, without the knowledge of the divine revelation, and also all members of other nations, who, though they may lave the verbal knowledge of this revelation, are witliout 
the spiritual feeling, the living principle which regulates the conduct. We are, we say, not only disposed but necessitated to number all such with the ignorant, whatever their acquirements may be in other respects, because they are without that which alonc can give due development and proper effect to the immortal spirit in man. In this state of ignorance, there have been the highest attainments in the arts, and there have bcen bold and valuable steps taken in science; but it is a remarkable fact that, even in the science of matter, there has becil no arriving at any thing like a general principle, until the light which guided the investigator was a light from Heaven: and there is perhaps not a more forcible evidence of the value of christian truth, as declared by the Saviour himself througli the medium of his Evangelists and $\triangle$ postles, than the fact that the great doctrines of philosophy were reserved until the dawn or the day-spring of the Reformation, when the purc doctrines of the word of God were substituted for the dogmas of mere men, who laboured to make the semblance of Christianity a fetter for all the nobler energies of the human mind, instead of that glorious liberty-that freedom from mental slavery and mental fear, which it is in deed and in truth. The moral lesson to be drawn from ignorant human beings which have superstition, as contrasted with those which have none, is a very important one. It shows clearly that there is in them an emanation of the spirit, an uplifting of the immaterial and intellectual principle, which cannot be satisfied with mere matter, or the plilosophy of matter, even in its utmost extent and its highest perfection. If there were no proof of divinity 
but this it might well satisfy any eandid mind, and that a strong argument has not been grounded upon it may seem a matter of espeeial wonder. Whatever name may be given to the system, or whatever may be the imaginary beings of the mythology-demi-gods, genii, fairies, or whatever else, they all stand witnesses for immortality, and for an inheritance and enjoyment to man, beyond the gratification of the senses and the fleeting enduranee of the body. They are the natural longings of the spirit for immortality-the breathings of the natural mind for the enjoyment of its God; and as there can be no sophistieation in them, they furnish irresistible eridenee that if the mind of man is in the least awakened, and he is any thing more than the mere animal, a feeling of the Godhead and of eternal things presents itself to his mind, whether he is or is not in possession of that knowledge whieh ean guide it to the true and profitable result. Thus the unbeliever stands reproved by that whieh he affects to despise; and he who has the knowledge of the true faith, has that faith strengthened by the involuntary testimony of those who are still ignorant of the nature of its revealment, and the foundation upon whieh it rests. There is scareely one superstition whieh might not be brought in proof of the doetrine whieh has now been stated, and proofs of this kind have an especial value that does not belong to any others; but although this is a subjeet of mueh importance, and withal very delightful, we must leave it, and return to our more humble but more appropriate subjeet of the Bysince.

Some of these plants which grow in mines are very 
liminous, and have a very brilliant appearance. The coal-mines at Dresden in Saxony are not the least celebrated in this respect. Mr. Erdman, the commissioner in superintendence of these mines, speaks of them in the following terms: "I saw the luminous plants here in wonderful beauty; the impression produced by the spectacle I shall never forget. It appeared, on descending into the mine, as if we were entering an enchanted castle. The abundance of these plants was so great, that the roof and the walls and the pillars were cntircly covered with them, and the beautiful light they cast almost dazzled the eye. 'The light they give out is like faint moonshine, so that two persons near each other could readily distinguish their bodies. 'The lights appeared to be most considerable when the temperature of the mines was comparatively high."

The luminous property of the plants of this family has not hitherto been explained upon any of the known principles of phosphorescence, but it is by 110 means inprobable that some of the meteoric lights which are displayed in the atmosphere may be occasioned by some of the smaller members of the family floating in the air; and that thus, though the jelly-like plants formerly alluded to are certainly not shooting stars of which the light has been quenched, yet those meteors may be owing to vegetable substances. This however is an extensive, as well as an intricate subject, and it is one upon which, for obvious reasons, we cannot enter.

There is a regular gradation of these Byssine from the Rhizomorpha, which have the spores contained within an envelope more or less perfect, to those which 
are exceedingly simple, and which in some of the genera proceed chiefly by offsets, or have the spores so minute that they hardly come within the range of observation. In sucl of these as approach the more typical Byssex, the spores when visible are external, and some of the plants are of very singular forms. Among these we may mention the Racodida, or rag-moss leathers, so called from their having an appearance somewhat intermediate between worn tatters of leather and shreds of cloth. They are obscure-growing plants, abounding in cellars and other places from which the light is excluded, and which have but little circulation of air. Some of them are very common in cellars where wine is kept, where they creep over the casks and bottles, and also along the roofs and walls, with wonderful rapidity, and often present very singular appearances. What connexion there is between those curious plants and the juice of the grape has not been ascertained; but it has been observed that, in cellars which have been long used for the storing of wine, the plants abound in the places where the wine is kept, whether in cask or in bottle, and even in those places enjoying a better light, where the process of bottling is carried on, but they rarely appear where the empty bottles are stored up, though the situation is, to all appearance, just as favourable for their growth as the others.

The plants which make their appearance, as "moulds," as they are usually called, upon the exposed surfaces of liquors or the vessels containing them, and also upon decaying fruits, and varions other substances, belong to this family; and they do not make their appearance 
until that upon which they appear has obtained a certain age, or has at all events undergone a certain degree of decomposition, Some of them are very beautiful in their structure, but so minute in the individual plant that they cannot be examined without the help of glasses. These very minute and simple plants appear upon an almost endless variety of substances; and some of the substances upon which they appear are of such a nature as to show that the plants cannot derive any part of their nourishment from them. They appear on the surface of ink, and of other solutions containing metallic substances which are unfavourable or absolutely poisonous to ordinary vegetation.

One of the most familiar, and therefore the best adapted for studying the habits of the race, and becoming acquainted with their office and use in the economy of nature, is the mould on cheese-aspergillus glaucus. This appears only in a particular state of the cheese, but not when that substance is in a state of putrefaction, neither does it appear in any way to hasten the decomposition. Fraudulent dealers often attempt to produce an imitation of it, by sticking into the cheese brass pins, which are soon in part converted into verdigris, and so produce an approximation to the colour of the aspergillus or mould. The fraud is, however, easily detected, even by the colour, which inclines to green, whereas that of the mould has a greyish hue; and the offensive coppery taste of the verdigris is not to be mistaken. Another means of procuring-not the coloured imitation but the monld itself-tends to show the connexion which this little plant has with the rest of the family, and in so far 
to point out the physiology of the whole family. The cheese is perforated, and a portion of wine, brandy, or some other fermented or distilled liquor, introduced; and this seldom fails in bringing the mould much sooner than it would naturally appear; and yet 110 plant of the family nakes its appearance in the mass of either wine or spirits, notwithstanding that they are so prone to come upon the vessels in which these are contained.

This single fact, and it may be seen in the case of very many of the Byssinz, is quite sufficient to let us see their place, and understand their functions in nature, so as that we may separate them from the fungi, as the proper agents of Autumn in the work of vegetable decomposition, and associate them with the lichens to which they more properly belong. They appear upon substances which are in a state of decomposition, or decay, by evaporation or some other means; but still they come not as destroyers, but as conservators. That they actually tend to preserve the solid or the flnid upon which they appear, in the state in which it is at the time of their appearance, we do not mean to assert; but they do not drain its juices, or decompose it. They follow the habit of the lichens, properly so called, and extract their subsistence from the air by their general surface, in a way which, however, it is much more easy to imagine in thought than to explain in words. Their appearance and growth are favoured by damp; and while they languish or disappear in a dry atmosphere, they revive again on the application of moisture.

The facts of their appearance in wine cellars, and not in similarly situated places in which there is no 
fermented liquor to give out a portion of its substince by evaporation,-_of their appearing on decaying fruits, on the surface of paste, when it begins to ferment and decompose, and in the cracks and crevices of cheese, into which a fermented or a distilled liquor has been introduced,--throw some light upon their economy and their office, though many circumstances connected with them are yet of so obscure a nature that we must speak of them with great caution. It seems that they have their situs upon organized substances only, and that thongh they do not act directly in the disintegration and decomposition of those substances, yet that they, as it were, wait upon the progress of other decompositions, and avail themselves of the gases or vapours resulting from them as soon as they are set free. In their own substance they are more or less decomposable, some of them melting into a liquid with a mere touch, and others being of a fibrous, tough, and comparatively durable nature; but whatever may be their own texture, they all appear to have one common office to perform-namely, that of fixing the volatile parts of other organized bodies, so that they may go to the common mass of materials out of which the vegetables, and through them the animals, are supported.

The office which they perform is thus intermediate between the office of the lichens, properly so called, and that of the fungi. The lichens are the primaries in point of succession; they come in situations where there is no vegetable, and not even a vegetable mould; and they elaborate such a mould out of the inorganic aliments, by acting upon the atmosphere and the 
moisture that is contained in it; and in many situations they continue their labours until they bave produced a soil in which plants of higher development will grow, giving place to these as soon as they make their appearance. But if by any means-and the means are often far bcyond the range of our understanding-the plants of higher development give way, the lichens again make their appearance; and as long as they have the necessary supply of moisture, they contend with the powers of desolation. It is this, rather than the time of their growth, which leads us to consider them as a winter vegetation, they being anterior in the succession to what we may call the flowering plants, while the fungi always come after, or after organized substances of some kind, and in some way or other contribute directly to the decomposition of these.

The Byssince have neither the primary character of the lichens, in bringing a vegetation upon places where none previously existed, neither do they perform the decomposition of organic substances by their own growth, as is done by the fungi. We never find them making their first appearance upon the bare rock, or upon any other surface when it is absolutely dry. They always require a certain degree of moisture in the atmosphere, though none of them are decidedly aquatic in their habit.

In respect of the times and manner of their appearance, they agree more with the fungi than they do with the lichens; and many of them resemble the fungi in the frailty of thcir structure, and the Heeting period of their duration; though in all these respects they vary 
greatly, according to the different offices they have to perform. The specific nature of these oflices is but little understood; though it is chiefly through them that we can arrive at any knowledge of plants which are so exceedingly simple in their structure, and which differ so much in their modes of growth from the plants which are rnost open and most attractive to general observation. 'Their history is so confused, that those well skilled in the vegetable kingdom lave referred hem to different classes, and generally to the fungi, until very recent times that the functions of plants have begun to be investigated along with their external distinctions, their nomenclature, and their real or supposed medicinal or other artificial uses, to which the labours of the earlier botanists were in a great measure confined. This step is a most important one in the progress of vegetable science; but it is one the taking of which is attended with many difficulties, and much liability to error; because the very knowledge of which we are in quest must, in many cases, be the chief means of its own discovery.

That which has been just now stated may seem a paradox to those who are conversant with learning at second hand only, and who have no idea of any lesson being acquired or acquirable, or even in existence, unless it has been prepared and modelled by some human teacher, after the same routine fashion as the common technical lessons of the schools. But if such parties will but pause, and think for a little how mankind took, or still take, the first start from igrorance, and also how any addition, great or small, is made to ฉ 3 
the general stock of knowledge, they will be constrained to admit that the subject of that knowledge is the only instrument which the mind could or can use in the acquirement of it. It is for this reason that observation, especially of the productions and phenomena of nature, is so exceedingly valuable, and that the progress of mankind in every useful art, and every means of rational and social enjoyment, has been so rapid since observation became so general. The grand superiority of this prosecution of study, this devotion of the powers of the mind to that investigation of nature in which they have been so successful as to prove to a demonstration that for this purpose they were given by our bountiful Creator, consists in this,that the philosophic pursuer of any one line of investigation marches across the range of lis subject, shedding light upon, and for the benefit of all around him ; so that, in the proper investigation of any of the more general departments, some light is struck out, which is available to the student of every science, and the practiser of every useful or ornamental art. The individual by whom all this is done, may be quite regardless, and even unaware, of the great and general advantages which are resulting from his labours. Indeed, the more successful that he is in this way, he has the less chance of being aware of it. The stimulus of his own subject captivates his mind, and he has no desire but to ascend from discovery to discovery, and takes no note that every new footfall of his in the path of truth scatters the seeds of knowledge and improvement wide over the uations. 
This is the noblest and most exalted oceupation in which a human being can be engaged, and it has this delightful and peculiar distinction from every other human pursuit-that it works altogether for good, and for good to all, without the slightest mixture or possibility of evil. We have no room to go into the details of the evidence, but the record of history is open to every reader; and if the general condition and progress of the whole people, under the influence of sound philosophy, and genuine Christianity-and as systems these are inseparable - in modern "times, is contrasted with that in the brightest periods of ancient science, or under a system nominally Christian, but without reason and without philosophy, such as that which existed in the middle ages, he will find the truth which we have stated to be altogether irresistible.

In consequence of the great services which these general investigators of natural phenomena and their laws render to the whole of society, and also in consequence of the many difficulties and uncertainties with which their labours are beset, the errors into which they fall deserve to be treated more lightly than the errors of ordinary men; and, indeed, to be treated in a manner entirely different. It is in the misstatement or misrepresentation of facts that the mischievous errors lie,-in detached matters, as it were, which are open to men of all capacities, - while the reasonings, founded upon those facts, in which alone philosophical errors can be committed, are themselves open to the judgment of evcry one who cones to the consideration 
of them duly prepared. The single fact is a matter of time, not involving in itself any reasoning, but depending entirely upon testimony of some kind or other; and thus, if it is of such a nature that it cannot be repeated, if an error is made in it, that error is perpetuated beyond the power of correction. But a theory or hypothesis, of whatever kind it may be, is always open to revisal and correction. From the very nature of the case, too, no theory or hypothesis, however probable it may be, can be regarded as established, farther than the facts bear it out; and as we never know how many facts remain to be discovered upon any one branch of science, especially of natural science, we are never certain that future discovery may not overturn that which appears at the time to be based on the most probable foundation.

Thus we can never regard any one general theory in the philosophy of nature as any other than a convenient instrument in the farther study of the department of nature to which it applies, always liable to be modified according as new truths may arise. But this justification of rational theories, which are necessarily to undergo successive clianges, is no reason why overstrained and visionary hypotheses should be indulged in by persons whose knowledge is limited,-and yet they are more prone than others to indulge in such hypotheses.

It appeared necessary, or at least expedient, to make these few general remarks, preparatory to offering a guess-for after all it can hardly deserve a higher name-at the probable use of the Byssince in the 
general system of nature, and the distinction between this use and that of the fungi, regarding the latter as the appropriate armies of Autumn. The Byssina do not, as we have said, appear directly to attack the substance of any organized body, and to decompose it; but from the places where, and the circumstances under which they make their appearance, it should seem that they lay hold of the gaseous and evaporizable elements of substances the instant that these are disengaged by the operation of certain other decomposing causes. Thus they tend to prevent dissipations of matter which would otherwise take place, when that matter is in a state in which the scattering of it to the winds cannot be prevented by the action of any other bodies.

This is, at least in so far as observation has been hitherto made, the leading function of these plants; and though it is rather an obscure one, it is by no means unimportant. Much has to be learned, however, before we can speak of it with any thing like certainty; and this is the reason why we have thrown it out as a mere hint, and not even as an hypothesis. If it were possible carefully to collect all the states of substances upon which, and of the atmosphere when, these plants make their appearance, we should be at least in a fair way of arriving at some foundation upon which to ground a theory of their functions.

We know that fermentation in vegetable substances is one of the states of bodies which calls these plants into activity; that a humid atmosphere is much more favourable to them than a dry one; and that, though many of them are luminous in thenselves, the action 
of light, which is so necessary for most other tribes of vegetables, is rather unfavourable to their growth than otherwise. We also know that a temperature rather warm is agreeable to them, though they can ill bear any great extreme either of heat or of cold. When we have stated these few particulars we have nearly exhausted the whole of our general information concerning them, and thus it amounts to comparatively little.

It does not even enable us to assign them a decided seasonal period; but, according to the most rational conjecture that we can form, they are Antumnal rather than any thing else, though, as we have said, they do not directly form any part of the Autumnal decomposition. Taking them in their whole extent and variety, they cannot be said to be very much under the control of any season, because such as are found in subterranean places enjoy but little of the varying action depending on the heat of the sum or the length of the day. Speaking of the time of the year in as far as they can be thus spoken of, we would be inclined to say that the period of the Autumn, the alternate drought and wet, when the decomposition of organic substances is going on most rapidly, by fermentation, or other action of the substances themselves, is the chief time at which they display themselves abroad in wild nature; and that they lay hold of the products of these decompositions, and, by retaining them, prevent them from being dissipated, until a change of the weather ensues, and they render up the matter which they have preserved to the general store of materials; but the way in which they do this, and the particular changes which they 
effect upon any kind of matter, are points mpon which we have not any certain information; in fact, we are obliged to speak of the greater number of them by negatives-by saying what they are not rather than what they are. 'This, however, is a step in knowledge, though a very elementary one; because when we can take any subject apart and consider it in itself, we are much more directly in the road to the knowledge of it than when it is blended and confounded with other subjects.

The consideration of these lumble and apparently insignificant plants may, by some, be regarded as possessing little interest. This, however, is not only a mistake, but a very unphilosophical and a very injurious one. If we would understand the revolutions of the year, or any other portion of the successions in the system of nature aright, we must be especially carcful to examine well the dark places of it. It is in them that the difficulties always lie; and if we do not at least grapple with those difficulties-if we cannot overcome them-it is in vain that we dazzle ourselves with the more conspicuous and brilliant portions.

In studying the year this is especially necessary. Taking the average for a considerable period at any one place, one year is so like another in all its principal appearances, that the labours of doing and undoing must bear, upon the whole, though not in the individual instances, a pretty constant and equal ratio. The spring presents us with nearly the same buds, the summer with nearly the same flowers, and the Autumn with nearly the same fruits, year after year. It is the 
same in otlier departments of wild nature. The same birds come and go, migrate within the country, or remain stationary in the same place, one year with another; and a common observer can see but little difference in their numbers, except such as are easily explainable by the particular character of the year. It is the same with the different races of small life, the greater part of which we know to perish in the winter months in countries where that season is severe. There are no doubt gradual changes wlich take place in long periods of time, and by which the state of things is at least greatly altered; but these belong to the progressive listory of our globe in the centuries of its duration, and not to any thing which comes within the brief span of an individual human life.

Now, seeing that the productions of the earth, in all the ordinary departments of nature, and where they are not affected by human culture, are the same year after year, within moderate periods of time, it must follow that year after year they are composed of exactly similar substances. In seasonal countries, witl annual productions, and indeed with all productions according to their periods, the annual produce is immense, and the materials furnished in a state fit for the action of those powers by which the several productions are elaborated must be correspondingly great. Thus the bringing of the materials of organic nature back to the state of passive or elemental substance, is as wonderful in itself, and as strong an evidence of Almighty power, as the beauty and activity of the same matter while it is obedient to the principles of 
life. In some respects it is more instructive; because when we arrive at the mere matter, we approach those laws of action that guide us in many of our arts, more especially such as depend upon chemical principles; and we have far more control over these than we have over animals and vegetables, obedient as both of these are to the hand of skifful management. Thus, until the years of its duration shall be numbered, the annual decomposition of the leaf, the stem, and the other seasonal produce of the year, is only one of the modes of that beautiful revolution, which brings every thing in its season, and distributes the bounty of the Creator equally over all the vicissitudes of the most varying year. 


\section{CHAP'TER VI.}

NOTES ON SOME OF THE MORE INTERESTING FUNGI.

Having endeavoured to draw the organic and functional distinction between the fungi properly so called, and those plants which approach the nearest to them in some of their characters, and apparently in their uses, though in reality in their situations only, we shall endeavour to complete our outline of this very curious and important, but very difficult branch of the subject, by a few short notes on the fungi as a class of plants, and on some of those individual members of the class which, either for the good or the harm which they do, are more peculiarly interesting to the public generally. The smaller fungi, many of which attack other regetables in the early stages of their growth, are known popularly by the names of blights, blasts, and mildews; and those of larger growth are known as mushrooms, or more popularly as toadstools-paddockstools, that is frogstools, in the northern parts of Britain. In former times, when the belief in fairies, or pyxies, as they were called, was general in the country, the mushrooms, especially the short-lived ones, which spring up during the night, and melt away before the sun has gained its 
meridian altitude, were called "pyxiestools," and they are the "midnight mushrooms" alluded to in the quotation which we made from Shakspeare in a former chapter.

There is something very curious in the origins and uses which the fanciful people who are without true knowledge, and therefore prone to superstition, ascribe to different natural productions. In the Highlands of Scotland, for instance, all majestic things, such as basaltic dykes, columns, caverns, vast masses of rock, apparently detached from their original situations, and the remains of forts and other structures, the construction of which is anterior to the period of recorded history, are ascribed to An Fion, or the Giants-which, however, may also be translated "the winds,"- - so that the real assertion is that these things are of unknown and uncertain knowledge. Small matters again, and things of inapparent origin and brief existence, such as the toadstools which the first rains of Autumn call forth upon the green-sward, are ascribed to the Bhodachian, or fairies. This term is just as puzzling and uncertain in its meaning as the former one; and all that we can say of it is, that it expresses a minute power as contrasted with the majestic one by which the more magnificent and durable structures are fabled to have been reared. The word "Bhodachian" literally means " the little folks;" and it is somewhat remarkable that the remains of the ancient Caledonians still left in the Scottish Highlands, who now generally merit the appellation of little folks themselves, should apply it to the Romans and the Picts; and there is no 
doubt that the name Pyxies, given to the fabled fairies, is derived from that of the latter people. There is even a colour in history, for a superiority of personal dimensions on the part of the ancient Caledonii, sufficient to warrant them in contrasting themselves as Fion, with the Romans as Bhodachian. The historian of Agicola says of them that they were men of great stature, and correspondingly powerful in the onset of battle-Magna corpora et tantum ad impetum valida. 'This is a curious coincidence between the statement of the Roman historian, which we have no reason to question, and the application of the popular names still retained in the Highlands; and there is no doubt that if it were followed up with due research, it would lead to some curious results; but though some reader may probably think it worthy of investigation, it is not a matter which bears upon the main scope and subject of the present work. One curious part of the matter is, that after the fungi were removed from under the dominion of the "little folks," by what name soever they were called, they should have been transferred to that of the reptiles; and that the toad in the one end of the island, and the frog in the other, should now usurp the mushrooms as thrones.

For popular purposes, the fungi may be very conveniently divided into three groups, under the common names of Blights, Puff-balls, and Mushrooms. The members of each of these vary greatly from each other; but still there is a distinctive character to each of the groups, and all the members of the same group have something in common, both in their appearance, and 
in the circumstances in which they appear. The blights are chiefly found upon the leaves and other annual productions of plants; and though their office is unquestionably an Autumnal one, not a few of them make their appearance, and perform their labours before the Autumnal season, according to the calendar. The causes of this appearance are exceedingly obscure; but there seems little doubt that, in whatever stage of the growth of the plant they appear, they are always consequent to what may be regarded as an Autumnal state of the plant, that is, as a suspension of its energy, of which the fungus takes advantage in consequence of the general law of its nature, namely, that of sucl a stagnation or suspension of the action of life in the plant, as places it, in whole or in part, in the category of that matter which is disorganized and reduced to the simple or elementary state by the proper operation of the Autumn. These are, generally speaking, very minute plants, but remarkably prolific, affording some of the most extraordinary instances of the vast number of distinct individual lives which can be accumulated in an exceedingly small space. Some of the most able and credible investigators of this obscure department of nature have ascertained that a square inch of surface will contain more than two millions and a half of fullgrown plants of some of the species, and seven millions eight hundred and forty thousand of some others, while each plant, even in the case of the latter, contains a progeny of more than ten millions of spores; putting these together, and allowing for the two thousand eight liundred layers of the plants, which it would require to s 3 
fill up a cubic or solid inch, we have a number at which even the imagination itself is bewildered, and which, though nobody can exactly comprehend what it means, it may not be amiss to express both in numerical characters and in words, in order to show the reader what mighty power the Almighty can concentrate within a very trifling space. It will be recollected, that the space of which we are speaking is only a cubic inch, or about the extent of the first joint of the fore-finger of an ordinary person, in length, breadth, and thickness, and yet the number of distinct germs of vegetation in it, when stated in figures, is $219,520,000,000,000,000$; and named in words, it is two hundred and nineteen thousand five hundred and twenty trillions, a number not only greater than that of all the human beings, but of all the warm-blooded animals that have ever lived upon the earth, since the moment of its creation; and all this, as we have said, within the small space of a single cubic inch.

We cannot say that the spore of the fungus in this case is a simple elementary atom of matter; 'for, though we cannot speak positively about substances which are so exceedingly minute, the analogy of all those parts of nature which we can examine with any thing like accuracy, leads us to conclude that every germ charged with the preservation of a life, whether animal or vegetable, is a compound body, because the action of life, in every instance in which we can observe or understand it, is the result of a union of parts. Nor is it the result of a union of atoms merely, but of a union of masses, both of which are mrobably, and 
indeed necessarily, compounds, inasmuch as we camnot suppose the individual atom, beyond which there is no division of matter, to be possessed of any sensible property.

Thus the germs of these ninute fungi lead us far more deeply into the principles of things than their exceedingly small magnitude would lead us to believe. Even in them we are unable to reach the final boundary at which matter exists-simple, original, general, and without having the properties of any one nameable substance, living or dead, organic or unorganized; but in them we make one of the nearest approaches to this wonderful boundary which can be made; and a very little exercise of imagination carries us to the boundary itself, and brings before the mind, matter in so simple and elementary a state, that it is under the influence of no law save the law of universal gravitation, which is inseparable from the very idea of matter; and as the power of this law upon it is always in proportion to its quantity, its influence upon the atom has necessarily the same incomprehensible verging upon nothing as the atom itself. In consequence of this reduction of the power of gravitation over the primary atoms of matter to a mere infinitesimal, we can at once see that matter in this state is ready to yield a perfect obedience to any power under whose influence it may be brought, if the strength of that power is any thing more than what to us is infinitely small.

Viewing it in this light, we obtain some faint notion of one of the most extraordinary displays of Almighty wisdom and power which is presented in the entiro 
system of creation; and though it is purcly a mental view, and one in which sense can add nothing to the thought, it is not upon that account the less instructive or the less delightful. When our senses are taken captive by subjects which make strong and startling impressions upon them, we probably yield a more ready obedience to the conviction of a present God in all the works of nature; but when the subject is such that sense is entirely excluded, having no subject whereupon to work, the mental perception is loosened from the chariot wheels of time, and we are immortal in the feeling of our Maker.

When matter is traced upwards to this perfectly elemental state, it may, to use a homely phrase, be said to be fit for any thing, and may become a portion of the body of any one animal, vegetable, or mineral, without the slightest means or power of resistance upon its part. Thus the powers by which things are organized, crystallized, aggregated, or otherwise conjoined into masses to which we give names, as specific in their nature, have only an infinitesimal existence to orercome- in their first begimnings; and as we have demonstrations around us every day that weight and measure arc no elements of power, we must conclude that in those perfectly elemental cases, the power of life, or whatever power it may be which acts upon matter, is to our understanding infinite over the atom. 'This, if we can arrive at it, is the grand evidence of divinity in the system, - an evidence which no sophistry of the sceptic can overturn; and the man who can once mise his contemplation to this pitch, may, and must, 
turn round and pity the ignorance of those who deny the Creator so luminously set forth, and grope in the dark for an unreal and imaginary origin of the system of things.

And we find this view of the primary working of nature fully borne ont by the whole system. In the course of this rolume, or of the other volumes of our series on the Seasons, we have had occasion again and again to refer to the fact, that the more complicated in structure, and the larger in size any one production of nature is, the life, whether animal or vegetable, with which that portion is endowed, is always the less safe from contingency - the more liable to be diseased or destroyed. This fact may be observed by any one who chooses to exercise ever so little of the faculty of observation; and this is exactly the stage of our disquisitions upon natural subjects at which we can most easily see and understand the reason. In the case of the atom, the power of life, growth, or whatever else it may be, is to our understanding infinite; and this infinitude (to our comprehension,) is necessarily a maximum, or quantity which cannot be exceeded or even equalled under any other circumstances. Hence, as matter is increased upon the life or the other action to which that matter is subjected, the abstract power of the life over matter is diminished in the same ratio.

It is impossible for us to tell the number of primary atoms which are in any one portion of matter; and probably those in the very smallest-as, for instance, in the spores of the fungi under consideration, whicl spread through the atmosphere in viewless vapour- 
may be more numerous than we could anderstand, or even number by means of our arithmetic; but it is certain from the evidence, as well as clear from the analogy, that in proportion as the quantity of matter is increased in any one single living or growing being, the frailty or destructibility of that life is increased in the same ratio.

In consequence of this, the smallness of the spores of those fungi which we are considering renders them proof against most of the contingencies to which larger vegetable substances are subjected, and to some of which at least the fungi themselves are liable after they are developed. What degree of change in temperature, either upwards or downwards, they are able to endure, we cannot know; but it is not unlikely that they can withstand every degree both of heat and of cold, to which they are or can be exposed, in the ordinary circumstances of any climate upon the earth. Their durability in time, depending on the same property of their extreme minuteness, is necessarily as great as that of their resistance to contingencies; and though we cannot say positively for how many years, or how many centuries, the spore of one of these small fungi will retain its vegetative power, yet we cannot say that it is positively shorter than any period which we can name, other than the unnumbered one of the duration of the globe.

But it agrees with the analogy that these spores should be as independent in space and situation as they are against contingency and time; and the facts show us that such is really the case. There is not a single substance, animal or vegetable, upon which one or an- 
other of these small plants does not make its appearance, when that substance is brought into a state of autumulal decay, either in Autumn, according to the calendar, or in any other season of the year, and from what cause, soever that state may be brought about. With the exception of the greater number of the fungi whose offices are similar to their own, and of many of the alga, especially the lichens or terrestrial ones, whose office is diametrically opposite to that of the fungi, there is hardly one organic substance, animal or vegetable, upon which some of those small fungi does not make its appearance to facilitate that decomposition and decay which appear, however, to be begun by other and very different means. Therefore the fungi cannot be regarded as the instruments of death, but merely as the agents of decomposition, after death, or a deadly state, in the whole plant or in part of it, has been induced by other means. From the spores or germs being so exceedingly small, - - so perfectly viewless by eye or by instrument,-it should seem that they can circulate in every fluid of the living subject, whether animal or vegetable, and also ride upon the wings of every wind which animal or plant can inhale as the breath of life. This extreme subtlety of penetration, together with their minuteness, render these the most extraordinary works in the material creation; and it is especially worthy of our most profound consideration, that in proportion as the weight and incumbrance of mere matter is thrown off, the impress of the Godhead is even the more conspicuous. This subject strongly encomages our contemplation a little farther than the 
extremest boundary of matter, and beckons us onward to the purely intellectual state of existence in which the free spirit shall hold communion with its God, and enjoy the knowledge of his work and workings untrammeled alike by space and by time. This is a subject upon which the embodied mind can dwell long, and upon which we hope the free spirit will dwell for ever, after the mortal has put on immortality; but we must leave it, earnestly recommending it to the contemplation of the reader, and proceed to our more humble but still very instructive subject.

The simplest division of the fungi, or those which consist simply of detached sporidia, unconnected with any thallus, and thus being, according to the common mode of our speaking of vegetables, really nothing but flowers or fruit, according to their age, are those to which the name of Mucedinales is given, from their forming what we in general call moulds upon the surfaces of organized bodies. In their appearance, ana even in the substances on which they appear, and also in the fleetness of their duration as individual plants, and the number and indestructibility of these spores, they bear a considerable resemblance to some of the byssinz, and this is the reason why the two lave sometimes been confounded with each other. The line of distinction between then, obliterated as it often is to common observation, is always perfectly clear in a physiological point of view. The byssus, which belongs to the algre, makes merely a resting-place of the substance on which it grows, and though it most generally appears upon organic substances, and such substances when in a state of positive 
or incipient decay, it is not absolutely necessary that it should so appear, because its dependence upon the substance is not for nourishment, but simply for locality and support. These byssa are called moulds indiscriminately with the fungi, and the external resemblance is so great that they are sometimes apt to be confonnded with each other. But the byssus never directly causes putrefaction or decomposition of the substance on which it grows, and it never has any deleterious property itself, neither does it indicate any stich property on the substance on which it appears. Its tendency indeed is rather in the opposite direction, and mould without corruption is generally understood to add to the sanative quality of that on which it appears.

With the fungus-moulds it is very different. They always corrupt that on which they appear, and they are generally, if not invariably, attended witl poisonous qualities either in themselves or in the substance upon which they act. There is another distinction; all the fungi approximate to animal matter in their composition, whereas the algæ, even those which most resemble the smaller mouldy fungi, are purely vegetable, and composed of carbon, oxygen, and hydrogen, without any admixture of nitrogen, which latter substance is contained as abundantly in some of the fungi as it is in substances which are decidedly animal in their nature. Hence, when the byssi are in a state of decomposition they never give out any very offensive odour, and never produce any injurious effect upon the animal systenı; while with the fungi, even those which have the greatest resemblance to these harmless vegetables, the 
case is very different. For instance, mouldy cheese produced by the byssus, is not only harmless but stomachic, and it is free from any offensive smell; whereas if the same cheese become so far putrid as to produce a fungus, how much soever that fungus may resemble the byssus, it has a poisonous quality, either in the fungus itself, or in the putrefying substance upon which the fungus grows. This is the broad distinction between the fungi and those other plants which they most nearly resemble in appearance,- the fungus is always in some way or other a minister of death, and communicates deadly qualities, either in itsclf or in that upon which it grows and tends to putrefy; while the byssus has no tendency of this kind one way or another. It would far exceed our limits to go into the details of all the members of this very numerous family; but there are some of them so interesting, from the mischief which they do in rural economy, however useful they may be in wild nature, that we cannot pass them over without notice. They are known by various names, such as those of brands-or burnings, blasts, blights, mildews, and moulds; and onc or other of them has engaged the attention of mankind ever since they began to cultivate the ground. In the carlier ages of human history, and indeed after civilization liad in many respccts made considerable advances, men found it impossible to account for the origin of these small but formidable destroyers, upon any principle of the philosophy with which they werc then acquainted, and therefore they referred them, as they did all other matters which were beyond their compreheusion, to supernatural agency, 
and sought to avert their evils, not by scientific means, but by supplications and sacrifices to some imaginary divinity, which they fancied to be the ruler of these vegetable pests.

Those ancient nations which had made some progress in human learning and in the practice of common observation, were in the habit of referring every particular department of nature to the charge of a particular god. Tous, this appears not only false but absurd; and yet it was the natural and necessary condition of a people whose minds were awakened to reflection, and who were without the knowledge of the true Grod. We need take no credit to ourselves for being differently situated from those nations; for had we been, like them, without the light of Divine revelation, a light which can come only from Heaven by the grace of God, we should certainly not have been in a better state than they were, and most probably in a worse one. These ancient nations regarded the different blights, brands, and mildews, as malign influences, shot down from the sky by malevolent powers; and the Romans, who considered the blighting as an act, without knowing any thing of the blight as a substance, gave that act the name of Robigo,regarded it as under the care of a divinity, Rubigus, to render whom propitious they kept rubigalia or feasts for propitiating the god, about the time when the small fungi in question make their appearance-or rather begin their attacks, for some of the most mischievous of them do not appear externally-upon the growing crops. These feasts generally took place in the month of May; but we have no accomt of any correspondence 
between the strictness with which they were celebrated, and the absence of blight and mildew upon corn.

As was the case with very many of the ancient superstitions, the notion that the blighting came from the atmosphere was continued; and by many it was regarded as an emanation shot down from the stars; and thus in the darkness of the middle ages, the astrologers continued to fill the place of the priests of Rubigus. The common names by which these very minute, but often very mischievous plants to the farmer, are still called, show that the popular belief has every where referred them to celestial influence, of some kind or other, and there is generally some allusion to burning or scorching.

And though those blights are certainly not occasioned by any influence of the stars, any more than they were ever prevented by Rubigus, yet it does appear that the atmosphere is at least one of the disposing causes to their appearance, and probably the chief one, in whatever form or on whatever plant they may appear. We cannot say that it is the temperature, the moisture, or any one single quality of the atmosphere, which affects the condition of the plant by that sort of premature action of Autumn which favours the excitement of the extremely small spores of these fungi, nor can we say that it is a quality of the whole atmosphere; as in passing over a field, for instance, different species attack different plants, and they attack different individuals of the same species, and different portions of the same individual. All these circumstances, together with their cxtreme smallness, and on inability to examine them 
in their early stages, make this one of the darkest subjects in the whole science of cultivation.

Very few plants are wholly exempt from the attacks of these diminutive foes; but the different ones are restricted to their own genera, or, at all events, families of plants, by laws which appear to be very perfect in their operation, but which are of difficult investigation, and consequently ill-understood. This is a difficulty inseparable from the study of all those productions of nature which are so very small that they cannot be examined but by means of microscopic glasses of great magnifying power. Those high powers cannot be so constructed as that they shall not give botlı refractive colours and refractive distortions in shape, to the objects which are seen through them; and it is quite impossible to separate these fictitious colours and shapes occasioned by the instrument, from those which belong in reality to the subjects examined by means of it. Thus it is necessary to use extreme caution in speaking of the details of subjects of this kind; and even with all the caution that we can use, they are hardly subjects for popular disquisition.

We have said that they are restricted by very perfect laws to the plants on which they make their appearance; and we may add, that the laws which restrict to states of plants appear to be equally perfect. It belongs to them, indeed, in their general character of decomposers of matter which has ceased to be useful, not to come into action until circumstances render that action necessary for the well-being of the whole system. They do not come as active and general destroyers, like the T 3 
locusts and sundry others of the insect tribes, which indiscriminately consume every green thing in their march of desolation. They are not borne along on wings, or on the currents of the air as these are; for we have every reason to believe that their spores are equally abundant in all the juices of every plant, whether circumstances call them into activity or not; and thus, however injurious they may be in the operations of art, their office, as a portion of nature, is a beneficial one. There is, we believe, no instance of even the most abundant and destructive of them attacking all the plants of a field of corn, but only particular ears, and sometimes particular grains in an ear, all the rest of which are sound and good.

The reason of their appearance is most obscure; and therefore the means of preventing which have been resorted to, are most uncertain in their effect, and in great part imaginary. Seed that is infected is generally believed to produce a growth more prone to infection than seed which is not; but even this is somewhat doubtful. A good condition of the ground, and a climate in season ascertained to be favourable to the species of grain cultivated, are unquestionably the most certain preventives of the mischiefs of these fungi; and of artificial applications in the preparation of the soil, a moderate quantity of lime appears to be the best that has yet been used, though it is said that in places where seaweed is attainable, a dressing of it is still more effective.

We shall pass over the Ecidiums, or dust-blights, which appear upon the leaves of very mumerous plants, and have often a very beauliful appearance; and also 
the Puccinice, or tuft-blights, and confine our notice to those which are seriously injurious to cultivated vegetables : remarking only, that the dust-blights actually grow within the lcaf or other part of the plant, and raise for themselves a thin pellicle of the epidermis, which they rupture when their spores are matured, and thus the damp is admitted, and the leaf decays. The tuft-blights again appear in little tufted dots external of the plant; but they also rupture the epidermis and lct in the water.

'The most destructive, or, indeed, the only seriously destructive ones to ordinary cultivation, belong to the genus Uredo, which is the Latin name for the blasting or burning by means of these fingi. This name is of course derived from the Latin verb Uro, "I burn;" and it was no doubt applied for the imaginary reason which has been mentioned. Two species of this genus have been long known to farmers,-Uredo segetum, usually called the "smut," or dust brand; and Uredo caries, which is sometimes called the "canker brand," or bladder brand; though these and a number of other names have been indiscriminately given to both of the species in different parts of the country. The smut is much more general than the other, and it is met with on all the corn-plants indiscriminately; whereas the other, hitherto at least, has been discovered chiefly upon wheat. In some places Uredo segetum is called the rust; and the name smut is given to thc other. Their distinctive characters, in the manner in which they appear, as well as in the mischicf which they do, are, however, not to be mistakell.

The snut (Uredo segetum) is the species to which we 
formerly alluded as containing such a vast and countless number of spores or germs in the space of one cubic inch. In the early stages of their growth these plants do not make their appearance externally, and the stems of corn upon which they have established themselves, instead of being sickly appear to be more vigorous than the rest, as if they were stimulated by some preternatural cause of fertility. And there seems to be not a doubt that, up to a certain stage of their growth, their irritation occasions an extraordinary degree of living action in the plant on which they grow, by which that plant increases the quantity of matter upon which they subsist. This is by no meaus unusual in the case of parasites upon plants; for many of the gall insects, and others, cause, by their irritation, an extraordinary growth in that part of the plant wherein they take up their abode. We have previously mentioned the galls and bedeguars, as remarkable instances of this; the former sometimes acquiring the size of small apples, and a cousistency little inferior to that of solid wood; while the latter display the appearance of a tuft, consisting of quite another regetable, than the wild rose or other plant, by the action of which it is formed. This smut attacks indiscriminately all parts of the plant, in which respect it bears some resemblance to the rust or blight, which is a puccinia, and often appears upon the grain plants as well as the smut, and is very destructive to the culms or stalks, and to the leaves, though it does much less injury to the young grain than the smut. Though the smutted plants seem more than ordinarily vigorous for a time, they turn 
pale and sickly as soon as the fungus makes its appearance, which it first does like a brownish or reddish powder, adhering to the surface; but it darkens as it ripens, and the black colour which it imparts is the principal reason why the name smut, which means soiler or blackener, is given to it. It often occupies the entire volume of the grains, and is also interspersed through all the tubular part of the culm and the vessels of the leaves; but it ripens and sheds its spores before the unaffected portion of the corn is ripe ; and in consequence the smutting ears are shrivelled, and the plants altogether stunted in their growtl. There is no esculent substance in the grains which are thus affected, and smutted and also blighted straw is substanceless and insipid, and useless as food for cattle. Fungi much resembling this in appearance, in size, and in office, infest peas, beans, liops, and, indeed, almost every cultivated plant that can be named; and whenever they appear in numbers they do a vast deal of mischief. None of them possess any offensive odour, and we are not aware that they have any of those poisonous qualities which so many of the fungi possess in their own substance, or appear to communicate to that upon which they grow; but they greatly reduce the quantity of valuable matter in the plants, and still more the quality of that which remains.

We have said that the causes of their appearance are both complicated and obscure; and though the abundance of the spores in the soil or upon the husks of the grain used for seed, may be one means of affording that appearance, there seems to be something necessary in 
addition to this, either in the character of the season, or the improper adaptation of the plant and the soil to each other. Damp situations, and crops which come up very thick, appear to be favourable to the growth of the fungus; a rainy Autumn also tends to the production of smut upon wheat sown in that season; and alternate sunshine and showers in the early summer, just before the plants come to form their flowers, are said to have the same effect. Various plants that are peculiarly subject to the ravages of these parasitical fungi, the common barberry among others, have been accused of communicating them to grain; but there does not appear to be any ground for the accusation, as the fungi are not of the same species, and as it appears that the spores of the fungi are taken in by the sponglets of the roots, and not absorbed by the surfaces of the stems or leaves. We cali readily understand how the rains may wash their exceedingly minute spores into the soil, so as to bring them into contact with the absorbing parts of the roots; and also how the varying sunshine and showers may alternately excite and check the growth of the plant, until that unhealthy state which is favourable to the growth of the fungus is brought on; but altogether, the subject is one of very great obscurity. The appearance of those fungi greatly reduces the quantity of nutritious matter in the same weight of the substance of the grain, in slight cases not less than about a third, and in more serious ones more than two-thirds; but of course the average cannot be taken. When smut decidedly attacks the ears, the substance of the grain is actively destroyed, and its 
place occupied by the remains of the fungi, the dispersed spores of which adhere so closely to the grains which are sound, that they cannot be detached by any known process.

In wet, cold seasons, especially upon thin and poor soils, and the poor and retentive clays in exposed situations, more than upon any others, the corn is very subject to smut; and the flour which it yields does not sponge, but remains tough like dough; or if a firmer consistence is attempted to be obtained by farther baking, a portion of the exterior becomes as hard as timber, while there is a lump of shrunken dough in the centre. The colour also is dark, the taste insipid or unwholesome, and there is but little nourishment as compared with bread made of sound wheat.

The fungus which produces this sort of disease in bread-corn, has in itself no offensive smell, and the taste which it imparts to the bread is negative rather than any thing directly offensive; and though there is no doubt that it renders the bread less wholesome, as well as less sightity and nourishing, yet it does not appear to occasion any very decidedly poisonous quality. Thu, it must not be confounded with mildew, which is a fungus of different form and character, produced under different circumstances; and though not poisonous in its own substance, yet producing a poisonous quality, always attended with injurious and but too often with fatal effects. We shall have occasion briefly to notice this mildew in a future paragraph.

The canker-brand, Uredo fetida, is a much larger plant, although still a very small one; and it attacks the corn 
in a different manner. It never appears on the stem or the leaves, but always within the glumes or husks, and even in some cases the proper tunics of the grains. The external appearance of these changes but little, so that a field may be very much infested by this fungus, without the fact being suspected by any but a very experienced observer. 'The diseased ears very often appear larger and better than the sound ones; because the fungrs does not shrink in ripening, which the grain always does to a certain degree. When however the diseased grains are opened, they are found not to contain a single particle of the farina of wheat, but to have its place occupied by the fungus, which is of a sooty black colour, greasy to the feel on account of the smallness and adhesive nature of the spores, and having a most offensive smell like that of fish in a high state of putrefaction. Being protected within the grain, this plant does not shed its spores, at least not so readily as the smut does. In threshing and preparing the grain, the fungous ears are broken; and the countless number of little spores which they contain, are dispersed all over the sound grains, and they are so small and attach themselves so firmly, that they cannot be cleared away by any process which has been hitherto discovered. If very numerous they darken the colour considerably, so that experienced judges can know grain which is much affected, though a lower degree, which hardly any one can distinguish, may produce very serious mischief.

It is to be understood that those grains which do contain farina, and thus are fit either for grinding into flour or using as seed, are sound in themselves, unless 
in so far as the appearance of the fungus may indicate a feeble and imperfect action of the whole field, as arising from unfitness of the soil for the kind of grain, an unfavomrable season, or both of these causes united. But in every case, the fungus utterly usurps the place of the kernel of every grain which it attacks, and thus the remaining ones are internally free from it. 'J'his is, however, no advantage, because the spores which adhere externally mix with the flour in the operation of grinding, and the product is an article of very inferior quality. There is nothing deleterious in the flour itself; and notwithstanding the very offensive smell of the fungus, it has not been proved, and is not indeed very probable, that it has any poisonous quality, especially in the spores, which are the only parts which mingle with the flour. It does not appear that any positive disease ever resulted from the use of bread tainted by this fungus; and there is evidence, as far as analogy can give eridence, of the perfect harmlessness of these spores, in the fact, that the spores of Ergot, (afterwards to be noticed,) have been ascertained to be wholly imnocuous, while the tunic in which they are contained is a poison capable of producing the most direful effects.

From the fact which has been established by carefully repeated experiments in the case of the ergot, we have every reason to believe that how poisonous soever some of the fungi may be in other paris of their substance, the spores of the whole of them are perfectly innocuous. That it should be so the reflective reader will not fail to perceive from the general analogy, nor will he fail also to perceive in this one of those instances of wise and 
benevolent design, which force themselves on our contemplation at every step of our progress in the study of creation and its laws. In order that they may be always ready to perform those offices for which they are appointed, the spores of the fungi, in one or other of the species, exist in the fluids of every animal and of every plant; and not only this, but, light as air, or at all events having individually so very small gravitating influence, that the very slightest attraction between them and the atmosphere, is sufficient to enable them to ride on the currents of that fluid, upwards, downwards, or laterally, with the same obedience to its motions and their causes, as the particles of water when they are in a state of invisible vapour. It is well known that the more elevated and therefore rarer portions of the atmosphere receive the vapours of water more freely than denser air at the same temperature; and there is every reason to believe that it is the same with the infinitesimal spores of the smaller fungi. 'Thus they are inhaled with every breath of every creature that breathes, and absorbed by every absorbing pore, however minute; nor is it until we come to the mysterious membrane, so frequently allnded to in the course of these volumes, which, by absorbing at the one surface and secreting at the other, divides matter down to the primary atom, that their entrance is forbidden.

These extreme faculties of nobility are necessary, in order that the germs of the fungi may be at their posts whenever the slightest casualty requires that they should be developed and perform their functions; and it will be at once seen that this universal admission into the 
substance of animals and plants renders it especially necessary that these germs should be so perfectly simple and innocuous, as that their presence may not do the slightest injury to the finest organ of the most delicate life. Their province is not to cut down the strength or impede the healthy growth or aetion of any one produetion of nature; for that would display an imperfection in the system altogether ineonsistent with and unworthy of its divine origin. It is only when in eonsequence of some local or temporary cause that some organic being, or part of an organic being, is in excess above what the healthy condition of its speeies can bear, in the proper balance of the system, and where, otherwise, unwholesome putrefaction would ensue in it, and produce either a poisoning or a waste, that the spore of the fungus awakens to its duty. Perhaps there is no part of the whole system of nature more truly wonderful, or more elearly demonstrative of Almighty wisdom and power and goodness, far above our finite comprehension, than the distribution and nature of those spores,-that the vis medicatrix natura-the healing power of nature-should ride upon every wind, enter at every pore, and circulate in every fluid, without disturbing the most tender function of life, until the wholesome state of the system demands its aetion, is a sulject of contemplation both long and delightful. Nor is it the less so, that the material substances, the offices of which we have here to eontemplate, are so immeasurably small. It was well said by the illustrious Hook, to whom experimental inquiry into nature is so decply indebted, that he "admired Nature's watches far more 
than her clocks;" and if we descend, or rather, if you will, ascend another step in the analysis, we shall be constrained to admire the spring and the balance far more than the watch,-and this, because it is one step nearer the Almighty primum mobile - the Eternal finger, which touches the elements of the system with the mystery of life.

There is one other general point, for the introduction of which the present is perhaps the most convenient opportunity that we shall have in the present volume; and thongh it is one which we believe has hitherto been seldom if ever mentioned, it is probably not the less interesting on that account. It is this: It is well known, and has been too fatally established by the experience of those who have wounded themselves ever so slightly, while engaged in scientific examinations of the human body in a state of decomposition, that the matter of probably every body, animal or vegetable, when in a state of putrid decomposition, is one of the most fatal poisons that can be applied to the same species in the living state. This has been proved to be true, not only in the application of the putrefying substance of a body wholly dead, to one of the same or of an allied species which is living and healthy; but it is equally true, of a corrupt, or rather corrupting, and a wholesome part of the very same individual. There are so many instances of disease and death brought on by local gangrene in man and other animals, and so many fruit trees and other plants are killed by canker-spots of local situation and comparatively small size, that we can have no doubt of the poisonous effect of decomposing matter upon the 
living subjeet of the same or of analogous speeies. It does not apply to the whole range of any one of the great classes either of animals or of vegetables-for several of them find their food in the putrefying remains of the others; and nuel less does it apply to the inseets and the fungi, whieh are espeeial deeomposers of putrid matter both animal and vegetable. But still in those whieh very muelı resemble eaeh other in their organization, there is an indieation of the general truth, even in the eases of those whieh subsist upon the pntrid remains of the others. Thus, among the warm-blooded vertebrated animals - the liyanas, and others which feed more exelusively on earrion; and also among the birds-the vultures and others whiel perform sinilar offiees-liave a emious antiseptie power in the stomach, by means of which the earrion which they gorge is bronghit baek from putridity, and restored to not an unpleasant smell, in the proeess of being eonverted into eliyme, before it leaves the stomaeh, and enters the intestinal eanal to midergo that final proeess of digestion whieh fits it for being taken up by the alimentary absorbents of the system. The ease is the same with those reptiles whieh take tlocir food in a putrid state, or retain it in the gullet until it beeomes putrid; and as this faet is general in all the eases in which we ean properly examine it, we have very strong analogieal reasons for supposing that it is universal. But there remains an important faet to be notieed: In that stage of the digestive proeess during whieh the food is brought baek from putridity, the functions of life in the animal sink very low, and in most instances it is dull in sensation and ineapable of 
motion. 'Thus, though these animals are fitted for the consuming of putrefying remains which would otherwise be injurious, they obviously hold this power at a temporary sacrifice, and thus give evidence that before the putrefying substance of any one organized body can be safely applied to the substance of another, even as food, there must be a very considerable difference between the natures of the animals; and even in their cases if the putrid matter is taken into the system by a wound, its effects are always injurious and sometimes fatal.

This brings us to the main point which establishes the grand use of the fumgi, in all cases where matter in this putrefying and poisonous state camnot be decomposed by the agency of animal destroyers, or by the mechanical and chemical operations of the elements. The putrefying substance of any one species, whether plant or animal, is a poison to that species if applied to the system; and in the case of such aninals and plants as do not come within the list of the scavengers of nature, whose special office is to destroy putridity, the food, whatever it may be, is a poison if taken in the putrid state; and it is to prevent the deleterious effects of this poison, that the insects and the fungi, according as the general physical circumstances are more favourable to the action of the one or the other, invariably hasten to convert this poisonous matter into a simple and wholesome pabulum.

'This not only shows us very clearly what an important office those little animals and plants perform in the grand system of nature's working, but it explains in a satisfac- 
tory manner the ground of the mistake into which those have fallen who suppose that plants, in the course of their natural operations, give out to the soil a certain matter which is a poison to succeeding plants of the same species. It is not any thing given out by the living and healthy which has this effect, it is the decomposition, or rather the putrefying decay, of that which has performed its functions, and requires to be converted into elementary matter before it is again available for the vegetation of the same species.

This explains in a very satisfactory manner why the general vegetation of tracts of country changes after the lapse of years, and changes more readily in places where there is a great annual "fall of the leaf," than in those where there is not,-in the deciduous forests of the temperate climates, for instance, more than in the evergreens of the equator or the pines and other coniferæ of the polar latitudes and the cold uplands. 'I'o take a familiar instance: What may be called the aboriginal forests of England, of the lowlands of Scotland, of the Welch hills, and of the whole of Ireland, are gone. It may be said that, in all of these countries, and more especially in the last-mentioned one, the woods have been destroyed, both by the torch and the axe. But even the wanton burning or cutting down of a forest is not in itself an extirpation, but the very reverse, as long as the soil continues favourable for the growth of the same species that have been removed. Many years of cultivation, after complete burning and rooting out, do not secure an upland field in the bleak moors of Scotland from being again overrum by heath, 
if it lies only a few years in pasture; and in India, no length of time under cultivation seems capable of defending the surface against the invasion of the bamboo jungle, if the soil is favourable for the growth of that extraordinary plant. Even in an oak coppice, which is periodically cut down for the sake of the bark and the charcoal; or in an osier bed, there is a longer duration of the stools, and a much greater and more vigorous ammual growth, than if the oaks or willows were allowed to remain undisturbed. 'This no doubt, in part, arises from the suckers having much of the condition of young plants; but it also arises, in part, from the absence of decaying matter in the fall of the year. A wide ficld would here open itself for considering the most profitable cultivation upon woodlands, and upon lands under every species of erop; but it is a field upon which our limits do not pernit us to enter, and so we mist confine our remarks to the humble but still very instructive subject of the fungi. 


\section{CHAPTER VII.}

PIRINIPAL FUNGI BY WHICH GRAIN PLANTS ARE 1NFESTED.

In the case of the fungi, as parasitical upon and destructive of the cereal grasses, or grain plants, there is a distinction to be made, according as the fungus consumes any part of the structure of the plant in the course of its formation, or as it destroys a full-grown and matured portion, or at least a portion near maturity, when in a state of incipient putrefaction. In the former case the fungus belongs properly to summer in its time, though it is Autumnal in its action; but in the latter case it is Autumnal in its time also. The smuts, cankers, and rusts belong to the first of these divisions; though the rusts, as coming upon the matured or nearly matured stems and leaves, are much more Autumnal than those species which attack the grains in their formation.

Agreeably to this part of their character, the influence of external causes in the producing of rust, is much more obvious than in the smut and brand. If showery weather sets in about the time that the bloom 
is on the wheat, or soon after this, rust is very apt to be the consequence, even though there is not the slightest fault either in the seed or the cultivation. Indeed, the better the condition of the soil, and the warmer the weather has been previously, rust is the more likely to appear; and so is it also if the showers alternate witl warm sunshine. The reason is easily seen : it is the cold resulting from the great evaporation, which chills and checks the vegetable action of the culms and leaves; and the injury done by this is always the greater the more that this cold alternates with a warm temperature. If this occurs in the early stage which we have mentioned, the injury to the crop is often very great, because the nourishment of the ear is then in the progress of elaboration by the action of the whole plant, from the root upwards. But as the grain approaches maturity, the danger from this cause lessens; for the lower part of the culm, which always has to bear the severest part of the struggle against the alternating cold and heat in these cases, is the first portion that ripens, or passes into the Autumnal repose of healthy straw; and thus, as the grain advances to maturity, the ear is thrown more and more upon the resources of its own absorption, and the action of the culm and the leares gradually ceases. Thus the final ripening of the grain is an operation performed wholly in the atmosphere, without any connexion with the ground; and, indeed, any action that the ground can have upon it after this, except in the radiation of heat or moisture, would be an injurious action, namely, either germination, or such a state of incipient decay 
as would bring a fungus upon it-one of those usually called moulds or mildews, of which we shiall liave to take some notice by-and-by, as plants wlich always communicate suspicions, and often deleterious qualities to any alimentary substance, animal or vegetable, upon which they make their appearance.

This progress of the ripening, or cessation of vegetable action in the culm and leaves, may be regarded as the proper Autumnal stage of the grain; because, as soon as the action of the culm has totally ceased, botlı the corn and the straw are preservable by simple drying; whereas, if vegetable action in them is stopped earlier than this, they are apt to ferment and rot. Nor can we help admiring that beautiful tempering of the plant to the weather, which makes it always the more secure against injury, the nearer that it is to perfection. Thus it is always an advantage, in as far as the quality of the grain is concerned, that the midsummer rains should set in late in the season, only, if they are too late, there is some danger of their also being too copious. Even in this, however, there is a very beautiful compensation; for the long dry summer makes the culms short and firm, so that they are able to bear the ears erect and secure, in spite of the floods of St. Swithin.

There is one remark more, which may not be irrelevant to this very important subject of the Antumnal state,- the Autumnal hazards, and the Autumnal protections of the grain-crops, as depending upon the activity of nature, and withont reference to those arts by which man endeavours to work and to second the 
operations of nature in his behalf. It is somewhat curious, but it has not hitherto been much, or even at all investigated, though it appears to be one, the investigation of which would be fertile in knowledge of the most useful description. It is this: the progress of ripening, even in the annual plant, is always upwards, while the progress of decay is downwards, unless some fungus, or other agent, comes in to bear a part in the bringing about of that decay. In proportion, too, as the part of the plant near the ground proceeds in a healthy ripening, the upper part of the plant is more secure against the ordinary contingencies of the elements. After the lower parts of the culms of corn are once fairly ripened, their stiffness prevents it from being injured by rains, which would suffice to lay it flat while the culm is in the growing state; and this diminished flexibility renders the grain less liable to be shaken by the winds than it otherwise would be.

There are, however, so many, so complicated, and so varied subjects, each demanding the exercise of a train of thought, and all of them highly interesting and profitable for instruction, which present themselves when we contemplate a field of wheat waving in the golden beanty of its Autumnal state, that we have space only to persuade every reader who has the opportunity, to go into the fields, and see with his own eyes, and know of his orn knowledge, the wonderful displays of Almighty wisdom and goodness, in the annual supply of bread to the children of men.

The inliabitants of Britain lie under especial obligations to know these things, in order that they may feel 
becoming gratitude for the pleasant places in which the lines of their heritage are cast. There is not another people on the face of the earth, whose staple breadcorn, even in the middle ranks of their society, is wheat; perhaps there is no country, in which, in all probability from the abundant supply of animal manure, the wheat is of such nutritive quality; and there appears to be none in which both that and all the other cultivated plants are more exempted from the ravages of destroyers, whether insects or fungi. There is no doubt that we owe much of this to the insular situation of our country, and to its diversified surface, by means of which the little winds are made to sport blithely over its surface during the whole season of growth and ripening; but we also owe much of it to our improved mode of cultivation, which is the result of knowledge, and the foundation of that knowledge unquestionably is the early and general distribution of the Book of Revelation.

We know not, with any thing like precision, the exact state of the productions of nature in the more early ages of our country, especially with regard to the fungi which attack and injure our grain-crops; but from what we know, by modern experience, of the injurious effects of some of those fungi, it is highly probable that some of those periodical diseases called Epidemic, which used to carry off such numbers, and of which few traces now remain, were owing to the bread being tainted by the admixture of some of those fungous plants. We may mention in passing, that the word "epidemic," as applied to disease, means something which falls, that is, occurs or happens "upon the people," from some 
external cause, in opposition to "endemic," which means a disease of infection, or one which is " of the people" themselves, and not from any external cause.

One of the most dangerous of the fungi infesting grain, as at present known, is that which is called by the French the Ergot or Cockspur. This is not absolutely confined to rye, the plant upon which it is most abundant; but the other plants upon which it occurs are the pasture grasses, rather than the grain plants, upon which, with the exception of rye, it is almost unknown. There are but few parts of the British islands in which rye is cultivated for any purpose, and none of any extent where it is cultivated as the chief bread-corn of the people. Where it is cultivated, too, it is always upon lands which are the very best adapted for it, namely, those which are too light and too dry for bringing any more valuable crop to maturity, and thus the rye which is grown in this country is but little affected by ergot.

On the continent, the case is very different; rye is a staple grain in most countries, chiefly because there are not domestic animals enough for allowing such a breadth either of wheat or of green crop as there is in Britain. Accordingly rye is cultivated upon various soils, and among the rest upon many that are cold and retentive, as well as upon the thin dry sands; and it is chiefly upon these retentive soils, or when rains are more than usually abundant and cannot get into the ground, that rye becomes spurred, sometimes to such an extent as that the effects of it upon the people are really dreadful. 
Acinula clavus, or Secale cornutum, is the name of this fungus. It conmences within the grains of the rye, and renders such as it attacks completely abortive, in the same manner as the canker brand; only it does not remain concealed within the liusk as that does, but projects, and protrudes in a lengthened, bent, and pointed substance, bearing some slight resemblance to the spur of a cock in miniature, (the Frencli name for which is ergot,) and thus our word spur is exactly synonymous with theirs. This is the fungus in its mature state; and although it is distinctly visible, it is not very large. Only one appears upon a single grain, and all the grains in the ear are seldom affected. The fungus is nourished entirely by the substance of the individual grain, and thus it ripens about the same time that the uninfected grains riperl, and of course comes to its full size at the same time that they do; and between this attaining of the full size and the perfect ripening is a very important stage in the growth of the spur, inasmuch as it depends in a great measure upon the state of the weather during this period, whether the spur shall become a fearful poison, or a substance unsightly and umpleasant merely, without being to any extent deleterious. It consists of a solid nucleus, containing the spores, and a peridium or covering, which is at first of a soft and clammy nature, and soluble in water. Thus if rains come before this external part hardens, it is washed away, and as it is the part containing the poison, the interior, or berry as it is sometimes called, thougl far from a desirable admixture in food, certainly is not a deadly one. On the other hand, if the weather during 
the period alluded to is fair and dry, the peridium hardens upon the berry, and its poisonous quality is great in proportion to the drought and warmth of this particular period.

Too much humidity, about the time that the grains are beginning to form, is the principal cause which stimulates the spur into action, just as it is in the case of smut or canker in wheat; and it is more apt to make its appearance when the crop is apparently in vigorous growth than when the action of the plants is more feeble. It is a general law, that plants are most liable to be injured by vicissitudes of the weather when they are in vigorous growth; and plants under artificial culture form no exception to this law. One can easily see why, even supposing equal growth and therefore equal susceptibility to the weather, the influence of untimely rains should be more injurious upon soils of some strength than upon light and sandy ones; the rain speedily sinks into the latter, while it remains on the surface of the former and produces cold by being evaporated. Up to a certain degree, this cold is favourable to the healthy growtlr of the cultivated crop, because it prevents the plants from being parched at the roots; the effect of which parching often is the strangulation of the ears in the husks. This takes place the more readily, the more congenial a rich soil is to the plant; and upon many of the very light lands where rye thrives well and is entirely free from spur, wheat, barley, and even oats would be choked in the husk.

From the scope of these few observations it will be seen that the grain-destroying fungi-or rather grain- 
preventing fungi, are most likely to be developed in seasons when the midsummer rains set in too early and in too great quantity; while, in the case of the spur, the poisonous quality is, in part at least, corrected by a continuance of the rain after the spur las come.

The spur, or ergot of rye, if it comes to maturity in dry weather, is very valuable as a medicine, if administered with proper skill. Given to females it produces very powerful effects upon the uterine system; and thus both mother and child are sometimes saved by ergot of rye, when otherwise the case of one or of both is become hopeless. It is a desperate remedy, however; and, like all other desperate remedies, it ought never to be administered until the requisite necessity lias arisen; and as the determining of this, so as neither to inflict unnecessary agony nor delay relief until too late, is one of the nicest points in the whole practice of medicine, it should never be tampered with but by persons of the greatest skill and experience.

When mixed with food, the effects of the poison upon the system are very dreadful, and one of the forms which is best known is that which is called by the nane of dry gangrene. It is very remarkable, but nevertheless true, that the effects of this fungus when mixed with food, are quite different from the specific medical effects above alluded to. It appears not merely to accumulate in the system, as is the case with foxglove and some of the other vegetable poisons, but it accumulates locally, and on the extremities rather than on the vital parts. It often does not appear to be $\mathrm{x} 3$ 
attended with much fever, or inflammation, or pain, $\mathrm{Ol}^{\circ}$ any symptom that would lead to the supposition that the body was in a diseased state. In time, however, it affects the extremities, to a greater or smaller extent; first with numbness and cold, and then with emaciation and drying up, until they at last become as brittle as touchwood, after which they separate from the rest of the body. We are not aware that there are any means of saving the limb or part of a limb, after the gangrenous symptoms are fully confirmed in it ; and if the mutilation once fairly begins, it is not easy to say where it may stop, or how extensively the disease may spread. A joint of a finger is of course the slightest injury; and it may extend in other cases to the withering of a leg till it parts at the hip-joint, or of an arm till it separates at the shoulder. Sometimes the parts are merely withered by the disease stopping in its early stage; but we believe that, even in these cases, the use of them is seldom if ever recovered. Delirium and death are not unfrequently the results of very severe cases; but they appear to be secondary, and indeed the whole action of this extraordinary poison is as inystelious as the effects of it are distressing.

In consequence of the particulars formerly stated, the occurrence of disease from the ergot is rare in this comitry. There have, however, been instances, and some of these from the fungus upon wheat, though in these it has not, we believe, been accurately ascertained whether the fungus was the same species as that on the rye, which has so often been fatal on the continent,most of them, indeed, occurred before the nature of the 
ergot was properly known, and there is reason to suppose that the fungus, in some of these cases, was not the spur, but one of the moulds or mildews, though which species is not kllown; and it is probable that some other diseases, which have been ascribed to the mixture of the seeds of the charlock or wild radish, and to those of other plants, were really occasioned by small fungi, though quite different ones from the ergot.

One of the most serious, and also the most clearly detailed cases of dry gangrene, occurred in the county of Suffolk in the year 1762 ; and it is worthy of the more attention, that the fungus occasioning it does not appear to have been ergot. A farmer in the village of Wallisham, about twenty miles from Bury St. Edmunds, had a portion of his wheat laid by the rains previons to the harvest. But the precise progress the grain had made at the time when it was thus laid is not mentioned, though there is reason to believe that it was too far advanced for being in much danger from ergot. In order that this damaged part of the crop might not injure the appearance and lower the price of the sound part, the farmer had it put up separately, and it was threshed about Christmas and sold at a low price to farm labourers and to other poor people of the village. 'This grain began to affect some of the people early in Jamnary; and about the tenth of that month its effects became apparent, and it appeared to accumulate by prolonged use, in the same manner as ergot of rye does. One family, consisting of a father, a mother, and six children, used to purchase two bushels of this damaged wheat every fortnight, and they ate no other for a conside- 
rable time. In the country, according to the testimony of the curate of the parish and a Dr. Wollaston, this wheat was known as "clog-wheat," "bearded wheat," or " rivets," which seems to show that the people wcre not unacquainted with it in those days, and that the fungus, whatever it may have been, was some one growing upon and adhcrent to the grains individually, and not one exhausting the grain in the course of its formation, as is the case with the ergot. The symptoms, however, had a considerable resemblance to those produced by ergot, and the consequences were of the same lamentable character.

After persisting some time in the use of this poisonous grain, the mother and all the six children were attacked within a slort time of each other. Violent pains in the lower cxtremities were the first symptoms that prescnted themsclves; but these subsided in the coursc of a few days, and were followed by insensibility, cold, and mortification. The following were the consequences, as stated by Dr. Wollaston, in his communication in the Philosophical Transactions:- "Mary, the mother, aged forty; right foot off, at the ankle; left leg mortificd, a mere bone, but not off. Elizabeth, aged thirteen; both legs off, below the knees. Sarah, aged ten; one foot off, at the ankle. Robert, aged eight; both legs off, below the knees. Edward, aged four, both feet off at the ankles. An infant aged four months, dead.

"The father was not attacked till about a fortnight after his wife and children, and in a slighter degrec: in him the pain was confined to two fingers of his right 
hand, which turned blackish and withered. Another labouring man in the same parish, who had eaten of this bread, suffered from numbness in both his hands for above a month. They were constantly cold, and his fingers' ends peeled." Some of this wheat was eaten by various other persons; but it does not appear that any lived so exclusively upon it as the family of whose fate Doctor Wollaston gives such painful details; but still it were much to be wished that the speeific fungus had been correctly ascertained.

It should seem that the violent pains whieh preeede the mortification in these cases indicate a cause somewhat different from that which is but too well known in France, as positively resulting from the use of rye contaminated by the ergot; and it is worthy of remark, that Raphania, and some other forms of disease, generally understood to be caused by the use of unwholesome bread-corn, are much more violent, as well as general, upon the system in their primary effects, without being followed by gangrene. Thus it is probable that there may be a series of poisonous fungi parasitical upon the farina of grain, in every stage, from its first rudimental formation in the ear to its last stage of being used as monldy bread,-it being understood that the moulds alluded to are all fungi, and not the little plants belonging to the algæ, which were formerly noticed. The proper understanding of those deleterious fungi which attach themselves to damaged grain and flour, and impure bread, and to many other articles of food when in a state of putrid decomposition, in places where the elements, or animal spoilers, are 
not eompetent to their reduction, is a subjeet of very great importanee. Those which attack bread-corn, or bread, are of especial interest, inasmuch as bread forms so large a portion of the food of the young and of the labouring elasses, and as these poisons are apt to undermine the eonstitution by continued use, even when they are in quantities too minute for occasioning violent and immediate disease. But we must defer the few remarks that we have to offer upon them until we have mentioned a few more of the forms under which they appear.

France is the country in whieh the ergot of rye has been studied with the most attention; or, at all events, where the disease has attraeted the greatest notiee. As early as 1676, the commexion between the gangrenous disease and the eating of "spurred rye," was clearly pointed out. From this time the notiees of periodical returns of the disease, of more or less malignant character, are very frequent, though we believe that they have not been so eommon of late years, probably owing to an improved state of agrieulture. The fact of the spores and their imnediately containing substanee being innocuous, where the external perideum has been washed away, eaused at one time some doubt as to the invariable eonnexion between the disease and the fungus. But it lias invariably been found that the disease is prevalent only in those years when the spur is upon the rye, and always most virulent in those distriets where the grain is most liable to be affected, and among that portion of the people that. live the most upon rye. 
M. Noel, who was surgeon to the Hotel Dien, or hospital, at Orleans, for thirty years, witnessed the disease four times, as an endemic, in the conrse of that pcriod. In these, and in other reported instances, there appears to be very great difference in the degree of fatality in the attack. Sometimes a large majority escape with only a greater or a less degree of mutilation, while, in other cases, an equally great majority are carried off by death. The poisonons nature of the ergot is farther proved by the fact, that animals have a strong aversion to corn which is infected by it; and expcriment has shown that, administered in any considerable quantity, it is poisonous to those animals which can eat safely of many plants which are injurious to others. This extends to birds and reptiles, as well as to all the mammalia upon which it was tried in the course of the experiments; and even to such of the invertebrated animals as could be made to partake of it. The symptoms upon most of these were, first, giddiness, loss of the contractile power of the pupil of the eye, paralytic affections, and unnatural excitement of the intestinal canal; and these were followed by gangrene in various parts of the body, and in the majority of instances by death.

The fact of almost every animal refusing to eat rye infested with the ergot, is a conclusive proof of its poisonous nature, even without the corroboration of the direct experiments. Man arrives at his knowledge in such cases by observation and experience, and consequently he is in continual danger of mistakes; but the instincts of the animals are unerring, as being 
altogether free from judgment on their part ; and therefore any lessons that can be derived from them are always lessons of truth.

The part of France in which the rye is most frequently infested by this fungus, to such an extent as to convert it into a dangerous poison to those who eat much of it, is strongly corroborative of all that has been said of the circumstances which are most favourable to its development. This part of France is the district of Salogne, between the river Loire and its affluent the Cher. The soil is a cold and hungry clay, of so retentive a nature that the rye has to be sown on drills about a foot high, in order to preserve it from maceration and destruction by the wet. The crops are poor in all seasons; and although rye is among the least scourging of all the cereal plants, the fields have to be fallowed and rested every third year before they can bear a repetition of the miserable crop. Even at this unproductive rate, of two crops in three years, the land is very soon rendered altogether unproductive for tillage, and has to lie in such wretched pasturage as it affords for a number of years, before it can again produce such rye as is fit even for poisoning the people with the ergot. If upon a district of such wretched character as this there should fall rain at the time when the ears of the rye are beginning to form, there is really no alternative to the ergot appearing upon it; and when it once comes, and the peridia are not removed by subsequent rains, - and it is doubtful whether they are ever wholly reducible by this means,disease is the certain effect of the use of it. There 
appears to be just as little certainty of preventing, or curing the disease of the grain, as there is in doing the same for the unhappy persons who are affected by it. With the latter, it is not very clearly ascertained what might be done in the very early stages, before the symptoms of the gangrene come on; but after this there is no safety for the affected part, and none for the patient, save amputation. The only sound conclusion that can be drawn from the most careful study of the case is, that the lands upon which rye is subject to this terrible fungus ought never to be sown with that grain. If there is any efficient remedy, that appears to consist in the amelioration of the soil only; and lime, sand, and animal manures appear to be the ingredients that are best fitted for these purposes. With regard to smut and brand upon the grain of our own country, though it does not appear that any of them is a direct poison like the ergot, the cure is in all probability very much the same; and all of them appear to be warnings to the farmer, that he is cultivating a particular species of grain upon fields which are not in proper condition for their wholesome culture. Alkaline leys and earths are, no doubt, in a great measure, fatal to the spores of these fungi; and if we could be certain that, in all cases, those spores are either attached to the seeds when they are sown, or contained in the soil, the application of the substances that liave been mentioned would, no doubt, be of very great use. But from the incalculable numbers, and the extreme minuteness and consequent levity of these spores, we never can know how completely the summer air may 
be loaded with them; and as none of our curative applications can reach that element, they cannot be regarded in a higher light than that of so many plausible quackeries. They have succeeded, and they have not succeeded; and nobody can say how much of the success may have been due to the particular character of the season, or the situation. There is still much to be learned upon this very important but most obscure page of the book of nature; but it is of so hidden and intricate a nature, that although our abilities were equal to the task (which they certainly are not), our limits, and the main object which we have in view, would equally prevent our entering upon it.

The fungi which we have hitherto noticed as parasitical upon grain plants, whether as simply deteriorating the quality and diminishing the quantity of the farina as food, or as communicating poisonous qualities to the mixture, all belong to that division which attacks the plants upon which they are parasitical, at some stage of their growth, and are excited by diseased action arising from an improper soil, from a more abundant crop than the soil and the season are capable of bringing to maturity, from unfavourable weather, or from a combination of those causes. In so far as the soil is concerned, the farmer is able, in a great measure at least, to guard against those very destructive enemies; but no skill and no experience can guard completely against the contingencies of the weather; and therefore the only plan, or at all events the safest plan, for the judicious cultivator, is to work to the average of the seasons.

It is not upon the corn plants alone that fungi, having 
injurious effects upon the human constitution, make their appearanee, or, more strictly speaking, come in multitudes which are invisible. The disease known under the name of Rapliania, which is very eommon in Sweden, and other eountries which like Sweden have a brief and preearious Autumn, subject to great vicissitudes of temperature, is generally understood to be oecasioned by the seeds of the wild radisl or jointed eharlock (Raphanus raphanistrum), which infests the eorn-fields of all the colder and more northerly parts of the Eastern continent. Very careful investigations, conducted by the Swedish philosophers, liave shown that the disease in question, which is a eonvulsive disease of a very severe description, is not produced by the spur on rye or by any fungus of analogous elaraeter, inasmuch as barley is generally the grain by living upon whiel the malady is commonly produeed, and eharlock is quite inseparable from the barley of so nortlierly a country; and hence the seeds of the charlock had been generally supposed to oeeasion the disease. But charlock is a very eommon field weed, and is just as abundant in places where Raphania is unknown, as where it is of frequent oceurrence. In many parts of Seotland the staple bread of the poorer people used to be made exelusively of barley-meal, and though the general introduction of the potato has superseded it in many places, greatly diminished the use of it in all, and eertainly supplied the people witl far more light and wholesome food, yet Raphania was little, if at all, knowu in Scotland. It is true that, from the poverty of the people in the more remote districts, and their strong 
belief in predestination, which made them equally unable and averse to the employment of medical men, the history of disease is not known. There is however some reason to believe that, in the northern districts, which resemble Sweden in the character of their climate, the violent spasmodic diseases which were endemic, after very rainy harvests in former times, were either raphania or something resulting from a similar cause.

Of late years these diseases, if they have not disappeared altogether, have certainly become much more rare; and though there are other reasons for this improvement of the health of the people, there is no question that much of it is owing to the general culture and use of the potato. It is true that the potato crop is liable to destruction by the early frosts, and the people are, in consequence, sorely pinched with want; bnt so far as we know, there is no poisonous fungus or other deleterions plant which attaches itself to the tubers of the potato, protected as these are by being imbedded in the ground.

The potato is indeed one of the most curious plants with which we are acquainted. A native of climes almost directly under the Equator, it yet improves in quality in the high latitndes and in the extreme wilds, yielding wholesome nourishment to man under those inclement skies where even the poorest of the grain plants either cannot be grown at all, or are liable to be converted into poisons by fingi.

When we consider the wonderful obedience of the potato to the hand of the cultivator, the range of climates over which it can be grown, and also its native locality 
in the Andes, we eamnot help seeing that it is admirably fitted, and obviously designed for the good of man, under eireumstanees which render other vegetable food difficult to be produeed or dangerous in the using. So far as the facts will enable us to carry the analogy with any thing like eertainty, it appears that places where grain plants are liable to be infested by spur or other fungi, are peculiarly favourable to the growth of wholesome potatoes. One of the most remarkable evidenees of this is found in the fact, that, in the upper valley of the Magdalena, which lies within three or four degrees of the Equator, and is both wild and elevated, the potato is native; and maize or Indian corm, the ehief grain which grows in places so tropical, is very subject to the attacks of fungi. It has been ascertained that the habits of the maize fungus resemble the spur of rye, though the action of the two upon the animal system appears to be considerably different. Like the spur, this fungus forms an elongated mass, in the place of the grains of the maize. Some animals are poisoned by this diseased Indian corn, while smaller doses excite them in a manner resembling intoxication. In others again the hair or fur drops off, the legs become weakened and wasted. 'The eggs of poultry are produeed without shells, in the same manner as they are when the hens are greatly alarmed; and if the inhabitants continue to eat it for a considerable time, their teeth are loosened and their hair falls off: it does not appeal however that any of the more violent symptoms produeed by the European fungi follow from the use of food tainted by this plant, for no mention is made either 
of violent convulsions or of dry gangrene of the extremities. The fact of the eggs being produced without shells, leads naturally to the presumption that this fungus is injurious to the reproductive system, but whether it has the same violent specific action as ergot of rye, has not been mentioned.

This fungus upon the Indian corm is by no means rare in the district of country which we have mentioned, and the character of that country is worthy of attention as calculated to throw some light upon the general physiology of those curious fungi. It is near the equator, and so varied in its surface, that while the mountain tops rise into the region of frost, the valleys are cleft down almost to the mean level of the surface; and so near are those extremes of climate to each other, that there are many points where one can take such a position as, almost'on any day of the year, to see every tropical luxuriance and beauty on the one hand, and nothing but Lapland on the other.

We have had occasion again and again to remark that the tropical and the polar influences, estimating the extreme of the former by its winter of thirsty desolation, and that of the latter by the intensity of its cold, are the two grand agencies, or which amounts to the same thing, the types of the two grand agencies, by which all seasonal changes are brought about, and a great part of the growing and living world is roused to action at one season and shrouded in death or lulled to repose in another. Now as this is the case, any one can see that when the extremes of those two agencies, and of the states which they produce, are within a few miles of each 
other in horizontal distance, their struggles and the resulting disturbances must be far more frequent and far more violent than when the agencies are six thousand miles in space, or six months in time distant from each other. The deep valleys arc as hot as ovens, whilc the mountain peaks are chilled by excessive cold. This produces a constant descent of the mountain air upon the valley, and a constant ascent of the air from the latter, reeking with most pestilcnt vapour, highly favourable to the growth of tropical plants, but destructive of luman life. The cold of the mountains too has very different effects both upon animals and vegetables than the cold of the high latitudes. The cold of the latter, whatever may be the degree of its intensity, is a dry cold; whereas upon the summits of the tropical mountains, the cold is a moist one, from the vast quantity of vapour which the rays of an almost perpendicular sun keep continually ascending or descending. Violent storms are the result of this; and in the more elevated tracts no season of the year, or time of the year rather (for there is but little difference of seasons), is safe from variations of the weather quite adequate to the prodnction of fungi upon grain.

This, as we have said, and other places resembling this, along the ridge of the Andes, are the natural liabitats of the potato. We believe that no species of grain plant is native, at nearly the same elevation as the potato is found wild; and this, together with the frequent and extensive poisoning of the grain by the fungus, is a reason why attention should be paid to the native plant, and the cultivation of the other dininished 
or abandoned. The same observation applies to the inexpediency of growing any European grain where it is habitually subject to poisonous fungi; but whether the potato should or should not be called in as a substitute, must depend ıpon the circumstances of the particular case. Ergot of rye is indicative of a retentive clay soil, and also of a dripping climate; and though, up to a certain extent, the last of these is favourable to potato culture, the first is always very unfavourable, as the tubers are constricted in dry weather, and soaked when it is rainy.

But in the places where barley and oats are no longer profitable culture, whether from heary rains or from an mucertain Autumn, the potato can always be introduced to great advantage; and, as the grain upon these last extremes of locality, for its growth, may be said to be in a state of living death, that is, a life constantly subject to suspended action, during the whole time that it is upon the ground, it is almost certain to be attacked, and converted into a poison by some kind of fungus, if it escape from the other casualties of the improper situation in which it is attempted to be grown; and if the people will persevere in this inproper culture, which, it is to be recollected, may become improper by too long continuance, as well as from the nature of the soil and climate, they must bear the consequences of their ignorance or obstinacy.

'There is one circumstance connected with those fungi that are parasitical upon grain in its early stages, and consune it in the instant of its formation, as it were, which is especially worthy of our notice, in a physio- 
logical point of view, and as showing an extraordinary coincidence between the animal and the vegetable kingdoms. The ergot of rye, and all the other poisonous fungi which, like it, attack the grain in the earliest stage of its formation, and substitute themselves in its place, forming themselves of substances which would otherwise have been grain, attack vegetable life in its most rudimental state, that is, in the ovary of the bloom, before the act of fertilization; and in consequence of this, though the general action of the plant continues its supply of matter, that matter goes to the fungus and not to the seed as the germ of a successor to the parent plant. Upon the animal system the effect of the fungus, especially in the case of ergot, is upon the first rudiments of life-upon the uterine system of the female; and though it may not be taken in such quantity as to produce the specific action which it has as a medicine, and cannot indeed produce that action except under particular circumstances, there is every reason to believe that it tends to produce barrenness, and also extreme weakness of constitution in such children as are bronght into the world. It is a long observed fact, that fewer children are born, more of them die in early life, and females sooner pass the period of fertility, in districts where unfavourable summers and Autumns bring fungi upon the bread-corn, than where it sustains no such injury.

The stationary population of many tracts of cold and upland country, while bad grain formed the principal part of their food, and from which there was no emigration to lessen their numbers, is an incontrovertible 
proof of this; and we have proof of the opposite, upon the general use of food of another description, not liable to fungal contamination, which may be regarded as au experimentum crucis. In Ireland, even in those parts of it where the general privations of the people, and the absence of almost every thing that can be called comfort, are extreme, the increase of the population and even the healthiness of the children, amid all their apparent wretchedness and misery, are equal, if not superior to those in the best fed and most highly favoured districts of the sister island. It las sometimes been said ironically, that the rapid increase of the Irish peasantry is owing to the potato being their staple article of food; and it is by no means improbable that this, like several other ironical expressions, intended only for ridicule, is literally and philosoplically true. It is impossible to ground the argument upon the case of Ireland, because we are in want of the other element of the comparison. $\mathrm{Up}_{\mathrm{p}}$ to the time at which the potato became the general food of the humbler classes in Ireland, and for a considerable time after it, that unhappy country was far more the victim of rapacity than the subject of philosophic observation and inquiry. There are some accounts on the record as to the numbers of the wealthier Irish that were plundered, and vague lists of the poorer ones who were murdered; but with regard to the true statistics and state of the comntry, there is not a spot on which the lightest philosopher, that ever played witl the destinies of mankind in mode and figure of scholastic jargon, can rest the sole of his foot. We are, therefore, constrained to seek the other 
ferm of the analogy in other lands; and though our limits preclude us from the details of the enmmeration, any one who is sceptical upon the point may tum to the recorded history of Northern Europe, and also to many parts of the central states; and he will find an establishment of the general principle, that wherever the bread-corn of the people is generally subject to attacks of fungi, the population is stationary, and in extreme cases retrograde. It is true that numbers are cut off by periodical maladies, which maladies invariably follow harvests in which the corn is more than usually tainted; and though famine sometimes had and has an influence on them, disease invariably did and does take the lead. But, even in the ordinary seasons, or leaving out those of extreme calamity, which of course brings the remainder above the average, fewer children are born, and more die at an early age, and the constitutions of the people are neither so strong nor so lasting in such countries, as in others in which the food of the people has no fungous taint. The people of Britain, for instance, consume less food which is in any way diseased or tainted, that is, taking them on the average of all ranks, than any other nation whatever; and it is admitted, on all hands, that they are more sinewed for work, better steeled for endurance, and longer lived than any other people on the face of the earth. This single fact speaks volumes of instruction, even in a selfish point of view, to those who have "the management of mankind," if they would only learn to understand it, and reduce it to practice.

From a careful contrast of the state of the population 
in countries where spurred grain is used, with that in which the grain is either sound, or the potato is substituted for it, it is impossible to avoid coming to the conclusion that there is an exceedingly rudimental injury done to the principle of life by these fungi, from which the same principle is entirely free in every case where the food has no contamination. Indeed the potato, in this and in some other respects, has, among the humbler classes of the people, especially in manufacturing towns, where the bread is purchased from bakers, some advantages over the bread. Potatoes are dressed at home, and therefore if they are of good quality and properly kept, they are always fresh and wholesome. Bread again is liable to many adulterations; more, indeed, than any other general article of food; and as the parties by whom it is sold-to the poor especially-care nothing for the health of their customers, they are very apt to use damaged flour, or to damage it in a most iniquitous manner, in order to gratify their wretched but only motive for carrying on the trade-that of obtaining the highest price possible for the most worthless commodity. It is not, lowever, any of the fungi which we have been describing that are the deleterious ingredients in the case of bread; for though fungous flour is often used, and really is a poison in the state of bread, the fungus in general belongs to the dirision of fungi which get the general name of moulds, and which do not consume the farina of grain as it is formed, but attack that and many other substances, when they are in a state of incipient putrefaction, under peculiar circumstances. Such being 
the case, the consideration of it can be more advantageously entered upon in our next chapter.

If we had space to follow out all the generalizations to which the subjects noticed in the present chapter would lead us, we should find many of them equally curions and important, and some unexpected, and even startling, but, at the same time, of the greatest importance, in the conducting of practical matters upon the great scale. The alternation of the aerial grasses, which produce human food on the summits of their culms in the air, and the potato, which produces food, having many corresponding qualities, at the extremities of fibres, or flexible under-ground branches, is one of the most remarkable, and the only one of which we can afford any notice. In the localities which we have mentioned as being, and probably as having in the lapse of years become, unfavourable for the growth of grain crops, experience shows that the potato can be introduced with the greatest advantage, and that under very different circumstances as to climate. The margin of a mountain bog in Ireland-even the bog itself, with very moderate drainage; a few mossy sods turned down upon the bare rock, and exposed to the dripping of the Hebrides; or a thin, exhausted, sandy or gravelly soil, such as occurs in great part of the north of Germany, and of Poland,--are all capable of yielding an abundant supply of excellent food, and materials for various other articles of living or of domestic economy, after every kind of grain upon them has ceased to be obtainable, in any thing like a fair crop, or become a poison when obtained. It is difficult to say in which 
of those countries the general introduction of the potato has been the greatest blessing. It lias been a very great one in them all; and although those ignorant persons, who are bold and vain-glorious in their ignorance, and therefore always attributing effects to wrong causes, have sometimes laid the blame of all the wrongs of Ireland upon the potato, that vegetable has been the blessing of the people, not their bane; and, under the pressure of other circumstances, which certainly do not belong to natural history, had it not been for the potato, Ireland, instead of overflowing with a vigorous population, who have plenty of sinews if they had kindness and good counsel, would have been reduced to a scattered and famishing remnant, few and far between.

But, prolific as the potato is, under those circumstances which are unfavourable for corn, and cliefly as an abundant population can be supported upon it, there is a limit beyond which it may be forced, and after which it will begin to become an evil. This, like every other bounty of Providence, is given to man for instruction, and not for idleness, either voluntary or involuntary. Man must not sit down and content himself with planting his potatoes, generation after generation, for an indefinitely long period of time, in the lope of always gatliering in the same excellence and the same abundance. There is no single species of culture permanent in unbroken succession upon the ground, any more than there is an individual human being permanent upon earth; and where the great breadth of a country is left, as it generally must be left, to the 
influence of natural circumstances, there is a progressive change to which attention must be paid, and the advantage of one improvement in cultivation is nothing but a stepping-stone in the way toward another. 'The potato in Ireland has obviously been cultivated beyond the limit; because upon those lands where it has been grown year after year for a long period, the native produce has become to a great extent abortive, and seed has to be imported, to the serious injury of the cottager. The plan, therefore, is to transfer the culture of the potato to the new grounds, and adopt another one, say pasturage and then agriculture, upon those which are exhausted. 


\section{CHAP'TER VIII.}

MISCELLANEOUS APPEARANCES IN AUTUMN.

Autumnal agents, and the appearances which their several actions produce, are so very numerous, and the limit of our volume is so nearly reached, that we must content ourselves with the mere enumeration of a few. In selecting these few, it will be our endeavour to take such as are either not generally to be met with in the popular books, or are of more than ordinary interest; and to hint at the mode in which the transition may be made from them to the analogous races, which we have not room to enumerate.

Foremost among those which we can afford to mention, we may with propriety place the more typical fungi, or those that make their appearance upon decaying substances, and hasten their decay, as distinguished from those noticed in the preceding chapter as attacking plants in the course of their growth, and preventing them from coming to maturity. Of very many of these, the uses are but imperfectly known; and though they all make their appearance upon organic matter in a 
state of decay, or in the decaying season, and appear to be stimulated by damp and a close atmosphere, there are not a few of them that grow simply upon the ground, so that we are unable to say positively what the specific plants or other substances are which it is their special office to hasten in their decomposition. We shall briefly notice two families or sections of them, which are remarkable for their pernicious effects-and these are, the "mildews," Mucoracea, and the "dryrots," which are fungi of very diversified appearances and characters; but all of them highly destructive of timber when it is placed in circumstances favourable to their development.

The mildews, or moulds, as they are sometimes called, (for the latter is a very general, and therefore a very indefinite term,) are exceedingly common, and appear upon almost every description of animal or vegetable substance, when it begins to decompose in damp and confined air. They appear upon ill-conditioned provisions, even though these are cured with salt; and although not probably poisonous in their own substance, at least in all the species, they are always to be looked upon with suspicion; and they generally, if not invariably, indicate poisonous qualities in whatever is infested by them. 'They also invariably have or communicate an offensive smell, which is different from that of ordinary putridity, and which may be characterized as being more sickening in its nature than directly offensive to the sense. This last property distinguishes them completely from the bysso-moulds, which some of them nearly resemble when seen by the naked eye, though when examined z. 3 
through glasses, they have, generally speaking, the form and texture of miniature mishrooms.

From various cases that have occurred, there is reason to apprehend, that these mildews or moulds are as poisonous as the ergots, formerly mentioned, though they poison in a different manner. 'They are, also, far more dangerous, and, therefore, they are still more worthy of attention. The ergots are confined in their time, for if the grains of the corn have once begun to form, the ergot never makes its appearance; and whether it shall or shall not appear in any particular case, depends much on the general state of the atmosphere at the time when the grain-plants are coming into flower; and if the grain is safe from those fungi at this particular stage of its growth, it is in no danger from them afterwards.

With the mildew it is very different; for there is no stage of its growth, and no state of its preparation for food, in which the farina of the cereal grasses, and that of wheat in particular, is safe from the attack of this offensive and poisonous fungus, which does not come until there is as much substance in the ear as shall serve it for nourishment. Upon warm and dry lands, and in dry seasons, the grain may be considered as secure against this unwholesomeness; but though it may bloom and ripen in the most kindly and promising manner, yet, if dripping and sunless weather shall ensue, so that the grain cannot be gathered in, or, if it is gathered in in too moist a condition, it is sure to be attacked by the mildew. If this is the case, the nutritious quality, weight for weight, of the flour, is much 
more reduced than when the grain is attacked in a more early stage by smut or canker-brand; these last two do not impair the quality of the grains which remain sound, they only contaminate the mixture; and, unless their quantity be so great as to render the article wholly unsaleable, they do not lessen its nutritive quality above one-third. The mildew, on the other hand, destroys very nearly four-fifths of the nourishment of the wheat, so that a five-pound loaf contains only as much support for the human body as a onepound loaf of sound and wholesome bread,-or a quartern loaf about as much as twelve onnces.

This is a serious matter enough, and it is the more serious that it falls chiefly upon the poorer classes of society, by whom, on account of the lower price at which it is sold by unprincipled dealcrs, this damaged bread is eaten. The reason of this great destruction of the nutritive quality is, that the fungus especially drains the gluten, the quantity of which makes somud wheat sponge so much better in baking, and also renders it such substantial food, as compared with most of the other species. But, bad as this is, it is not the only evil or the worst one; for mildew invariably imparts a poisonous quality to the grain, the flomr, the bread, or the other article of food, whatever it may be, which it infests. In consequence of this, it is impossible to say how many of the diseases by which wet harvests were always followed in former times, and are often followed still, are produced by mildew. Instances of this are of too frequent occurrence; and, what adds to the misery and the danger is, that the mildew is apt to 
come upon the wheat at every stage, from its first formation in the ear, to its delivery to the consumer from the baker, and even aftcr it is in the house, if it has been dishonestly made, or kept too long in a damp and improper place. The poor are in but little danger from the last of these; but they arc very liable to suffer from the first, which is by far the more common of the two.

Flour made from mildewed corn, at whatever stage the fungus may come upon it, whether in the field from an unfavourable harvest, in the rick by improper housing, in the granary, or even after it has undergone the operation of grinding, (for it is liable to be mildewed in all these cases, if long subjected to a close and damp atmosphere,) is not only of inferior price in the market, but wholly unsaleable to a respectable and honest baker, or to families who have any knowledge of that important article of food. Therefore it is sold at a very low price, and, on that account, it is eagerly sought after by the unprincipled part of the trade, who are, unfortmuately, too numerous, and, still nore unfortumately, lave the power of compelling the poor to purchase any trash, however meagre in nomrishment, or deleterious in its nature, by always keeping them a few shillings in debt, and consequently being able to threaten them with the summary vengeance of that most unwise abortion of law, which, in this free country, gives the creditor more tyramical power over the debtor, whom he has wheedled or seduced into debt, than the slave-naster has over his purchased slave. This sometines ascends a step higher, and the iniquity 
is chargeable on the miller, nay, probably on the cornmerchant;-for the first necessary of life, being a tempting article to the cupidity of the unprincipled, is very generally in the hands of monopolists; and a monopolist, let him monopolize what he will, is always one of the worst and most injurious members of society.

Flour from greatly damaged grain of any sort, but more especially from mildewed grain, cannot by itself be made into a loaf, which would be saleable under almost any circumstances; and, on this accomnt, the one fraud of using it necessarily leads to many other frauds. If such flour were used without any admixture, it would not sponge or expand, but remain tough and waxy, if moderately baked, or harden like a bricklat, if that operation were carried to a greater extent. It would also be of a dark and disagreeable colour'; and its taste and smell, to say nothing of its deleterious qualities, would be those of earth which is accumulated in damp places, without any free exposure to the air. It would, in fact, be so unsightly as to be unsaleable, and so offensive to the palate, that it could not be eaten.

Those disagreeable qualities are, in all probability, wise provisions of natme, intended to protect the ignorant against the poisonous ones; and it is in order to provide against them that the shameful iniquities of the dishonest tradesman are perpetrated. Colour is obtained by an admixture of what is called " mountain meal," that is, pure clay, obtained from naturally" decomposed feldspar, of which, it is well ascertained, that large quantities are exported from Cornwall every 
year, for the express, though not avowed, purpose of adulterating bread. This substance is perfectly harmless, and, in so far as the acetous fermentation precedes putrefaction and the fungus in bad bread-and it is especially injurious to the digestive organs-the mountain meal is a corrective; but there is no nourishment in it, and the use of it is a fraud, much of the same kind with that of the wine-merchant, who boasted of promoting temperance by selling a mixture of one part wine and nine parts water coloured with logwood.

Instead of the pure clay, common alum, which is a mixture of clay and sulphuric acid, is frequently used. This also gives colour, and, if used in any considerable quantity, it would be very injurious; but, as it destroys the sponging quality, the quantity used must be very limited; but still, small as it is, it tends to accelerate the somring of the bread.

Neitler of these substances would in any way tend to make the bread sponge, and, therefore, something which contains stareh-if but little gluten, is resorted to. The very worst potatoes, boiled in the filthiest manner, and strained through a searce, with full benefit of the poisonous extract of the skins, is what naturally suggests itself as cheapest; and accordingly it is used in great quantities.

By means of these ingredicnts, bread from very bad flour, may be rendered as white as that from the very best; but it is a sickly whiteness, and wants the delicate tinge of golden bloom which stamps a gemine wheaten loaf, and which 110 craft can imitate. Such bread expands in the oven, especially when put into an 
overheated oven, by the action of which it is burned externally rather than baked through. Thus, one mal-practice of the fraudulent baker co-operates with another; but it leaves a mark whereby it can be distinguished by external inspection; and it may be adopted as a general maxim, that a baker whose loaves are habitually burned on the outside, sells unwholesome bread. The reason of this is easily explained-that is, the reason for using the oven at too high a temperature. This excess of heat causes a much more rapid and violent expansion of the gaseous products of "the mess," than a lower temperature would do, and this separates it into grauular portions. Such separation is, however, very different from the sponging of bread made of wholesome and uncontaminated flour. The latter is raised into vesicles, from the tenacious nature of the gluten, whereas the former is merely divided; and as in the division the gas in great part escapes, it requires a much higher temperature; and this renders it necessary to heat the oven to such a degree, as that, generally speaking, it chars the external part of the loaf. When a loaf of this kind is cut, it canuot be cut with a smooth surface, but crumbles before the edge of even the sharpest knife. If kept long uncut, the central parts collapse; and if a cut surface is exposed to the air, it hardens and champs; and in both cases it very speedily becomes monldy, if placed in damp air, and the moment that it does so, it becomes a poison. Even good flour, if adulterated with the mixtures that have been named, may be converted into unwholesome bread; and thus, in this particular 
instance, the casualties of nature, and the fraudulent practices of man, are equally injurious to the public.

The mixtures which have been mentioned, do not destroy the unpleasant smell of mildewed flour; and hence certain perfumes are introduced. These do not and cannot impart the odour of wholesome bread, which, though a gentle one, is equally peculiar and grateful; but they conceal the bad hugue, which, unfortumately for the public, answers the same purpose.

We may mention one well-autheuticated instance of the dangerous consequences of fungous bread, which occurred in the vicinity of London within these few years, though, unfortunately, it was not traced to its course in the bread so as to determine whether it was owing to bad flour, or the dishonest treatment of good flour. The beadle's wife, in the hamlet, bought a loaf which had been baked on the same morning, ate a slice of it herself, and toasted two for lier son, a young man twenty-one years of age. Very soon after eating the bread, both mother and son were seized with violent disorder of the bowels, such as is especially characteristic of poison having been taken. As there was not the slightest reason to suspect that any known poison could have mingled with the food, or, rather, as the contrary was well known to be the fact, the bread was examined. It was found to be of dark and varied colours, and full of very minute fungi, which fungi were the only part of it to which the poisoning could be attributed, as a careful analysis showed that it contained not a trace of any one of the ordinary poisons. The bread was soft, totally destitute of that elasticity 
or springiuess which good bread always possesses, and it was so tough and waxy, that it could be drawn into strings like thick paste when it is sour. Its taste and smell were, also, both offensive. In order to make sure whether the cause of the disease was, or was not, in the bread, a portion of it was given to the dog and cat. It very speedily affected them in the same manner, thus removing every doubt as to its deleterions quality. The next point was, to ascertain whether the poison was in the fungi, or in the substance of the bread; and experiment showed that it was in the latter; for a small bit of the bread, after the fungi had been carefully removed, produced the same symptoms; and the fungi, given in substance to luman beings and to domestic animals, produced no bad consequence whatever.

This is a very important part of the matter, and shows that there is a kindness in the growth of this little vegetable, and in the unsightly appearance, and unpleasant taste and smell, by which it is accompanied. We must say "accompanied," for it does not appear that the taste and smell of the fungus itself are any thing different from those of simple and harmless vegetable mould, which, though it would make but sorry food, is unquestionably not a poison, but would pass through the alimentary system, certainly not with harm, and probably with advantage. This fungous mould upon bread appears to give a wholesome warning, and to declare, as expressly as though it were written in words, "This bread is poisonous."

We are not aware that the particular manner in 
which the bread, in the Hammersmith case, had beell manufactured, had becn inquired into; or that the quality of the flour from which it was made, or the substances which had been mixed with it, had been ascertained; but an experiment was made which showed that a poisonous quality is imparted to ordinary dough, if kept so long as that the mouldy fungus comes upon it. A quantity of dough was kept in a damp place until covered with the mould; the mould was then removed with the greatest care, and the dough thus cleared of mould made into a loaf and baked. This loaf had the same poisonous qualities as the bread which had led to the experiments; but the mould which was removed from it produced no bad effect whatever, either upon men or upon domestic animals.

These facts show how very necessary it is to be careful in the manufacture of bread, and even in the keeping of it after it is manufactured; and that it would be very desirable to subject those bakers who adulterate flour with sulphate of alumina and other matters, which tend either to sour the bread, or make it retain an undue quantity of water, in order to increase its weight -which is one of the objects of the fraud-to the sererest penalties of the law, as criminals of the rery worst description.

We have already said, that the pure alumina is not in itself injurious, though, from the tendency which it has to absorb moisture, there is no doubt that it greatly accelerates the poisonous state of the dough or the bread; and as those who are base enough to adulterate flour are not very likely to be particular in the 
preparation of the bread, the safest conchusion, and probably the most accurate one to which we can come on the subject, is, that all bread adulterated with mountain meal is, in a greater or less degree, poisonous. The sulphate of alımina is far worse, because it lias a great tendency to bring on the acetous fermentation, and that is immediately followed by the poisonous state of the dough or bread, as indicated by the presence of the fungus. If the dough is in this condition, the operation of baking has no tendency to correct it, as is proved by the fact, that the Hammersmith bread was baked the very same morning that it was eaten. It is highly probable, also, that the mixture of potatoes with the flour, especially from the quality of this ingredient, and the filthy manuer in which the mixture is made, invariably tends to produce the same result; and the conclusion to which the whole of the facts lead us is, that bread should be made of sound flour; in a dry place, and with the very minimum of water, otlierwise there is no security that the bread shall not occasion disease;-and it deserves to be horne in mind, that the effects of most vegetable poisons accumulate in the system, undermine the constitution, and, in the cnd, prove fatal, even though their beginnings are scarcely discernible.

There is a corroborative evidence of the mischief produced by sulphate of alumina, in the starch used for preparing for the loom sail cloths, and other hempen and linen goods, which are used without nudergoing the operation of bleaching. It is well known that if such goods arc exposed to damp in close places, they 
are subject to mildew, which greatly injures their texture and strength, and renders them comparatively worthless. This mildew is in all probability not very different from that which poisons bread, as it is produced upon a similar substance, namely, vegetable starch fermenting by moisture. Sulphate of alumina is very often mixed with this starch because it renders it more fluid and ropy, and thus makes it go farther and makes it more easily applied; but we believe that cloth which is dressed with starch of this description, as well as from starch made of damaged grain or flour, or of potatoes or their admixture, is far more liable to mildew than cloth dressed with the starch of wholesome flour. It is true that, in the case of the cloth, there is a remedy. The salts of mercury prevent the growth of the fungus, the red oxide being the one generally used for the purpose; but, in the case of food, this cure would be worse than the disease, and that it is of much real use in the case of the canvas has not been established upon good philosophical grounds; because though it prevents the appearance of the fungus, we have no satisfactory evidence to show that it tends to prevent or even to lessen or retard that diseased state to which the fungus is owing.

In passing, we may remark that there is the same doubt as to the efficiency of Kyan's mode of preventing dry rot in timber, which has attracted, and is still attracting, so much of the attention of those who are interested in shipping. The application of which he makes use is, we believe, bi-chloride of mercury, or corrosive sublimate-one of the most deadly of the mineral 
poisons; and thus it becomes a grave question whether the saturating of the timbers and planks of a ship with this deadly poison may not be more destructive of the lealth of the seamen, than conservatory of the said timbers and planks; while it remains to be slown whether this application, even though it should in all cases prevent the appearance of the dry-rot fungi, can, in any case, convert a picce of bad timber into good. Of this, however, we speak by the way only, bnt we may perhaps revert to it afterwards.

There are various articles of food besides bread which are liable to show poisonous qualities by the appearance of fungi. One of the most remarkable of these is bacon kept in damp places after it is cured, and becomes what is called "rusty" - the rust being really one of the fungous moulds or mildews; and it is of little consequence which one, or whetler always the same one, as they seem all equally to indicate a poisonous state of that upon whicl they appear, and invariably consume that ingredient of it in which its nutritions quality chiefly consists.

There are no recorded instances of the poisonous effects of this description of pork in England, though from the extent to which that article is used, and the disposition of the poor to purchase at the cheapest rate, withont any regard to quality, there can be little doubt that it is a fertile source of disease, if not an obvious cause of death. In France the case is somewhat different, probably because the pork generally is of inferior quality to that of England, and probably because the diseased states of it are disgnised by those seasmed A. 13 
preparations of which the French are so very fond, and many of which, though they disguise the poisonous quality in the seasoned article, certainly do not correct or remove it. One description of food, the occasionally poisonous nature of which, as sold in France, has been unfortunately but too well ascertained, is that which is called Italian cheese. This consists of scraps of pork, mixed with various other substances, highly seasoned with spices, made into a solid pie or cake, and retailed in slices to the poorer people. In the instances in which this Italian cheese has been ascertained to be poisonous, fungous mould has always appeared upon it, of a bluish or greenish colour, similar to that which occurs on rusty bacon in this comntry; and whenever this makes its appearance, the article is always to be suspected, though it is probable that, as in the case of mouldy bread, the fungus is merely the sign or the warning of the poisonous quality, and not that quality itself; though in this case the experiment has not, we believe, been made. Little is known of the specific nature of those fungi which appear upon tainted provisions, and operate in decomposing their substance, but the general analogy leads us to conclude that they come to perform what we have stated to be the grand function of the fungi, that is, to decompose and turn into elementary matter, substances which have become noxions in their organic state. We cannot positively say that those moulds are Autumnal in their time; but in a state of wild nature Autumn is the principal period, and at whatever time they appear, their action may be regarded as decidedly an Autummal one. 
Of the larger, and perhaps more characteristic fungi, the puff-balls, the toadstools, and the mushrooms properly so called, we have but little room to speak; and though from their abundance there is no question that they perform an important part in the economy of naturc, the part which they actually do perform is, in the case of many of them, but imperfectly understood. The puff-balls, of which there are many species, usually grow upon dry heaths and pasture lands; they are, gencrally speaking, of a round shape in the pcridia or upper portion containing the spores; and when this bursts, the spores or germs are distributed like a smoke arising from the plant, and in consequence of their cxtreme minutencss and levity they are dispersed everywhere. Many of them have the property of being exceedingly repellant of moisture, so much so that it is hardly possible to wet them with water; but the use of this property in the economy of nature is not known.

Another family, the Tuberacea, of which the esculent truffle is perliaps the typical specics, are remarkable for many having their organs of fructification-though somc, as for instance the root-beard, come up to the surfaceupon which the peridia lie, under ground, and thus have something the appearance of potatoes Those which remain wholly under the surface are preferred as articles of food, and as such they are highly prized; but some of those which come to the surface are also esculent. The truffle, tuber cibarium, which is the most prized of the family, has so strong and so pecnliar a flavour, that dogs, and cven pigs (which latter have a keen scent for substances under gromnd) are cniployed 
in finding them out. They are natives of light dry soils, very generally distributed, and apparently capricious in their appearance, but their use in the econony of nature is little known. It is probable, however, that their function, as well as that of many other fungi which grow upon or under the ground, withont attaching themselves to and decomposing any particular organic substance, consists in the decomposition of carbonic acid, and probably also of atmospheric air; at least one would infer as much, from the quantity of nitrogen which they contain.

The Phallacere are another remarkable family of fungi, which are very peculiar in their character, and very Autumnal in their appearance. They sometimes grow upon rotten wood, and at other times upon the surface of the ground; and the circumstances under which they grow, the rapidity and vigour of their growth, and the extremely offensive odour of some of the species, are all equally worthy of remark. In their young state they are enclosed in a membrane, something the shape of an egg, in which state they remain for a day or two, but afterwards, the rising column within bursts the valve or envelope with so much force that it occasions a report as loud as that of a pistol. Previous to this the stinkhorn (Phallus foetidus), which is by no means uncommon in many parts of Britain, especially in thundery Autumns, is by no means offensive; but as soon as the membrane is burst, and the stem rises, the snmmit of the latter is covercd with a slime of a dark greenish colour, the odour of which is more intolerable than almost any other that can be named. It belongs to the 
same class with that of carrion, or other animal matter, in a state of rapid and offensive putrefaction, only it is still more intolerable; and, like carrion, it attracts those flesh flies which deposit their already latched larvæ in tainted meat or other animal substances in a state of offensive putrefaction. It seems, however, that the flies do not resort to this offensive slime, as a nidus in which to deposit their progeny, but as a kind of food which is peculiarly savoury to their own palates. Those who have devoted their abilities most ably and most successfully to the study of the fungi, are pretty general in describing a remarkable property of this most offensive and fleeting fungus. When it is kept at a moderate distance it is absolutely intolerable, and enough to sicken one habituated to all the smells of an operative chemist's or colour-maker's workshop; but when brought close to the nose, its intolerable odour is not felt, and it has then a smell somewhat resembling those ammoniacal salts which are used for preventing fainting fits, or for recovering those who are under their influence. It is also not a little remarkible that this, the most offensive to the smell of all the known fungi, is not only not poisonous, but that the white part of the stem which bears this offensive slime on its summit, is neither unwholesome nor umpalatable as an article of food. The slime melts away in the course of a few hours, and as it is the receptacle of the sporæ, these are dispersed at the same time. The more numerous appearance of these curious fungi in thundery weather than when there is no electric action of the atmosphere in Autumn, is a singular matter, but it is one which is without the linits 
of our present knowledge, and one upon which it would be equally unwise and in vain to speculate, though there is no doubt that they perform some action on the earth which accords with the thundery state of the atmosphere.

The larger fungi, which appear in such innumerable hosts in the Autumn, especially in the temperate and cold latitudes, are of an almost endless variety of shapes. Many of them are exceedingly destructive of timber, especially when it is of imperfect growth, laid in damp places, or a confined air. Some of these, the Tremellince for instance, are shapeless in their appearance, and so jelly-like in their substance, as popularly to get the name of "witches' butter ;" others of more consistency bear some resemblance to a number of ears stuck over the surface of the timber: of which last some have at times been admitted into the Materia Medica; others again are branchy, and resemble tufts of the fibrous lichens, and of these several are esculent and remarkable for their sapient qualities. The Pezizacec are a curious race, exceedingly numerous, and remarkable for being without any appearance of a stem. Their name implies that they are travellers on foot, and some of them are of large size and grow with extraordinary force. Among them the Ditiole, or down rots, are, in some of the species, remarkably destructive of timber, by insinuating minute portions between the fibres of the wood and tearing them asunder with very extraordinary force, considering the soft substance of the fungus. The power with which these and various other dry rots rend asunder the fibres of timber, and by thus exposing 
it to the air and damp, hasten its destruction, is truly wonderful. They penetrate throughout the whole mass of ligneous matter when in a state of decay, and rednce it to dust in much shortcr time than onc would be apt to suppose. Some cascs of the force of growth in these fungi, not against wood, but against stones, which werc obscrved in the streets of the town of Basingstoke, may be noticed. Some stones on the pavement were observed to rise gradually day after day, until they were several inches above thcir ordinary level, and underneath toadstools of a large sizc were found, by the force of vegetation in which these stones had been elevated. Upon another occasion, as is mentioncd by Mr. Jefferson in the Hampshire Advertiser, in the carly part of July 1830, these fungi grew so abundantly under the pavement, that the contractor was thrown into some alarm lest he should have constantly to renew his work. At first a stone measuring twenty-two inches by twentyone, and weighing upwards of eighty pounds, was heaved an inch and a half out of its bed by the growth of a fungus about six inches in diameter; and within a few weeks after, another stonc of about the same size and weight was raised up by two smaller ones. We believc the midsummcr rains set in early and rather heavily that year, and thus stimulated the fungi to an extraorainary growth. These facts are curous as showing, that feeble and fibreless as those Autumnal destroyers appear to be in their own nature, they are armed with powcrs, by means of which they can overcome great resistances; nor arc we acquainted with any ligneous plant which could in so short a time overcome the 
resistance of such a weight as that of these paving stones.

The dry rots, properly so called, whose ravages have, of late years especially, been so formidable to house and ship-owners, do not belong to this family of fungi, but approach nearer to the toadstools properly so called. There are a good many species and rarieties of them, and some of them assume rery varied forms according to the circumstances under which they appear. One, Memulius lachrymans, is so exceedingly destructive as to have got the name of "the dry rot," by way of eminence. These destructive merulii must not be confounded with the esculent morel (Morchella), which grows underground, and though it decomposes matter of some kind or other, cannot be regarded as an enemy to timber in any condition, although it is often found in woods.

The characteristic dry rot often spreads like mere cottony fibres, without putting out the proper form of its fructification, though when it does put that out it is exceedingly delicate and even beautiful in the reticulated structure of the hymencam, or portion containing the spores, and corresponding to what are improperly denominated the "gills" of a common mushroom.

The ravages committed by the various dry rots are far greater and more rapid than those who are not acquainted with them could possibly imagine; and the best known and most destructive species well merits the name of Lachrymans, for truly it is the cause of much sorrow, if not weeping, to every one whose property it attacks, whether on land or upon the sea. In 
cold climates, and also in extremely hot ones, at least upon the native timber, it is rare, if not altogether unknown; and a moderate temperature, and humid and confined atmosphere, are the circumstances, of a meteorological kind, which are most favourable to its destructive progress. Examples of this often occur in oak posts, of which the weather-line, or line between the earth and the air, is wholly or partially shaded by vegetation. Some fungus of the kind will make its appearance there, and cut the post asunder, in the course of a few years, or even of a much shorter time, while the parts in the air and in the earth remain perfectly sound. So, also, dead trees are felled by the fungus at the weather-line, while not a single plant of the kind appears either upon the part above or upon the root. When, however, the tree is laid prone, if it is in a damp and confined situation, and one wherc mosses do not come to its assistance and coat it over, and retain stagnaut water about it, the fungi very speedily assail and decompose it in its whole volume.

It is in houses and ships, however, that the destructive ravages of these fungi are most severely felt; and they are, like the pestilence, walkers in darkness, and never make their appearance on the external surface, or where either air or water can play freely around, Hence the mischief is often so confirmed, as to be beyond cure, before its beginning is even suspected. Instances are mentioned of houses having the lower timbers and flights of stairs so speedily destroyed, as to require twice replacing in the course of four or five years; and so insidious is the fungus in these inveterate 
cases, that it will attack books and papers, and reduce them to a state in which they crumble into powder upon being touched. Nor can it be got rid of by any well-known process, excepting a thorough ventilation; for, though all the infected timber is carefully removed, and every appearance of the fungus obliterated, it speedily reappears upon the new timber, if placed in the same damp and confined situation. Indeed it is by no means uncommon to commence its ravages while a house is in the progress of building, and the lower timbers have to be replaced before the structure is finished.

In ships, the ravages of the fungus are still more serious, inasmuch as the escape from a rotted ship is a very different matter from that out of a house, from which the timbers are partially rotted. In the mercantile and the royal navies of Britain, the ravages of these fungi have been severely felt; and we may mention one or two instances in the latter, which rest upon undoubted and unquestionable evidence. The Queen Charlotte, a first-rate ship of the line, in the building of which seven years had been spent, was launched at Deptford in the year 1810; and in the course of two years, and, we believe, without having been on actual service at all, this ship was so completely rotted, as to be totally unfit for going to sea till at least twenty thousand pounds were expended in repairs. The Rodney, another new ship, launched in 1809, caine home in 1812, so utterly rotted as to be paid off; and the Dublin, launched in February, and put in commission in August 1812, had to be paid off, 
s totally unfit for service, in the December of the following year. Many other instances might be given of the havoc committed by these fungi; but we can afford to mention no more of them, only we may hint that it is by no means a rare occurrence for vessels to be so mucl damaged while on the stocks, as to require extensive repairs before they are fit for launching; and that others have barely put to sea before they had to be broken up and sold for firewood, as quite unseaworthy, and incapable of being rendered so without an expense equal to that of building a new vessel.

Besides the decomposition of the timber, which is an effect, there is nothing discoverable except the fungus; and, therefore, the object of those who attempt to cure this disease in the wood, is usually to prevent the appearance of the fungus. But oak and other timber is so frequently reduced, in a very few years, to a paste or powder, according as it is wet or dry, having an earthy smell in both cases, without the presence of any fungus, at least, any one visible to the naked eye, that we must come to the conclusion, that the rot, whether wet or dry, may take place without the presence of any of the fungi which are usually denominated dry rots; from which, again, it follows, by obvious and necessary consequence, that the disease is one thing, and the fungus another, and that the disease always takes the precedence; so that the development of the fungus, instead of being the original cause of the disease, is only a consequence of it, and not a necessary and invariable consequence, but one which requires a confined and damp atmosphere for its development, in 
addition to the unwholesome state of the timber. 'The most philosophical conclusion to which we can come, and the one which is most in accordance with the general function and use of the fungi, is, that the timber subject to rot, whether wet or dry, is diseased from its very first evolvement from the acorn, or the other seed. It has been supposed that timber which is felled during the season of growth, or sap-wood, has a proneness to rot, from which timber felled after the Autumnal ripening, and heart-wood, is exempted. There does not appear to be much truth in this, if, indeed, there is any; for though, in diseased timber, the sap-rood certainly rots first, whether the fungus appears on it or not, the heart-part of the same wood does not long survive. We never heard of a single instance of rot, either wet or dry, in the oak-timber of the Scotch Highlands, even when cut as copse-wood for the sake of the bark, which is, of comrse, always done in the season of growth; while we have seen the most carefully-selected heart-wood, of winter-felled trees, from some of the royal forests in England, which had first been carefully dried and seasoned in the stack, and then kept for more than twenty years in a dry atmosphere, very speedily attacked by the rot, both with and without fungi, when placed in damp and confined air, - sooner rotted, indeed, than the very rorst white pine of Canada; and, with the experience of these facts, it is impossible not to come to the conclusion, that the cause of the disease is really the bad quality of the timber; and that, if timber of this description is once grown, there may be a great deal of quackery exercised 
upon it; but there is no possibility of converting it into good timber, any more than there is of converting the pines of the South Sea, which are rotted almost the instant they are dry, into the sound timber of the Scandinavian Hills. It is true that many saline mixtures, especially the salts of mercury, and pre-eminently among these the solution of bi-chloride or corrosive sublimate, may stay the evil for a time, that is, they may not only prevent the fungus from appearing, but, as long as they give out poisonous effluvia, resist the decomposing action of the atmosphere, in the same manner as they resist the miasma of disease, when used in the fumigation of infected places. It is a grave question, however, whether the injury done to the liealth of human beings by the exhalations of such poisonous substances, may not far more than counteract the value of their conservation of the timber of ships or houses, which, after all, is but a very temporary one.

We have not space for going into the argument; and indeed the data are not sufficient for giving it a regular form; but it appears to us that the defect of all timber liable to the rot, whether accompanied by fungi or not, is a deficiency of carbon in the original composition; and consequently the only effectual means of preventing this rot in timber, is to devise means for growing it with the proper quantity of charcoal or carbon in its composition. This would demand attention to the climate, the soil, the situation of the seed at its first germination, all of which are peculiar matters, and would not, though we had a perfect knowledge of them, be proper subjects for popular description; though those fi. I: 3 
who are interested may, if they choose, take the hint, and profit by it in their practice. In early times, when only the pine of the north of Europe was used in the timbering of houses, and naturally grown oak in the construction of ships, dry rot was unknown, or, if known, it did not attract attention as it has done in more recent times. The more uniform temperature of the seasons may have some effect in this deterioration of the timber; but probably more injury is done by the forcing of the young plants in the nursery, which may occasion unhealthy wood at the first; and there is reason to believe that, as the tree begins, it is likely to continue.

The Autumnal fungi make their appearance in the woods, especially those of the colder latitudes, in the fall of the year, and obviously for the purpose of decomposing those decayed substances of the season, which defy the ordinary action of the elements in the inclement season of the year. Accordingly they are most abundant in countries where the snow comes down early and lies long; and the Autumn and spring the seasons of alternate rain and drought, and as such the most favourable for vegetable decomposition; - -such as the woods of the northern parts of Scandinavia, and of Russia both European and Asiatic. Many of those fungi are very beautiful in their colours; and though, taken as a whole, they are rather suspicious, yet several of them are eaten by the Russians without any bad consequences. Some of these are as much as a foot in diameter, of a most brilliant red when young, but passing through orange to brown as the spores come to 
maturity. These splendid ones are most frequent in climates which are rather warm; and there are esculent ones among them, but those which have the gills yellow are always to be suspected. One poisonous species, Anianita Muscaria, so called from its being used to kill flies, serves the rude natives of Siberia instead of an intoxicating liquor. It is simply eaten in substance, and the effects depend on the quantity taken, and also on the nervous system of the person taking it. The following quotation is from Doctor Greville, to whom we are indebted for so much valuable information on the fungi: "So very exciting to the nervous systen, in many individuals, is this fungus, that the effects are often extremely ludicrous. If a person, under its influence, wishes to step over a straw or a small stick, he takes a stride or a jump sufficient to clear the trunk of a tree; a talkative person cannot keep silence or secrets; and one fond of music is perpetually singing." The fungus is swallowed without mastication, it having been ascertained that if that operation is performed upon it, it becomes a poison, even in much smaller quantity than what is required for the species of excitement sought by its use as a luxury. If a very moderate quantity - say the size of a common pea-is swallowed by the hunter when he returns fatigued from the forest, it is said to have the same stimulant and restorative effect as a draught of good ale or a glass of generous wine; but if it is indulged in to excess, the consequences are nearly the same as those which result from excess in these. One large one or two small ones are sufficient to keep up the intoxication for a day; and the effect is 
said to be more pleasant, and less productive of bad consequences, if a copious dranght of water is taken immediately, and thus a singular species of grog made in the stomach of the drunkard. Not the least singular circumstance connected with this intoxicating fungus, is that the liquid discharge consequent upon the taking of it, can renew the intoxication either in the same party or in others; and thus by one man eating a single fungus, a party of five may be kept in a state of inebriety for a whole week. No scientific analysis appears to have been made for the purpose of ascertaining whether the extraordinary properties of this are owing to any peculiar principle which it contains; and the whole history of it would be very questionable if the accounts we have of it did not rest on authority which is above all possibility of question.

Many others of the fungi have most singular properties, and the whole race are well worthy of being carefully studied by every lover of nature and of the wonders of the Creator's works, which are often found in places and substances where we should but little expect them. We liave, however, no room left to enter further into the subject, nor can we do more than merely glance at one or two of the remaining very numerous races, which take part in the labours of the Antumn.

Among these, certain species of spiders hold a conspicnous place; and the labours which they perform are often very curious in themselves, and always very important in their effects-far more so than the minute size of the animals would lead us to suppose. As the winged insects, especially flics of different sorts, are 
seasonal, and always numerous in proportion as the summer is warner than the winter, their numbers require to be thinned toward tile close of the season, because at that period their food begins to diminish. But it is a general law of nature that no class of animals shall habitually be cut off simply by death, without being useful to some other class, by their substance serving for food. Accordingly, when the food of the flies, and consequently their usefulness in the economy of the season, begins to diminish in the Autumn, the spiders make their appearance in greater numbers and variety, and weave their webs in more curious fabrics and with more industry than at any other seasoll. In neglected apartments, and other sheltered places, there are a few all the year round; and so there are in the woods and fields during the whole period of growth; for the spiders are the regulators of the number's of the flies during the season of their usefulness, as well as the instruments of the increased destruction which the Autumn renders necessary; and in erery case, that tribe which is especially set over another for its regulation is at all times prepared for the performance of its work, if such a cliange of the weatler should occur as to render it necessary. 'T'lus, for instance, a few days of Autumnal weather will bring out the Autumnal spiders even during that which under ordinary circumstances is by far the hottest time of the year. If the previous montlis liave been very lot and dry, the Midsummer rains are thereby protracted; the rains, when they come, are more copious; and the evaporation is consequently much more abundant, and the cold 
correspondingly greater. The cold produced by this evaporation often gives such a temperature, immediately after the rains, that the spiders appear in numbers, and are most industriously employed in the construction of their webs, which are nets for the snaring of their prey. But if, as is not unfrequently the case, the weather should again set in hot and dry, the spiders vanish, and do not reappear until the Autumn has considerably advanced.

These remarks do not strictly apply to spiders of all species; for as these animals are required to perform labours of different kinds, in places of varied character, they themselves must be as much diversified, both in their structure and in their liabits, according to that general law by which every production of nature is adapted to its particular purpose, whether we may or may not be sufficiently informed for appreciating the beauty of the adaptation. Accordingly some of the spiders do not spin webs at all, but run along the ground hunting for their prey, some of them by simple speed of foot,- -as is done by the dog genus among carnivorous mammalia and others,-lying in wait and springing upon their prey after the manner of the cats. Many spread their webs upon the ground, or rather on the surface of the matted regetation, with a curious labyrinth, in which the spider remains until the agitation of the web gires notice that a prize has been entangled; and when this is the case the spider hastens to the feast. Some have supposed that the suaring spiders, whether their webs are constructed on the ground or anywhere else, discover their entangled prey 
by the sight. In the case of the spiders in question this cannot be true; because a spider cannot alter the direction of light, so as to see round a corner, as the Irishman's gun is alleged to have altered the law of projectiles in shooting round one; and we have not only the analogy, but the fact in every observed case, to make us conclude, that though the spider does not "live along the line," it certainly does "feel in the thread,"- -that is, every thread of the web ;-in the case for instance, of the Great Garden or Sceptre Spider, Epeira diadema, which posts itself on a central platform, or closer network than the rest. Every radiating thread which goes from this platform to the extremity of the web, not only brings intelligence to the spider of every thing that comes upon the section of the web connected with this thread, but brings intelligence which no other organ could communicate; and the intelligence thus brought is essential to the safety as well as the subsistence of the spider. Those spiders are exceedingly pugnacious; and their mode of hostility consists in the victorious one swathing up the vanquished in a shroud of the same material of which the web is made; which material is indeed the weapon used against all sorts of strong prey-for these spiders fight for food, and not for fame. The heaviest spider contains of course the greatest quantity of this matter, and is at the same time the strongest. The important discovery to be made by the spider is the weight of the one which invades its territory; in order that it may advance to conquest or escape from destruction, according to the information it receives. It also requires, or at all events the line 
communicates to it, the fact as to whether that which is on the web is or is not a spider: this may obviously be done by the invader trying the lines; and this is not a species of information that can be communicated by sight, any more than the fact of the weight. This spider is so very common in gardens in the warmer parts of England, especially those near cities and towns, where garden flies are more abundant than in open places, that any one may study it; and the study is very curious and highly instructive. Countless other phenomena and productions of the Autumn would claim attention, would space permit; but as self-information is by far more valuable and more lasting than lessous given in words, we can only conclude by entreating the reader to go into the fields and see with his own eyes the crowning of the year with the bounty of the Almighty Creator and Preserver.

TIIE END。 



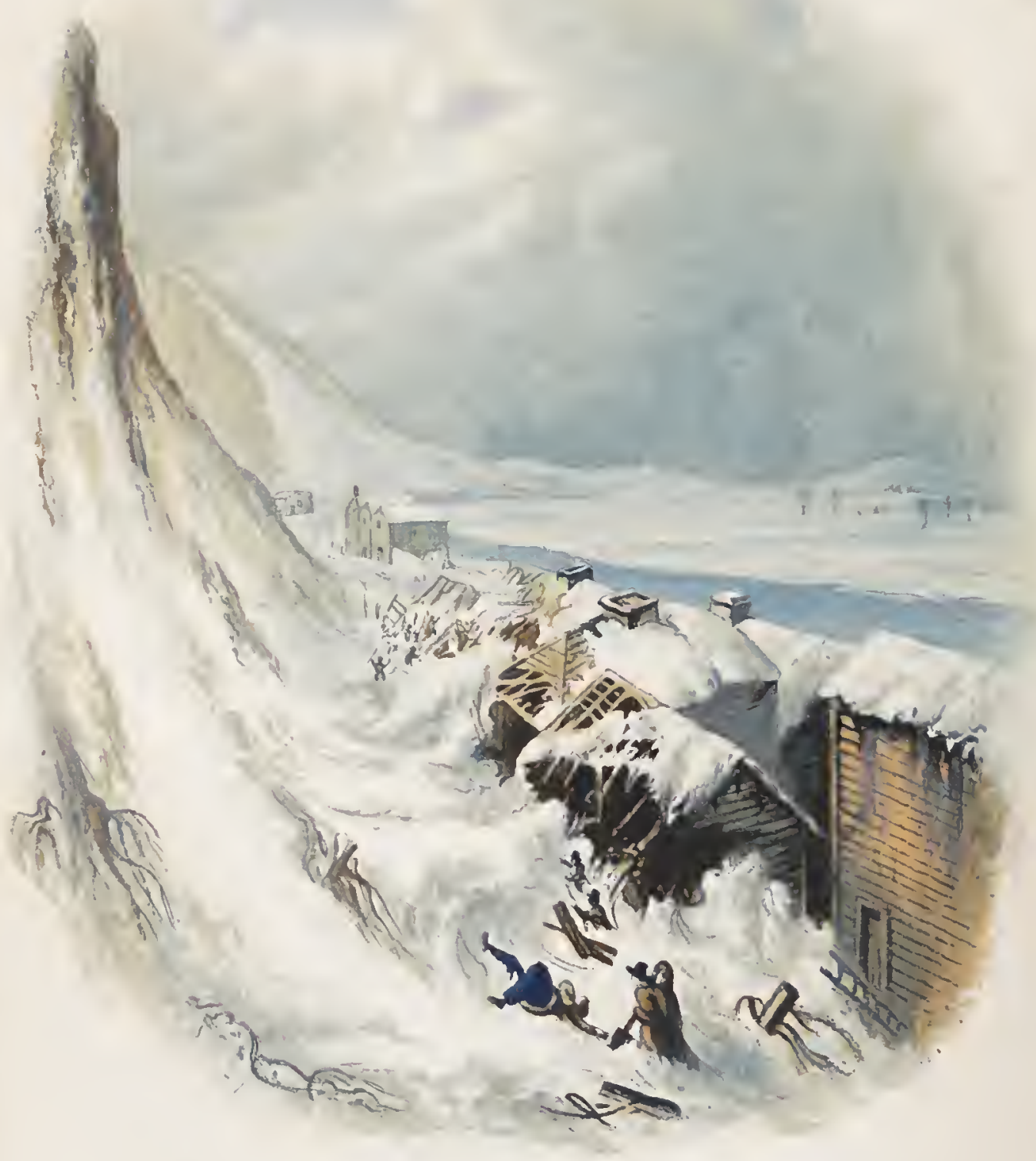

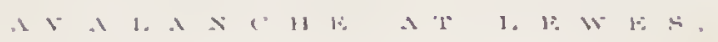




\section{W I N I R.}

B Y

R(IBERT MU])LE.

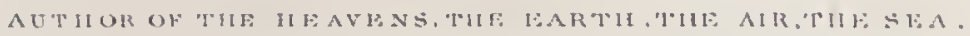

s. sese.

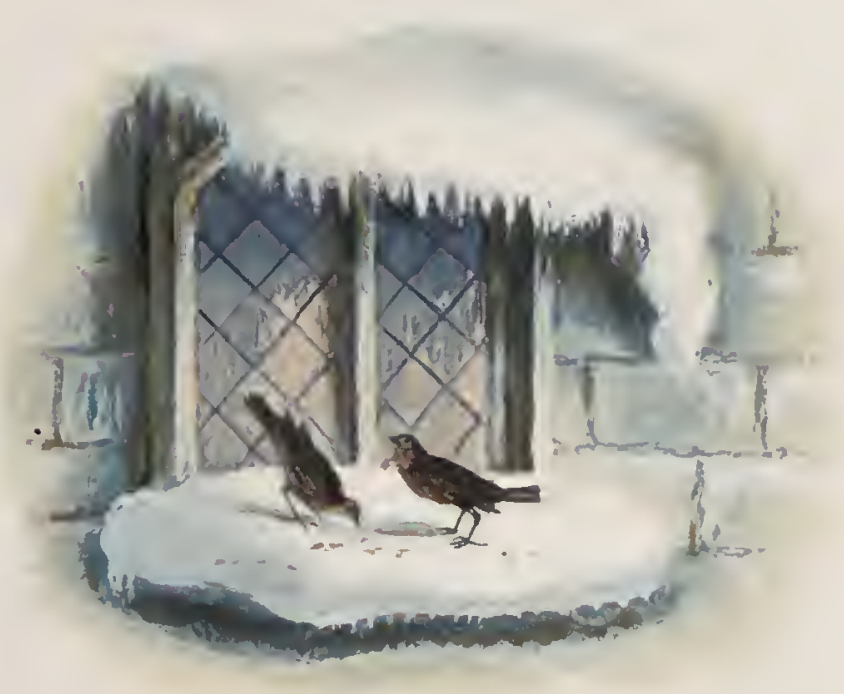

W I N T I I 18 ]3 I $K$ K I .

\section{J.ONDON.}

THOMAS WARD \& CO. PATIBROSTLR ROW.

MI)(COXXVII. 



\section{WINTER;}

OR

TH CA USES, A PPEARA NCES,

A N D EFEC'TS

$O F$

'THE GREA'T SEASONAI, REPOSE

OF NATURE.

BY R. MU D I E,
AUTHOR OF "THE HEAVENS," "THE MARTh," FT".

THIRD THOUSAND.

LONDON :

THO M A W A R \& C O.

27, P'ATERNOSTER ROW. 


\section{LONDON:}

R. CI.AY, PRINTER, BREAD-STREET-IIILL, DORTORS' COMMONS. 


\section{P REF A CE.}

Winter is the season of nature's annual repose,the time when the working structures are reduced to the minimum of their extent, and the energies of growth and life to the minimum of their activity, and when the plrenomena on the earth are fewer, and address themselves less pleasingly to our senses than they do in any other of the three seasons. There is hope in the bud of Spring, pleasure in the bloom of Summer, and enjoyment in the fruit of Autumn; but, if we make onr senses our chief resource, there is something both blank and gloomy in the aspect of Winter.

And, if we were of and for this world alone, there is no doubt that this would be the correct view of the Winter, as compared with the other seasons; and the partial death of the year would point as a most mournful index to the death and final close of our existence. Bnt we are beings otherwise destined and endowed,the world is to us only what the lodge is to the wayfaring man; and while we enjoy its rest, ollr thoughts can be directed back to the past part of onl jollney, and on hopes forward to its end, when we shall reach 
our proper home, and dwell there securely and for ever. This is our sure consolation-the anchor of lrope to our minds, during all storms, whether they be of physical nature or of social adversity; and let the one or the other be ever so dark and gloomy, this lope can limn them with hues of the most enchanting delight; and in the very depth of the Winter, we can command the spring, the summer, and all the gay seasons of the times and the lands of the sun, to stand mustered before us in full array, and clothed in variety and beauty, which never could by possibility fall on the retina of the eye of some, though we were to ransack the world for its clsosen landscape, and tax the year for the very hey-day of its perfection. We can do this, and we can do it when the Winter night is moonless, starless, and dark as a pit dug to the earth's very centre where sunbeam never came, and when all the angry voices of the Winter are howling and thundering around us, with far more certainty and mental satisfaction than we could do, if laid on the most flowery bank, in the sweetest day in which summer ever beamed on the earth.

We are beings of sensation, certainly; many and exquisite are the pleasures which we are fitted for enjoying in this way, and much ought we to be grateful for their capacity of giving pleasure, and our capacity of receiving it; for this refined pleasure of the senses is special and peculiar to us out of all the countless variety of living creatures which tenant the earth around us. They eat, they drink, they sleep, they secure the succession of their race, and they die; but not one of 
them has a secondary pleasure of sense beyond the accomplishment of these very humble ends. We stand far higher in the mere gratifications of sense; and in the mental ones there is no comparison, as the other creatures have not an atom of the element to bring to the estimate.

The Winter is, therefore, the especial season of man - our own season, by way of eminence; and men who have no Winter in the year of the region in which they are placed, never of themselves display those traits of mental development which are the true characteristics of rational man, as contrasted with the irrational part of the living creation. It is true that there must be the contrast of a summer, in order to give this Winter its proper effect; but still, the Winter is the intellectual season of the year,-the season during which the intellectual and immortal spirit in man enables him most trimphantly to display his superiority over "the beasts that perish."

Such are the feelings with regard to the Winter season, under which the following pages were composed; but whether the execution does or does not come up to this feeling, is a matter to be determined by the reader, not by the author.

In order that this volume might be somewhat in accordance with the character of the season after which it is named, I have endeavoured to make it more reflective than the former ones of the series. But the matter of it does not easily admit of prefatory analysis, and therefore I must refer to the Table of Contents, and especially to the book itself, which, if it should be found

$$
\text { A } 3
$$


to have no other recommendation, is at least original, and different from any which lias been previously written on the subject, numerous as these are, and valuable as are some of them.

There are two points of difference between the volumes both of this series and the former one, and most books upon similar subjects, to which it may be as well to call the attention of the reader, lest that which has been done purposely, and in the belief that it is an improvement, should be regarded as oversight and imperfection.

In the first place, every thing like system has been avoided with the utmost solicitude; and thus, the transitions from the earth to the air or the sun, from one part of the earth to another of the very opposite character, from plant to animal, from sea to land, from natural appearance to moral reflection, and from nature to the Author of nature, may seem abrupt, and without any obvious connexion. 'That they have none of the apparent regularity of the systems of the schools, I will admit; but then, the regularity of these is only in the artificial parts of the systems, and not in the nature of the subjects which they embrace; so that, if a student were to go forth to any locality, be that locality what it might, he would not be able to trace a correspondcnce with the system there, but would find himself in a state of constant transition from one part of the artificial system to another, if he followed the succession of subjects as he met with them in rature.

Now if the observation of nature is to be pleasant, and to operate profitably in teaching us to take heed of every thing, which is clearly the grand prastical use 
of it, we must not go forth in quest of a genus, an order, or a class, we must be equally prepared to understand and enjoy all that we meet with, in the order in which we may happen to meet them; and over that order we ourselves liave no control. This is the system of nature which presents itself to our observation; and though, as compared with the artificial systems of the learned on these subjects, it appears to be no system at all, yet it is the only natural one. There is always a natural reason wlyy any production or appearance is met with in one place and at one time rather than another; this reason should be one of the main objects of our observation; and it is one upon which, from the mode of their arrangement, the natural systems can afford us very little assistance. These systems all have reference to the productions of nature as if they were dead subjects, which we could place in any juxta-position which suited our fancy; and what we meet with is living and active nature, of which all the parts and all their changes liave adequate causes, which tie them down to place and to time.

'The other part refers to the natural theology; and in this I have endeavoured to avoid what appear to me to be the chief errors of those who have treated of the subject,-namely, that comparison of the working of God with the working of man, by means of which it has been attempted to heighten our admiration of the former; and that comparison of the instincts of animals with human reason, by injudicious allusions to which, our belief in the immortality, and even the existence of the nind, is apt to be shaken. 
It was my original intention to follow up the four volnmes on the Heavens, Earth, Air, and Sea, and these four on the Seasons, by other four on the Natural History of Man, as a physical, intellectual, moral, and social being; but as a series of books may be too long, as Man stands in many respects insulated from the rest of nature, and as the work which I intend to publish respecting him must necessarily be of a different character from this and its precursors, I liave, on mature reflection, deemed it better that it should appear in another shape, and thus be a distinct work in form as well as in substance.

\section{ROBERT MUDIE.}

Grove Cottage, Chelsea, November, 1837. 


\section{ANALYSIS OF 'THE CONTEN'IS.}

\section{CHAPTER I.}

GENERAL OBSERVATIONS.

Winter of the year, of the day, and of life... Revivals and resurreetions... State of Winter... Imperfeetions of the deseriptions of Winter... Idols and mytlologics, and their infuenee upon our conceptions of uature... Rational view of the year..............p. 1-33

\section{CHAPTER II.}

SOME NOTIONS AND CHARACTERS OF WINTER.

Different Winters... The scasons work for good, and follow cael other harmoniously...All nature works liarmoniously, in an existence and in suecession...Safety of life in Winter...Seeds and eggs... Early parts which bring rain...Signs of Winter rains...Tranquil sky preceding Winter... Immortal hope, and dread of annililation ...Morning and evening...Night visions...The sleepless miscr... Vanity of woridly consolations... Various adaptations... Philosophieal argument for immortality...Substanee and state...Substanee and life...Pauses and renewals in nature... Necessity of repose...Sleeplcss night...Phantasma... Placidity of Winter .............pp. 34-99

\section{CHAPTER III.}

COMING OF WINTER.

Coming of the tropieal Winter...Blighting winds... Drying and watering of the soil...Loealities of tropical Winter... Vegetation there... Coming of the Polar Winter... Regions of greatest eold and lieat... 
Places of the maxima of the two Winters... Varlatlons in the coming of Winter... Elcments of tempcrature... Winter on mountains... Modifications by latitude...Hasty Winters...Repose of the Polar Winter...Effects of culture on the seasons .................pp. 99-139

\section{CHAPTER IV.}

PREPARATIONS OF NATURE FOR TINTER.

Erroneous views and false conclusions on this "subjcct... Means of avoiding such...Preparation of nature and the season mutual... Various adaptations to Winter...Gcological reasonings as to the cliange of scasons...The race of the Mammoth...Permanence of relative tcmperature... Preparations for the cold winter... Retention of heat in cold climates... Nature's preparations on all for activity ...Study of nature contrasted with worldly pursuits ... Close of worldly, life ... Preparation for the Winter of life... The trade of Wisdom...Contcmplation of the universe... Immensity... Eternity... Physical proof of a Creator... Mental occupation... MIental abstraction ... Remarkable case of mental absence combined with great talents... Winter the proper season for abstract study...pp. 140-185

\section{CHAPTER V.}

PREPARATION OF VEGETARLES FOR WINTER.

Vegetables not passive to the seasons... They have a part in the seasonal changes...They maintain their spccific characters...They obey their own laws... Thcy accumulate stores in the autumn to support their vigour in the spring... Winter bulbs producing spring flowers... Instances in conciferæ... Particulars of the cabbage tribe... The Winter store of some is in the leaves; in others in the stem; in others in the roots; and in some in tle flowcr buds... Distinctions of bulbs seated above and below tlie collet... All deciduous trees and shrubs accumulate stores... Habits of roots... Effects of different soils upon thenı... Roads upon differcnt soils...Adaptation of roots 
to climatc...The Epiphyla... The Taccina...Yam... Hottentot's bread...Thick-leaved plants... Adaptation of tubers and thick leaves to the dry Winter of the tropieal countries... Polar adaptations... Contrast of the dry Winter and the humid... Winter drought necessary for bulbs... Plants adapted to the polar Winter...Lichens... Mosses... Some particulars of the mosses...Peat bogs, their formation and effects... Epoch of the mosses... Effects of bogs on trecs... Substrata of bogs... Polar mosses... Causes which retard Winter...

1). $186-233$

\section{CHAPTER VI.}

PREPARATION OF ANIMALS FOR WINTER.

Animals in Winter... Provisions of allimals for sccuring their race in its succession... Very remarkable in insects, espceially annual ones ...Spring labours of some solitary female insects... Places of deposit for insect eggs... Animals have no forethought purpose; they do not know what they are doing, even in those cases in which they appear to display the greatest skill... Consequences of admitting the eontrary... Animals are not their own adapters, hence thcy ncver err...Fertility of the sea in Winter...Cuntrast of land and sea at this season...Phenomena of water in freezing... Greatest density of water... Motions of water which precede the formation of ice... Effects of frost on rocks... Winter decompositions...Progress of ice in its formation... Winter birds by the sea... Migratory movements of birds, and their impulses... Mammalia in Winter .....pp. 234-265

\section{CONCLUSION.}

The "Book of the Seasons" needs not be, and cannot be written by a mortal hand...It is written...It is universal...It is readable by men of every tongue... We cannot go where it is not... Alexander and Diogenes... Danger of false study... Final consolation of the rich... Of the ambitious...Possession and enjoyment... The proper study of nature...Succession of revolving years.........pp. 266-276 


\section{ILLUSTRATIONS.}

THE Frontispiece represents, from a drawing mate upon the spot at the time, the Avalanche, or slipping of the snow at Lewes, in the Winter of 1836 , an occurrence which is rare in this country; and which is much more frequent in the mountainous parts of warm countries than in cold ones, as the heat of the earth softcns the under part of the snow, and makes it slide. After heavy falls of snow the small avalanches from the roofs happen sooner in houses in which there are fires than in empty ones.-The Vignettc represents a Cottage Window and some Birks. 


\section{W I N T E R.}

\section{CHAPTER I.}

GENERAL OBSERVATIONS.

No portion of the year has been more londly declaimed against - we may say, calumniated, - - than the Winter. It must be admitted that it is the opposite of summer, the contrast of repose to activity, in so far as the vegetable world, and many of the smaller kinds of animal life are concerned. But alternations of activity and repose are essential to the healthy condition of the whole of growing and living nature, whether animal or vegetable; and in the case of many animals-indeed of the most of them-the alternations are far more frequent than those which, in the whole of nature, correspond with the different positions of the earth's surface to the sun in its annual course around that luminary.

Besides the summer and the winter of life, which, in the ordinary course of nature, fall to the lot of every individual of the human race who is spared to enjoy or 
to suffer, as it may be, the customary term, which is, in the end, closed by decay, and not by disease;- - besides this, man has really a summer and a Winter, and indeed a brief, but not inappropriate or uninstructive epitome or type of all the seasons of the year, in the lapse of every day of life, every rotation of the earth upon its axis.

In the whole of nature, indeed, the day is beautifully emblematical of the year; and they who have discernment call, between any one sunrise and the next succeeding one, bring all the seasons under their review, and thus have a type or monitor of the year in every day of their lives.

Very little reflection may suffice to show us that such must be the case. The system of nature is onethe workmanship of one Creator, and the obeying of one fundamental law; and, therefore, throughout the whole of it, similar causes must produce similar effects. Now the seasons of the year are the result of one revohution-that of the earth round the sun, in the course of three hundred and sixty-five days and a fraction, at an average distance of ninety-five millions of miles from the centre of revolution; and the times or tides of the day, at any place on the earth's surface, or at any season of the year, are also the result of a revolution-that of the particular place, through the circumference of the parallel npon which it is situated, in the course of twenty-four hours, as measured by the sun. If the place be immediately under the equator, its distance from the axis of rotation is about four thousand miles, and the portion of space through which it is 
carried in the course of the twenty-four hours, is about five and twenty thousand miles; and, according as the place is distant from the equator, its distance from the axis of rotation diminishes (as the co-sine of the latitude); and the space through which it travels in the twentyfour hours diminishes in the same proportion, till the pole, or extremity of the axis, is arrived at; and there it is the mere turning round of a point, which, as it occupies twenty-four hours, the same as the twenty-five thousand miles under the equator, could not be discerned, even if we were to suppose a hmman being insulated in the air, so as to notice the whole diurnal rotation of the earth.

In the effects which result from each of these, there is a gradual succession; and though there are not, in the revolution of the year, except in those climates where the sun is absent or present for days or weeks, any phenomena so marked as the rising and setting of the sun at the beginuing and end of the solar day, yet there is the same gradation of temperature, if not of light, in both. In the soft tints and freshness of the morning, we have a most appropriate type of the spring, which advances into summer as the day advances; and as the greatest heat of the year, under average circumstances, is after midsummer, so the greatest heat of the day is, under ordinary circumstances, after mid-day, and longer after it in proportion as the whole day of the sun's presence is longer. Then the evening is beautifully emblematical of the autumn, even in the richness of its colours, told upon both the earth and the sky, as compared with the morning. 
In this daily revolution, there comes a successions of changes upon all that grows or lives, similar to what takes place in the course of the year, but much more conspicuous in animated nature than in the vegetable kingdom. In both, however, it is sufficiently conspicuous to attract the attention of even a careless observer, though in both kingdoms some species are more diurnal and others more nocturnal in their activity. Mankind, as being naturally diurnal, liave most lively perceptions of the first of these; and if this general law of nature is violated, the violators are sure to pay the penalty, both in body and mind. They who, from dissipation, the habits of fashionable life, indolence, or even from causes which are justifiable in their objects, turn a portion of the natural night into day, and a corresponding portion of the day into night, always impair and derange the system of their bodies; which derangement is, as matter of course, accompanied by incapacity for thought, and a fevered state of the feelings, over which the natural reason, and every species of restraint both religious and moral, lose their proper influence; so that, without taking any actual depravity or impurity of motive or pursuit into the account, persons who deviate from this very simple but very essential law of nature, invariably lower themselves both in the physical and in the intellectual scale, and in so far hide their talents in the dust.

On the other hand, those who time the occupations of the twenty-four hours to those portions which nature obviously points out, never fail of enjoying the advantage, even though they may not aim at that advantage, 
or even be aware of the possession of it. The sinewed frame, the bounding step, the hand without tremor, the keen eye, and every sense on the alert for its appropriate enjoyment, are the certain rewards of adjusting the hours of labour and of rest to those periods of the day which nature has obviously intended for the purpose.

There is one coincidence between what may be called the seasons of the day and the seasons of the year, which is not a little remarkable. In the cold and the temperate latitudes, the Winter, both of the day and the year, is occasioned by the absence or the diminished action of the solar beams; and in both cases the maximum of cold is, in consequence of physical causes requiring time to produce their effects, thrown later than the time of the sun's greatest absence, - after the Winter solstice in the case of the year, and after midnight in the case of the day. In tropical climates, again, there is a double Winter of the day; one arising from the absence of the sun, uniform in its character all the year round in proportion as the place is near to the equator; but there is another one which resembles the Winter of the dry season in the same latitudes. A little after mid-day, towards that hour when the solar heat produces its greatest effect, the people are overcome by it, obliged to remain within their houses; and they spend this portion of time, which is unbearable for any purpose of activity, in a siesta or mici-day sleep, from which they rise refreshed, and pursue their labours until the night is far adranced.

In the warm season, the necessity of this is felt in Spain, and in several other parts of the South of Europe; 
but during the Winter season it ceases to be necessary. In like manner, it ceases to be necessary in trepical countries during the period of the rains, at what times soever these rains occur; and in some places on the sea coast it is rendered unnecessary by the refreshing breezes which set in from the sea, as soon as the land becomes sufficiently heated for causing a continual ascent of the air from its surface. But in countries which are flat and inland, so that there is nothing to cause a circulation of the heated atmosphere, two or three o'clock comes every day upon the people, with all the withering and enervating influence of a burning Winter. In the cities of South America, eastward of the Andes, the effects of this are probably more striking than in any other part of the world; and if one passes along the streets during those sultry hours which are devoted to the siesta, one finds the same stilly repose which might be supposed to reign in a city over which the destroying angel had just passed, setting the seal of death upon every living thing. Man and beast are equally affected, and there is nowhere either a sound or a sign of life. The doors and windows of the houses are open, and the people with their household animals are stretched prone on the floors, all in the quietude of sleep-sleep much more general, and probably also much more profound, than is to be met with in temperate climates during the silence of the night.

This continues for a few hours, until the heat abates; and then the people come abroad to occupy and to enjoy the creming with the same renewal of freshness 
and vigour, as early risers in temperate climates enjoy the morning. Under such circumstances, though there is a diminution of the length of the active day, from its being only upon the average equal to our equinoctial days, or only twelve hours of sunshinc, and the warm night, or time of the siesta, occurring in the middle of it; yet the people have the advantage of two morning freshmesses in the course of it; and as merc length of time is only one element of activity, and energy the other,-each of which may be diminished without any lessening of the efiective result, if the other is increased in the same proportion, - the high temperature of tropical climates is by no means so unfavourable to liuman exertion as a superficial view of the matter would lead us to believe. In all climates, indeed, there are wonderful compensations, which clearly prove that man is a universal inhabitant of the earth, and the only inhabitant of it which can be said truly to possess this character.

This universality is as true in respect of times of the day and seasons of the year, as it is of local position upon the surface of the earth; and though the enjoyments of human beings vary, and indeed must vary, with all those variations both of time and of place, it is difficult to say which is calculated to afford the highest degree of pleasurable enjoyment, or which presents the widest and the most gratifying field of contemplation to the well-informed mind. It is true that the circumstances of locality, and even those of season-though perhaps in a much lower degree-modify the general character of the inhabitants of dificent regions; but 
still the enlightened mind, imbued with true love of the knowledge of nature, and of nature's God, never finds a desert in any place, or desolation at any season. From the equator to the highest latitude which can be trodden by human foot, and from the ardour of summer to the extreme depth of Winter, even where it falls most heavily upon living and growing nature, there is always enough for instruction and for gratification; and we have evidence, in some of the accounts of recent royages and journeys to the extreme north of the American continent, that those regions, though very different in their character, are not less redolent of instruction and pleasure than the most sumny lands on the surface of onr planet.

But thougl such be the fact in nature, and such the evidence placed upon record by those who take nature honestly for their guide, yet we find, in very many of the accounts, and more especially in those which purport to be drawn up expressly for popular reading, a very different delineation of the state of things, with regard both to places and to seasons.

This arises from narrow and partial views,-from taking the agreeable of one place or one season, and the disagreeable of another, instead of fairly balancing all the elements of each. Thus, in the case of Winter, if we examine the accounts which are given of this season, even by those who are understood to view it with the most philosophic eyes, we find in them little else than an accumulation of horror upon horror, and rnin upon rnin; as if one part of the year were brought about expressly and for no other purpose than that of 
spoiling the beauty and destroying the productions of the other parts! Congregating clouds, rolled volume upon volume and mass upon mass, till the sun is hidden, and the darkness of twilight broods over the earth for the live-long day; torrents of rain, in consequence of which the erewhile placidly gurgling brooks of the summer become torrent floods, sweeping their banks with destruction, and converting the meadows into lakes and seas; whelming snows, flung heaps upon heaps by the angry winds, crushing the forests under their load, smothering the flocks upon the mountain, and suffocating the weary and benighted traveller upon the heath; intense frosts, under the influence of which the waters congeal into crystal, the earth rings like iron, the mountain peaks are rent into fragments, and the powers of vegetation are suspended, wlile the wild beast cowers in the fastness of its den, the bird closes its weary wing under the thicket, and man has to put all the resources of warm habitations, increased clothing, and artificial fires, into exercise, so that he may preserve the shivering and palsied life till the return of the sun and the spring; - these, these are the colours in which even the masters of seasonal description limn this portion of the three-score-and-tenth part of the human span: and, were we to rest satisfied with such descriptions, splendid as they are in themselves, they would lead us to the dismal conclusion, that every day of our lives dawns to hope and closes in misery.

Now the effect of those gloom-inspiring descriptions is far worse than if they were merely idle words; for 
however powerful or pathetic those delineations of the horrors of Winter may be, and how much soever the marvel-loving mind may gloat over them, as it does over the senseless pages of an unnatural tale of fiction, such as we see issuing from the press in almost daily succession and ephemeral life, for speeding the way of the idle and the dissipated,--Surgit amare aliquid; there is some moral bitter which bubbles up with the "dribble," and nauseates the cup to the pure, or poisons it to the tainted. It is not in our nature to lose sight of the ana$\log y$ which there is between the seasons of the year and the corresponding periods of man's ordinary sojourn upon earth. We cannot help applying those analogies to our own individual case; and thus, if we are tanght to contemplate, in the Winter of the year, nothing but those horrors and desolations which are the most prominent characteristics of it in the regions where it is most decided and striking, we can with difficulty refrain from regarding that season of our life which brings us to the tomb, and which should gradually prepare us for it in a better spirit, with any thing but the most gloomy despondency or the most hopeiess and bitter despair.

But the Winter of life is that period of it during which very many of the human race stand especially in need of consolation from every subject with which an analogy can be traced. Under many circumstances, the consolations of religion are capable of supporting the mind amid the suffering of the body; but there are cases in which the agony of the flesh is hard to be borne. The body will not quit this sublnnary world, which has been the scene of all its enjoyments, without pangs which 
none can feel but they who are actually under the operation of them. Be the lines of life what and where they may, there is bodily enjoyment, not only in those blithe years which precede the cares of the world, but also as long as hope in the world continues to gild the black and roughened story of to-day, with that radiance of anticipated prosperity and joy which comes to smooth our nightly pillow up to a very late period of life. This is the real sweetener of life; and but for this, the rubs and disappointments of life could not be borne for one single short day, even in the case of that man whose neighbours envy him the most for the success of his schemes, and the fulness of his enjoyments. Up to a certain period-and, with the majority of human beings, this period is very near to that of final dissolution-this hope in the world can bear us up under the pressure of very great misery, far greater than can be borne by those who impiously rush into the presence of the Almighty, stained with the blood of self-murder. Persons who give way in this cowardly and criminal manner, are of weak minds-that is, the connexion between the mind and the body is easily deranged. Compared with those who are so nerved as that they can bear it out, they are what cast-iron is compared to mialleable iron,-they break under the hammer; and they do so just because they have not previously been hammered enough. The world has been too easy to them; and so when even a little hardship does come, the connexion between the senses and powers of action and the reasoning faculty is suspended, and they are no more for this world. 
But waiving these, there is a something in the sensal part of the human body which is unwilling to die, and so starts back in horror at the very thought of the last triumpli of physical circumstances over us. The eye has seen so much beauty, that it is unwilling to be closed; the ear has heard so much melody, that it too would linger a little space before passing into the region of unbroken and unbreakable silence. It is the same with the other senses that have local organs, and also with that general "sensation of life," which is probably the head of union among the rest, by means of which they sympathize so readily with each other. Our faitl in the immortality of the soul and the resurrection of the body may be ever so strong, and, mentally, we may "long to depart;" but still, there is a strife of nature against the thought, that this frame of ours, which lias been so active and so full of enjoyment since the very first dawn of consciousness, should mingle in darkness and concealment with the common mass of matter, through the countless years and ages which may pass away, before "the trumpet shall sound, and the dead shall be raised."

It is only by means of experience that we can meet any of the physical contingencies of life; and as we can have no direct experience of this death of mortal hope, or hope in the present life, it becomes our duty to fortify ourselves by all the indirect means to which we have access; and as this must be done before we have the stimulus of necessity-for after that it comes all too late-we must employ the means, while ignorant of the effect which those means are ultimately to produce. 
Now, in this, as in all other matters, we find that the bountiful Author of our being has not left himself without a witness, our weakness without a support, or on ignorance without a guide; and as this may be reckoned the extreme of helplessness in our mortal state, the support and the guidance are given equally to the mental and the bodily part of our compound nature. Revelation sustains the mind by the assured hope of that immortality upon which it is to enter, the moment that it is separated from the body; and the hope of the body is sustained by the knowledge that there are other worlds in the creation, and that therefore, when the years of our earth in its present condition are numbered, the gracious promise that, in the fuhness of God's appointed time, we shall be called from the long slumber of the tomb, to inhabit a new world, wherein shall dwell righteousness, is in perfect accordance with the economy of the grand system of nature, as we have beheld it with our own eyes.

The ordinary course of nature is, indeed, full of resurrections, which are so general-so universal, we may say-in every thing upon which we can bring our minds to bear, that to decry or to doubt that we also shall partake of this renovation and return which we find to be common to all nature, is impossible.

It is true that we do not, and from the nature of the case it is obvious that we cannot, witness the resurrection of any one individual body, or member, of the great family of crcation. There is one stage of the progress from first to second being or life, in which the matter of the being is utterly beyond the reach and ken of 
any, or of all, of our senses. This is true to the analogy; and, indeed, a very little reflection may suffice to convince us that it could not be otherwise, without a total change of the laws and economy of nature. In ourselves, the stroke of death puts an end to all sensation of every kind; and very often, before the vital system has ceased to act, and "the pitcher is broken at the fountain, and the wheel at the cistern," as it is figuratively but beautifully expressed, "the lookers out at the windows are darkened" - all sense and perception are at a final end. This is a most merciful provision, and the mercy of it always extends to the full measure in which it is required by the particular state and case of the individual; so that, by means of it, the fearful struggle which the strong man makes at parting, how painful soever it may be to the sorrowing friends around his couch, is not one jot more felt by him, than lie felt the pressure of his body on the same couch, while in the balmy sleep of perfect health.

The knowledge of our own bodies is certainly the first knowledge which we acquire on our coming into the world; and, for this very reason, it must be the last which remains with us when we go out of the world. It is not meant to be alleged that this first and most elementary portion of our knowledge extends to the form, or the size, and much less to the structure of our bodies. These are matters of secondary knowledge, obtained in the very same way, or at least by the very same sort of process, as any part of external nature. With regard to the anatomical structure of the bodythe parts of which it is composed, and the functions 
and uses of those parts, - there is probably not more than one in a hundred thousand of the whole human race that has any knowledge at all; and what is known by the best informed, is small indeed in comparison with that of which they are utterly ignorant.

If one notices the continual motion of the limbs of an infant, especially of the hands and fingers, one can easily see what practice it must have before it can ascertain the length of its arm, or even of its finger; and then, when the eye begins to notice, and the muscular measure is attempted to be used in concert with the optical one, a thousand unsuccessful attempts are made before the most conspicuous object of sight can be touched. The distance of the object is a matter of little moment, so that its optical attraction is strong enough; for the infant's hands are stretched out as readily to grasp the bright lamp in the middle of the room, or even the moon in the sky, as they are to get hold of an object within arm's-length. All these prove, beyond any doubt, that the measuring of lineal distance, which is perhaps the simplest step in our knowledge of external nature, is not a sensal perception, but a mental inference from former experience.

There is one point here which is well worthy of our attention,- - the fact that, after the infant can at all use its hands and arms, it never misses the way to its month; and this shows clearly how beautifully the deductions of experience adapt themselves to our necessities, even in the most helpless state of our nonage.

We cannot follow this train of argument up to its 
source, but probably there is a feeling of life in the first pulse of the embryo, long before the form of its body is completely developed; and, as this is inseparable from life at the opening, so it is the last to cease at the close. But it has nothing to do with the growth of the body, or with its decomposition after death; for both of these are purely physical matters, of which there can be no sensal perception in the subject in which they occur.

This close resemblance which there is between the very beginning and the very end, makes it necessary that we should consider them jointly; it being impossible to understand the one without a knowledge of the other. Nor must it be supposed that this inquiry is foreign to the philosophy of Winter, as one of the marked periods of the revolving year, widely as it may differ from what is usually said or written upon the subject. Winter is not a stage in the progress of seasonal action, during which any specific function, either of vegetable or of animal nature, is performed. It is really an ending and a beginning, with a pause between, of longer or shorter duration, according to the latitude and other climatal causes, and also the habits of the particular vegetable. In the case of some plants, which are quiet or stationary during summer according to the calendar, it is the season of growth; and in such plants-as, for instance, many of the mosses and the seaweeds-it is the natural summer; for the summer of a plant is the time of its growth, and the multiplication or continuation of its species, at whatever time of the calendarial year it may take place.

'The proper' function of Winter,-if the term function 
ean be applied to that which is negative, and depends upon the withdrawal or abatement of stimuli, and not on their development or increase,-is the subsidence of that which has come into leaf in the spring, flower in the summer, and matured seed in the autumn, into a state of repose, from which it shall again be awakened, to rum anew the annual course, when the stimuli of the following year are applied to it with the requisite degree of intensity.

The state of Winter, which may not unappropriately be called the repose of nature, is that which lies between the ending of the action of one year, and the beginning of that of the next. No definite length, as already hinted, can be assigned to this pause between action and action, or state of Winter repose. It may be so brief and momentary, that no note of it can be taken, even by the most delicate measurers of the lapse of time; it may extend to days, or weeks, or months: and, in the case of very many seeds, and some plants, it is protracted by nature, or may be protracted by art, to several years-to an unlimited number, in the case of seeds which are protected from the action of every cause, both of germination and decomposition. Nor are instances wanting, in which, at the very same instant of time, it may be Winter in one part of a plant, autumn in another, spring in a third, and summer in a fourth. Thus it is quite impossible to give a general description of the Winter state, as connected with the revolution of the earth in its orbit, or with the earth's surface, the atmosphere, or the weather, as they are found on the average of years at the particnlar place referred. 
to-be the geograplical situation of that place upon the earth what it may; and this is, in all probability, the reason why we have no general account of the wintering of nature, which can be considered as philosophical, and reaching the principles of the season and the use of it in the economy of nature. Instead of this, we have descriptions of particular scenes and phenomena, of which, as has been hinted, the terrific ones alway get the preference, - on account, no doubt, of the more striking contrast which they form with the summer, and the wider scope which they afford for lofty and imposing declamation. These may be, and they generally are, very impressive, nor are they by any means barren of instruction; but they do not furmisl the kind of instruction which is most desirable, as liaving a connexion in general knowledge, and a use in an intellectual and moral point of view. They do not form steps in that ladder by which we ascend from nature to nature's God; for this must be done by studying the harmonies of nature, and not the contrast, - the unity, and not the division.

A clear and correct perception of this unity is, perhaps', the greatest benefit which the study of physical nature has derived from revelation; and next to the bringing of life and immortality to light, it is probahly the most general and important blessing which the gospel has bestowed upon the human race. It is also the most pleasing, and perchance the most powerful inducement, which we have to the love and the knowledge of divine truth.

It is also a perception which they who mudertake 
the commendable office of schooling us, should be especially upon their guard against weakening, inasmuch as there is in the observation and study of nature, pursued upon purely human grounds, a tendency to break down this union of nature, and to substitute for the God of nature a pantlieon of imaginary divinities, all of them partial and limited in that part of the system which fancy assigns to them; and thus they are not gods, but men, exaggerated in a fanciful and unnatural manner, according to the characters of the notions by which they are contrived.

Observation, in so far as it can be depended upon in a matter to which the application of it is so difficult, does, indeed, lead us to conclude that the very first glimmering which men have beyond the province of the senses, is that of one invisible and incomprehensible governing power. But, as soon as this exceeds the merest glimmering, it becomes a fertile principle, which produces superstition, if there is no light of revelation to guide it to the truth. It leads the mind to the phenomena and the productions of nature, the causes of which become subjects of anxious desire: and this, thongh the speculations concerning these vary with the physical condition of the country, so as to make some of these false systems monstrous, while others are only absurd. But, whether it be

\footnotetext{
"Moloch, horrid king, besmeared with blood Of infant sacrifice ;"
}

the car of Mahadeo, to crush the self-devoted victims under its wheels; or, more horrid still, the war-god of 
the Mexicans, upon whose loathsome altars the daily victims were immolated; - whether it be the gods of the ancient Egyptians, including monkeys and mice, reptiles and vegetables, in the motley group; the personifications by the classical Greeks, whose gods are stained with every vice and crime that can degrade human nature; mad Ambition, overtopping all in the number of its victims; Mammon, first-born of the horseleech, and far more insatiable than the fire or the grave; or any other of the Christian idols-the idols of those who call themselves Christians:- the origin and principle are the same, whatever difference there may be in the modifications.

Such are the results in respect of the general system and phenomena of nature, or rather the mass of detached and contradictory parts of which it is represented as being made up. But this is not the part which applies to that breach of the unity of nature which, we have said, giving the description of Winter in its horrors and its desolation only, and leaving out, or casting into the shade, its use in the economy of the year, is calculated both to produce and to perpetnate. In all conditions of human life, that which affects man himself comes lome to him with more lively interest than that which he sees in the rest of nature around him. The events of the external world, if they are not altogether indifferent-as every thing is which is either unknown or unheeded-have, at the most, only a secondary effect, the result of a chain of reasoning, longer or shorter according as our minds are more or less cultivated; but whatever affects 11 personally, tells at 
oncc upon the feelings, and takes the catcgory of good or of evil, according as the impression which it las is pleasurable or painful. 'This, being more connected with our merely animal nature, precedes that inquiry into the causes of external events which is the original source of polytheism; and, as it is not necessarily connected with any one particular modification of that, it is more generally distributed, and more inveterate in its continuance. Hence, we find a principle of good, and an opposite principle of evil, with a being, as the source and the governor of each, in mally nations, of the rest of whose mythology, if they have any, we find no account on record.

The transfer of this into the system of naturc around us, is a very likely consequence, if it be not a necessary and unavoidable one; and we accordingly find that the opposite parts of the year, if these happen to contrast strongly with each other, arc embodied in the mythological representation of this natural good and cvil. Nor is it unworthy of remark, that the drought or the cold is the evil, according as the one or the other is the season of umproductiveness.

Egypt is a country in which, from physical circumstances, the seasons are very strongly marked; and thcre is every reason to believe, that the mythology of the ancient Egyptians was of native origin, and not imported from any other country. Now, in so far as that system bore upon good and evil, as connected with the alternating parts of the year, Isis, Osiris, and Anubis werc the good gods; and Typhon, as opposed to them, was the malevolent one. There were many 
other's; and, as has been the case in all countries which have had inferior gods, or heroes, or saints, to whom religious homage has been paid, they multiplied greatly in the course of time; but the four which have been named were the chief, if not the only ones which had particular dominion over the causes of fertility and barrenness in the different seasons of the year.

And this portion of the Egyptian mythology was merely a figurative embodiment of the natural causes which are peculiarly conspicuous in the valley of Egypt. The sun and the rain have much less apparent influence in bringing the fruits of the earth to maturity than they have in most other countries. The annual overflowing of the Nile, and the new soil brought down and deposited by that periodical flood, are the obrious causes of growth; and the thirsty deserts on either side, by constantly draining off the moisture, so that the air is kept comparatively dry, notwithstanding the great evaporation, is the principal means by which the sterile season is brought about. $U_{p}$ to a certain stage, this abstraction of the humid air is highly favourable to vegetation; so that, with skilful culture, the crops of Egypt are excellent in quality, abundant in quantity, and not subject to those failures which are but too common in such countries near the deserts as have to depend on the rain of heaven for their fertilizing liumidity.

Of the fertility of Egypt in ancient times, and, indeed, at all times when its political state has been such as that the people could cultivate their fields with safety, there are many proofs on the record, to which 
may be added its progressive state at the present tirne; and we have an instance of the abundance of "corn in Egypt," in the history of Joseph and his brethren, and the subsequent scenes which led to the bondage of the Hebrews in that country; though, in the same history, we have intimation that there were unfavourable seasons in Egypt itself, which did not arise from any thing in Egypt, (for the seasons there are remarkably uniform, ) but from the failure of the rains in that upper country, whence the flood of the Nile is derived. When the flood did not rise to a certain height, those parts of the valley most distant from the ordinary bed of the Nile were not watered naturally, and could not be artificially irrigated; and thus, in seasons when the water was low, the desert invaded the cultivated ground, and could be driven back only by an unusually high flood of the river.

To common observation, there was thus a contest between two opposing powers-the fertilizing water and the scorching heat; and as the observation, that this same contest arises from natural powers duly balanced, belongs to an advanced stage of inductive science, and not to such mere beginnings as constituted " the learning of the Egyptians," it was very natural that they, as all ignorant persons continue to do, should regard that power which appeared to counteract their exertions and defeat their purposes, as a natural evil.

Of the three beneficent divinities, Isis was typical of the productive power of the earth; and, by a farther extension of the fable, of the general principle of fertility or maternity. Osiris was typical of the fertilizing 
power on the earth, and, by the general interpretation, of the principle of paternity, in every sense in which that principle can be understood. These two, under some names and similitudes, are common to the mythology of every people who have made such advances in knowledge as to be able to generalize natural causes, though they have been differently received by different nations, according to the difference of physical character in the countries where the systems originated.

Though all the systems of this kind of which we have any knowledge are of great antiquity, we speak of them in the present tense; and we do so, because mankind in themselves, and uninfluenced by the light of revelation, are the same now as they were then: and, if they were placed in exactly the same circumstances as those ancient nations, they would form similar systems of mythology, and of every thing else.

Anubis, the third of the good gods of the Egyptian year, was typical of the overflowing of the Nile, and in this sense, at least, peculiar to the mythology of that country. The dog, as symbolical of the dog-star, was the emblem of Anubis, as the flood of the river came where that star rose at a certain time. Fanciful analogies may be traced between Anubis and some of the gods of other mythologies; but the following out of these would be foreign to our present purpose, which is not in the least affected, either by the number of the emblems of physical good, whether they be one or many, or by the natural agents which those emblems typify, whether they be humidity of temperature, or any other means or stimulus of productiveness. It is 
quite sufficient that they are symbolical of physical good.

Typhon, though in the first instance symbolical of the burning influence of the desert, came at length to be equally symbolical of every kind of evil, moral as well as physical. It was the same with the good gods; and in this lay the mischief of the system, and of the portion of it which remains to the present day-the same in principle and effect as formerly, however it may differ in form; and very many who would spurn the direct imputation, are deeply imbued with it, and tend to its perpetuation, while they fancy that they are inculcating doctrines of very different nature and tendency.

We have felt it necessary to go at some length into the case of the divinities of the Egyptian year; because, with the exception perhaps of Anubis, they are expressive of what has been, and would still be, the belief of mankind with regard to the tropical summer of humidity, and the tropical Winter of drought, if mankind, in tropical countries, were destitute of revealed truth, and sufficiently advanced in natural knowledge for inquiring into general causes.

But men who do not understand the doctrines and the lessons of revelation are just as little influenced by it as though it had not yet come into the country which they inhabit. The influence of revelation has nothing to do either with geography or chronology. It comes not into lands in their breadth, or into ages in their succession. No doubt the means must be in the place, and at the time, otherwise the people cannot profit by them; but then the profit is wholly in their 
being brought home in the proper manner to individuals: and if the understanding and the conduct are not influenced by the doctrines and the precepts of Christianity, the inhabitant of the most nominally christian country in the world is, even with the most solemn professions and observances, as much a heathen as if he had lived in an age when the glad tidings from heaven had not been declared to the children of men. Nor does the amount of merely human science, or even of moral conduct, avail any thing in this respect; for though the one may prevent the party from falling into physical absurdities, and the other may make him a good member of society, in as far as human laws and institutions are concerned, they do not reach the spiritual part of his character, which is the only sure foundation of a moral one that will hold fast its integrity amid all the vicissitudes and temptations of life.

When we come to the middle latitudes, in which there are, in many places, two Winters, produced by opposite causes - the one by drought, and the other by cold - we find the evil, as it regards the year, or as it is figuratively transferred to the final retribution of human misconduct, also made up of two parts. Thus, in the notions which the Greeks and Romans had of the future state of the guilty, the punishment alternated between an extreme of heat and an extreme of cold; the one obriously borrowed from the burning up of the dry plains by the summer's heat, and the other from the suspension of growth and the withering of annual vegetation by the Winter's cold.

Then, in countries which are in latitudes so high as 
that cold is the only, or by far the more general, check to vegetation, - and where that cold is augmented by the heavy rains of the autumn and the early Winter, -we find that these are the causes of evil in the year, which work in opposition to the genial beams of the sun, as the agents of beauty and fertility, and of all that is pleasing and profitable in the economy of the year. Hence it is that our bards who sing of the year, and all others who address themselves to the fancy and feelings of the people, make their pictures of Winter such contrasts to those of the other seasons. Spring is all freshness and hope, with opening buds, springing herbs, busy birds, sportive lambs, and all the other attributes and accompaniments of young life, full of the most cheering prospects and the most delightful anticipations. Summer is also redolent of every beauty and every charm which can captivate the sense-all beauty to the cye, music to the ear, essence to the smell, and delight to the whole sentient nature of man. Autumn, also, is so full of the realisations of the hopes of spring and the promises of summer, that it is an especial season of joy and joyous description, not merely to those who find, during that season, their chief return for the labours of the year, but to the whole people, in so far as they are dependent on the fruits of the earth, or take their pleasure upon its surface.

It may be partly from the desire of heightening the interest of these by the contrast, that Winter is usually clothed in gloom and desolation, and made, in so far as the year is concerned, the very type of the evil genius 
of the mythologists, though it is probable that there is a good deal of mythologic feeling that mingles with this simple desire of producing effect. Ignorant and ill-constituted minds, of which there are but too many in the world, are always much more sensitive to the ills and reverses of life, than they are to its pleasures. They complain when they ought to render gratitude; and by mingling for themselves the cup of bitterness, they turn that which in itself is, and to them should be, the honey of life, into gall; and, if this is done for any length of time, its withering influence is shed upon the whole of nature, as well as upon all the incidents of life; and the hapless selftormentor may "travel from Dan to Beersheba, and find it all barren."

'There is no real security against this whappy condition, but in the consolations of true religion; for if these are wanting, the man who is envied has no real security against the incurable malady of the mind, and he may rise from success to success, to any height in the estimation of the world, with only a heavier load of misery at every step. Just so, he who is sustained by those hopes which the world can neither give nor take away, may, according to the world's estimation, sink from misfortune to misfortule, and from suffering to suffering, to a far greater depth than unassisted human nature can bear; and yet he shall be more calm, more contented, and more joyous, in the very furnace of worldly affiction, than the man withont hope is mpon its bed of roses.

Religion alone can furnish the root of this amarantls 
of life-this plant of the heart which cannot be withered; and when it has once taken root, there is not an object or an event in nature, but which may be made to furnish a flower or a leaf, to increase the greenness and beauty of the tree. "Seek ye first the kingdom of heaven, and all other things shall be added thereto," is the counsel and the promise of Him who is both " the truth and the life;" and all who follow the counsel, are sure to enjoy the complete fulfilment of the promise. All things will not, of course, be added, in the literal meaning of the words; for, instead of knowing all things and doing all things, the knowledge and the actions of every individual are confined within very narrow limits. But still the spirit of the promise is sure; for, according to the measure of all that he knows and does, every man will be complete in the participation of the blessing. The things which a man knows are "all things" to him; for, between the unknown and the non-existent, there is not, in so far as the individual is concerned, a single handbreadth of difference.

It is in this, indeed, that the great superiority of christian consolation above all other consolations consists,-it is full and complete as far as it goes; and, therefore, although the pleasures of the man who knows little are neither so numerous nor so varied as those of the man who knows much, they are as satisfying to the mind, and produce equal contentment and enjoyment. With all mere worldly matters, of whatever kind they be, the case is widely different. Be their object what it may, and the means by which that D 3 
object is pursued virtuous or vicious, one and all of them are "daughters of the horseleech," and will not be satisfied. Nay, the more ardently and the more successfully that they are pursued, they become the more insatiable. Learning, honours, fame, wealthevery object of mere earthly ambition, be it what it may, gradually absorbs the whole mind, and becomes both a vice and a misery, for which the world has no corrective or cure, and no opiate but the blank oblivion of extinguished thought. Hence it is that so many who bask for a time in the sunshine of the world's adulation, fall so certainly, and often so suddenly, into the shade of utter neglect; and that he who in middle life was a philosopher, a statesman, or a hero, shides a dotard or a driveller into a neglected grave, known ouly to the worms. Even if matters ended here, religion would be the pearl above all price to the human race; but when we bear in mind that eternity approaches and brightens as life draws to its close, the gift of revelation becomes truly "unspeakable"-above all praise, above all gratitude.

'Those who feel in this manner, aright and in earnest, can find no gloomy object in nature, and no desolation even in the sererest depth of the Winter; and when we reflect but a very little, we find that nature and sound philosophy respond to this delightful influence of religion; and thus establish the truth, that the God of nature and the God of revelation is one and the same: and we begin to wonder why, even without the influence of religion, any subject, any scenc, ol my season, should inspire gloomy thoughts. We find 
the explanation in the same inestimable volume which teaehes us the only eertain way of avoiding the evil in our own ease. When the earth was ealled into existenee, elothed with plants, furnished with animals, appointed to run the course of its days, its seasons, and its years, in all the variety of their changes of time and place, and given to man as a heritage for knowledge and for enjoyment,-_" when the morning stars sang together, and all the sons of God shonted for joy," over the aceomplished work of a new world and a new race, eapable of knowing and serving their Creator,-then "God saw every thing that he had made, and, behold, it was very good." Man alone fell from his goodnessman alone was capable of so falling; and therefore all the rest is still under the original benediction-as good as it was at the begimning, in its laws, its productions, and its phenomena, though not so good to fallen man. "Unto Adam he said, Cursed is the ground"- -not in itself, but "for thy sake," that is, "mnto thee;" and the whole passage shows that the curse alluded to the pain and labour which man had to undergo, while estranged from the law and love of that God who alone can restore the lost enjoyment, even in this life. But it is the nature of man to put the evil from himself, and lay it upon ereation around him,-to lay the burden of his own curse upon that system of nature whieh is as fair and as good as ever. There is really no evil exeept moral evil, or evil done through the ignorance or the viee of human beings. The helplessness of childhood, the decay of old age, sickness, death, and all the contingencic's which befall 
IIs without any fault on our part, are not evils; they are part of the constitution of our nature, or results of the laws of that creation by which we are surrounded, and in which we must bear our part; and if we ourselves are not in fault, then there is fault nowhere. It is the same with all the changes of the weather, and with all the vicissitudes of the seasons. Whatever our feelings with regard to them may be, the one is just as necessary, as useful, and as good, in the system of nature, as the other. We cannot change that system, though we would; and it is well for us that we caunot, for assuredly we should spoil it. The fable of the farmer who had the control of the weather, and rendered his farm completely unproductive, is a lieathen fable; but the moral will remain a good one in all ages. All seasons are, in themselves, equally beneficial; and if they are not equally so for our operations, then it is we who are out of season-erring through ignorance or waywardness, and paying the forfeit for our own folly or vice.

'This is the rational view of the year, - the one under the influence of which we ought to enter upon the study of the whole year, or of any particular season or character of a season; and in this view, the repose of the Wintcr, whether produced by heat or by cold, and whether of longer or of shorter duration, is just as necessary as the budding of the spring, the blooming of summer, or the ripening of autumn. The natural agencies by which the phenomena of the seasons are brought about, are as much in harmony with each other at one time of the year as at another; and 
although there are such differences in the appearance and apparent progress of nature in them, we cannot say with confidence that any one of them is more eminently conducive than another to the crowning of the year with the bounty of the almighty and all-wise Ruler of the year. 


\section{CHAPTER II.}

SOME NOTIONS AND CHARACTERS OF WINTER.

As Winter is the season of nature's repose in the vegetable kingdom, and partially in the animal; and as even the elements are at rest, for a time, in those places where the Winter is of decided character and of considerable duration, it camnot be defined or characterised by any peculiar agent or species of action, as is the case with the other seasons. There is, indeed, a contest in the early part of the season, during the transition from the autumnal to the wintry state; and there is another at its close, in the transition from Winter to spring. These contests are often violent; and they are usually most so, while they last, in places where the repose of Winter is long, and the difference between Winter and summer is great. But where this is the case, they are usually of short duration; though, where the Winter is less decided, they may extend over the whole of it. There are also, as we have had occasion to mention in the volumes on the other seasons, two Winters-a tropical one, resulting from heat, and a 
polar one, resulting from cold-for the repose of cach of which a very different preparation is nccessary. In different years, too, and in places differently situated, even though not far from each other in latitudc, the Winter sets in very differently; and thus, whatever has to abide it in a state of repose, has, according to the usual working of the system of nature, to be preparcd for it in a different manner.

In tropical climates, the pools and brooks and all the smaller waters are completely dried up, and their beds and channels converted to dry sand or dust, deprived of all those matters which give the mud at the bottom of the stagnant or slow running waters their tenacity. Thus, there is no protection by means of water during the dronght, and no stability of place for any germ of life deposited in the bed of the waters when the rains come. The violence of those rains is also generally in proportion to the severity, and often, though not always, to the continuance of the drought; and thus, when the rains come, the channels of the brooks and rapid streams are not only swept to the bare rock, but the rock itself is rent in pieces by the violence of the high-swollen and headlong torrents, or ground and abraded by the sand and gravel which the water hurries along its surface. If those seasonal streams roll prone to the sea along steep channels all the way, then the whole, to the full extent of the flood, is cleared of every substance which the weight of the waters can move; and not a germ of animal or of vegetable life can remain, neither is there any soil left in which the latter could be rooted. Such places have, 
therefore, to remain in their desolation, until the winds bring them a supply from other places which have not been scourged by the floods; and this, of course, does not come, or at all events does not remain, until the swelling of the flood has subsided. In many situations, especially mountainous ones, where the rains come with extreme violence, the quantity of matter brought down by the swollen torrent often dams up completely those narrow passages which have been cut through the rocks by former floods. These dams, from the resistance of the rocks on the one side, and the weight and impetus of the water on the other, often become stronger than the undisturbed banks of the channel above; and so the water accumulates till it forces a new chamnel for itself, through which it rushes with the utmost impetuosity, tearing up the soil, uprooting the trees, tumbling down masses of rock, and converting the whole surface into a rnin. As it rolls onward, the materials which it tears up and hurries along from one place, become auxiliaries, which greatly assist its power in committing devastation upon the next; so that, before it can arrive at the level grounds, where it deposits its rubbisl, converting former pools into banks, and former banks into pools, the whole aspect of the surface is so changed, as that those who were previously familiar with it, can hardly know it again.

Such is a specimen of what may be called nature's ploughing; and, violent as it is, it is generally followed by a most luxuriant vegetation, though that vegetation is very different from what we see in our comparatively quiet seasons. It may be said, that this is a spring 
action, not a Winter one; and the saying is in part true, for Winter is in itself a repose and not an action. But this alteration of the surface must be completed, and the floods which produce it must subside, bcforc there can be any springing of vegetation upon the newly-formed lands. Thus it in reality bclongs to the Winter', as indeed do all those warrings of the elements, whether violent or mild, which precede the annual springing of nature; and though, in the order of time in nature, these Winter contests with the spring come after the repose of Winter, the knowledge of them is necessary, before we can understand either the usc or the manner of that repose.

This will readily appear, when we consider that no season, no production, and no power or agency of nature is final and for itself only. They are all for the system, working harmoniously together, so that the economy of things may be conducted according to the established laws of nature; and each so assists another, that the whole working of the system seems one succession of acts of the most disinterested goodness, in which all labour for the good of others, without recciving or requiring any return from those which immediately receive the advantage. But the benefit goes round, and each receives its full and proper share, until the period comes when it has accomplished the whole of its appointcd labours; and then it renders up its substance to the general store for the good of the whole.

All the parts of mature, considered in themselves singly, are thus dependent upon other parts, and incapable of sustaining themselves without the assistance 
of these; but the whole is self-sustained, or, rather, it is sustained in the golden balance of that law which the Almighty Creator has given it, so that not a jot can fail in obedience to that law; for, when by any of those vicissitudes, which form much of the perfection of the law, and without which it could not be a "law of life"-for life is vicissitude, constant action and change - it ceases to be under the law in one form, it comes under the law in another, without the slightest pause or interval. It is this which raises the works and the workings of nature, or, rather, the wisdom and goodness of God as manifested in them, so immeasurably ligh above the workings of mall, as that they are not subjects of comparison, and shows them to be so different in kind, that though man may and should study them to the utmost of his power, and studying them aright, camnot fail to love them with all his soul, admire them with all his imagination, and so strive to obey his portion of the law at all times, and with his every power and faculty, yet that he cannot even in the slightest degree imitate them.

This view of the reciprocal harmony of all the parts of the system of nature, and the consequent stability and perfect security against failure or derangement, which is obtainable only from a general grouping of nature in all its parts and in all its successions, is so beantiful in itself, so demonstrative of wisdom that cannot be fathomed, and goodness which can never be enough appreciated; and it is, at the same time, so fraught with the most cheering and the most delightful instruction to man, both individually and collectively; 
that it is impossible to refrain from dwelling a little upon it, if the slightest pencil of its heavenly lightfor truly it is a light from heaven, the illmminating emanation of God, as the God of the material creation, beaming through his works, as the light of spiritual truth beams through his word-falls upon the eye of the understanding. This, too, is the reason why the mere contemplation, in their individual characters, of the most curious, the most extraordinary, and the most striking events and phenomena of nature, have a cold and feeble effect upon the mind, and slight influence upon the disposition and condnct, as compared with those broad and general views in which the law arises high above those that obey the law, and the Lawgiver high to infinitude above both. The lost, or the hidden links of this wonderful chain-they are infinite in number-cannot be discerned, even in fancy, by the most richly endowed mind, even in the moment of its most rapt inspiration, when struggling to cast the incumbrance of the flesh behind it, and be a free spirit in the creation of its God; but still enough is traceable in nature to satisfy us in respect of material things; and though between them and the spiritual world there is a gulf fixed athwart which the mortal eye cannot look, revelation supplies us with as much of the analogy as serves for all purposes of peace, of profit, and of pleasure; and when we reflect on the great privileges which we enjoy in the capacity and the means of this twofold knowledge, our gratitude should know no pause, and our reverential adoration no bounds.

In order that men of all minds and all habits-which 
are necessarily as diversified as the associations and the pursuits of men-may have access to those general views, and participate in the advantages which necessarily flow from them, they may be obtained from contemplating nature in a variety of ways; the clief of which, however, may be reduced to two general heads -generalizations of co-existence, and generalizations of succession: and it is not a little encouraging, that these two exactly correspond with the two grand elements of all our intellectual and rational knowledgeof all that can occupy our thoughts beyond what we have clirectly obtained by the use of our own bodily senses.

If we take our survey of co-existent nature ever so wide, we find the law of disinterested benefit rumning through the whole of it. The sun is the highest object of physical inquiry of which we liave any knowledge; and we know the sun only as a benefactor, though beyond calculation the greatest of all material benefactors; but as to what benefits the sum, so that it continues to bestow its bounty without weariness and without waste, we lave no knowledge whatever. It has been observed that comets are lessened in their apparent dimensions as they contimue to revolve, and hence some have supposed that the sum is fed by comets. This is, lowever, a merely gratuitous conjecture, which neither has received, nor, from the nature of the case, can receive, any proof. 'There is no loss of matter' occasioned to the sun by all the bounty which that luminary dispenses to the planets and satellites which compose its circumrevolving train; for the matter of the sun, as indicated by gravitation-the only ccrtain 
test of matter-has not diminished in the least, since Philosophy was first enabled to weigh the heavens in her scales; and we have no reason to believe that all the light, the heat, and the other influences which the sun has shed upon its attendant planets, since the moment of its first ereation, would turn the finest balance against an infinitesimal monad of gravitating matter. But as the energy of every agent must be great in proportion to the effect which it produces, the action of the sun must be great beyond any thing of which we can form an accurate conception, or, indeed, any conception at all; and as action is as much a work of the Creator as matter, and ean no more be originated by a ereated being than matter can, the analogy of the whole of nature, in as far as it comes within the scope of accurate knowledge, leads us to suppose that the energy of the sun, although standing in neec of no supply of matter, must be kept up by the agency of some eause or other", though what "messenger is made a spirit," what "minister a flame of fire," to keep up this energy, without which death would rule the whole planetary host, is above all mortal ken.

The notion of the comets, besides being totally incapable of proof, is one which admits of a reciprocating conjecture, namcly, either that the comet feeds the sum, or that the sun lights up the comets; for a comet is generally the brightest, and attended by the largest coma or train, soon after it passes the perihelion. 'The trains or tails of these bodies are of immense length, and they are sometimes darted out with almost incredible velocity, that of 1680 laving been projected to the E 3 
length of thirty millions of miles in a single day. All our conjectures about the uses of these vast but filmy and unsubstantial bodies, either to the sun or to any thing else, are, however, vain and unprofitable; and we are left to regard the sun as the ultimate created benefactor, between which and the all-beneficentCreator, we cannot interpolate a single link.

With the moon, the case is nearly the same; and the benefit which the moon confers upon the earth is a mere trifle compared with that bestowed by the sun. Whe principal part of it is the influence of the moon, as a mere piece of matter, upon the atmospheric fluid and the waters of the ocean, the tides of both of which are of much use in the economy of the earth. It is true that when the moon shines by reflecting the beams of the sun upon the earth, those beams are deprived of the heating and other energies of the red end of the spectrum; and the opposite energies of the violet end have consequently a larger share in such effect as is produced than they have in the case of the undecomposed beams as they come directly from the sun, but the effect is very obscure; and we do not know of any emanation whick the moon sheds of itself, or of any service that it receives or requires from any body in the system, other than the gravitating influences of the earth and the sun, which retain it in its orbit. These speculations respecting the celestial bodies, are, howerer, vague speculations; but they are Winter ones, for Winter is the proper season during which to study astronomy.

When we narrow the field of our consideration to 
our own planct, we find the same law still in operation; and we generally can obtain a knowledge of the cycle, or circle of reciprocation, which comes round till the benefactor with which we begin becomes the benefited in the end. It is true that we are unable to say what good all or any of those creatures which the earth supports, render to the earth in return for the support which it affords them; though the analogy leads us to conclude, that all the parts do-though we camnot always discern the means or the mode, mutually support each other. Thus, the atmosphere exists not for itself, but for the benefit of the land and the waters, and of all that live or grow in them; and the land and the waters are so constantly restoring to the atmosphere, at one place and by one means, what they are receiving from it at another place, and by other means, that the quantity and composition of the atmosphere appear to vary but little, if indeed, upon the average, they ever vary at all.

The sea and the land also obviously work for each other, at the same time that each of them works for its own living and growing inhabitants, according to their several wants. An enumeration of the particulars would be too long for the general argument, and it is not necessary; but we may mention the single instance of water which the sea is continually receiving from the land, and as continually returning back again to it, though in a very different manner. 'This water has already performed all its required ofices upon the land, and washed that and its productions from many impuritics which, were they to remain, would operate 
as poisons, so that the beauty and activity which are displayed on the fair earth would perish in the accumulation of their own curruption. This, among other most important services, the running waters prevent; and such of the impurities as are not decomposed and rendered harmless by the maceration of the fresh waters, or taken up by the plants with which these waters abound, more especially in temperate and cold climates, where the decomposing action of the solar beams is less powerful than it is near the equator, are borne onward to the sea, for the economy of nature in which they are peculiarly fitted; it being part of the law of the system, that whatever has become injurious in onc part of nature, is, on that very account, highly sanatory for another part. 'Thus, the discharge of water by the rivers into the sea, not only keeps up the full average in that expanse, but carries along with it many substances which the sea wants, and which have become encumbrances or nuisances upon the land.

In this way the land is the benefactor of the sea, and that it may continue to be so, and at the same time perform its own more immediate part in the grand action of the system of nature, the sea reciprocates, and by so doing returns the advantage. The water is taken up by the atmospherc in a state of perfect purity, and conveyed over the whole of the land, even to the most elevated parts-indeed, in the greatest abundance to them; and the comparatively uniform temperature of the sea in all climates and at all seasons and times of the day, while the land is almost continually in a state of change, from cold to leat, or the reverse, 
cooperates with other causes in making the air to circulatc so as not only to distribute generally the watcr which it holds in the state of vapour, but, by the friction of contrary currents, to cause that watcr to accumulate into clouds, and fall to the earth in rain or snow. It is worth while to notice the accommodation which is afforded to the land by the falling of water in a liquid or a frozen statc according to circumstances. At scasons when and in situations where the water falls liquid in the state of rain, it invariably has some immediate office to perform, either in the way of refreshment to the earth and its productions, or in that of ablution. For either of these purposes, the rain comes exactly at the time when the growing vegetation requires it, or when the earth requires to be washed on the surface, or saturated so as to retain moisture for the roots of plants after the air is dry and the surface parched.

Thcre are some circumstances in the adaptation of rain to seasons and to soils, which are wcll worthy of our attention, if wc would rightly understand the perfect wisdom of design which pervades the whole of creation, and with what benefit to nature and to man that design is carried into cxecution. We are apt to complain of the gloomy skies and the pelting rains which generally usher in the English Winter, and also of the conflict which, in the average of years, takes place between the Winter and the spring, before the latter scason gains the ascendency, and the young year buds and bourgeons in all its freshncss. But these come for the most bencficent of purposes; and therc are protecting powers in those pelting rains, and 
seasonal contests, but for which vegetation would suffer most severely. Were this the case the animated races would also suffer, as the foundation of all support to them, either immediately or remotely, is in the vegetable tribes, whatever may be their habits, or the nature of their food.

The soil in many parts of England is, from its light and porous nature, and the depth to which the action of the summer sun penetrates into it in consequence, so much dried that were it not for the autumnal and the Winter rains, a few years would reduce it to such a state that it would be incapable of producing any vegetation superior to tire stunted lieath which is found upon the elevated sandy dowus in the southern counties. Some of the stiff soils again are so thoroughly baked into clods by the heat and drought, that were it not for these rains, they would speedily acquire the consistency of brickbats, not to be broken but by the blows of a mallet, and not capable of being reduced to a useful tilth for the purposes of agriculture, except by great labour. Such soils absorb the rain which falls, and retain it near the surface; and there are various ways in which the water so retained becomes a powerful instrument in reducing the clods. To a certain extent it does this directly by its own action; but it does more in a secondary way. Remaining near the surface in much greater quantity than where the soil is less retentive and admits of its more free passage downwards, though more of it is retained, there is more evaporated than upon the open and thirsty soils, and this produces a greater degree of cold, both at the surface and in the 
air over it. The difference of temperature in thesc two kinds of soil, even when they arc similarly situated both in position and in elevation above the mcan level of the earth, is very perceptible to the feelings of those who visit them.

The additional cold brings on frost much sooner-that is, with less intensity or continuance of cold in the atmosphere, as applied to the surface, and not considering the manner in which it is affected therc; and the expansion in freezing the water which is in the retentive clods, and which is very generally distributed through their volumc, rends them in pieces with giant force. There is also another circumstance which contributes to the same result : the retentive surface, though it becomes very cold in itself, and tends to cool the air over it, yet prevents the radiation of heat from the earth from being so great as it would be were the surface more dry; and this, besides the effect which it has at the surface, is favourable to the roots of trees and other deep-seated vegctables, which usually thrive well and attain a large size upon such soils, compared to what they do upon those that are of a more light and frec charactcr. These rains differ from the coating of snow that lies for the greater part of the Winter on places where the climate is more severe, for they throw out the roots of the surface vegetation, whereas the snow protects them while it lies; but still they makc a sort of approximation, by preserving that which is deeper in the soil, and while sucl soils are, in general, not well adapted for Winter crops, the annual weeds are thrown out, and the strength of the land is preserved till the 
scason comes round at which it may be made available for the purposes of the husbandman.

Nor is the prolonged contest between the departing Winter and the coming spring without its advantages, though it is severe upon those cultivated plants which are too tender for the situation. But there is no doubt that the trials to which the regetation which is adapted for such places is subjected during the riolent action of the spring, tends to harden it, so that it is tempered to endure the cold dry winds of April or May, which would completely destroy it if it had previously been protected from any kind of check. Any one may convince himself of the truth of this, by taking two plants of the same species, the one of which has been sheltered and the other freely exposed during the angry part of the season, and leaving them equally to feel the severity of a bitter night when the season is more advanced.

We liave no space for going farther into the adaptations of co-existence, but any reader may, and should, follow out the chain into all the cases which can come within the range of his observation; and if he does so, he will not fail to find that the beautiful reciprocity to which we have alluded, is equally conspicuons throughout the whole, and that the law of nature, in this particular mode of viewing it, is so admirably calculated to ensure the greatest good of all nature, that the hand of the Almighty is as visible in it, as if the evidence thereof were writtell in a book, or graved with the graving of a signet.

If we take the adaptations in their succession in time, we find that, in whatever subjects we study them, and whether the period at the close of which the one suceeds 
the other he longer or shorter, there is still the same perfection-the same benevolence of design in the system. Each works less, apparently, for itself, than it does for that which is to follow. The day is a preparation for the ensuing night, and the niglit for the day by which it is succeeded; and though some of the growing and living productions of the earth are nocturnal and others diurnal, each is refreshed during the time of its repose in such a manner as that it acts with more vigour and effect in the time of its labour. The growth of the stem and the leaf is often a nocturnal growth, and when this is decidedly the case, the progress made in a single night, after a warm day, and by the radiation of heat from the earth, and the moisture which comes more freely to the plant from the nocturnal air, is often wonderful,--so great, indeed, that were the plant to continue it through the day, it would be worked beyond what it could bear, and so perish, as over-stimulated plants often do, through the excess of their own growth. Whatever the production of nature happens to be, or the time and the length of the time of its natural activity and repose, the one invariably prepares it for the other, and each is equally beneficial in its turn. Every one who is wise enough to be up and feel it, must know low delightfully fresh the whole of nature is in the early morning, not merely in those creatures which are to be active during the day, but in the very air of the time. So strikingly is this the case, that one who has been watching and weary during the night, actually feels an awakening in the coming in of the dawn searcely less refieshing than 
carly awakening from wholesome and balmy sleep, and incalculably more so than any thing which is felt by those who doze and loiter upon the bed of sloth until the sun has gained a height in the sky, and the character of day is confirmed.

This, by the way, is a violation of the law of nature, similar to what would take place, if there were, by any strange anomaly of the seasons, an instant transition from Winter to summer, in a region whose natural character it were to have an intervening spring. Langonr, prostration of strength, and mental incapacity for any effort of thought, are the price which the sluggard pays during the day for the indulgence of the morning; and if this criminal indulgence is continued until it becomes a habit, there is no return to activity and usefulness, but the unhappy sufferer lives in tenfold fatigue under the mere labour of being alive, compared to what the active do under the most vigorous exertion, until some trifling hardship comes, and then melts away like a mushroom in the Winter flood. It is the same with all the productions of nature, when either a protracted Winter or a premature summer brings those seasons much nearer to each other than the average time of the place where it occurs.

Thus, when we view them in a proper manner, and in accordance with the principle which is so obvious throughout the whole system of nature, we find that, varied as the seasons are in different latitudes and different localities, one of them is just as essential to the well-being and perfection of nature as another; and that, in seasonal climates, we could no more have the 
spring without the Winter, than we could have the autumn without the summer.

It is true that as Winter is a pause or suspension of those powers or energies upon the surface of our globe which are most active during the other parts of the year, its coming, and the preparations of nature for its coming, must both be different; and it is equally true that as there are two distinct kinds of Winter, the tropical and the polar, resulting from causes the very opposites of each other, the comings of these and the preparations for them must also be different. Nor are these the only differences; for if they were, Winter would be an easy study compared to what it is in reality. But besides these, which are the extremes of contrast in the Winters of latitude, there are a vast number of minor Winters, arising from local situation, from differences of surface and elevation, from the characters of surfaces as naked, or as clothed with vegetation of different kinds, all of which have their peculiar characters and require their peculiar adaptations of every thing that is exposed to them.

All these circumstances, and many more that might be enumerated, render the Winter a far more extensive and more perplexing study than would at first thought be supposed,-more so, perhaps, than any of the other seasons, though in the majority of the productions of nature they are times of activity, while to a very large proportion of those productions, Winter, whatever may be its predominating cause or its character, is a time of repose. It is necessary, however, that this repose should, taken on the average of scasons, be perfectly safe for 
all that reposes; and that, in places which are decidedly seasonal, the pause which takes place in the Winter should be so complete, as that the action which follows in the spring may be a new action.

In the case of annual plants, which are committed to the seed curing the Winter, and perish in the whole structure of the parent plant, there is comparatively little difficulty, because while a plant is in the seed, it is more secure against external contingencies and vicissitudes than it is in any other stage of its existence. If a seed, that is, any seed, has been properly matured, and has not germinated, or moved toward germination, there is, perhaps, no natural degree either of dry heat or of dry cold that will injure it, for one season, or in numerous instances, for many seasons. The coats or testie of most seeds are also of so waterproof a texture that they are not very liable to be injured by humidity, at least at temperatures much below those at which they germinate, though, if they do get soaked they are apt to mould, to dissolve, or to have their texture destroyed by the freezing of moisture within their substance; and any of these is, of course, fatal to their germination. Provisions against these contingencies are made, either in the structure of the sceds themselves, or in the fact of their germinating in the head of the parent plant or otherwise, and being rooted in the ground before the Winter sets in. This last is the case with some of the Alpine plants, and also with plants which belong to those high latitudes where the snow falls early in the season, to a considerable depth, and lies long as a protection to the surface and the surface regetation. 
The case of those small animals which are committed to the egg during the inclemency of the Winter, approaches, perhaps, as near to that of plants committed to the seed as the condition of animals can approach to that of vcgctables. It is probable, however, that the eggs of the animals are more delicate than the seeds of the plants, as those in the high latitudes are in grcat part committed to the waters, where the Winter temperature is but seldom lower than the freezing point of water, and frequently not so low-considerably higher, if the water is not frozen to the bottom. The eggs and other germs of life which are committed freely to the waters, in order to produce new individuals when the warm season returns, sink down before the progress of the freezing; and, probably from the intcrrupted radiation, there is much more heat accumulated under the ice than one would be apt to suppose. We have examined this on the small scale, and found the effects such as to be conclusive on any scalc. This power of the ice to accumulate heat and retain warm air under it, may be no unimportant auxiliary in the conserving of those germs of life which are seasonally committed to the waters in high latitudes, and also in bringing the principle of life in them forward, so as to be ready to start into full activity when the spring returns, or a gleam of the sum over the Winter snow causes a momentary tempcrature equal to that of spring. The more rapidly and the more intensely that the frost sets in, the accumulation of heat under the ice appears to be the greater. Ice forms most rapidly when an intensely cold wind blows with vclocity over the surface; and this is the usual character F 3 
of the weather in far northern and momtain districts, when the pools and shallow waters receive their coating of ice in the early part of the Winter, or not unfrequently in the end of autumn according to the calendar. It often comes immediately after a heavy deluge of rain, which converts every shallow into a temporary pool. The cooling of the surface, and the air over the surface, produced by the evaporation of a portion of this stagnant water, is, no doubt, the immediate cause of the frost. But, upon the principle which we have already attempted to explain, the water which tends to produce frost, by cooling the mere surface and the air, tends also to retain in the earth a very considerable portion of that action of heat which, were the ground less humid, and the sufface unfrozen, would escape by radiation. In places where the climate is not very severe, and there are no mountains from which air considerably below the freezing point can descend, when the temperature begins to warm at that point, and the frost to give way, then the ice speedily yields to the joint action of the atmosphere above it, and the radiating heat under it; and so familiar are the country people with this, that the brief duration of "frost on the full pool," is a proverbial expression among them. At early times of the season, the very intensity of the night frosts is often the canse of their brief duration, by producing a phenomenon which the same country people call "the leaping of the frost," or "the frost leaping to the sky." 'This phenomenon is by no means liked by the cultivators in the cold districts, whose scanty harvest is not mnfequently protiacted to the verge of Winter or far 
within it, and the crop serionsly injured by the rains. The eause of this dislike is the fact that the "leaping" of the frost is one of the most certain signs of a rainy day, or succession of rainy days, more prolonged in proportion as the frost has been more intense, and its disappearance more rapid. These treacherous frosts are seldom hoar frosts, or "white frosts" as they are termed, which form speculie of ice of the dew upon the herbage without eoating even the shallowest of the pools. They are "black frosts," or frosts which eongeal the shallow waters without forming any speeulie upon the herbage; and, indeed, there is seldom any dew ont of which such specula ean be formed on the nights during which such frosts oecur.

The "leaping" occurs in a great measure by the following means:-the intensity of eold at the surface makes the air heavy and little disposed to any kind of motion there, while the eongealing prevents the radiation of heat from the earth. The lower air is thins eold and tranquil, but it is shrunken in volume, and the npper strata descend upon it, eondensing and giving out both lieat and humidity in light elouds as they deseend. The lower air is too cold for taking up this humidity, and there is also comparatively little evaporation from the surfice, as the eold air there is stationary. The eloud therefore continues to accumulate; and as it does so it tends more and more to intermut whatever heat may radiate from the earth, and thus the heat remains and raises the temperature of the lower air over the frozen surface. But that portion of heat which the said sufface arrests in its radiation from the earth attacks the frozen portion on 
the under side. Between the two, the ice soon disappears, and then the portion of radiant heat which is held pent up escapes, and there is considerable evaporation at the surface. The vapour ascends from the surface, as there are no surface fogs in such states of the weather, but it ascends no farther than that region in which the cloud is forming, as the air there is parting. with humidity, and not taking it up by evaporative power. By this means the cloud is increased, generally to such a degree as to become a nimbus, or rain-cloud, and the rain itself usually comes about twelve o'clock, if not earlier.

This peculiar kind of weather is but little known in the warm and dry districts, where there are no lofty mountains near at hand to bear their part in the production of it. Unfortunately for them, however, the farmers of the cold districts of the nortl, whose labour, even in the most favourable seasons, receives but a scanty reward compared with that of their brethren in the more favoured districts of the country, know it but too well, for it often ushers in drizzling and continued rains which rot their scanty crops, or more violent weather which beats them into the earth; and in either case they are deprived of that which they can ill spare.

Sometimes, generally indeed, among the more experienced and observant, the signs of its coming are seen, though seldom sooner than the evening before it happens, and then it is too late for any thing but the mere securing of such portions of the crop as are cut down and ready for gathering in.

The experienced rustic knows the signs of the coming 
of this peculiar state of the weather, and probably knows them much better than the most profound of our philosophers, albeit he is unacquainted with any philosophy upon the subject. There is a peculiar stillness of the air on the preceding day, and the curions little spiders that weave the gossamer which festoons the sky, and emmeshes the stubble ficlds in a flimsy but lustrous network, are busy in their acrial royages and their terrestrial labours. Not a cloud is to be seen in the antumnal horizon, and the air is so transparent that every leaf of the trees, which are now in the finest of thcir colours of decay, may be told at a very remote distance. There is something peculiarly refreshing to the feelings in those more than usually clear skies; and the cause of their transparency tclls in a way which must be felt, but which cannot be adequatcly described. The reason is that the saturated atmosphere has no tendency to drain the humidity of the skin. In those tranquil states of the atmosphere, when it is, so to $\mathrm{cx}$ press it, hanging between the dry and the wet, and when the latter is to come through the agency of cold, without any formidable resistance of heat, the electricity of the atmosphere appears to be as passive as any other of those powers of which the air is the vehiclc or the medium; and therefore human beings appear to exist and act in it, without its exerting any influence upon them further than as it is taken into the lungs in respiration. This atmospheric tranquillity and passiveness gives wonderful facility to all the senses, because there is not the same drain upon the body as there is when the atmosphere is in a state of activity. Lxternal 
nature has not, at any time, much influence upon the sense of taste, because that is a sense of contact, and performs its office upon such subjects only as are taken into the mouth; but it is really wonderful how much the eye becomes piercing and the ear keen in those peculiar states of the atmosphere when its evaporative power is nearly suspended, and the cloud has not yet begun to be formed so as to obstruct the vision. Objects are much more distinctly seen than they are when the atmosphere is in a state of active evaporation, even though the degree of light is botll apparently and really the same; and although theory would tempt us to the opposite conclusion, there seems to be more refractive power in the transparent air at those times than there is when vapour is rapidly ascending from the surface of the earth. That the sight slould be more perfect we can readily understand, because the particles of vapour in the atmosphere, though much too minute for being individually discerned either by eye or instrument, must be found out by so very subtle an agency as light, and must oppose and disperse it. We cannot so well understand why very low and remote objects, such as rocks on a distant shore, should come into the visible horizon in those peculiar states of the atmospliere, and not when the set-fair sky is cloudless; but still the fact is beyond question, as any one who lias the opportunity and chooses to use it may verify by personal observation. Very curious refractions and reflections of the rays of light, both of the direct light of the sun and moon, and light reflected from the eartl, or from one cloud to anotler, are often produced in fogs and hazes, especially 
near the sea; but it does not appear that the ascent of vapour through the dry air increases the refractive power of that fluid, although we have the evidence of the barometer to the fact of its increasing the weight.

This is not only a curious fact in the action of the atmosphere upon light, but it is one which is of considerable use to us in the obscrvation of nature, especially in that part of it which relates to the weather and its changes. The general conclusion is, that the refractive power of one transparent fluid is lessened by the admixture of another transparent fluid in a state of extremely minute division, though the divided fluid is natmally, and when in its own continuous mass, by far the more refractive of the two; and this militates against the hypothesis, that the refractive power in all cases increases with the density; and thus gives us a hint that, notwithstanding all that has been said and written, we still have much to learn on the very curious and highly important subject of light.

The upland farmer, whom experience has taught to watch for, and in as far as he can avert, the various effects of those unfavourable changes of the weather, is in all probability quite innocent even of that slight degree of speculation upon the subject to which we have alluded; and, though his judgment is in most cases quite correct, he is in all unable to mention with precision any one of the circumstances upon which that judgment is founded. Still the judgment itself is not the less accurate on this account; and while, according to our ordinary notions, the farmer is ignorant of all philosophy, he is in truth an experimental philosopher 
of the very best description; and the great merit of the improvement introduced into the philosophy of the schools by the illustrious Bacon consisted mainly in persuading mankind to discard the idle dreams of fancy, and form their judgments of every case upon its own proper evidence. By this means much mysticism and absurdity have been got rid of, and the difference between the rustic observer and the sage has become merely one of degree, and in many matters they are reciprocally the instructors of each other,- - nor is it easy, in many cases, to say which of the two is the more benefited.

In this we have another striking proof of the identity of the God of nature and of revelation. The hopes of revelation are full and complete to every one according to his acquirements, and so also is the knowledge of nature; and the application of that knowledge to useful purposes, to all who seek it in the way of well-founded experience. It matters not whether the subjects of that experience are many or few; for they are complete as far as they go; and the feeling of this completeness not only gives confidence and pleasure, but it is a vital and growing principle, and produces a constant desire of knowing more and doing better, not from the vain desire of superiority and fame, but from the pleasure of the occupation itself. This delightful power and temper of mind, and also the complete and satisfactory vicw of the phenomena and the laws of nature, in so far as these are known to the party, cannot be obtained upon any other than a religions basis; for without that, knowledge is painful to ns, as well as labour or disease. If the 
faith and the lope which religion alone can inspire, are not within us, and in constant and lively exercise, there are places in the path of every kind of knowledge which we fear to tread; and the more lovely that creation seems,-and it is ever the more lovely in proportion as our knowledge of it is the more extended,-the more lovely that it seems, the thought of it is the more agonizing. There is doubt and fear on every side; and unless our confidence of immortality is founded rpon "the Rock of ages," the terrible spectre of amililation is ever and anon starting up to the alarmed mind, and entering into the soul with a direfulness of torment which no language can describe.

Truly it seems in tender mercy to the frailty of our nature that God has so ordained that the true philosophy-the granderr and perfection of the system of nature-cannot be appreciated, or even seen, but through the medium of revelation. Could it be so, the burden of life would be too heavy for any mortal to bear. 'To leave all those connexions and possessions, the knowledge of which is open to the capacity of every man, - to forget, to be forgotten, and never again to remember or to be remembered,-to leave relations, friends, possessions, pursuits, all that give us pleasure,-aye, even to lose the gratification of the senses once and for ever, is agony enough for a heart of any feeling. But when we are so far informed as to be able to look abroad over the wonderful structure and system of the universe,to contemplate sun after sum, planet after planet, and combinations of suns accumulated without end, in that space "whose centre is every where, and whose circum- 
ference is no where," and to which even the very boldest flight of imagination cannot assign a limit in any one direction; and when we are able to see and to appreciate with what wonderful perfection and skill the whole is framed, from this stupendous vastness to the atomic plant and the exquisitely organized animalcula, as perfect in all its parts and as instinct with life as the oak or the elephant, at the same time that it defies the natural vision of our eyes, and leaves our finest instruments on the verge of uncertainty;-when we are capable of understanding all this, and also the wonderful endowment by means of which we are so capable:then, the awful thought that, after a few years spent in pain and toil, all this shall be blotted out, and we shall be as though we had never been-senseless and lifeless inatter,

\section{"To lic in cold obstruction and to rot"}

for ever and ever, without consciousness and without hope of any return to the knowledge even of our misery,

\section{"Oll! 'tis horrible;"}

indeed, the hell-torments which the guilty mind ever pictures in the agony of its fearful conviction, are only greater than the direful withering of this terrible boding of annihilation-tle most sternly and stubbornly dreadful of all the agonies to which a being on earth can be liable.

And, unless in the way of life-the good tidings of immortal life and immortal bliss of unspeakable comfort and delight to a redeemed race, which is freely declared and fully made manifest in the gospel of the Eternal 
Son of Jehovah - we have no security that the terrible phantom above alluded to shall not invade us at any and at every moment of our lives. If the delightful volume of the word of the ever blessed God had tanght us nothing more than this, it would have been to us "the unspeakable gift" of its holy Author; and the delivery from the direful horror of this annihilation would be cheaply purchased by a long endurance of the severest suffering which conscious existence can be made to endure.

Winter is the season during which this fearful thought is most apt to arise in the minds of those who have not the well-grounded hope of religion to sustain them, and it is also the season at which the consolations of religion come most readily and most powerfully to the minds of all who have this hope. 'There are many reasons why this should be the case, both in the Winter of the year and in the Winter of life-and even in the Winter of the day; and without a knowledge of these it is not possible to enjoy any of those Winters as they ought to be enjoyed.

In all the three, there is an abatement of the objects which excite the senses, and in the Winter of the day and that of life there is a lessening of the energy of the senses themselves. When the shades of night begin to veil the landscape from our view, and terrestrial objects are withdrawn from our eyes, the thoughts, as it were, come home, and our trains of reflection become of a less cheering and discursive character than they are when all nature is freely displayed to the senses-more especially in the morning, when the refreshment of 
sound and balmy sleep has renorated all our bodily powers, and rendered onr whole frame capable of bounding with new life in obedience to every stimulus from without and every mental suggestion from within. Every one feels this; and the different feelings of the morning and the evening come so near to each other in time, and are so often repeated in the course of our lives, that they form, under all circumstances, a most ready and convenient epitome of the contrasted seasons both of the year and of life. So exceedingly useful, indeed, is the day to us, as an artificial memory and constant monitor, that it not only bears but yields pleasure and instruction in a frequency of repetition, which would be all but intolerable upon any other nameable subject. It las also this advantage, that the enjoyment which it imparts and the lessons which it teaches, are such as to address themselves to every individual of the hunan race, whether his acquired knowledge be small or great, and his mental powers neglected or cultivated. The obvious reason of this is, that the varying stimuli of the day address themselves equally to both parts of our compound nature,- - they are equally for sensation to the body, and for reflection to the mind; and according as the one or the other of these is most in exercise, the occupation and enjoyment of the day are physical or intellectnal. It is the same with the seasons of the year and the ages of life; but for the reason already mentioned, the day, as the easily-observed and brief epitome, is the one upon which to ground the illustration; and then the application to the others follows almost as matter of course. 
In the morning, the address to the senses comes first and most powerfully, and it comes wholly from the earth and its productions and inhabitants; for the same sun which gives us a new and fresh revelation of terrestrial nature every morning of our lives, veils all else from our view in the very brightness of its beams. The sun alone rides dominant in the sky; and to our observation at the time, appears to exist wholly for the benefit of ourselves and the rest of nature around us, as if the radiant and glorious orb were nothing but an appendage to our earth. All the incentives to the hourly, diligent, and joyous performance of our daily labours which could possibly be drawn from human sources are nothing in comparison to this. The dread of want, the desire of wealth; the fear of shame, the ambition of fame;all of these, and every other human motive, named or unnamed, which operates either as a whip to drive or a cord to draw us in the path of activity, are insignificant as compared with the silent morning call from all nature around us, to be "up and doing." They are partial, one addressing itself more to one individual, aud another to another individual; and they are fitful and uncertain in their occurrence, the very opposites often alternating with each other in the case of the same individual, and with very brief intervals of time. 'Thus, the miser of the one hour or minute is often a very prodigal the next -aye, he is a miser with the one hand and a prodigal with the other at one and the sane instant. In hoarding and hedging his money he squanders his time; and purchases full coffers at the expense of a hollow heart and a vacant head-the first destitute of any thing 
which can be called a fceling, and the second equally guiltless of all that is worthy of the name of a thought. A man who is thus motived, may be the nominal owner of what would make thousands happy-in the expectetion, but leave them miserable to their heart's content in the possession. To him, the dawn of the morning brings no hope, and the closing in of the evening no repose; while, in the darkness of the night, he is "scared with dreams, and terrified with visions,""his bones are pierced in him in the night season, and his sinews take no rest." That which he cherishes, and which holds dominion over his soul, with a grasp not to be loosened, was not secure in the possession of those from whom he obtained it, and this forbids the feeling that it can be secure in his. Thus, the hum of the gnat, the chirp of the cricket, and all the small roices of the night, sound in his alarmed ears like the tapping of hammers and the grinding of centre-bits; and midnight robbers are certainly attempting an entrance. 'The hungry cat, become desperate in the extremity of her appetite, collects all the strength which she has left into one daring effort-springs toward the shelf npon which stands a plate with a fragment of meat, scarcely discernible by the eye during the day, but palpable enongh to another sense in the night. Her strength is nearly sufficient to reach the prize, but not quite. She impinges upon the edge of the plate, and down come plate and fragment and cat, the first with a crash, which shivers it to fragments on the cold and carpetless floor. "The house is burst open! Thieves! Murder!" But, mum: fear is the 
inseparable adjunct of extreme coretousness; and so the miser is mute, from the habitual dread that "every one that findeth him shall slay him." 'Then eomes the torture: he dares not move; and the breath which he labours to stifle as a means of eonecalment, bursts from him in groans of inexpressible despair. There he lies, prone on his back, with his tecth set, his lips and eyelids widened to the ntmost, and his whole visage knotted and corrngated, like that of a man who has been thrust through with a ragged spear in the frenzied fury of a battle-field. And well had it been for him, had he been thrust through by any spear, or laid on the bed of death, feeble and flexible as the rag which even a beggar easts away, by the withering destruction of a gun-shot wound. But the man is alive in every nerve, and life in each is an extreme of anguish, which eonld not be execeled in that place of final retribution, the thought of whieh at all times " dogs him like an injured ghost." Every sense is on the rack; but none of them brings one tittle of information; and the pain of the uncertainty eould not be eompensated by all the wealth of the world. The body is at length overcome, and the senses forego their watehing. He dozes; yet the tendons start, the museles quiver, and his very slcep is the extreme of fatigne and exhanstion. But the agonized mind knows not the oblivion of sleep any more than the body enjoys its repose. The barb of the arrow rankles in his soul; and his dreams are so terrific that, in merey to the reader, we must leave them under the veil of silence-they may be imagined: they cannot be deseribed. 
Such is a slight delineation of some of the circumstances of one mode of engrossment of the whole man by a motive purely human. It is a matter of feeling, not of quantity; and therefore, the rank and habitation of the party, or the kind or tale of the hoard, does not affect the general condition. He may be a monarch or a beggar; his dwelling may be a palace or a hole in the earth; and his darling wealth may be the price of nations, or a single old farthing lidden under a clod. It is the total engrossment of the man, soul and body, by a motive which is merely human, which gives the picture its truth and character; and all the rest is a question of mere differences.

It may be said that, in the miser, we have selected the most sordid character in the whole list. There is a mistake in this; for there are many who are deeper both in crime and misery than the miser, and who yet carry their heads high, and by general admission honourably before the public. But the miser possesses that which many covet, and this brings down the odium upon lim. But be it so that the miser is the most sordid character, and as such an unfair specimen; and so let us take another.

Glory-military glory, has been, in every age, placed foremost in the list of merely human motives; and although there are some who do not, at the present day, rate it so high as it was wont to be rated, it is still the most gorgeous idol of a very large majority of the human race; and in such esteem is it and all its insignia held, that the most royal and appropriate costume in which a monarch can appear, upon the chief occasions 
for displaying his regal splendorr, is that in which he would be most appropriately bedight were he to march at the head of a mercenary army, for the purpose of cutting his liege subjects to pieces, levelling thcil labitations to the ground, burning their crops, and carrying off their flocks and herds as food for their wliolesale butchers-according to the ancient and nost honourable practices of war.

What may be the original cause of the ligh estimation in which the perpetrators of such doings have in all agres been held, we presume not to divine. Some nations pretending to a little civilisation, have chosen for the emblems of their divinities the most ravenous of beasts, and the most poisonous of reptiles; and among the lieroglyphics of honourable distinction, as they are awarded by kings and continued by heralds, the lion and the eagle have always been held in more estimation than the lamb and the dove. The devil has not unfrequently been the chief and sometimes the only object of adoration, while the ministers of good, under what figure soever tlicy have been represented, liavc been left in utter neglect. It may be said, indeed, tliat all the idols of rude nations are worshipped more for their barbarity than for any thing else, and that the primary sacrifices are usually characterised by the most revolting cruelties, as though that God of whom the mind at its first awakcning camnot remain uttcrly ignorant, delighted more in the blood and the mangled carcases of his creatures than in any thing else. Then if the gods of the more civilized of the heathen nations are a little more free from the liorrors of those of a ruder stage of 
existence, their crimes-crimes after the manner of men, but exaggerated above the standard of human atrocity-are more conspicuous than their virtues.

All this tends to slow that, in a state of nature, and without that light which is from above, men live in much more strong and labitual fear of evil, than they do in gratitude for good. This is " the old Adam," and perhaps it is never wholly subdued. Our self-love makes us prone to attribute to ourselves all the good that falls to our portion, and to attribute all the evil to some cause without; and if our belief be that that cause is too wise for our cumning, or too mighty for our strength, we go about to wheedle it with prayers or appease it by sacrifices. This, modified by the habits of nations and the characters of times, appears to be the real source of military glory, - the cause why he who has been the instrument in the slaughter of the greatest number of thousands, has been placed first in the foremost rank of the human race.

When we divest our notion of a hero of this remain of the superstition of the most barbarous times; and farther, when we compare the tinsel and the strut of the professional slaughterer of man with the humble attire and unheeded life of the slaughterer of those animals upon which man feeds, we cannot fail to observe that there is something not only humbling to human pride, but absolutely ludicrons in the pomp and circumstance of the former; and if a soldier were to appear in the ordinary costume of other people, bearing about his person the tools of his trade, the pointing finger and the griming face woukd soon sneer him out of society. 
The words of the satiric poet present so very graphic a picture of this species of delusion and folly-one may almost say mania-that if any one studies it he is not likely soon to forget it:-

" $O$, valiant man, with drawn sword and cock'd trigger, Pray tell me, don't you cut a pretty ligure?"

It would be no bad tentamen of the influence of military glory upon the heart and the feelings of men, to see a hero of name, who was at the same time a man of good sense and calm reflection-for assuredly soldiers, and especially soldiers of eminence, possess those qualities in no inferior degree-read that short passage, and hear him speak out candidly as to the figure which he made. Soldiers are often styled the defenders of their country, and there may have been many occasions upon which they have deserved the appellation; but there is always a fault somewhere when such defenders become necessary; and if the annals of all the wars that ever were waged were to be fairly scrutinized, it would be found that the real and original cause of each and all of them has been either frivolous or criminal,criminal, indeed, in all cases; for frivolity becomes a crime of no common enormity if it leads to the wholesale destruction of human life.

It is not our wish, however, to enter into the social or the political merits or demerits of any one denomination of human beings, our object being merely to show that there are certain invisible but very powerful agencies in the times of the day, the seasons of the year, and the ages of life, for which no substitutes or 
compensations can be in any station, employment, or pursuit of mankind. It may be thought that these have little or nothing to do with the Winter; and we innst admit that, though the analogy which we wish to trace is both strong and general, it is by no means obvious, nor does it lie mpon the surface. But the Winter of the year is a pause of seasonal nature generally, after it has completed one periodical effort, and before it begins another; and as the day, and human life, and every thing which is periodieal, follows a law which is analogous in principle, though differing in the details and the phenomena, we can best arrive at an accurate knowledge of any one of them by considering and comparing them all; and the general repose with its uses can be best understood, through the medium of those which mark the pauses of a more brief or more individual eycle.

Whaterer point of view we may eonsider them in, the action of matter is, in all cases, more powerful than the substance of matter; so that, by the influenee of the former upon it, the power of the latter is, in time, and often in a very short time, worn out. When this is the case, a pause becomes neeessary; and that pause is one of rest and refieshment, or of death and dissolution, or the passing of the same matter into a new form, according to circumstances-eircumstances which we ean, in but very few cases, understand.

But still, the understanding of these prineiples, in as far as it can be obtained, is a matter of the greatest eonsequenee, not merely for professional or professing whilosophers, but for every individual of the human 
race. It involves the most extensive and sublime gcneralisation; and is, in fact, the ultimate and completing step in the true knowledgc of the matcrial creation, without which all the rest, by whatever name it may be called, is nothing but mere beginnings, unworthy alike of the subject, and of the faculties of reason and reflection which the Almighty has kindly bestowed upon the student, and for the use of which that student shall be called to account. For this reason, and also becausc it is wholly omitted or but slightly passed over in the books which are commonly in the hands of popular readers-indeed in all books that have come under our notice,-we propose to consider it at some length, being filly convinced that if we can succeed in making it intclligible to the reader, ncither our labour nor his time will be lost; but that, on the contrary, many grounds of difficulty and doubt will be cleared, and that comexion betwecu the Creator and his works, which many pretend to sec when they do not, will be felt in all things with that assurance of faith which alone can give peace and confidence in this world, and hope in the world to comc.

It may be supposed that this should have becn done at a more early stage in the progress of these littlc volumes on the year; but the truth which we wish to illustrate is an inductive truth, which cannot fully be appreciated until we are in possession of the facts upon which it rests; and for this reason we wished to have at least an outline of the four seasons, in some sort, before ns, previously to entering formally upon it. We have felt in our own casc, secn in the cascs of others, 
and are convinced that, if the object were to prevent the bringing home of a general truth to the mind so as that it should produce no real conviction, the surest way would be to give an à priori enunciation of it. This is the case, as every man may ascertain in any place or among any class of society, with all those subjects which are professed to be taught by formal lules, without demonstration, reasoning, or explanation of any kind, other than the mere fact of the mechanical application of the rule. In technical matters there are many things which must be taught in this manner, because the use of them does not depend upon the knowledge of their nature, -as, for instance, it is not necessary to school a man in the full knowledge of the making and the properties of iron and steel, and the growth of asl-trees, or their superiority for spade handles, in order that he may better know how to use a spade in digging the ground. In every thing merely mechanical it is the same, for in learning to do, we must imitate, though we may improve upon, our patterns. But when our object is to know, especially to know some very general and very important principle, the method of proceeding must be different; for we must understand the particulars, before we even attempt to state the general conclusion which is to be drawn from and supported by those particulars; and the more general the truth which we wish to inculcate, the more necessary it is that we should see that it rests upon clear and satisfactory evidence.

Now, when we contemplate the periods of all 
material things that run in cyeles or courses, of which we have the beginning, the eontinuanee, and the end presented, either to our personal observation, or by the reeord of authentic history, we find that they are in the balance between two principles, the one of which originates and maintains the succession, and the other tends to bring it to an end, and constantly sueceeds. In some eases there is only a temporary pause for rest or refreshment, after which a similar eycle is performed anew; and in other cases there is the final pause of death or dissolution, after which the matter composing the being or thing passes into a new form, and yields obedience to other laws. Of the two prineiples or powers which are thus set in opposition to each other, and upon the contest between which, motion, and growth, and life, and all the other actions and displays which oecur in the material creation, obriously depend, we have no general names, and can frame no definitions which will equally mect all the rarious cases. One of the most convenient substitutions which we can make, is that of substance, or being, simply considered, on the one part, and action, or state of being, on the other part; and it is a very remarkable comeidence, and strongly confirmatory of the propriety and truth of these distinctions, that they shonld agree exaetly with the two essential parts of human speech, noun and verb, into which the whole of every language may be resolved-the other parts of speech, whatever may be their number and the way in which they are used, being merely modifications of these two, or abbreviated forms of expression, in which the sense of a phrase or 
sentence is embodied in a single word, and that often a very short one.

This correspondence between the two essential parts of human speech and those of the natural subjects of human thought, proves more than one would be apt to suppose. It furnishes indubitable evidence of one of the most important, and, at the same time, the most delightful adaptations to be met with in the whole system of nature, full as that glorious system is of proofs that all the parts of it are made for each other. The world, the complete and the sole subject of man's observation as an inhabitant of the world, and the medium through which man receives all his knowledge, except the portion which he obtains from personal observation,and that is but a trifle as compared with the whole, even in the case of those who are not very learned,-are, in their two most essential parts, completely adapted to the two essential parts of that knowledge. Such being the case,-and that such is the case must be seen and felt by every one who reflects but for a moment,-it is impossible to feel or to express enough of gratitude to that all-bountiful Being who has so admirably fitted man the student, and nature the subject to be studied, to each other. So forcible is the lesson which this implies, and so clear and legible to all are the terms of the implication, that we must stand self-condemned if we neglect to profit by that which is so especially adapted to our faculties and our nature. The further we pursue this subject, it appears the more beautiful, the more instructive, and the more delightful. Lamguage, in its practice, is not a specific gift to the 
human race, as is the structure of the body or any of the organs of sense; for if it were so, then it would, as these are, be the same to the whole of the hmman race, whatever part of the globe they happen to inhabit, in like manner as the general anatomical structure of the body, and the allocation of the senses and the forms of their organs, are the same in their more essential characters, in the people of every land under, the sun. But language is conventional as well as acquiredhuman beings do not possess it naturally, they only possess the faculty of acquiring it, just as they do that of acquiring any other art; and this faculty is brought to be a habit by practice and communication with each other.

'That a single human being placed alone in the world would ever of himself acquire any language, is by no means likely; for there is no transmission of language by hereditary descent, farther than as the organs of speech in the children may resemble those of the parents, and thus be better adapted for articulating similar sounds; and the influence of this is much slighter than we might suppose, for we find that children acquire the particular sounds of the district in which they are born, even though not used by their parents and those immediately about then. Connected with this, there is one matter worthy of notice, as showing how far an analogy will extend in nature, and how closely it will hold even where we should not expect it. The more nearly that the parents speak the natural dialect of the place from which they come, the more their children retain both the enunciation and the 
idiom; while the children of those whose speech has been more refined and cultivated, fall more readily and completely into the idioms and the peculiar sonnds of the new place. The children of a vilgar Scotch family continue to speak vulgar Scotch in London; and so do those of the lower Irish retain the brogue of that country ; while the children of educated parents from either country not only show little or none of the peculiarities of that country, but have much proneness to acquire the peculiarities of the place. The same holds in the case of cultivated animals and plants; the more highly that they are bred, that is, the more that their characters and qualities depend upon the operations of art, the more prone are they to degenerate and take up a particular character from the district; and so inveterate is this tendency that it cannot, in many cases, be prerented by any means, except a change or renewal of the breed from another district. This, equally with the case of human speech, shows that there is no assistant principle in nature by which human art, or the productions of human art, can be in any way perpetnated. On the contrary, there is always a resistance of nature to the operations of art, whatever those may be; and, indeed, it is this resistance, and this standing up of nature to the tool of the workman, which enables him to perform his labour and accomplish his purpose.

Human art, whether rude or refined-whether it be the application of the most profound science, or of so. little science (there is no art without some science,) as. that it passes mheeded-is, therefore, no part of the system of matcrial nature; and when we speak of the 
action or the working of that system, we must leave all human action and working out of the question, as being foreign to the subject of our inquiries.

There are two advantages in this, and they are both very important ones. In the first place, our subject is quite untrammelled by foreign considerations; and so we can go directly to it, and pursue it upon its own grounds, with no embarrassment, and comparatively little chance of error. In as far as philosophy and its practical results as conducive to our comforts go, this distinction is of the utmost importance. The want of making it was, in fact, the trammel, which so long kept the philosoplyy of the schools chained to visionary and absurd hypotheses, inapt as an instrument of wisdom, and inapplicable to any useful purpose; so that the philosopher dreamed away, "refined from reason," and sublimed into a visionary region in the cold clouds above all usefulness; while the labouring man went round and round, like a mill-horse, in the same confined and beaten track, without any assistance from the light of philosophy, or the inventive and improving faculties of his own mind. If any man of more mental energy than the rest attempted to generalize farther, he was instantly caught between the horns of a dilemma, or had to steer his course between a Scylla and a Charybdis, against the one or the other of which he was in continual danger of being diven by one or another of those currents of thought, over the course of which the thinker has really no more command than the inariner has over the currents of the sca. The mixing of man as a rational being with that system of nature, 
in which all is obedience, perfect obedience, to the law without any reasoning, was such, if pursued far enough, as to lead to the one or the other of two results, both of which are equally withering to the mind, and equally destructive of that confidence witlout which there is no sure happiness for man even in this world. In this state of matters, the words of "The Preacher," which are intended to portray the vanity of all the occupations and acquirements of man, when he does not "remember his Creator," are most emphatically expressive: "In much wisdom is much grief: and he that increaseth knowledge, increaseth sorrow." 'The alternatives are the mortality of man, or the doctrine of Materialism, as it is usually called; and the eternity of matter, or in other words Atheism; and between these, it is impossible for any one, who takes the whole compound man along with lim as part of the system of material nature, to steer, without rmming upon and being entangled by either the one or the other. It is doubtful to say which of them is the worst, for both strike at the roots of all moral obligation, reduce man to a mere creature of this world, lead him to make the most of its enjoyments by what means he can, and, like a dog, "liave liis day."

Secondly, when this separation and distinction of man as the observer, and the system of material nature as the subject of his observation, is once clearly seen and duly felt, it becomes the strongest of all plinlosophical arguments for the immortality of the intellectual part of man-an argument so strong indeed, that we are not aware of any that has been brought or can be 
brought on the other side, capable of shaking it in the least. As the mind of man forms no part of the system of material nature, it cannot be in any way under the laws or subject to the contingencies of that system; and cannot be in any respect more subject to disease or death, than it is to mechanical division or chemical decomposition. Death, in our common understanding of it, and as it is in the ordinary course of nature, or accelerated by those events which, from our imperfect knowledge of their real causes, we call diseases and accidents-the disease meaning some state of the body in which it is "not at ease," and life does not part in that gentle manner which marks its close in the regular course of nature, and accident something which "falls upon" the body from without, without any particular affection of the body itself to impair its functions, -death in either of these ways, or in any other in which we can have any experimental knowledge of it, is not, neither can it be, the death of matter, it is only the final stoppage of a certain kind of action in a certain portion of matter, not one atom of which, considered as mere matter, is one jot nearer death, when the life of which it is the instrument ceases, than when that life is in the prime and meridian of its activity. Different kinds and combinations of matter, as they are perceptible by our senses, have different species and degrees of life; but the life of matter (if the term may be allowed,) taken in the abstract, or generally as the substance of the whole material creation, is nothing more than the simple fact of existence. Such life as it has in this very general sense is nothing more than the fact of having been 
created; and the reversal of this, which is amnihilation, is the only death that it can undergo; and that, should it ever take place, must be nothing other than a passage into a state of utter and final non-existence, which is an operation that we can no more understand than we can understand the act of creating; but assuredly it must be an immediate operation of the Divine Being, and not obligated to any created agent, for it is inconsistent and absurd to suppose that any one created being can put another out of the pale of the universe, to whatever cxtent it may be capable of acting upon and changing it within that pale.

This brings us exactly to the philosophical proof of the doctrine of immortality :- The only knowledge that we have or can have of mind, bears a very close resemblance to our abstract notion of matter; for all the explanation which we can get or give of either of them consists of negatives. Matter in the abstract is nothing else but matter considered apart from every quality which belongs to any of its particular states; or, if we camnot separate the idea of substantive matter from that of having weight and occupying space, yet we can follow both of these down to the very confines of nothing. In like manner we camnot, perhaps, altogether separate the idea of knowing from that of mind; but we can imagine the knowledge to be so feeble and so flecting as to pass away like an unconnected part of an umremembered dream; and by far the greater number of our own thoughts belong to the same category; and if any one tries without preparation-and preparation would reduce it to no trial at all-to recollect a thought, 
unconnected with action, for every day during the last month, the number of blank days will appear not a little startling.

The general argument from the system of material nature which we have already adduced, as excluding mind from that system, renders the impossibility of the mind being at all affected by matter self-evident; and as it is utterly inconsistent with those notions of mind which are grounded upon revelation, (aud they are the only true notions of it that we can have,) to suppose the mind capable of any dissolution, so that it could pass into another mind in a manner similar $01^{\circ}$ analogous to that in which the same identical quantity of matter passes from the body of one material being to that of another,-there is really no species of death to which mind can be subject, except that final passage into nothing to which we have alluded under the name of annihilation. But we have seen that this is a work of the Divine Being only; and it must be palpable to the understanding of every one that can think, that one created spirit can no more annililate another, than one material body can turn another material body into rothing.

Such is the philosophical argument for the immortality of the human mind, when it is divested of all the techricalities of the schools; and it is equally consistent with the words of inspiration and with the common sense of mankind. Thus far it is necessary for us to know and to understand, before we can be in a fit condition for considering that general analogy of the various parts of the system of nature, the mention of which has 
led us to these remarks; and so we shall proceed to give a very slight outline of that analogy-such as we give of most subjects, but which may perhaps have a better chance of being read than if it were more prolonged and elaborate.

All the parts of the system of material nature are, then, as we have said, made up of two general elements-substance and state; the former having weight in the scale and occupying space, and the latter not. "State" is a more convenient term tlian action, because some states are, according to our ordinary modes of expression, passive or neuter; but still, every state and every change of state is the result of action; and thus the real allusion in every case is to action; and the distinctions are, whether the subject or substance acts of its own energy, is acted upon by some energy from without, or appears for the time to be under the influence of no kind of action; though the influences of the different objects in nature upon eacli other are so many, and act in ways so varied and so little known to us, that however permanent and quiescent the state of any being or body may be, we never can with certainty pronounce that it is neuter. Water is really more actire in itself-more under the dominion of its own powers, when lying still in ice or snow, than when rolling in waves, or thundering orer the rocks in a cascade; and it is more under its own action when liquid, than when expanded into steam, and exerting a force little short of that of gumpowder.

We shall not however allude much to the inorganic parts of the matcrial creation, for they have but little 
to do with the common phenomena of the seasons, or of those other periodical changes which come more directly and properly within the scope of our analogy. Vegetables and animals do this, and therefore we shall direct most of our observations to them; and here we have to include man in so far as he is merely animal, - that is, as he is borm, comes to maturity, and dies; and is, like the rest of animated beings, supported by food, and affected by the seasons, the weather, and other external causes, the same as that material nature by which he is surrounded.

Thus restricted, we may say that every vegetable and animal, every growing and living thing in the material creation, is made up of two parts, -its material substance, of which the being itself can neither originate nor destroy a single atom; and its peculiar action or life, which makes it an animal or a vegetable, or one species of either and not another; and this begins and ends with the individual in such a way as that we know not whence it comes or whither it goes. This last, as determining the grand outlines of the character of every individual, may be considcred as the essential part of it, as the agent, while the mere matter-the substance of which its frame or body, however shaped or organized, or whether large or small, is composed-can be regarded only as the instrument with which that agent works. The identity, or oneness thronghout the whole period of its existence, by mcans of which the plant or the animal is all along itself and not another, is in the agent, and not in the instrument. It is truc that there is an external identity by which, in all specics where the 
knowledge is of sufficient importance, the individual may be known from other individuals; but this is always produced by the agency of the life, or that agency modified by external causes, and never by the passive instrument or mere matter of which the structure or body is composed. This is proved by the fact, that the cxternal marks of identity do not change with the changes of matter in the body. These take place more slowly in plants, and more rapidly, as well as more completely to the whole body, in animals. No calculation upon such a subject can rise much higher than a guess, and that only a rude one; but it has been estimated that the whole matter of the human body, under certain circumstances, must be changed every seven years, while some parts are removed and replaced many times in the course of one day, or even of a single hour. In some animals the change may be quicker than in man, and in others it may be slower ; but, whaterer may be its rate, it is never the immediate cause of any change in those external appearances upon which we ground the bodily identity. "The Ethiopian does not change his skin," although the epidermis is constantly scaling off; neither does "the leopard change lis spots," though his covering moults regularly; and, to some extent or other, it is the same with every creature. Nor, when the external identity passes away, does it in the least alter the identity of the agent, that is, of the life. Even in those cases in which to common observation all apparent identity is lost, the identity of the agent remains the same: the egg and the bird-the spawn, the tadpole, and the frog-and the egg, the caterpillar, 
the inert pupa, and the airy and brilliant butterflyare, in each case, through all their changes, the same identical life.

In all the details of terrestrial nature, whatever they may be, it appears that the properties of the instrument as matter, and the interferences of external agencies, always become, in the course of time, longer or shorter according to circumstances, too powerful for every individual agent, and ultimately put an end to its working; and not only this; but, before the final pause comes, and the action of the individual is never again to be revived, many shorter pauses are required; and if they are forcibly withheld beyond a certain time, the agent loses command over its instrument, and the final pause comes on.

This final victory of the dull and silent properties of mere matter over the activity of the most energetic life in matter, is in accordance with all the terrestrial actions which we witness in those parts of matter which are not under the influence either of life or of growth. The only exceptions which we know, are those of the motions of the planets, and the action of the beams of the sun; and they are so stupendous, and we know so little of their causes, as existing in any thing but the mere phenomena which we see, that we camnot bring them into the comparison. All mechanical actions in terrestrial matter, however powerful their causes may be, are ultimately brought to an end by gravitation; and compoumds and aggregates are liable to be dissolved by so many chemical agencies, that we cannot confidently assert that any one inch of the solid, any one drop of the liquid, or 
any one breath of the aërial contents of our globe, is in the sarne state now as when first created. The probability is that it is not; for all that we meet with on the surface of the earth, or dig from under it, is either a ruin, or a new individual formed out of the old materials of something else,

It is this inability of the agencies of the individual beings of nature to maintain their power over their material instruments, without temporary pauses, and a final stop, which forms the beauty of nature's adaptation to days, and seasons, and durations of different species of life, and makes the study of these successions so profitably and so delightfully instructive. The times of duration in some are so brief, that we cannot distinguish their labour from their rest; and the action of others is so slow, that we can take no note of it excepting after long intervals; but we have no reason to suppose that mere difference of time can remove any of them from under the power of the general law. If the action of life in any thing whatever extends beyond the limit of a single day, or even one changing tide of a day, there is always a pause in some part of its action, or a portion in which it works with more energy, and another in which it works with less.

The agent in the being, whether that being is regetable or animal, is so adapted as that it cau elaborate its body or instrument out of the materials which are around it; and it can in so far yield to circumstances, and have its appearances modified by them; but it can no more tune its instrument or keep it in tune for an unlimited time, than it can originate itself at the first. 
Of the transmitted origin of generations in the vegetable kingdom, some notice is taken in our volume upon Summer; and that of animals will be readily understood, in as far as it is understandable or the understanding of it is necessary by any one who eliooses to attend to it with the requisite consideration. In all cases, however, it is deeply mysterious; and the very point upon which we most ardently desire to obtain knowledge, is the one upon which Nature lets fall her impenetrable veil. We can, in imagination, and partly also in reality, follow the investigation either way, until substantive matter eludes our ken; and we are constrained to admit that, in the cases both of animals and of plants, the transmission from generation to generation is not, in any sense of the word, a transnission of matter, but only a transmission of agency. This, however, is one of the most obseure subjects which can oecupy the mind even of the most profoundly learned and most reflective of the human race; and therefore it is no fitting subjeet for a small popular volume, which eourts and addresses itself to the public generally, and not the learned. Our principal concern, too, is with the plant or the animal only in those stages of its existence in which it can be a proper subject for popular observation; and therefore we waive all the more intricate and obseure portions, only remarking that no vegetable or animal has any more power in itself of prolonging its existence beyond the period which is natural to its being, as modified by the circumstances in which it is placed, than it has to command its own origin, or create out of notling that 
matter of which its organization during its appointed period is composed.

The pauses of nature to which we have alluded, by whatsoever names they may be called-whether nights, ardent heats of days, Winters of cold or of parching drought, transmissions from generation to generation, simply rest to the wearied without reference to times and circunstances, or any thing else-and they all partake more or less of the characters of Winter, as we understand those characters-are really the tumings of the instruments of nature, which fit them for the more rigorous exertion of the same or of new agencies, according to circumstances; and, be the pause or the transition what it may, there is a freshness and vigour of rellovated or young life after it, for the occurrence of which, by any other means, it would be in vain to hope. If it were not for the pause and the repose of the night, we could not have the freshness and the inspiration-the bodily inspiration, and the ready obedience of the body to the mind, which is the natural consequence-which we feel and profit by every morning of our lives, and which no means of our own can procure. If it were not for the pause of the Winter, we conld not have the activity of the spring; for all nature is exhausted and languishing even before the heat of our summer is nearly over; and a very few months' continuance of the same ardour would exhaust every growing thing, and, by necessary consequence, every living one; so that the whole would be gone without any adequate provision for a succession of the same species, or, indeed, any provision for them 
at all. So, also, if there were no renewal by generation, the wearing out of the individuals wonld be a final ending of the race, whether animal or vegetable; for even in those vegetables which are capable of being continued by division of the parent plant, there is a tendeney to deeay which is not to be found where the continuation is by secdlings, or in the ordinary way of generation.

That all these pauses and renovations are part and pareel of the system of nature, and essentially necessary to the proper working of that system, no one can venture to deny; and it is equally elear that the individuals acted upon, and the ageneies which act upon them, are equally well adapted to each other, so that each must, before they came into existence, have been equally known to the Author of the whole; and that both the law and the lawgiver are one. It is thus that the more we generalise in our considerations of nature, whether as eo-existent, or as suceessional in time, the more we are impressed with the convietion that the whole is the production of One Intelligence, whose wisdom and whose power know no bounds; but who has ordained that every ereature which he has made shall be, and is, the best adapted to the place, the scason, and all the other circumstanees in which he has seen meet to place it.

In this view of them-and it is the only correet and rational one which we can take-the pauses of nature, at whatever intervals they may oeeur, and whether in their duration they be long or short, are as essential to the proper working of the system ats the limes of its 
greatest activity. They arc, indeed, even more so, if we can admit of any distinctions of this kind in a creation which is cqually perfect in all its parts and all its occurrences. For, as there is no healing power inherent in any one production of nature, by virtue of which it can recruit its activity of itself, the reactions of those pauses, which all have more or less of the character and the effect of Winter, restore it again, so that it runs its course ancw with renovated vigour.

Taking all the organs and means of sensitiveness, the human race, as they are, independently of mental considerations, the most generally observant of the whole terrestrial creation, are also the most generally affected by all those seasonal circumstances; and man is affected by them in a different manner from any of the rest, and for a different purpose, namely, that of acquiring knowledge, while all the others yield only a brute and unconscious obedience.

The freshness of the dawn, the breath of spring, and the morning of young life, bc it what life it may, all have a most wonderful effect in tuning the instrument of plant and animal, so that the extent to which it can work is far greater than at any other time; and they who understand these things, and have resolution and industry to avail themselves of them, never fail in reaping the advantage. But the refreshment and renovation which come after the pauses of the night or the Winter, and also the vigour of young life, belong wholly to the system of material nature; and even with man, they are first and chicfly for the present world. They have their uses to the immortal or intellectual 
part of man, no doubt, because the body is the medium of instruction to the mind; and even when the subjects are of a spiritual nature, referring chicfly to the future state of man, and to him in the present life rather as a moral and accountable bcing than as at merely animal one, the lessons can still be addressed to the mind only through the medium of the body. The eye and the ear, in reading and hearing, are the organs: by which even sacred information is communicated; and though we who are in possession of these organs are unable to tell how the mind may commune with its God when all is dark and silent to the sense, and has been so from the very commencement of life, we must believe that the mental impressions are very different from those at which we arrive through the medium of the organic senses. There is no doubt that, in a human bcing possessing life and feeling, there must be some awakcning of the mind, however slight, and different from that of those who are in full possession of their senses as the inlets of knowledgc. We have every reason to believe that, in the case of all human beings, the general sense of life or of bcing alive,-or, as it has been called, the sensc of muscular resistance, -is the foundation of all the allocated senses, or the one which exists before any of them is or can be exercised, and of which one and all of them are nothing more than organic modifications. But as the single and unaccompanied exercise of this gencral sense is long anterior to the nse of speech or any other means of communicating information, it cammot possibly be made matter of philosophy. 
Yet still this general sense continues through life to be the most sensitive of the whole, to be the soonest worn out by fatigne, and the most refreshed by repose. It is upon this sense, far more than upon any of the senses which are allocated to specific organs, that the influence of the morning, of the spring, and of all the other seasonal refreshments of nature, tell, and perhaps tell with greatest and most beneficial effect, when there is no object present to attract strongly any of the other senses. Those tormenting affections which are usually called by the names of languor, listlessness, lowness of spirits, and ennui, and even that which we misname mental derangement, are nothing but deranged states of this sense; and under the strong influence of them, the local senses can afford but little relief, let the objects presented to them be as choice, and in healthy states of the body as delightful, as they may. Let one of these modes of gencral derangement of the sensal system be but severe and confirmed enough, and the sweetest music grates upon the ear like the sharpening of a scythe or saw, or the crushing of a cinder; the most lovely forms and the most delicate colours pain the eye; the finest perfumes are repulsive to the nose; and the choicest viands taste of rusty brass, or some other mincral poison equally offensive.

It would be foreign to our purpose to offer any remark either on what may be called the medical causes, or the medical treatment, of those most heavily afflictive states of the system, in which all is ailing, and yet no specific ailment can be complained of or named. But there are few of the more reflective part of man- 
kind who at all times escape them; and they seem to fall most heavily upon those who are least able to bear them.

In their severity they set all the ordinary resources of nature at defiance. Sleep, which comes in the extreme of fatigue, of hunger, and of cold, and which, in excessive cases of these, appears to lay the somower gently on the pillow of his long and last slumber, flies the couch, be it the most downy, of those who are afflicted in this manner. Then, the visions or spectres of the night are fearful; and as no eyelids nor muffling up in the clothes can exclude them, and no resolution can drive them away, they "make night hideous." Those spectres of the sleepless night are curious subjects, and set our philosophy at defiance. We know that they are mere phantasma-creations, or rather feelings without any creation, of the disordered sense; but they come so palpably, and so like objects of real vision, that the fevered frame starts and quivers at their phantasmic approach as much as if they were realities which could and would hurt. An allusion seems to be made to them in the night vision of Eliphaz the Temanite, which is so powerfully described in the fourth chapter of the Book of Job: "In thoughts from the visions of the night, when deep sleep falleth on men." [That the narrator is represented as sleepless-as in the state to which we have alluded, is clearly implied.] "Fear came upon me, and trembling, which made all my bones to shake. Then a spirit passed before my face; the hair of my flesh stood up: it stood still, but I could not discern the form thereof." The state of 
the system to which we are alluding, as being painful beyond tle utmost extrene of known and localized pain, could not be more truly or graphically described than it is in this quotation. 'The fear, the trembling, the shaking of the bones, are the last feelings which the patient has of himself before the phantasma begin to haunt him. Then a spirit- $\pi \nu$ ò-an unsubstantial - passes before his face, and stands still, but as formless as it is substanceless, - "I could not discern the form thereof." Even so with the phantoms which haunt the conch of him whose general sense is untuned, and who yet cannot sleep. The phantasma welter and tumble like waves, and seem to be living things, but they have no resemblance to any living things that we can see with our eyes when the light of the day is abroad. Such as we speak of are confined to the night; but there are some diseases during which day phantoms make their appearance, and will not quit until the disease abates, even though the person whom they haunt is all along quite aware that there is no reality in them. The day phantoms are, however, in general more definite than the night ones, and consist of liuman beings and other resemblances to which names can be given. The night ones, so far as we are aware, are always formless. They seem to come out of the deptli of the darkness, into which their outlines melt and vanish, so that only a portion is seen. This portion is usually, if not invariably, a lead or face of some kind or other, always ugly or horrible, and often seeming to mock the sleepless sufferer with the most grotesque but insulting grins; sometimes the phantom 
advances, magnifying as it proceeds, like the shadow in a phantasmagoria, till it seems close to the face, and abont to overwhelm the patient; but just at that instant it vanishes, or changes to another which is dimly seen in the distance. In this way horror and torment are often suffered during the whole of the night, which is lengthened to an age; and the miserable sufferer can neither rest his body nor exercise his mind. 'Thought in bed, after a refreshing sleep, when there is nothing to attract the eye or the ear, is often one of the most pleasing and satisfactory occupations in which one can be engaged; but such a state as that mentioned is the very opposite; and yet the sole cause is a peculiar exhaustion of the nervous energy, to which no appropriate name can be given. Gloomy states of the weather, and gloomy seasons of the year, are apt to produce this state, though in a slighter degree and without the phantoms; and we believe that the most effectual remedy is vigorous bodily exercise, which shall bring down the tone of the motive system to that of the sentient one, and by that means procure sleep, which is in all cases a temporary cure; and this shows that repose is wanted, but that one part of the system is not exercised to the requisite degree for it.

In the morning this disordered state is never experienced, especially by those who are up and active betimes; neither is it ever felt in the morning of life, or at an early stage of it, unless by those whom the fashions of society prevent from having the proper exercise of their muscles. It seems, indeed, that the extreme energy and readiness of muscular action, of 
growth, and of all the other energies of nature which are displayed after the pauses, is an accumulation which has been making during the pause; and though nature has so adapted it as that it carries on the individual till the next pause, yet that it gets weaker and weaker as that pause approaches, more especially if that pause is to be final, and not a mere temporary rest.

We find this exemplified alike in the day, the year, human life, and every other periodic time to which we can liave recourse. It is found even in the varied motion of a planet in its orbit. There is a serenity, a stillness and repose about the evening, especially after a sultry day, during which nature has been fatigued by the action of the sun, which is not felt in the morning, although the air is equally free from clouds and wind. It is true that we may in so far go along in this difference, because we in so far partake of the activity of the morning and the tranquillity of the evening. The autumm, too, is, in countries like Britain, usually the most tranquil season of the year; and until the weather actually breaks, the nearer that it is to the Winter, it is the more tranquil; and we may, so to imagine it, see the seasonal part of nature preparing to lie down in peace upon its couch for the period of rest. The "green old age" of human life, after the restlessness of youth and the passions of middle age liave subsided,after we lave been taught by experience, (the only teacher to whom we will listen in such matters,) that pleasure is a delusion, and ambition a phantom, and that success and renown in the pursuits of life are apt, 
like the light of the sum, to shime equally upon the evil and the good,-that particular stage of life bears some resemblance to the tranquillity of the closing day and the closing year; and we believe that the balance of experience is in favour of all those three periods, as being the best in their several cycles for the exercise of profound and continuous thought.

'Thus there are many circumstances which render the Winter of the year a most necessary and desirable season; and were we to add to the list all that it does in the way of bringing families and individuals into closer contact with each other, and thereby giving scope for all the courtesies and charities of life, we should not fail in being convinced that it is not behind any of the other seasons in real interest and value. Our business, however, is more with the appearances of nature in the Winter; and these can be best understood by shortly noticing some of the prevarations which nature makes for the Winter, the more marked styles of its coming, and some of their actions which are continued through the season, or are in a state of the greatest activity during the pauses of the rest. 


\section{CHAP'TER III.}

TIL COMING OF WINTER.

As thint pause in the activity of nature, which properly deserves the name of Winter, is owing to two causes, the very opposites of each other, and as both of these canses are subject to many modifications, the coming of the season is necessarily of that varied character of which no general description can be made accurately expressive. These two causes, to which we have had occasion to allude again. and again, may, perhaps, in their primary signification, be regarded as modifications of only one active cause-the beams of the sum - which are the grand agent in vegetable action, and also in animal life in as far as it is connected with the year, and changes with the vicissitudes of that. Water, which is the other stimulus to plants and animals, is more passive in its nature, and seems to have no influence either on the one or the other; unless when it has a certain temperature,-or in other words, when it is under the influence of such a degree of the action of heat as suffices to restrain its natural tendency to 
crystallize; under the full influence of which it has 110 more stimulating effect upon any thing that grows or lives, than the erystals of any other mineral have, be that mineral as stubborn as it may.

We eamnot, in strict propriety, say that the beams of the sun-or rather the heat of those beams, for that is their most general and powerful infuenee-and water, are not, logically, the antagonists of each other; as the one is known to us only as action, or in the effects which it produces, while the other is known as substance, having qualities, and subject to effects produecd upon it. 'This distinction may, to some, appear to be a nice one, and to bclong to the eategory of subtleties, rather than to that of useful distinetions; but it is a very useful one, and indeed indispensable, if we wish to have clcar and satisfactory notions of the general principles and working of the system of naturc.

Feat, though a different mode of action from life, whether animal or vegctable, yet belongs to the same elass; while water, and even that action of water which characterises the polar Winter as distinguished from the tropical one, belongs to the class of substances, and not to that of actions properly so ealled. 'Therefore, when a vegetable passes into the state of quicsecnee from the influencc of that superabundanee of heat above moisture which brings on the tropieal Winter, it docs so without any violence of eontest with the prineiple of life in it. The very same agency which, cxacted in a more moderate degrec because of the cold produced by evaporation in the rainy scason, stimulated the plant to activity, brings it to its seasonal repose during the ardour of the dry season. 15 3 
'I'hus, the plant of the tropical climate needs no specific preparation for the dry and warm season during which it is to remain in a state of inaction. It passes quietly into that state as into a sleep after fatigne; and very often it is so constituted as that no ordinary climatal heat, and no continuation of such heat, if the natural concomitant of dryness is along with it, can do it the smallest injury. But if, on the other hand, those plants which are specially adapted to the seasons of tropical countries, are exposed to moisture in the season of their natural repose, they are as certainly destroyed as they are when exposed to frosts in the season of their activity.

It is not possible to lay down any law in these matters, which will any thing like agree with the latitrides, or the succession of the seasons, as these would be produced by astronomical causes alone, upon a globe of miniform surface both as to level and as to component matter. In almost the extreme of both Winters, too, there still remains something for the vegetable kingdom to do-something that would run to waste by being carried into a region in which it could not be available for any natural purpose: and the law of nature is, that not a tittle of the action of nature shall be exerted in vain, any more than an atom of the substantive matter of nature shall be lost. In the colder regions we have the mosses, which are to languish and become inactive in the summer, but, as will be more particularly shown in another chapter, are in vigorous growth when that of the flowering vegetation of the place is over for the season. The plants which in 
this manner continue to grow in the winter of the cold latitudes, (which they do-not only in situations where the humidity on the exposed surface, though not actually frozen, is on the verge of freezing; but also in places where a coating of snow or ice cuts off for the time all communication between the atmosphere and that part of the earth which is seated deeply enough for remaining unfrozen, and therefore tends, by the uniform disposition of heat, to diffuse its action equally in all directions, to impart a portion at least of its action to the colder surface, stratim, and atmospliere over it) prevent the waste of this action, which, were it to get to the frozen surface and the wintry air, would be so diffused through the latter as to be incapable of producing a useful effect at any given point. 'The frozen surface, whether it comes under the denonination of snow or of ice, works in concert with those vegetables, just as in all latitudes and situations the parts and productions of nature work in concert with each other; and thus, if there is any energy of nature, however small, available for any purpose of natnre, there is always some production of nature ready to profit by it, so that not a nameable fraction of the energy of the system shall be lost.

'l'hough different in mode, it is the same in principle in those climates and regions where the Winter is the result of an excess of heat and drought. For as, in the cold latitudes, there is a constant tendency to the radiation, from the earth to the atmosphere, of heat-which, were it to reach the latter, wonld be dissipated, and so produce 110 useful effect in nature-so there is in the dry 
and parched Winter of the warm latitudes, a constant tendeney to the evaporation-it may almost be ealled the radiation-of moisture from the depths of the earth; and were this moisture to reach the atmosphere, dry and thirsty as that is, it would be lost and dissipated without producing any useful effect. This waste of humidity in the one extreme of the Winter, would be as contrary to the general and invariable law of the system as the unprofitable waste of the aetion of heat in the other; and therefore there are, in many situations, vegetables prepared and adapted for turning it to account, in like manner as the mosses of the cold latitudes turn to account the heat which otherwise would be lost in the Winter there.

It must be borne in mind, however, that, as all the powers, functions, and eapacities of nature, in whatever beings or substances they may be displayed to our observation, are finite, there must in every ease be a limit beyond whieh they eamnot be displayed. This holds very conspieuonsly in both of the general kinds of Winter. The dry and parehing Winter is oceasioned by the evaporative power of the atmosphere becoming greater than the attraetion of the vegetables for humidity; and though the native plants of hot and dry places are, by the peeuliar texture of their epidermis, much more able to bear a parching atmosphere than the native plants of a temperate region in which rains are frequent, yet it is not only agreeable to the system, but a necessary consequence of it, that these plants should, under some ciremmstances, give way to the drying or craporative power of the air, so as to leave some spots of the deserts absolutely plantless. 
When this shall be the case, is, however, not determinable by any generàl reasoning, but must depend on the nature of the particular case ; and even that is always of a compound and difficult nature, as depending upon many causes, the whole of which require to be carefully observed. Thus, though heat is the general agent in producing the parching Winter, it is not the only one; for the parching east winds, which are often so injurious to vegetation during the early part of the season in Britain, are, usually, if not always, cold winds. Their cold is chiefly owing to their great evaporative power. They are east winds, originating in the flat and fenny parts of the continent, which are completely soaked and saturated with humidity during the Winter; and thongh the air when it leaves them is loaded with moisture to the full extent of what it can retain in solution, yet when it reaches the land in England it becomes a drying wind. As such, it not only gives us a slight example of the Winter of drought, but is injurions to certain early kinds of our cultivated vegetables; though it must not hence be inferred that it is upon the whole injurious, or that the eastern counties of England upon which those dry and parching winds of the spring and the early summer have frequently an injurious effect, have a worse climate than the western counties which escape them. The truth is, that there is in reality no such thing as a bad climate, a bad season, or even bad weather, though such be our phraseology in our grumbling. No season or weather is ever sent from one place to another in the character of a hostile invader. It always comes in consequence of being exactly what is wanted for the greatest 
good of the place at which it occurs, whatever may be the opinion of men respecting it, and whether it be the most favourable for the operations of art or no. We must purchase our experience of the weather and the seasons, as well as of every thing else; and even when we have purchised it we must study and understand it before we can in any way profit by it. Hence it would be wise in us could we spend in the acquisition of this knowledge, and the means of using it, that time which we spend in complaining that the weather is not what we wish it to be-or even in the offering up of needless, unavailing, and not altogether unimpious prayers for changes for which we can liave no rational ground of hope, and which would, in all probability, be productive of the most mischievous consequences if it were possible for us to bring them about. We cannot even imagine, unless we are out of our senses, that the general laws of nature can or should be changed-especially for the gratification of our crpidity or our caprice, which are the usual sources of on grumblings at the character of the day or the season. Were we to reflect for a moment, we might soon convince omrselves that our arrogance in these matters is fully as great as our impiety. Are we better judges of how any one part of the working of nature ought to be conducted than $\mathrm{He}$ who saw the whole history of every individual part of it, before it pleased His almighty goodness to command a single atom of it into being? If we are not, then we ought to leave the government of the world to God, and pray only for his guidance in the governing of ourselves. The withering winds from the east, to which we have 
alluded as giving some very faint idea of the coming of the dry and parching Winter, offer no uninstructive lesson upon this subject. They wither some part of the vegetation, it is true; or if they do not actually wither it, they check its growth; and the places and seasons affected by them, are not so favourable for some kinds of cultivated produce, as those which are free from them. But they have a most beneficial effect in drying the great breadth of the flat İands, which are most valuable to the farmer; and it is not unworthy of remark, that the places both of England and of Scotland which are most subject to these winds, are exactly those upon which the best and most abundant crops of corn are produced.

Though we have instanced those blighting days in the early part of the year in our own country as having some analogy to the tropical summer of drought, yet it is necessary to mention also, in what the two differ from each other. 'They are both the results of heat in the regions where they occur, for the surface wind always comes from the colder country to the warmer one; but they come upon a different kind of vegetation, and when that vegetation is in a very different state. All that which is properly seasonal in the country which has the tropical Winter, has completed its seasonal action and is in the proper condition for repose when the Winter comes upon it. Our blighting winds of the early season come upon the vegetation in a young stage of its animal career, when the growth of the individual is the greatest possible, and the state of that which is newly grown is consequently the weakest. 'There is amother difference 
connected with this one, and in part at least the cause of it, of which it is necessary to take notice. The tropical Winter is ushered in by a constantly diminishing evaporation,-not from a lessened evaporative power in the air, but from the fact of there being less moisture upon which that power can act. The heat is, in consequence, gradually on the increase up to the time of the pause of seasonal nature, in countries of tropical character, and during its continuance, whether that be longer or shorter.

The tropical Winter is therefore a season of the repose of maturity, and comes gradually, and as one may say, pleasantly on, without any disturbance or commotion of the elements. The heat is predominant in the atmosphere, on the surface of the earth, or in the earth itself to a considerable distance below the surface. There is no doubt an action of heat, and a very powerful one, in all the three; but the moisture, by means of which this action has, in the earlier part of the season, had so powerful an effect upon vegetation, is gone-evaporated to the upper regions of the air, and thence conveyed away to other places by the current. Then, though the colder air which comes to the arid place along the surface of the ground may contain moisture up to the point of saturation when over the cold places from which it comes, it becomes a dry and drying air upon the warmer surface, for the very same reason which gives this character to our spring and early summer winds from the eastern sea.

The depth to which the action of these great heats penetrates into the earth and dries it, depends upon 
various circumstances, the chief of which are the nature and form of the ground itself, and its height above the level of the sea, or its distancc otherwise from water, which the dry season is unable to exhaust. The depth from which, especially in a very porous soil, the action of the great heat of tropical climates brings up, in the state of vapour, as much moisture as suffices for the healthy and vigorous growth of numerous specics of plants, when there is no rain or even formation of dew, is much greatcr than one would be apt to suppose. Therc are various places in Britain, where the retiring sea has left large breadths of mere sand, not much elevated above the prescnt high-water linc, and certainly withont any thing else but finely granulated sand, to a depth lower than even the line of spring-tide ebb. But the sea-water pcrcolates through this porous mass, just as the water of the Thames does through the substratum of that level incumbent ipon watcr-washed gravel, and of course once the bed of the river, which extends, with somc variations and partial interpolations of clay, from Chiswick to Westminstcr; and while the sea-water thus percolates through the sand, its saline ingredients are in great part filtcred away, and it becomcs pure, wholesome, and well-adapted for the purposes both of vegetable and of animal life. Upon such grounds as those to which we are alluding, many species of vegctables have more rapid and more healthy action than they have upon any soils of a difierent character. Upon those loose and sandy soils, the plants, contrary to what we would at first thought be apt to suppose, do not suffer so soon or so severely from dronght as they do 
upon the more retentive soils, especially the stiff clays; and from the humidity, even in the most lieavy rains to which such soils are subject, the vegetation does not suffer at all. They are also firm under the foot under the influence of every kind of weather; and they may be worked at all seasons, with ease and safety. In passing, we may remark that soils of this description are most frequent in the lower valleys and along the banks of the estuaries of the larger rivers-the very places which are best adapted for the sites of large towns and cities, and the numerous congregating of human beings; and one would almost imagine that those banks of light and porous deposit are formed for the express purpose of furnishing the numerous inliabitants of such places with esculent vegetables, in the greatest abundance, of the best quality, and with the least labour.

In proportion as those deposits are, in their substrata, of a more porous nature, and are nearer the level of the sea, they have more of a tropical character, and the soil obeys, or works to, the influence of the sun to a greater depth. There is far more in this working of the earth in its solidity, as it may be termed, than those who are not in the liabit of reflecting upon such subjects would be apt to suppose; for when, by this means, the active depth of the soil is doubled, one acre of surface becomes equal in value to two; and as this working in depth is much more steady and uniform, under all atmospheric vicissitudes, than that of the mere surface or of a limited depth, the value is proportionally increased. 
The depth from which moisture sufficient for the vigorous action of some kinds of vegetables will come in some of these situations, is truly wonderful, — so much so as to leave one in doubt whether the very conversion of the surface into sand may not absolutely be, in some instances at least, a means of fertility to those regions which have no rain during great part of the year, and no springs or surface streams. The great desart of Adjmeer, on the left bank of the Indus, which lies between the Punjaub, or Land of Streams, and the singular periodical marsh known by the name of the Runn of Cutch, is a remarkable instance of this. Over a very large extent of that part of the world, there is not one fountain "welling-out," or a single river or" rill to be seeu on the surface; and even the rains are uncertain, as the clouds which form and fall when the air reaches the comparative cold of the southern slopes of the Himalaya, pass over this thirsty sand in a state of invisible vapour. Even when rains do fall, the thirsty and porous soil very speedily drinks them up, so that their effect upon the surface regetation is both trifling and momentary. But though the surface is thus parched up, and the inhabitants-for there are inhabitants in this desart-can find no water in quantity useful for drink and other domestic purposes, till they dig wells to the depth of two hundred or three liundred feet; yet the influence of the sun, and probably also that of the radiating heat from the eartl, can fetch it from this depth in the state of vapour; and members of the gourd family and other plants can arrest it at the surface and turn it to the purpose of a very vigorous 
growth-a growth exceeding any to be met with in places which, according to our notions of their physical condition, are far more favourable for the growth of any vegetable. In the desert which has been mentioned, the water-melon, one of the most cooling and grateful, though, from the coldness of its juice, not the safest of fruits under a burning sun, attains a diameter of a foot or more,- - and that on the bare sand, without vegetable mould, manure, or any other attention by inan than the mere placing of the seeds or the plants in the situation where it is wished that they should grow.

This protracted giving out of humidity from the ground long after there remains none on the surface, or in the atmosphere over it, and the peculiar structure of many of the plants of such places, make the coming of the repose, or Winter of drought, considerably more mild and slow than it would be if the whole of its supply of water were derived from the surface, the mere depth to which its roots penetrate, and the atmosphere over that surface. It is by no means improbable that some of the species of plants which grow in those situations, and defy the utmost ardour of the heat and drought, may be able to attract humidity by means of the great quantity of alkali which they contain. This alkali is, of course, either potass or soda, but more frequently and more abundantly the latter, especially upon the most arid surfaces; and those alkalis have, generally speaking, a great tendency to attract humidity; and in consequence of this they can maintain their existence in places, where plants which have not these ingredients so abundantly in their composition must yield to 
the dry Winter, and repose in their bulbs or their seeds.

But whatever may be the character of the vegetation upon which it comes, the tropical Winter invariably establishes itself without any struggle of the elements; and it does this whatever may be the time of its coming or the length of its duration. It may be the only Winter of the year, as it is in regions of a decidedly tropical character, which have not that supply of linmidity which is required for a perennial or unceasing growth; it may be the mere brief power of common growth which, in the temperate climates, arrests the progress of the leaf and the shoot, in order that it may mature the flower and make certain of the perfecting of the seed; or it may be the simple power of the heat of the day, which takes place in all latitudes and climates when the weather is sufficiently dry and warm: but whatever may be its use or its duration, it invariably comes gradually and gently, and very little specific preparation is necessary for its coming.

For this description of Winter no specific preparation of the vegetable kingdom is necessary, as it is, like the fine dry weather of what we consider a favourable autumn in our latitudes, merely a reposing of the preserved parts of the vegetation, which are not liable to liave their texture destroyed by the alternate freezing and thawing of their juices, as is apt to be the case in these latitudes, where the Winter is a prolonged contest between the different agencies which disturb the atmosphere.

There is also an astronomical cause for this tranquillity 
with which the dry Winter of the tropical climates sets in. At the equator, the influence of the" sun upon the surface of the earth differs very little in the course of the year,-so little that, for several degrees on each side of the equator, the only difference of seasons that can be traced throughout the whole course of the year may be said to be owing to terrestrial causes alone. The length of the day throughout the whole year differs but little; and though, at the equator itself, the meridian altitude of the sun shifts about forty-seven degrees in the course of the half-year, and back again the next, yet this is so small a deviation from being directly over head, that the difference of solar influence occasioned by it is but small in comparison with the changes from the same cause in the high latitudes.

At the poles, the celestial causes of the differences of seasons are the greatest possible,-the contrast being six months of the constant presence of the sum, as one summer day, and six months of its absence, as one Winter night. These are not indeed quite equal to each other in length, as the refraction of the atmosphere brings up the sun sooner, and retains it longer, than the absolnte mathematical division of the year. But this difference is not great, and so we need not encumber ourselves with the consideration of it in a general sketch. The change of the sun in declination is from about twenty-three degrees and a half below the horizon at the Winter solstice, to the same above it in the summer; and as-the daily change in declination, which is very little at and near the solstices, excepted-the apparent daily course of the sun is parallel 
to the horizon, there can be no difference in the temperature of the whole twenty-four hours, either at the midsummer or the midwinter, at the poles. The average amnual temperature there, according to the theoretical calculations, is that of freezing, at the mean level of the earth; but as there are causes arising from the natmre of surfaces, and the distribution of sea and land, and of the influence of the sun upon these, and the resulting actions of the atmosphere, which, in all latitudes, make the observed temperature differ from that which calculation gives, it is probable that the poles themselves are not the places of greatest cold. Neither pole has been reached: to attempt the south one appears to be out of the question; and though the north may be reachable, it never has been reached. But from the reports of those adventurers who have, of late years, braved the horrors of the polar climates, and brought, as the reward of much toil and danger, a very scanty stock of information, and nothing of practical valne-except that there is little more knowledge to be had,-it seems that the greatest cold is toward the magnetic pole, which is about a sixth part of the quadrant from the pole of the earth's rotation.

'This is rather a curions matter, at least in the estimation of those who make short work of the economy of nature upon our globe by referring the whole to the celestial causes, which can be stated with mathematical precision; and leave out the terrestrial modifications, which are the most difficult, and therefore the most rnecessary to be explained of the whole. But it is in perfect accordance with what, upon close and careful 
examination, we find to be the case throughout the whole of those more mighty workings of nature, in which the air and the water are the chief parties. The strifes among men and other little things upon the earth, are always productive of heat, or heat is productive of the strife-for it is not easy, or even possible, to arrange them in the order of cause and effect, according to any settled law. But the more mighty strifes of the elements appear to be attended with cold; - the region of cold is the region of storms, and the storms which usher in the cold weather in climatal latitudes are ever the most violent. 'Thus the tranquillity in the region of the pole is, in all probability, the reason why that is not the place of lowest temperature; and the whole action of nature there, is, very likely, nothing farther than the congelation of a certain portion of water in the Winter, and the thawing of the same again in the summer, performed in the most tranquil manner, without wind or any other angry demonstration in the atmosphere.

This tranquillity may be regarded as the predominating character of both the polar Winter and the polar summer, after they have fairly set in; and the line of the greatest cold is the region where the setting-in of both is accomplished with the most violent action of the elements. This line is not a parallel of latitude, or probably any thing nearly approaching to one; for none of the isothermal lines, or lines of equal temperature, are parallel, neither do they remain constant to the same latitude for any two seasons; and, although there are not yet any data for the laying down of this line of greatest cold in all longitudes, or even at a series of 
distant points round the earth, yet there is no reason to suppose that it follows a different law from the rest; and is nearer the pole in some latitudes and more distant from it in others, according as it is affected by terrestrial and atmospherical causes.

But in whatever latitudes it may be situated, we are to regard it as the locality of the maximum of the polar Winter, just as the line of greatest heat, whether it happen to be on the equator, or to the north or the south of it, is the maximum locality of the tropical Winter. With regard to this last, there are some indications, in different parts of the circumference, which may guide us in our endeavours to ascertain the position of the other. In the middle of the great oceans, the line of greatest heat is probably upon the mathematical equator of the globe, or at all events it appears to cross that equator at some point in the middle of each of those oceans.

In America it is certainly on the south of the equator; for the snow does not descend so low, or lie so long, upon the mountains in Upper Peru, about fifteen degrees or one-sixth of the quadrant south of the equator, as it does upon those which are immediately under the equator itself. The exact coincidence between the distance of the line of greatest heat south of the equator in the American continent, and tlat of the line of greatest cold south of the pole in the same, is not a little striking; and it is the more valuable on account of the fact in each case having been ascertained by independent observations, made by men of talents and reracity, without any view to the establishment of any 
relation $\mathrm{or}^{\circ}$ coincidence between the two. Thus while those who go to the observation of nature in the hope of establishing theories which they have framed or fancied in ignorance of the facts, are in most cases disappointed; they who observe in that right and candid mammer which seeks only to know what nature actually is, find theories already established, and fit to be made the instruments of knowledge.

In the western part of the eastern continent, the line of greatest heat is certainly on the north side of the equator, though at what distance from it has not been observed. In the same longitude, the line of greatest cold is certainly much farther to the north than it is in America, though whether it extends beyond the pole, has not been, and probably cannot be, ascertained. The probability is that, somewhere about the longitude of Spitzbergen, the line of greatest cold may pass beyond the pole, and be actually thrown upon that in the north of America; and the fact, that the lines of greatest cold and heat, in the only situations in which they have been established, are exactly ninety degrees, or a quadrant, from each other, though they both lie at about fifteen degrees south of the pole and the equator respectively, gives no small probability to the hypothesis. Senegambia, which appears to be about the hottest latitude in Africa, is in about fifteen degrees north, or at the same distance from the equator on the one side, as the lottest parallel of South America is from it on the other.

It is probable that in the eastern parts of Asia, the line of greatest heat is again to the south of the equator, 
though the character of the earth's surface there prevents the establishment of it by actual observation. The sea at Torres' Straits, on the north of Australia, is probably the hottest of all seas; and the land to the south of it is also very torrid; but local causes are so much in operation there, that they forbid us from attempting to draw any general conclusion. It is somewhat curious that the direction of greatest cold should point toward the magnetic pole, and that the line of greatest heat, when not obviously disturbed by local causes, should seem to be at the distance of a quadrant; and it is not less curious that the magnetic and the electric or heating agencies should also appear to have their lines of action across each other; but the knowledge of these subjects is in its infancy, and it forms no necessary part of our main subject, in the present state of knowledge; though at some future time-of the arrival of which there is no reason to despair-they may be found closely connected, and each of them capable of throwing much valuable light on the other. In matters of this kind, when they are prosecuted in the spirit of true philosophy, and not with a view to the establishment of any of the fancied hypotheses of those quack doctors, who are the pests and nuisances of the paths of knowledge, we never have any occasion to despair. A century - a day, before experiment decided the point, and Benjamin Franklin, the printer, sent up his paper kite, and fetched down the lightning of heaven, demonstrating that it is identical with an action excitable in all matter, and retainable in some, that lightning was one of the mysteries of nature, generally 
believed to be the result of some supernatural working, by means of which the ordinary course of things was broken in upon and disturbed. And, as the heathen of old placed the thunderbolts - by which they really meant the lightning, as the thunder is merely noise, and in itself, like all noises, (would it were the same with noisy persons!) incapable of doing either good or harm-in the hands of Jupiter; so the Christian world, for a long time, continued to place the same bolts immediately in the hands of the Almighty, as though a special interposition of His power had been necessary to accompany the turning of a monsoon, or the fall of a shower of rain in the warm season of the year! The plain man, whose object was truth only in all his investigations, dashed the bolts from the hand of Jove the Thunderer, and did more to vindicate the majesty of God than if he lad penned a thousand homilies expressly on the subject. The example, though a splendid, is not a solitary one; and, with the encouraging example of so many, we need not despair of arriving at knowledge, if we seek it in the right path, and with the zeal and single-heartedness of truth.

Thus it appears that it is no very easy matter to find the head quarters either of the polar or the equatorial Winter,- that is, the place at which each of them may be said to have complete sway during its season; and yet this, and much more than this, is necessary before we can be in a condition to have any rational conception of the coming of either of them, far less to give any intelligible account of it.

The tropical Winter (and the summer in both cases 
is only the otler end of the balance to the Winter,) begins, or has its maximum, at a certain curve which surrounds the earth, not very far from the equator in any case, though sometimes on the one side of it and sometimes on the other; and probably dividing the globe nearly into two equal portions, though not by a plane section, as would be the case if the division were made on the plane of the equator or upon that of a meridian: and from this particular line, wherever it may be situated, the energy of this Winter subsides; and may be understood to reach its minimum in the locality of the greatest cold. Of the region of the maximum of the polar Winter, or that of the greatest cold, we cannot speak with so much certainty. Theoretically, it ought to be a point, and in the pole of the circumference of greatest heat, if that circumference were a circle. But, as told upon the surface of the earth, this circumference appears to be a curve of much irregularity, and therefore, the pole of it cannot, npon any known principle, be a point. According to the theory, which is the only guide that we can have in the matter, though by no means a safe one, the pole of every part of the curve should be a quadrant or ninety degrees distant from the curve itself. Local causes must, of course, disturb this not a little; but still this is the result to which the principle tends. Hence, where the curve of maximum heat is on the equator, its pole, or the point of greatest cold, should be at the pole of the earth's rotation; if the curve is on the opposite side of the equator to the pole referred to, the pole of the curve should be the same distance short of the 
pole of the earth, as is found to be the case in America; and if the curve is on the same side of the equator as the pole is, then the pole of the curve should be as far on the opposite side of the pole of the earth as the curve of greatest heat is from the equator-as we have conjectured, from pretty strong probabilities, may be the case in the longitude of the western parts of Africa and Europe.

Thus, though we have not, and are not very likely ever to obtain, data sufficient for enabling us to determine the exact locality, and the form and extent of the place of greatest cold-the home and especial throne of the polar Winter-yet we have some vague means of estimating what it is not, and thence more vaguely guessing at what it is. It is not the pole of the earth's rotation, as the astronomical theory would lead us to conclude, if we rested wholly upon it without taking into account the terrestrial modifications. It does not lie on the circumference of a parallel, as is apt to be supposed by those who, in a manner rather too hasty, suppose that it is connected with a revolution of the magnetic pole round the pole of the earth's rotation; and though the greatest cold hitherto observed has been in the neighbourhood of the present locality of the magnetic pole, there is not sufficient ground for believing that there is any absolute connexion between that pole and the place of greatest cold. About the close of the sixteenth century, the line of no variation lay very nearly in the longitude of Siptzbergen, and of course the longitude of the magnetic pole must have been the same; but the establishments which the Dutch then had on 
the shores of Spitzbergen for their whale fishery, shows that the climate of that island could not have been much more rigorous at that period than it is at the present time; and Spitzbergen is in a latitude considerably nearer the pole of the earth than the present locality of the magnetic pole.

Compared with these negatives, there is unfortunately but little of a positive character that can be added. That, in the northern hemisphere, the head quarters of the polar Winter are in the north, is a point which every one will admit; and that it is not a point or pole, but a patch or zone, follows from what has been stated on the irregular position of the circumference of greatest heat. Probably it is very irregnlar in shape, and far from uniform in cold even at that time when such a region must be under the complete and tranquil domination of uninterrupted frost, so severe as not to have left a single particle of moisture in the atmosphere. Those places of the zone or patch-which must not be confounded with the polar zone of geographers, as the two do not coincide-whereon the greatest number of quadrantal ares at right-angles to those parts of the circumference of greatest heat, from which we may imagine them to be drawn, fall, should, upon the hypothesis, be the coldest; and those upon which the fewest fall should be the warmest; but how these alternate with each other, and how they differ in their average temperature and their seasons, are matters of observation which it is impossible to explain theoretically.

Such, in brief and very imperfect outline, are the lead quarters, or places of maximum influence, in the 
two opposing causes which bring about the two kinds of Winter that vary the year in the contrasted regions of the globe. Our next business is to inquire where the coming of either of them is attended with the greatest violence, and in consequence of this reeds the greatest preparation; and to ascertain, if possible, the general reason why this should be the case, but without entering into any of the minutix, for which, indeed, there are no satisfactory data. The general answer to this inquiry-though a very vague and indefinite one, is, that the contest must be most violent where the one comes upon the other in the greatest strength and with the greatest rapidity; and in order to understand, in a rough and general way, where this may be expected, we must attend to the positions in which the two powers are placed with regard to each other on the surface of the globe. The three circumstances of different latitudes, different lengths of day, and different elevations above the mean level of the earth, are almost the only ones which we can afford room to mention, - the more local ones being very numerous and difficult of explanation.

In latitude, and without taking any notice of variations in other respects, the canses of the two Winters overlay each other, in the whole surface between what we have described as being their respective head quarters; and early diminishes in power as it approaches the head quarters of the other, until it is, upon the mere consideration of latitude alone, hardly capable of producing any effect. If this were the only circumstance upon which the state of things depended, there would 
really be no seasons, and very little action, or growth, or life of any kind upon the earth, -no vegetable useful to man could grow in England, no land animal useful to man could be supported; and, a little fartler to the north in latitude, and a little higher above the surface than its mean level, would be under the constant and umbroken dominion of ice. There would be no contest of those opposite causes of Winter any where; and no currents, either of the atmospheric air or the oceanic water; - the whole would be in unbroken tranquillity; but it would be a tranquillity of the most melancholy description-the unbroken quietude of death. That the axis of the earth's rotation makes an angle of about sixty-six and a half degrees with the major axis of its orbit the one way, and one humdred and thirteen and a half the other way, seems so very trifling a matter, that the majority even of persons who consider that they have been well educated, and lack nothing in wisdom, would be, and actually are, apt to turn away from the consideration of it, as from a trifle not wortly of attention; and yet, were it not for this trifling circumstance, all their wisdom and all their toil could not find them so much as a single potato to eat; for, were it not for this little circumstance, simple as it is, the greater part of the earth's surface would be utterly barren and unprofitable.

But the change of the sun in apparent declination northward and southward, which is the result of this simple relation between the plane of the orbit of revolution and the position of the axis of rotation, shifts the seasonal action, and brings about those commotions of the elements which, though often both fearful and м 3 
formidable at the time, are the real causes of the beauty and the activity which afford us so much pleasure and profit in the kingdoms of growth and of life.

'The shifting of the sun in declination, which is the apparent result of this obliquity of the earth's axis, as seen from the surface of the earth, is only over fortyseven degrees of the meridian in the one half-year, and back again over the same in the next. But this, although the same in itself in all latitudes, tells very differently upon the different latitudes of the earth,the change being a maximum at the equator and a minimum at the poles. The simple element in measuring the influence of the sun upon the earth when at any distance from the zenith, is the cosine of the zenith distance; and the measure of the difference of influence at any two distances from the zenith is the difference of the cosines of those distances, - the cosine of the zenith distance being the same as the sine of the height above the horizon, and expressible by a straight line let fall from the sun perpendicularly to the plane of the lorizon, that plane being supposed to be produced as far as may be necessary.

If the sun is in the zenith, the perpendicular will fall exactly upon the place alluded to, and the elementary measure of the infuence of the sun will be expressed by the whole distance of that luminary from the earth; and if the sun is exactly in the horizon, the line expressing the measure of its influence is reduced to 0 . Near the zenith the differences are very small, so that at sixty degrees from the zenith, or two-thirds of the quadrant, the measure has only decreased one-half; 
and as the horizon is approached, the sines become nearly equal to the arcs.

Hence, the nearer that any place is to the pole, and consequently the less the meridian altitude of the sun, the greater is the difference of solar influence with the same change in declination. We shall not state the numerical differences; because there are no results that agree with them; but any one who has access to a table of natural sines, will find numbers expressing the proportions, either in the cosines of the zenith distances or the sines of the altitudes, which are, of course, exactly the same numbers.

The estimate according to the sines, is made on the supposition that the sun is the same number of hours above the horizon at all seasons and in all latitudes; whereas, in the quadrant from the equator to the pole, the length of the summer day and the Winter night is of all variations from twelve hours to six months. By the combination of all these circumstances, the agencies in the high latitudes are brought not only to a difference from each other at the different seasons-to which the slight difference at the equator, as depending on the varying influence of the sum, is really as nothing,but they bring each up to a terrible power of attack or of resistance, according as the turn of the season is toward summer or toward Winter. They have this power altogether independently of the presence or the absence of humidity; though their influence upon that is productive of many of the most remarkable phenomena which are displayed during those periods of violent action. 
There are not in the tropical latitudes any general causes to bring up the small portion of polar action which is there, to a degree capable of producing any thing like a cold Winter, either at the mean level of the earth, or for a considerable height above it. The summits of the lofty mountains, indeed, in every latitude, have a polar character; and upon these the colrflicts of the two opposing agencies are perhaps more violent, and certainly more fiequent, than they are in the most angry regions near the poles. But furious as are those elemental strifes on the tropical mountains-and in some places they are fearful - they are limited in their range, and brief in their individual duration. The most violent hurricanes of wind, with driving snows, which make the noon-day under an almost vertical sun as black as midnight, armed with the lightning gleams and the thunder volleys, displaying characters very different from the most furious storms of the high latitudes, are often raging in a certain zone of elevation, while the most elevated peaks are still in the cold solemnity of their perennial snows, and the valleys below are basking in the heat of a tropical sun.

This character belongs, in some degree, to the lofty mountains of all latitudes; and as the latitude increases, it comes lower down, is more extensive in the range upon which it is displayed, and more seasonal in the times of its appearance. It is thus a Winter extending into every latitnde where there are mountains of sufficient height; and it is a Winter which in some situations is quite peremnial; and consequently, though it partakes of the cold of the polar Winter, it is a Winter 
of different character. Its plants and its animals have not a long Winter of pause, and a short summer of great activity, as those have which winter and summer in the polar climates. They have a peculiar character, and are not suited for places where there are trains of settled weather of any length. The plants which are found native upon such places, languish and waste away when they are brought down to the valleys or the plains, in spite of the utmost attention of the most skilful cultivator. Flowering plants are but few, and what are met with are not conspicnous either for their beauty or their usefulness. The lichens and the mosses form the characteristic vegetation of those stormy places,the former on the rocks and the cold and dry heights, and the latter in the humid places and by the runs of water. Of the smaller order of animal life there are few. Birds are not numerous, and they are confined to those genera which can subsist on the coarsest food, or bear hunger the longest, and best brave the violence of the storms. Mammalia are not abundant, at least where the situation is too elevated for the growth of trees or shrubs; and they are, in the more seasonal localities, either such as remain dormant for a time, or fleet-footed ruminantia that can bound among the crags and cliffs, and endure a great deal of labour in searching for their widely-scattered food. Among birds, the more powerful eagles and the long-winged vultures, are the most conspicuous; and they drive about in search of animals that meet with the casualties which are so common in these, the most stormy wilds of nature. The animals appear to be as peculiar in their 
nature as the plants: they have little disposition to quit their dwellings in "the munition of rocks," and they do not feel at home or thrive when they are brought into more kindly places.

Altogether, therefore, this mountain zone of what may be termed perpetual Winter, is distinct and apart from the lower places, which have the average climates and seasons of the latitudes in which they are situated; and thus they must be left out when we endeavour to explain the coming of the cold Winter, and the preparations for its coming.

But still, as the latitude increases, and the seasons become more marked and contrasted with each other in their characters, the mountain Winter comes down, and in so far blends with the Winter of the year, in many of its characters. It comes earlier, no doubt, than the Winter on the plains; and it comes with more uncertainty and greater violence. But the time of the tranquillity of its snows is longer; and, contrary to what those who have not observed or studied it, it departs more rapidly and with much less variation and fury of the weather, than on the plains, where it is upon the whole less severe, and of more brief duration. The reason of this latter circumstance is, that, by the time that the mountain snows begin to melt and pass into vapour, the plains and valleys have become comparatively dry and warm; and they draw toward them the mountain air and the evaporated moisture along with it. There is, thus, nothing left upon the mountains by which the serenity of the atmosphere can be very much disturbed. The plains and valleys are at the same time 
greatly benefited; and they thus escape those blighting winds, to which allusion has been made, as injurious to the wide plains near the sea, when that is of no great breadth, and the country beyond it cold and humid.

Such are some of the means, as depcnding on difference of latitude, length of the day, and elevation above the mean level of the earth's surface, by which variations in the coming of Winter are produced. There still, however, remain some circumstances, connceted with the more rapid changes of the solar influencc, arising from the same absolutc changes in declination, and the more rapid alteration of the length of the day in the ligh latitudes, to which it may not be improper to pay a little attention. The average altitude of the sun, in every latitude, bcing the compliment of the latitude or the difference between it and ninety degrees; and the variation of influence, and also in the lcugth of the day, being greater in proportion as the altitude is less; it follows that, after the summcr solstice is past, the days will cool and shorten more rapidly in proportion as the latitude is higher; and, as what is taken from the warmtl and length of the day is added to the cold and length of the night, the night must gain faster upon the day, as the latitudes are higher. The change, or the cause of change, in the heat and length of the day, is most rapid near the time of the equinox, as then the declination varies most rapidly. We need scarcely add, for it is self-evident, that any cause or agency which acquires strength at a more rapid rate, must be sooner able to accomplish its work, whatever that work may be, than one of which the incrcase is slower. In very 
high latitudes, too, there is not, except upon very peculiar surfaces, any thing like a summcr pause in nature, or a languor of heat, to be followed by the refreshment of the midsummer rains, and the growth of the midsummer shoot and the after-math, and then by the agreeable screnity of a warm and dry autumn, such as has delighted, renovated, and emriched us in England, in this present year 1837. In high latitudes, the rains do not set in so soon; and they do not come with the lightning and thunder, or any of the other traces-faint ones it is admitted-of the turn of a monsnon, by which the midsummer rains are ushered in in England, espccially after a summer that has been very dry and snltry. They are protracted till September, or at all events till August, unless in latitudes so high as that the powers of Winter are not wholly subdued eren in the hottest part of the summer.

When those rains do come, the cold is so rapidly getting the better of the heat, that a very little addition produced by evaporation suffices to reduce the temperature to the freezing point; and the moment that this is the case, the Winter may be said to have commenced; for the cold gains rapidly, and, unless by currents of air from a warm sea, or some other local means, the frost does not relent until the Winter solstice is long passed, and the summer influence of a new year comes into operation. In very high latitudes, and also in peculiar situations in latitudes not so high, the cold often gets the mastery before the rain comes on; and in such cases, the fall of humidity from the atmosphere is in slow from the very first. This is most frequently the 
case in situations where the difference of temperature in the summer and the Winter is very great; and where, marshy places excepted, the surface of the land is comparatively dry. The moisture which is on the surface is usually frozen before the snow comes; and the shallow waters are also mantled with ice.

This extreme rapidity of the coming of Winter, is not brought about so much by the action of the atmosphere at the place itself, as by the invasion of a cold atmosphere from another. The setting in of the Winter in Canada is perhaps one of the most remarkable examples of this. Labrador comes upon it; and the coming partakes not a little of the sublime. The biting wind first sweeps over the surface, getting absolutely colder by the evaporation which it produces. The surfaces of the shallow waters shoal into fibres of ice as if by magic; and as the effects of the wind increase, its velocity accelerates, until it acquires the violence of a hurricane. As soon as the surface is frozen, the congelation mounts upward, every atom of water in the air is turned into snow, which careers along in serried array, whelming and whirling, turning into ice in the deeper waters and the marshes of the woods; and encasing the whole land in one thick and solid mantle. While it continues, the people are confined to their houses; and the strength of them is put pretty severely to the test, by the combined thumping and thundering of the wind and the snow. But it is too violent for being of long continuance, and too confirmed in its character for admitting of any return of those last remains of summer which it has driven from the land. It is speedily over"; and 
those parts of the country which were not passable during the summer, become solid paths. The atmosphere is serene and quite dry, so that it is very healthy; and those who take exercise in it soon get warm. Friends whom the pathless marshes had separated from each other during the summer, pay their visits; the woodsman marches forth to his labour in the forest; and life on the snow is really more desirable than in the opposite season of the year, when the temperature equals that of the West Indies; and any one who ventures to try the shade of a tree on the marshy ground, is almost smothered, and stung to distraction by myriads of insects.

But this Winter, violent as it is, is as safe for the ground vegetation as it is sanatory for the people, and favourable for their journeyings by land. The snow comes on before the ground has been cooled to any considerable depth; and after it comes and settles, there is no more radiation of heat from the earth to the atmosphere; but it continues to be given out by the lower strata of the earth, and thus ascends as far as it can come, reducing the frost which has penetrated into the ground, and cherishing the roots of the plants which are there. This office extends to the roots of trees and shrubs, as well as to those of the herbaceous vegetation, the stems of which have died down. Thus, while the buds are safe in their hybernacula, the deciduous leaves have fallen, those of the conifere and other evergreens are protected by the firmness of their epidermis, and all the portion of the tree which is above ground is in a state of safe repose, the rootlets for the coming 
year are making progress under the protection of the snow; and Canada, notwithstanding the violence with which its Winter sets in, and the intenseness of the frost while the Winter lasts, is a country peculiarly favourable for timber. This rapid coming on of the Winter is as favourable to many of the humbler species of vegetables; but in the beginning of the season, Labrador is apt to come again, in less wholesome visits, with alternate frosts and fogs, especially in the lower parts of the valley of the St. Lawrence; and these destroy the spring, and are unfavourable both to autumn-sown crops, and to the getting in of the seed of the spring ones.

Further to the north, beyond the limits at which it is of any use to attempt cultivating the ground with any view of obtaining crops of farm or garden produce as substantial food for human beings, and even around the spot which has been understood to have the maximum of cold in these longitudes, and where mercury is a solid metal, capable of being hammered on the anvil, but not touched with impunity by the naked fingers for a considerable portion of the year, there are still some means of enjoyment in the Winter for those human beings who can adapt and reconcile themselves to a climate so different from any that we are accustomed to in the temperate regions of the globe. Over the middle latitudes, the hunter pursues and secures his game, in places which, from their marshy nature, are quite shut out from man when the frost is gone; and the people of warmer latitudes are made gay and comfortable by the furs upon the skins of wild 
animals of these apparently inhospitable regions, which are killed by thousands while the snow is upon the ground, and the whole surface is rendered solid by the frost.

Meanwhile, still further to the north, where the land, in this depth of Winter, does not afford even wild animals as game, or any other species of food for human beings, the Esquimaux retires to the ice, constructs his Winter hut of masses of snow cut from its surface covering, spreads his skins upon the snow bench, lights his lamp; and just because the temperature is below the freezing point, he lives as dry and comfortable as many peasants of more temperate, and, in the common acceptation of the term, more civilized countries. He yokes his dogs to the sledge, and travels over the ice wherever he lists, and with no mean velocity; and, whether to secure the little stock of provisions which he has, according to the success of his summer labours, laid up for the Winter, or to supply the place of them when they are exhausted, he resorts to the breathing holes, which the aquatic mammalia, chiefly seals of some species or other, instinctively keep open in the ice; and by skilful management there he contrives to find a supply of fresh provisions for himself and his family in the very intensity of the polar Winter. Thus, to the very extremest verge of the globe, it is fit for the habitation of human beings; and the promise to man is fulfilled; for, in all the varied climates, and their still more varying productions, man may have dominion orer the earth, and subdue it.

The phenomena of the coming of Winter upon the 
Polar Sea have not been so well observed as those upon the land where the character is most decidedly polar. Where the ice on the surface remains unbroken and unthawed during the summer, the coming must be much the same as that on the upper part of a lofty mountain, from which the snow is never cleared. Winds may blow from it to the unfrozen parts where the temperature is higher, and they may sweep along its surface with varied degrees of violence; but there can be no very great commotion of the elements over an icy surface of permanent duration and considerable extent. Where the ice is in detached masses, with unfrozen portions between, the elemental commotion must be much greater. Every detached field or "floe" of ice, gives out a wind from it in all directions to the unfrozen water around it; and thus it may happen that, when the surface is mottled by numerous masses of ice, of considerable size, and at some distance from each other, many winds from all points of the compass may at once be "warring" within the horizon, which is visible from the top of a ship's mast. Those winds are often very violent, working the surface of the unfrozen sea into tumultuous waves, and dashing the smaller pieces of ice against each other, or tilting them up on edge, till they ride many fathoms above the surface of the water, and probably, in some instances, become the nuclei of icebergs, though these are understood to be in gencral formed on the precipitous shores; and, being softened in the under part by the radiating heat from the rocks, which they arrest in its progress and prevent from reaching the air, there to be 
diffused, they tumble into the sea with indescribable splash and thundering sound.

When, from causes which we do not understand, the Winter storms of the high latitudes come on earlier and with more fury than usual, they not unfrequently invade countries much further to the sontl, much in the same way that we have said the storms of Labrador invade Canada. These sometimes invade Scotland, and occasionally, but more rarely, England, as early as the montli of September,--not that the snow comes all the way from the polar regions; but cold winds come, and convert the humidity of the atmosphere into snow; and the air, which is much cooled and also loaded with this, drives the warmer before it, at the same time turning its moisture into snow; and thus the invading storm reaches to a greater or a less extent, in proportion to the cause to which its occurrence is owing.

In such a climate as that of Britain, those storms of invasion, when they arrive early in the season, cannot be called Winter storms; but they tend to make the Winter both early and severe; and the mischief which they do to vegetation is greater than if the snow were to lie unthawed till the turn of the year. If it were so to lie, it would afford the same protection to vegetables as the snows do in the more tropical climates; but the cold is not able to hold ont; the snow terminates in rain; and the evaporation thence resulting ushers in black frost upon the naked earth, from which regetation suffers much more severely than it would do from any load of snow upon it, however great. Another snow storm generally follows, indeed, not long after the 
black frost, though that frost may alteruate with rain and sleet in the interim, and thus make the state of things worse; and in whatever way it terminatcs, the mischief is in general done before the snow which is to be permanent for the Winter, comes on. 'Those invasive stornis which come only occasionally, do not belong to the common econony of the season; and thus there is no preparation of the vegetables against them. In all these cases of contingency, the cultivated plants suffer first and most severely, because they are, in most of the species, more delicate in their nature than the wild plants; and also because the Winter vegetation, which serves to protect the roots of that of the summer, in situations where there is no suow to protect them, is removed by the cultivator.

To enter into the details of all the varieties of the polar Winter, till so low latitudes are arrived at, as that it and the Winter of drought form nearly equal powers in the vegetation of the year, would far exceed the limits within which we must confine this part of our subject; and so we must take a rapid glance at the preparation which, in the various latitudes which are affected by it, are made for this description of Winter. 
CHAPTER IV.

PREPARATIONS OF NATURE FOR WINTEK。

It is a well-established law of nature, and one which equally agrees with and illustrates the wisdom and goodness of nature's Almighty Author, that, while every power in nature is completely able to perform the work or the office for which it is appointed, and while there is always a surplus capable of meeting those variations of seasons and circumstances, which, as we can neither understand their nature nor their use in the system, we call contingencies, there is still no waste; whatever is not required for one purpose being always applied to another.

In every case, too, the object is just as instrumental in bringing about the result which we observe, as the agent; so that there is, in nature, really no such relationship as that of a workman and materials, unless in so far as we consider simple inorganic matter as obedient to the laws of vegetable and animal life; and this, though a common mode of speaking on the subject, is probably a very incorrect one,--as it is evidently 
speaking according to the manner of man's working upon subjects in which man, or any thing that he can conceive or do, has not the smallest concern. It is true that the vegetable or the animal has the power of appropriating and assimilating as part of its own structure, the carbon, the oxygen, the nitrogen, the lime, the silex, and the other elements that we are in the habit of calling simple, of which its structure is composed. But this simplicity is really uothing more than another name for the very limited extent of our knowledge; and, we are at present unable to say into how many elements any one of those substances, which are simple according to our present opinion of them, may be resolved, after we know a little more. But, even granting that any of these elements, as we call them, are all of them now absolutely simple, we cannot regard them as being passive in any one of those combinations into which they enter, even under what seems to us the most powerful of all physical dominions, - the dominion of the life of a warm-blooded animal; for there must be, in the substance which is assimilated, be it what it may, qualities which adapt it to the assimilating organs, and which therefore may be said, not simply to obey these, but to work jointly with them in the producing of the effect. The elementary system, for instance, digests and assimilates food, and makes it fit for the growth, or the repair, according to circumstances, of all the parts of the body. Experience shows that the food must stimulate the digestive organs, in order that these may be enabled to digest the food; and in cases of indolence of the system, a more stimulating quality 
must be imparted to the food, in order that it may excite the system to the requisite degree.

In every case it is the same; and our separation of the parts and ipowers of nature, by means of which any agency is brought about, into agent and subject, is merely in accordance with the limited and imperfect system of our working, and, as such, at variance with the system of nature. Thus, when we, in common parlance, speak of the heart and the circulation of the vital fluid, by means of its pulsations, we are apt to describe the heart as the only active part, and regard the blood which it propels merely as a simple and passive fluid, just as water is when we propel it artificially by means of a forcing pump; nor have there been wanting men of the most profound learning and the most pious intentions, who have put this view of the subject into writing, and laboured, with much apparent self-satisfaction, and no little commendation from the public, to show that the heart of a warm-blooded animal is much superior to any pump which can be constructed by human art; and upon this they have raised a sounding structure to the glory of the Almighty Creator, for being vastly superior to any human engineer in-the art of pump-making! Standing alone, and out of the context of the circumstances, this sounds very like impiety, if not blasphemy; and belongs to the same class with those sincere but mistaken ascriptions of glory to the Almighty, in the poems of Sir Richard Blackmoreone of the best of men and worst of poets-which are turned into ridicule with such happy wickedness, in

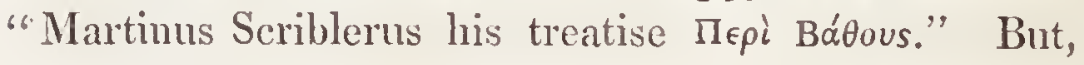


in truth, they are the very opposite of impions in the intention; and it is by the intention only that the individual from which any thing proceeds ought to be judged. Upon the rest of the world the effect is different; and as a world awakened to wisdom is very apt to be somewhat awakened to wickedness at the same time, there is a bane in the putting forth of those wellmeant effusions of ignorant piety, which stands more in need of the putting forth of the antidote along with it, than if the same sentiments were given to the public in the pages of a profane author.

There is no further analogy between the heart of an animal and any sort of pump of human construction, than that each of them propels a fluid; and this no more establishes their identity, than the fact of "a river at Monmouth," and the hypothesis of "a river at Macedonia," with "sawmons in them both," established the general resemblance of those places, or the likeness of Harry of Monmouth to Alexander of Macedon. The water which the pump impels neither assists in the working of the pump nor has the slightest tendency to keep that engine in a state of repair. On the contrary, all using is waste and wear; and the natural tendency of the water is to consume the instrument, by rotting if of wood, and by oxidation if of metal."

The relation between the propelling heart and the propelled blood in the living animal is very different from this; for we are unable to say to which of them the fact of circulation is the more owing. Probably it is to the propelled fluid; for we know that if respiration-by means of which the superabundant charcoal 
which the blood has taken up as the refuse of the working of the system-is removed, is suspended for a very short time,-or if any gas not fitted for the performance of this purification is inhaled,-the motion of the heart, and all the functions of life in the body, are not again to be excited by the most lively stimuli, after the lapse of a very brief portion of time. We also find that all the functions of life may be carried on for a considerable time, without any derangement indicative of disease in any part; while some topical malady of the heart is making rapid progress, and even converting the valves, and some of the other working structures of that organ, into bone; whereas if the blood is only very slightly diseased, if the disease is not thrown upon some particular part, which it destroys, for a time, the whole functions of the system become deranged, and denth ensues.

But though these instances would lead us to conclude that the stimulus is in the circulated fluid, rather than in the organ which puts the circulation in motion, yet it would be inaccurate, as well as unwise, to come to this as a general and ultimate conchusion. A certain condition of the heart, as well as of the blood, is essential to the healthy performance of all the functions of life in the body; and the only just conclusion to which we can come, is, that they act mutually and reciprocally, - that the heart is not prepared as a passive organ, upon which the blood shall act as a stimulating fluid, neither is the blood prepared, as a passive fluid, upon which the heart shall act; for their preparation is mutual as well as their action,- they are made for each 
other,- - they cooperate in the performance of a certain function;-both are indispensable to that performance; and thus no one of them possesses, or can possess, any portion of the active energy, unless in comnexion with the other.

Thronghout the whole of nature it is the same; and this is the reason why, when we speak of the preparation of nature or of any part of nature for any season or any occurrence, we must speak with explanation; and, whatever may be our intentions, we are in great danger of being misled ourselves, as well as of misleading others, if we do not. Our first thought of every kind of working is after the mamner of men, - as an active worker and passive materials to the performance of every single work; and when we turn our thoughts from our own working, and that of the rest of mankind around us, to the grand working of the system of nature, this narrow, and mistaken, and misleading view of it is apt to cleave to us with very stubborn inveteracy; and the direct and inevitable tendency of it is, not only to give us most false and unworthy notions of nature, but to make us think and judge of the Great Author of nature, as of the same in kind with beings of mortal clay, how much soever our fancy may represent him as elevated above them in degree.

This is exactly the feeling which the heathen had, and have, of the gods of their idolatry. They derive their notions of these from the study of nature, and from studying it after the manner of men,- the only way in which it can be studied by those who have not the light of revelation to guide them. We, how much 
soever we may attend on the rites of the Christian religion, and how earnestly and fervently soever we may seek for information on the Christian doctrines and mysteries, are really very much in the same state with the heathen, if we do not carry the notion of the God of Revelation, as made known to us in the words of his own inspiration, along with us when we turn our thoughts to those workings of nature; from which it seems hardly possible that they can be constantly withheld, even by the most ignorant or the most worldlyminded of our race,-from both of which categories we are all most anxions to exclude ourselves.

God is a spirit; and therefore his only direct and immediate act upon material nature is the act of creation-the single fiat which called all the worlds, and all their productions and inhabitants into being, each instinct with every power and faculty requisite for making it contime to act in obedience to the place, the office, and the time, which it pleased him to assign to it. Man, it is true, has what we in common language call a certain "freedom of choice;" that is, he acts upon and even against the ordinary laws of matter in some of his operations. But, even in these, there must be an adaptation of that which he applies, to the purpose to which he applies it; and when he endeavours to work in concert with any natural power,-as he does when he cultivates a plant, or breeds, that is trains, an animal,- - he must be content to follow nature, for he cannot and dares not lead. The fact is, that by all his skill in cultivating, either the nembers of the vegetable kingdom or of the animal, man does nothing 
inore than find out adaptations of certain parts of nature to each other; and in proof of this we may mention, that in every case the merely theoretic cultivator, however plausible his theories may be, or however useful in the hands of practical men, invariably ruins himself, if he ventures to put his own theories into effect without practical experience. He may prepare his soil, and he may also prepare his plants; and both may be done in the best manner as regards each, considered individually; and yet, when he comes to put them together, he generally finds that there is failure, until he has learned by experience how the adaptation is to be made,- - until he has aetually seen that the preparations of the two are suited to caeh other.

The relation between nature generally, as acted on by the season, aeeording to our notions, and the season, as acting upon it according to the same, forms no exception to the general law; and thus, when we speak of the preparation of nature for the Winter, or for any other season, we ought always to understand, though we do not express it, that the season is prepared for nature, - that is, for the vegetable and animal productions of nature,-just as much as these are prepared for the season; only we see the one preparation in individual subjeets which we can examine, and the other is general to the whole.

We see different effects upon different productions of nature, but we are not able to say why they should be. In summer, and early autumn, the potato seems a plant of far more power and vigcur of growth than the. grass upon the meadow; and the moss is a slow and 
crawling thing as compared with the mushroom, which "springeth up in a night," and that with such force of growth as to heave stones of considerable weight out of their places. But the potato is blackened by the very earliest frost, even when that frost can scarcely be traced upon any other field-plants, except by those who are up betimes, and see it as a hoar-frost upon the grass; but the grass shakes off this hoar-rime, and is as green and as beautiful, or even more so indeed, in the warmer districts of England, and in all comntries which have clinates similar to that of England, in the winter months, even when the snow has been just melted from it, than it is in the very heat of summer. The fungus, too, notwithstanding the rapidity and vigour of its growth, scareely waits the severity of the frosts, but melts away, without leaving any memorial of its existence, in the abundance of those very rains, to a more moderate degree of which its growth is owing; but the little moss, all feeble and slow as it seems, loving the surface and courting the shade, looks rich and gay, and flourishes apace under the rigour of the Winter.

Many instances of a similar nature might be adduced, to show that the different productions of nature receive the Winter in very different ways; and that thus, the preparation of nature for the Winter is a very vague as well as a very varied subject. Still, amid all the variations of appearance at the time of its coming, and of state as to action or repose during the period of its contimuance, there is a preparation of the whole of nature for the coming of 'Winter; and a preparation of Winter for the well-being of nature, whaterer may be its 
state during the season. Among the vegetables, which from their nature must abide the seasons as they revolve, without power of migrating from one place to another in the individual, some prepare themselves for a state of repose during the season, and others for a state of activity, while there are others still which may be said to remain indifferent to the changes of season, and to have very nearly the same appearance, if not the same growth, all the year round.

Among animals there are similar differences, thongh the manner in which they are displayed is not quite the same. The fact of most animals being endowed with locomotive power is one cause of this; but there are other canses. Among them, as well as among plants, the adaptations to different seasons, and consequently what we call the preparations for the Winter, are most conspicuous in the land ones. The waters, at least the waters of the sea, have very little change of seasons, unless in particular places where the depth is small, and the natural currents are in consequence interrupted; and, unless in the extent to which it is actually frozen in the cold season, the sea knows no Winter. The scorching Winter of heat is, of course, never known in the sea; and the most powerful action of the summer sun, which produces the dry Winter upon the land, though it strikes downward and stimulates animal and regetable life to the depth to which they extend, has a tendency to cool the air near the surface, except where the water is so shallow, and the bottom of such a character as that much of the heat is returned from that by radiation and reflection. The reason of the cooling and

$$
03
$$


refreshing of the air in all sitnations where the water itself is so deep as to absorb or dissipate most of the solar heat, is an obvious one :- the more directly or perpendicularly the rays of the sun fall upon the surface of the waters, there is the less reflection back again into the air from the surface, and the less refraction by that surface; and consequently, when the depth of the sea is sufficient for the purpose, the solar action is always the more completely absorbed and extinguished by the sea, the more perpendicularly that the rays fall upon the surface. But the rays themselves are hottest when they fall in this direction, and they also act most powerfully upon the water, and consequently have the rreatest eflect in raising its temperature. Now both the heated water, and the heat constantly applied to the atmosphere, tend to increase the evaporation, and by means of that both the coolness and the moisture of the air orer the sea. 'I'his is the reason why the sca breezes set in so readily, and are so refreshing, in warm climates and at wam seasons; and why the above comntries have a sumner of the most delightful growth, when the interior of the comntry is in all the desolation of the Winter of drought. From these and various other considerations, which will readily ocem to every reader who is in the least acquainted with the economy of nature, it is obvious that in noticing the preparations of nature for the Winter, we may leave the sea entirely out of the question, and confine ourselves to the land.

Of the preparations of nature for the Winter, or, more aceurately to express it, of the adaptations of nature, that is of the productions of nature, to the condition of 
that season, there are three principal branches: First, the preparation or adaptation of the earth itself; seeondly, that of the vegetable kingdom; and thirdly, that of the animal.

The seasonal influence of the sum and the atmosphere upon the cold matter of the earth, and without any reference to the influenee which that may have on the productions of the earth, is a matter of emparatively minor importanee; seasonal aetion, of whatever kind it may be, penetrates to only a very little depth into the solid mass of the earth: of the effects which it produces, even to this very limited depth, onr knowledge is most vague and imperfect. We do know, that, in the comrse of the warm season, the earth does receive more heat from the direet beams of the sum while that luminary is above the horizon, than it gives out by radiation during the night, when the direet beams cease to act; and in eonsequenee of this there is an aceumulation of heat in the soil and other solid matters of the earth, to the depth to which the influence of solar heat penetrates-which is ill-known, and probably very different in different soils; but as to whether this acemulation, or any part of it, remains so as to inerease from year to year, we have no data which ean assist us in arriving at any thing like a satisfactory eonchnsion. The question has been mooted by some of those who are anxious to pry into the very dark suljeet of the progressive history of our planet; and there are some shadowy grounds for conjecturing that there may be a gradual increase from year to year, though at a rate so exceedingly slow that the differenee might not be detected ly 
an instrument in the course of a lifetime. From the tree ferns and other gigantic remains of plants which are found in the strata of temperate countries, especially in the coal measures, - and of which there are not now any living rivals except in tropical, or at all events warm countries as compared with those in which the remains are found,-some have supposed that there has been in the northern parts of the world a very great cooling of the earth, or at all events of the climate, (and the one could not be cooled without cooling the other,) since some early period of the earth's history, of which the date camnot be so much as guessed at, farther than that it must have been very long ago, anterior to the formation of all the strata of aqueous deposit which are nearer the surface than those which contain the remains alluded to, but posterior to the formation of the strata which lie under them.

But, though at first sight this is plausible, a very little reflection shows that it is founded upon false reasoning, inasmich as there is a discrepancy between the two parts of the comparison. There are tree ferns in the strata of the north, certainly, and there are tree ferns in the tropical forests at the present day, which rival even the palms themselves in the majesty of their appearance. It by no means follows, however, from this similarity of size and general structure, that the fossil tree ferms, and other plants resembling the present living ones of the tropical countries, were of the same species, or required the same high temperatme for their growth.

In the gencral system of regetable action, large 
growth in the individual is not the proper lesult of high temperature, but rather the reverse-at least within certain limits. Heat is, no doubt, neeessary to the large growth of most of the species of vegetables with which we are acquainted; but still, heat is not the element of large growth in the individual. That element is humidity; and thus the only certain conclusion that ean be drawn from the presence of those remains of tree ferns in the strata of temperate climates in the northern hemisphere is, that the said elimates must have been more moist when elothed with these ferns than they are at the present day.

And there is pretty strong evidenee of this fact; and also that we may deceive ourselves if we reason from comparisons of what may have existed in former times in some regions of the world, and what actually exists at present in regions very differently situated. The skeletons of reptiles of vast size, which, from their form, must have been inhabitants of the waters, are met with in the strata of various parts of Europe; and they are especially abundant in those of some parts of England. The strata in which they are found, are of that character which shows that they have been formed by gradual deposits at the bottom of the waters, and not by any violent commotion which agitated the surface of the earth generally, and accumulated the bones of the animals of all latitudes in one common grave. They eannot be results of the flood recorded in the book of Genesis, as the old opinion represented them to be; for, according to the saered historian, men and land aninals were indiseriminately drowned by 
that flood; and thus the skeletons of men, which are not more perishable than those of beasts, could not fail to be found, at least in some of those collections of the spoils of the general deluge. But not a single human skeleton has been found in the fossil state. Besides, a flood of water would not destroy and accumulate in masses those animals whose proper and natural element is the water; though by what change of the earth these vast and singularly formed animals became extinct, we cannot so much as conjecture. Indeed, the more we examine the solid strata of the earth with the hope of finding in them a record of the changes which it has undergone, the more we are perplexed; for, to the very lowest depth to which the miner can dig, we find in all things the evidences of revolution and change, which, unless in so far as they come within the period of human history, (and that seems but a moment in duration, and is but as a span in extent, in comparison with the whole,) we are in utter ignorance of the times when, and the means by which, these revolutions were brought about.

'The case of the northern elephant, of which there appears to have been no living specimen within the historic period, and its comparison with the living elephants now found only in the south-east of Asia, and the central and southern parts of Africa, forbids us to infer a warmer clinate in former times from the existence of the tree ferms in the strata of temperate countries. The bones and the teeth of this northern elephant have been found in many caverns; and the teeth so abmundantly in Siberia, that a considerable 
traftic in them as irory has been carried on. The Siberians called it "Mammoth," the animal of the earth, as the bones were never found exposed on the surface, but always at some depth under the accumulations of soil. The learned, too, supposing that it had been the same species as the elephant of the opposite extremity of Asia, were led to the same conjecture about the Siberian chimate in former times as that which has been brought forward respecting the tree ferns. But when, about the close of the last century, an elephant was found embedded in a mass of ice, completely preserved, excepting in so far as it had been mutilated by mechanical means as the ice was broken, or torn by the ravages of wild beasts and birds of prey after being so far exposed as that these could reach it, opinion respecting the mammouth was completely changed, and changed upon the most satisfactory and conclusive evidence. Its covering, consisting of thick woolly fur immediately upon the skin, through which long and strong bristles proceeded, forming such a covering as alpine and arctic animals are furnished with for enabling them to endure or throw off rain and snow, showed it to be an animal better fitted for enduring the extremes both of humidity and of cold than any which is now to be met with alive in the same latitudes. All elephants too are vegetable feeders; and though they are partial to the most sweet and delicate vegetables when they can obtain them, yet their common food in their native haunts is of a much coarser texture than the natural food of any of the rmminating animals. They are not absolntely aquatic; but they frequent moist and shady 
places only, are fond of the water, and, like the whole of the order to which they belong, they are prone to wallow in the mire. At the time when those elephants inhabited the northern parts of Asia and Europe, we must therefore conclude that those parts must have been much more humid, and have produced herbaceous vegetation of a much larger growth and coarser texture than that which they produce now. Their bones have not hitherto been found at any very great depth below the surface, or embedded in any thing but accumulations of rubbish, or in ice; and therefore they form, as it were, a sort of intermediate link between the epoch of the great aquatic reptiles and that of the present state of things, - though how far removed in time they may have been from either, and whether nearer to the one or the other, we have no means of judging. But, against all this mass of evidence, it is impossible for us to come to any such conclusion as that the high latitudes of the northern hemisphere have become colder in the lapse of year's. There is also no astronomical argument for any such occurrence. That the poles of the earth's rotation are absolutely stationary with regard to its own surface, we have every reason to believe,indeed, we cannot even imagine any physical cause in the earth itself or external of it, by which the position of the axis of rotation with regard to the mass of the earth could possibly be changed. There are some causes which alter the position of the axis with regard to the plane of the orbit; but the surface always moves along with the axis, and keeps its relative position. The change in the obliquity of the ecliptic is a reciprocating 
quantity ; and when it has diminished for a long period of years, (which it is doing at present, though very slowly,) it will again begin to augment; and the limits within which its changes are confincd could not make much variation in the absolutc quantity of heat in any latitude ; though, if it were much greater than it is at present, the seasons would be more contrasted with each other than they are now. The absolute, or average temperature of any latitude would not he changed by any alteration of the obliquity; because, whatever were added in the one half of the year, would be subtractcd in the other. Therefore, in whatever light we view the matter, there is not the slightest reason to suppose that any one latitude upon the surface of the earth has become colder on the average now than it was at the moment of its creation, unless we adopt some wild hypothesis which has not a single fact to support it.

Take the opposite hypo thesis, - that the earth is getting warmer in consequence of treasmring up in each year a certain quantity, or rather degree of the action of heat, which it receives from the solar influence, and does not again give out by radiation. Even here wc cannot be certain of the fact, though we may have our conjectures. There are abundant evidences that the earth is more dry now, in every latitude, than it was in the earlier periods of its history. In Britain, many of the pools and marshes, the effluvia from which used, in former times, to distress the people with aguc, are now gone, and their places occupied by fertile meadows or cultivated ficlds. On a small scale this has been effected by human means-by drainage and other contrivances; 
though the results of these are probably only as a drop in the bucket in comparison with what has been done by nature in the ordinary course of change. In the bottoms of many of the lilly parts of the country we find the surface covered with rich meadow grass, below which there is an accumulation of decayed moss, converted into peat or turf, in such quantity that the people cut it for fuel; and in other places we find beds of the same material under corn fields, and even under the beds of sand on the estuaries and by the banks of rivers. Of all species of vegetation, moss is the most retentive of moisture and the worst conductor of heat. On this very account it is one of the means by which nature provides for the safety of some plants during the severity of the Winter; but as it resists the entrance of the action of heat into the earth, as much as the escape of the same action by radiation, we may assume it as a general truth that a moss-clad surface is, under all circumstances, a cold one; and that the diminution of mossy surface is not only a means of warmth, but that when it takes place in the course of nature, it is evidence that there is an increasing heat in that part of the earth to which the action of the sun's rays penetrates. As to heating or cooling from any cause of heat in the earth itself, independently of the action of the sun, we can say nothing with any propriety, as we are in utter ignorance of the state of the interior of the earth, and of all that goes on there. But this, though by no means an irrelevant part of our subject, is only an incidental one,- our main object being the preparation or adaptation of the earth for the Winter. 
Now, there is no doubt that, in all countries which have the Winter a cold season, there is an accumulation of the action of solar heat as preparatory for the Winter. The higher the latitude, and consequently the colder the Winter, the greater is this degree of the action of heat which accumulates in the ground toward the close of the summer. The cause of this will be at once understood when it is considered that the increased heat of summer, in the high latitudes, is chiefly owing to the greater length of the day and the corresponding shoriness of the night; and that the radiation of heat must bear a much lower proportion to the absorption, when the day is to the night as three or four to one in point of length, than when they have a ratio of equality, or nearly so. It wonld not be easy to estimate the relative difference, even upon the general principle; and though it were so estimated it would be of very little use, as both the absorption and the radiation at any particular place must be modified by the nature of the surface, and also by that of the soil, as far below the surface as the action of the solar rays penetrates. But as these modifications occasioned by soil and surface have, probably, nearly the same relative effect in all latitudes, the general law must hold upon the average, that in proportion as the latitude increases, there must be a greater accumulation of heat in the earth at the end of the summer, in proportion to the average temperature of the whole year; and, as we shall see afterwards, this accumulation of the action of heat in the earth, is one part of the preparation or adaptation of the earth for the Winter. 
There is not only a greater accumulation of heat toward the close of the summer season, in proportion as the latitude increases, but there is also a greater power of retaining it in the earth during the Winter. In lower latitudes, where the snow and frost do not set in until near the winter solstice, or even after it, the earth is greatly cooled by radiation; whereas, when the cold weather sets in, and the snow falls soon after the autumnal equinox, or otherwise early in the season, the surplus heat is retained in the ground, ready to perform its office, when circumstances render the performance of that office necessary.

What has been stated forms the chief preparation of the earth itself for the Winter; and it is both pleasing and instructive to observe how well it works for the benefit of vegetation, of every thing that is committed to the earth or the waters during the Winter, and of all that depends upon these when the season comes round and calls them again into activity. In proportion as the climate is more seasonal, there is more of this surplus action of heat accumulated in the earth during the summer; and as Winter comes the more inmediately upon summer the higher the latitude, the accumulated heat is more completely retained there than in places where there is a long and variable autumm.

This accumulated heat, when the frozen surface or the snow comes on early and prevents its escape, not only nourishes the roots of plants, but stimulates them to an early growth; and the roots of all seasonal plants are the parts which act first in the season, and their lualthy and rigorous action, as it precedes, so it also 
promotes the growth of the stem and all the summer development, and thus is very essential to the general well-being of the plant.

It is matter of common observation that, in places where the autumn is short, the spring is equally so; and that summer follows as closely upon Winter at the one period of the year, as Winter does upon summer at the opposite period. It is not the mcre surface action of the sum at the time which renders the progress of vegctation, in the early part of the season, so rapid, and so free from checks and reverses as it is in the high latitudes. The heat in the earth is the principal cause; for though the stems of all the herbaccous plants have died down, the substance of the permanent ones, - of all, indced, which last throughout the Winter,-is accumulated in the roots; and these roots are kept in such a state of excitement by the confined heat, that the stems are ready to start the instant that the ground is clearcd of snow. Even in these high latitudes and elevated situations, wherc flowering plants are but few, and where the averagc tcinperaturc of the year is low, the benefit of the imprisoned heat is not lost, even before spring has opcned the prison doors, and given the exposed portions of the plants to the action of the sun. The lichens, whose hardy nature makes them feel but little the differences of seasons, feel the benefit of this heat, and partially grow under the snow; and that in a much more genial temperaturc than if they were upon places free of snow in the same climate and locality. 'The mosses, too, are Winter growers, in less exposed situations than the lichiens; and they owe their vigour, in the inclement. 
season, ahnost entirely to the retention in the earth of the accumulated action of heat, of which we have been speaking.

But, though there is, as the latitude increases, and the difference between summer and Winter becomes more marked, a tendency to the aecumulation and retention in the earth of a greater portion of the summer's heat, yet this docs not increase the average temperature of the year, though it renders it more serviceable to vegctation. As the summer becomes warmer in proportion to the Winter, the length of it diminishes; and though, from the retained heat in the ground, the long day, and the short night, the period which vegetables require to come to maturity shortens as the latitude and difference of scasons increase, yet there is a limit, beyond which not a decidnous tree, and no flowering plant, can complete its course so as to bring its fruit to maturity in the course of the year ; and therefore at this linnit, and beyoud it, there can be no snch plant. With the exceptions of some of the dwarf willows, which creep among the moss and lichen, and are secure under the snow of Winter in all situations in which they occur, some of the more stunted and hardy of the coniferæ, which take two years to ripen their seeds, are among the last seeded plants to be met with, before the chief part of the surface is confined to the mosses and the lichens; and there is an ultimate limit of vegetation, beyond which not even one of these last is to be met with, and the earth, when the snow renders any part of it visible, contains not a particle of organic matter, but simply rock, or the dull and barren powder into which that 
roek has been divided, by the aetion of the weather, in alternate freezing and thawing. These last are the regions in which the eontrast between the Winter and the summer is the greatest of any; but the summer sun, although constantly above the horizon for many weeks, is so low, and the beams of it fall at so small an angle to the surfaee, that the greater part of their energy is refleeted away into the atmosphere, and produees comparatively little effect upon the earth.

The preparation of the earth for the Winter, as we have now attempted to explain it, really resolves itself into at preparation for the spring, or the spring and the summer blended into one eommon and brief season, as we find it in the high latitudes. But this is what we might, and, indeed, should expect. All the preparations of nature, whatever they may be, are preparations for the aetivity of nature; and repose itself, whether it be the mere sleep of the night, or the pause or the hybernation of Winter, forms no exception to the general rule.

The shortening of the time necessary for bringing the annual growth of vegetation to maturity, with the increase of latitude, and of difference between the opposite seasous of the year, may be found in the island of Great Britain. There are many of the long-growthed plants of the south whieh eamnot bring the time of their action within the compass of the short season of the north, and hence they do not find a place there; but in the case of such as ean accelerate their maturity, there is a marked shortening as we proeeed northward, so that at Cape Rath, the northernest point of Seotland, in any place where a crop of barley can be at all 
obtained, there are two or three weeks less between the sowing and the reaping than there are in the south of England; and when we extend our observation to the highest latitude at which the same kind of crop will grow in Norway, the period which it requires in order to come to maturity is still less.

In these adaptations there is something so very beautiful, that they whose admiration escapes it must be dull and callous indeed. The season and the plant work together, and afford the most conclusive proof that they are parts of one system, the workmanship of one Maker, who has endowed them with such delegated powers as that the one works for the other, merely of its own nature, and without the slightest stimulus of any kind from without. At any single place, the adaptation of the parts of nature to each other are such as to excite our admiration; but when we contemplate them in the breadth of their contrasts, they hold us rapt in astonishment that such things should be, and be for us and for our good. Truly, when we look upon that system of nature which is given us for instruction and enjoyment in this world, and reflect that it is given to us as a sure heritage for the whole term of our lives, and secured to us by the very law of our being, if we will but be wise enough to make it our own by knowing it, we can never fail in being nore grateful to the Almighty for this, the universal possession of our race, which may and should be enjoyed by all, but can be appreciated by none, than for any or for all of those minor distinctions of merely liuman origin, which the changes of society, of which we can have no 
foreknowledge, may eitler give or take away, witlout any merit on our part in the one case, or any demerit in the other.

When we consider this subject aright,--even as men of this world, and without allusion to the volume of inspiration, or the glorious hopes which it opens to the mind that we shall one day, and that not a distant one, be elevated "above this visible diurnal sphere," and know all the workings of systems of worlds far better than we can in the present life know the growtl and liabits of the most familiar plant,-when we consider it cven in this simple and lumble point of view, snch as might be taken of it by a reflecting man who has no well-grounded hope in the life to come, and who, on that very account, is subject to bondage throngh fear of death all the days of his life,-we may find grounds of consolation and gratitude-aye, and joyous exultation, that we are what we are, even when the winds of the world's chancings are the most contrary and stormy, and the waters of its adversity are gushing: around us in the high-tide swell of their most angry surges. In helpless poverty, in hopeless captivity, in the very extreme of ontward privation, if the nuind has kept its allegiance to nature and nature's God, sound, full, and without suspicion, all these matters press but lightly; and the beggar on the dunghill nuay be more rich than the king on the throne, and he who is loaded with fetters may be far more free than the monarch who has a hundred millions of slaves all obedient to his nod.

If we could but bring oursclves to think in this manner 
- to prize the heritage which God has given to us upon the certainty of our existence-the very law and constitution of our own nature, and of all the system of nature around us, - above all the trifling heritages which men possess and call their own, the addition which we should thereby make to the serenity and happiness of our lives would be beyond all estimate. Nor would the advantage gained in this way, in the least impede our progress in the acquisition of that property which is essential to our enjoyment of life, and the right discharge of our duties to our brethren of mankind. Care, the care of the world's wealth, is a canker which not only eats into the core of our enjoyment, and withers all our kindly affections, but which blights and stunts the growth of that from which it springs. We cannot, by taking care, in the proper sense of the word, add one farthing to our possessions, any more than we can add one cubit to our stature; for the rack upon which it keeps us narrows all our views, and hinders us from seeing and profiting by circumstances which we conld turn to the most profitable acconnt if our minds were at ease, and we could in a calm and dispassionate manner scrutinize the state of things around us.

And what does it all amount to in the end? The practice of getting the mere worldly desires gratified, or rather of following after their gratification, to the exclusion of every thing else, monopolizes the whole man, body and soul; so that when once it is confirmed into a habit, there is pleasure in nothing else, and in that which absorbs all else there is care and pain. 'The toiling man of business, who dnudged and hedged every 
day, upon the maxim that " a penny saved is a penny" gained," at last retires, full of wealth, and redolent of every comfort which money can purchase. But is he comfortable? See him :-for there are many such in the purlieus of every large city and town-set down in the most trim habitation, and wanting nothing that the wealth of the world can procure. But the beauties of nature, and the luxuries of art, are all lost upon a character of the description to which we are alluding: he totters about for a year or two, and then he is glad to creep into the oblivion of the grave, as a refuge from the dull torment of his own vacant mind.

Some may imagine that this is a case taken from the lowest and most grovelling portion of society; and therefore not adapted to an expression of the majority of the human race. Be it so; and let us take any others-the candidates for fame, for instance, as those who seek distinction on account of what they do, rather than of what they possess; - a worn-out hero tottering on a staff, the man who has been lauded with the wealth of one country for the "most glorious service" of having done his best toward the depopulating of other countries, sinking into sheer inanity, or losing in the cabinet those laurels which he won in the field; - the orator, who in the prime of life carried the public by the ears as easily as a warrener carries rabbits by the same appendages, fallen in to the last garrulity of life, to which the sexton will barely listen; - -these, and a thousand others which might be mentioned, all tend to show, that if mankind have no mental resource beyond the thought of their wealth or their honours, whatever may be the 
extent of the one or the nature of the other, they muct inevitably one day become miserable, and the inisery to such persons is the sad desolation of utter despair. How much soever they may have shone in their day, and with what loudness soever the tongue of applause may, have trumpeted them, a time assuredly comes, when the lustre becomes dim, and the adulation mute -when new idols are produced, a new generation grows up, and, if the kindly grave interpose not in time, they are ejected from the world as antiquated and useless things, before their senses take leave of it for ever, and they are consigned to the clods to moulder there.

To the man whose thoughts have been through life wholly occupied with the affairs of the world, this Winter of life is a season of sad desolation. As long as there is so much of life and health as that hope in this world is not wholly extinct, the new project, or the expectation of the additional gain, may buoy up the fading system; but be the natural health and strength of that system what they may, and the ties by which the soul is bound to the dust of the ground ever so strong, there is a weakening at the last; and when it comes, the mhappy patient feels like Laban: "You have taken away my gods, and what have I left!" Such must be the case with every individual of the human race, whose gods are of such a nature as that they perish or decay with time, or can be taken away by any human means.

Such a man must be prepared for the final repose of the body, the ultimate Winter of life, as well as those whose thoughts have been ofherwise occupied; whose 
hopes brighten as the external world darkens aromd them ; and who, by the preparation of the spirit for immortality, triumph over the gloom and despair whieh are inseparable from the margin of the grave, to those who have nothing to support the frailty of the flesh in the day of extremity. Those desolate persons are, to use a homely simile, not mulike a deeidnons tree in the last antnmm of its existenee, after which it is to be green no more, bit to stand in the world a blighted and nnseemly thing, until it shall be cut down and cast into the fire. The flowers are long over, the fruit is gone, the leaves do not heal off in that kindly manner which they do from a decidnons tree, in whieh the living principle is to repose during the Winter. They remain till they are torn by the storms and seattered by the winds; there is not a vestige of a bind upon any of the twigs, nor a trace upon the roots of that peculiar cicatrix from which a new rootlet is to spring. All the part of the tree above gronnd is completely given $n$ p to the deeonposing influence of the atmosphere, and all the part below to the same influenee of the damp earth; while the contest between these opposite powers, at the water line, or mere surface of the earth, very speedily cuts the bole of the tree asmmder there, and lays it along the earth to rot. It is mueh the same with the man whose whole sonl is absorbed by the wealth of the world, and the eaptivations of worldly ambition. In the Winter of life, those airy hopes of the vanities of carth whieh were so tempting in the spring of life, and so allengrossing in its summer, are eonverted into cankers as it draws to a close; and those possessions which were 
so endearing as long as fabrics of greatness could be reared upon them by the intoxicated fancy, become chilly and eroding to the feelings; and to those who have made the world their only heritage, the anguish of the death-bed is always in proportion to the glory which is then gone, and the wealth which is then no longer of any avail.

This palling of the joys of the world upon the sense, as life draws to a close, is the signal that the body is in a state of preparation for its Winter; and there is a lesson of admonition in it; that, when the Winter of the body comes, the whole man is not in a condition of desolation. The blunting of the senses, and the inadequacy of the possessions and pleasures of the world to furnish that enjoyment which they do in early life, when the individual still has the course of life to steer, and the duties of life to perform, are hints, as plain and as expressive as can be given, that at this advanced age there is an occupation for the mind, which is its own, and has no reference to worldly gains or worldly honours; and the lessening of the zest for the enjoyments of the world, is evidence that the intuition of nature is, that man should, as the course of this life draws near to its close, turn his thoughts to another. Then, again, there is an appropriate similitude in the deciduous tree, which casts its leaves preparatory to the Winter, but which preserves the buds, the energy of the surface of living action between the wood and the bark, and all the other parts and principles which shall fit it for obeying the stimuli of the spring, when these shall come upon it in the requisite degree of strength. 
The principle of vegetable life is not extinct, or lessened, in the tree which is to bud and be green again, while it stands with its bare twigs in the Winter, any more than when it is in the full breadth of its leaves, and the full beauty of its blossoms; it is only concentrated; and the concentration is a means of safety, for it is matter of general observation, that the power of endurance in every kind of life is inversely as the extent of substance through which it is diffused.

Many other grounds of the most valuable instruction might be pointed out, as illustrative of the close analogy which there is between the Winter of the year and that of life; and how, as material nature prepares the natural substance for both, it becomes man to take good heed to the mental preparations. As these last do not come in the course of material nature, or depend upon physical causes, they must be made and kept in readiness for the time at which they are required; and the Winter of each year as it comes round inculcates this, in a mamer which should be more impressive than if it were declared in words, however appropriate, or however eloquent. In all seasonal countries - and the more strikingly, the more seasonal that they are-there is a very decided falling off in the gratifications of the senses by natural objects, as compared with what occurs in the summer'; but in proportion as the earth becomes less attractive, and is withdrawn from the contemplation for a larger portion of the twenty-four hours, the heavens are more clearly displayed; and their unaltered lustre contrasts strongly and strikingly with the faded condition of the earth; and, in places where the customs of society do not 
wholly seduce the minds of men from contemplation and reflection, the nocturnal sky of the Winter formis a most delightful subject for study.

It must not be imagined that the delight arising from the contemplation of the heavens on a clear Winter's night belongs only to the professional astronomer ; for truly he may be the one which is least impressed by it. Persons whose trade, or profession, is closely commected with the striking in nature, are very rarely they upon whom nature makes the most lively impressions. The fisherman feels not the grandeur of those cliffs under the shelter of which his hut is placed, or the sublimity of that sea upon the produce of which lie and his family depend for their daily bread; the shepherd cares not for the graceful swelling of the hills, or the picturesque character of the rocks; and the farmer sees no beauty in the undulations of the golden grain to the breeze, farther than the hope which he has that it will fill his garner with abundance. The case is still the same with those whose pursuits approach nearer to being of an intellectual character, provided that the object of them is a trade; and the converse also holds, for an artist who has a very intense feeling on his art, an author who is similarly affected toward his subject, or any other individual in any of the professions which are generally supposed to have most of mind in them, almost invariably fails of success as a tradement, and is to a certainty eclipsed by those who have not a tithe of his endowments.

One feels a disposition to lament this; and yet it is probably well that it is so-at all events it is in accordance with a general law of nature; and whatever is thus 
in accordance cannot be wrong, whatever may be our feelings with regard to it, or onr wish that it should be changed. The trade or the profession, whether the reward in the hope of which it is carried on be money or fame, or any of the other means of distinction for which mankind toil, has no reference to any thing but this world, and is not even a happiness to the individual who devotes himself to the pursuit of it.

There is something remarkable in this separation of the trade, or the other pursuit, as a matter of profit, from the love and pleasure of the study of that very subject whence, in the case of a trade, the profit arises; and it points most directly to that separation from the cares, gains, and ambitions of the world, which, as we have hinted, is essential to the right preparation of the intellectual part of man for the Winter of its separation from the body. This camnot be illustrated by the example of a more appropriate case than that of the heavens as they appear on a bright and cloudless Winter night. All that then appears to the eye of a common observer, mighty and majestic as it is in seeming, and more so in reality, is disregarded by the professional astronomer for the sake of something else which is dimly seen, or wholly unheeded by common cyes. Some star seems periodically to wax and wane; there is some nebula, or little luminous clond, in some part of the heavens, which no artificial aid to the sight can scparate into stars, as it does the countless host which compose the broad and curions girdle of the milky way; or there is a cavernous darkness of indescribable depth breaking in upon the light, as is observed in the curious star in Q 3 
the dagger of Orion-if star it be-which resembles not any other portion of the risible heavens, but is like a dark pit of unfathomable depth, with a margin of snow illuminated by the beams of the sun.

These, and subjects like these, in so far as that they lie out of the ken of ordinary mortals, are the ones about which the professional students of the hearens vex themselves, and very often rex themselves in vain. By the great body of mankind these minor marvels of the astronomer are apt to be overlooked; but it must not be thence inferred that there is in the observation of the heavens no interest for such as are ignorant of, or cannot enter into, these more nice and recondite parts of the wonderful structure which the withdrawal of the beams of the sun reveals to us in the sky of a Winter's sight. "The heavens declare the glory of God, and the firmament showeth his handy work," as much to the unlearned as to the learned, though the manner and the object of the two are different.

Upon the countless radiant bodies by which the depth of surrounding space is lighted up, the revolution of our year, and the changes which take place in the lapse of years upon our earth and its productions and inhabitants, liave not the smallest effect. Our globe may belong to the system, and must belong to the creation of which they are the grand constituents; but it is so insignificant a portion, that, though it were in one moment to be annihilated, and the whole of its history blotted out from the book of remembrance, the absence of it could be no more nissed from the system, than a single grain of sand would be missed from 
the great African desert, or one drop of water from the oceall.

The contemplation of this does not bring infinitnde to our understandings, because no finite being can form an adequate idea of infinitude. But it gives us the idea of what is intermediate between this and the finite things with which we are conversant in the ordinary affairs of the world. It takes away the limits, as it were, breaks down the fence, within which we are pent up in our common experiences of the things of this life-and opens to us space and duration, to neitler of which we can even fancy any limit. When we contemplate the stupendous frame of nature arond ns, reduced to the semblance of one vast hollow sphere, by the mere incompetency of our eyes to discriminate the different shining specks which mark it on the bhe concave, we are lost in utter astonishment, even if we have not the assistance of a single astronomical law for our guidance. It is in rain that we endeavour to bring the largest measures of which we have any knowledge to bear nipon this wonderful structure, and give us even a guess at its dimensions : for if we take a boundary, be it ever so remote, and exhausting all the millions, billions, trillions, and so forth, which we name in our arithmetic, but do not and cannot comprehend, we have not, in reality, approached one hair-breadtl nearer to the limit of creation. Let us, just for the sake of convincing ourselves of the wonder which every moment in the open air brings to our contemplation, and of which the Winter night gives us the most splendid revelation that we can obtain, while we contemplate it with the eye of the body, - 
let us, for this purpose, imagine to ourselves that the optical concave which we know to arise merely from the limited nature of our sight, is a palpable realitythat there is, in truth, a solid firmament of a blue colour, spangled over with stars, in the centre of which the earth that we inhabit is placed. We may suppose it at any distance; and, as great and small are mere differences, not essential parts of the consideration, we may suppose it so remote that the beams of the sun, fleet as is their progress, could not reach it in a thousand ages; and further, we may suppose that the thickness of this firmament is equal to its distance from us, or to any number of times that distance;-nay, we may imagine that distance after distance and firmament after firmament are repeated without end, or till we have strained our fancy to the very last, and the mind begins to be lost in the magnitude of its own conception; we may do this, and we may repeat it and repeat it till the longest life draws to its close in the enmmeration,-but are we nearer to the verge and boundary of the creation at the end than we were at the beginning? After we have wearied and wasted all the powers of our minds, are we one single iota nearer the boundary of created space thin we were at the point from which we began our imaginary estimate? We are not: it goes on and on,so that, begin where we may, the termination is at the same distance from us. And this is the creation by our God, considered in the one and simple attribute of the space which it occupies-to us immeasurable and incomprehensible. Yet, of his merciful goodness to us, we are given to fecl, though not to understand, or to express 
this immensity; and we have reason to believe that, among all the living creatures which people our planet, we alone have this feeling of the works of the Creator. Are we to have 'this feeling for the mere threescoreand-ten years of our sojourn upon earth, and then go into final nothingness, and know this wonderful creation and its still more wonderful Author, no more? It cannot be ; for setting all revelation, and every consideration of a religions nature aside, it would be at vilriance with every law of nature, as we find those laws manifested in all the parts of the system which come most truly and completely under the range of our plain and every-day observation. Throughout the whole of it, we find not an idle piece of matter, or an unoccupied principle of action. We in no instance fund a plant or an animal endowed with a power or faculty for which it has no use, and which it does not use up to the full extent of what is given to it; and it would be passing strange that there should be one anomaly in the system, and that that anomaly should be man, for whose instruction and use so much of the rest is obviously made. The information which he is capable of receiving from the measurable parts of the universe, and the feelings which he has of those parts which are not measurable, especially the latter, are of comparatively little use to him in the ordinary business of the present life; and yet they are more striking-more calculated for making an impression upon the mind, if that mind is in any degree expanded, than those subjects which are essential to his physical welfare; therefore, upon the simple physical consideration of the matter, 
and without the slightest allusion to any thing of at religious character, we must either admit that man is destined for something greater, more extensive, and more durable, than the other animated tenants of our globe, or that in him the perfection of design and execution, which are so apparent in the rest of nature, are completely violated and departed from.

This view of the matter is quite as perplexing to the infidel and the atheist as it is to the believer in the word of Divine Revelation; for granting that the whole is the production of chance, and that there is a regular succession of fortuitous causes, if regularity can be predicated of such causes, from the shime-begotten worm, through all the gradations of insect, reptile, and so forth, up to man, why should Chance, the goddess of those who know not God, bungle in the higher part of her work, after being so perfect in all the inferior ones? No reason can be assigned for this; and, therefore, the conclusion to which the unbeliever is inevitably driven, is, that the power to which he assigns the origin and conduct of the creation, is wholly inadequate to the task, and fails at the very point at which its efficiency should be most conspicuously displayed.

Such are some of the most obvions conclusions to which the consideration of the displays of Winter are calculated to lead the mind which has no prejudice to warp it; and though we have alluded to creation in its extent only, the allusion might be made with equal force and conviction to it in the succession of time. In this we have, of our own unassisted perception, not the slightest idea cither of a begiming or of an end. 
We can imagine that a world, or a system of worlds, may come to an end; that our globe, or that the sun of our system, and all the plancts and satellites by which it is attended, may pass away in their present forms, just as a plant or an animal ceases to be in its specific form, and passes through the medium of the dust, to the common mass of created matter; but of the nonexistence of the whole universe, or even of the fimal destruction of any one single particle of the matter of which it is composed, it is utterly impossible for us to form the slightest notion. We cannot inagine a natural beginning or end to any thing existent; that is, a begimning or an end produced by physical or secondary causes; because that would be erecting matter into a power superior to itself, the notion of which involves a direct contradiction and palpable absurdity, and therefore cannot be entertained by any one having the slightest claim to the character of a rational being.

But though we are unable to form a definite judgment of this beginning or ending of nature as an entire system, we can trace a feeling of its continuance, time without end, in some state or other; though of that state we can form no adequate conception that can be expressed in words. There are no objects of the senses which can assist us in the expression of this interminable duration, any more than there are to aid us in expressing what we feel with regard to the unbounded extent of creation; and, therefore, neither the one nor the other comes within the range of what may be called our sensal perception and experience, or forms any part of the subject of our intercourse with 
our fellow-men, or otherwise with the business of life. Thus it belongs properly to those states of the mind which are temporary withdrawals from the present life and all its cares and concerns, and which are very essential for preparing us to meet that final withdrawal from them, which must once be made, so that we may meet it with the proper degree of resignation and hope, which alone can make the close of life one of the most joyous of its scenes.

Winter is the scason of the year during which those contemplations which withdraw the mind from the present life, arise the most naturally, and can be pursued with the least interruption; and, to ns, it seems given for the express purpose. When seasonal nature is in a state of activity, its attractions for the senses constrain us to pause before we can reach those lofty considerations. And, no doubt, it is well for our enjoyment, upon the whole, that the changes of the revolving year are calculated to produce, in their sucession, such differences upon the mind, because they prevent that fatigue and listlessness which are ever the result of too long and close indulgence in any one train of thought. 'i'hus, though the mind is not, and camnot be, in its own nature, influenced by any of the changes which the year brings about in the material creation, as physical causes can produce no direct effects upon it, yet the trains of our thoughts are differently directed in different seasons; and though external nature does not prepare the mind for the season, yet there is a preparation of the mind itself, which answers the same purpose, and should be carefilly attended to. 
As, from its very natme, the mind needs no pause or refreshment during the sleep of the night, so neither does it require any annual pause during the Winter. But in deep sleep of the body, the mental aetions, or trains of thought, do not return in what we eall memory, though they do, more or less, in those disturbed states of shmber in whieh the trains of thought whieh pass through the mind are ealled dreams; and to those same dreams, our waking thoughts often have a mueh more close resemblanee than we should be apt to suppose. We speak not of what is called "absence of mind," but whieh should properly be called "abstraction;" as the mind is not absent, it is only so eompletely ocempied by the train of thonght in whieh it is engaged, that the communieation between it and the senses of the body is for the time suspended. These mental absences are, in some eases, carried to sueh an extent, that they bear a very close resemblanee to the mental trains of thought during profound sleep of the body, of which not one iota is remembered, or ean possibly be reealled, so as to be available for any one purpose, either of future thought or of aetion; and thus, if the expression may be allowed, the mind may be absolntely lost to all usefuhness in the depth of its own abstraction, by being rapt away from all connexion with external things, just as is the ease when the senses are loeked in the oblivion of unbroken sleep. Persons in whom this depth of abstraetion becomes a habit, are generally awkward in the ordinary affairs and eondnet of life, though they are, without exception, capable of the most elear and profound thinking. There was a re- 
markable instance of this philosophic abstraction when carried to "absence," in the case of the late Dr. Robert Hamilton, professor of mathematics in Mareschal College, Aberdeen. The aneedotes which are told of his "ahsence," are very numerous, and to men who never have their bodily senses overeome by intensity of thought, some of them were of the most ludicrous description, though they were, one and all, highly characteristic of that goodness of heart, and love for the best interests of his fellow-men, by which the whole life of this most excellent man and profound philosopher was characterized. We shall not repeat any of these ancedotes, but content ourselves with saying, that not a few of them were as lndicrously absurd as mental absence could by possibility render them. But the works which Dr. Hamilton published are almost mnivalled for the closeness of their reasoning, and the beautiful clearness and simplicity of their style. If we except "Euler's Elcments of $\Lambda$ lgebra," - and that is confined to a single. snhjeet,-there is probably not, in any language, a schoolbook at once so plain and so profound as "Hamilton's Introduction to Merchandise." This great man, too, who, upon his walks, could not keep himself ont of mires and ditches, or escape withont the assistance of others, when he got into them, was the first who cxposed the fallacy of the sinking-fund,--the palpable absurdity of paying ofl debt by money borrowed at interest, when the debtor and borrower lo not engage in any manufacture or trade, ont of the profits of which they ean pay the annual charge upon what they are owing. The analytical sophisms of Dr. Price, whose understanding, 
though a clear one in many matters, appears on this particular one to have been entangled in the mere meshes of calculation, - these sophisms, together with the eloquence, and, still more, the political influenee of Pitt, found the sinking-fund many alvocates; and though there were a few upon the opposition benches of both Houses who doubted, or, at all events, did not go the whole length, yet there was a pretty general floating belief among all partics, that this same sinkingfimd worked marvellously, though mysteriously, for the financial grood of the nation. But the "absent" philosopher of Aberdeen eleft asunder the nucleus of this arithmetical jugrgle, with the same ease and certainty as the lightning shivers a rock; and when his little work on "The National Debt" first found its way to the metropolis, the Commons, and even the more solid wisdom of the upper House of Parliament, were astonished, nay, eonfounded; and although there have been plausible speeches made upon the subject since, as a matter of expedieney-sueh as that by the late Marquis of Londonderry in 1822, when he implored the Commons House not "to lay their suicidal hand upon themselves, by making the sinking-fund stand prostrate at the feet of circumstanees;" yet no man has ventured to defend it upon principle, or to describe it as much better than a mere "tub to the whale." But with this same Dr. Hamilton, who was so elear and so powerful in written argunent, there was a sad falling off' when he had to blend argument with external action, or display of any lind; for, thongh one of the clenrest and most successful of teachers in his writings, 
his labours in the class-room were all but a perfect failure; and other professors, "by rote," who were to the full as shallow as Dr. Hamilton was profound, were far more successful in the craft and mystery of grinding pedagogues and pill-men than he.

We have mentioned this case, and mentioned it at some length, thereby showing that, in order that the usefulness of man in his day and generation may be a maximun, there is a medium to be observed in matters of thought, especially in those profounder ones which lead ns far away from the practical paths of life. And the school of nature, as its progressive lessons present themselves in the course of the year, is finely illustrative of this. Of the seasons, there are three-the spring, the summer, and the antumn - which draw the mind toward the details, by alluring it with the fascinations of the present world; while there is only the Winter left as the appropriate season of abstraction; and thus we have three-fourths of the year more adapted for direct observation and the gratification of the senses, and one-fourth more appropriate for mental exercises. Nature, as it exists, and business, as it is carried on, are not to be neglected in the Winter any more than at other times of the year'; and, indeed, for all labours within-doors, more especially for those which require a considerable degree of thouglit in order to perform them rightly, Winter is preferable to any other of the seasons; and where leisure and other circumstances admit, Winter is also the proper time for enjoying the society of our friends: for thougl the pleasure, including that of the senses, may be greater in the summer; the 
communications of society are more of a lome character, and should also be of a more intellectual kind, than they are at any other season of the year; and though many spend their. Winter leisure in sociality, and not a few in dissipation, yet nature and reason tell us that the Winter was made for otler and nobler purposes. The right improvement of the sucessive Winters of our years prepares us for the ultimate Winter of life; and if we do not make the preparation, the severity with which that Winter will come upon us will cause itself to be felt.

In as far as the body is coneerned, the preparation of man for Winter resembles that of the other animals, only it is slighter in degree, as man las more resouree than they; and we find that the provisions of nature for the safety of animals are always less, in proportion as the resourees of those animals are greater. In those who are exposed to the weather there is, however, a general increase of the power of enduranee in all Winter animals, and in man among the rest, luring the Winter months. 'The preparations of animated nature can, however, be more advantageously treated in another chapter, after we have briefly adverted to those of the vegetable raees. 


\title{
CHAP'IER V.
}

\author{
PREPARATION OF TIE VEGETABLE KINGDOM \\ FOR WINTER.
}

WE have already endeavoured to explain, that when we speak of the preparation of any one portion of the material creation for Winter, or any other season, or for any event to which, in the ordinary course of nature, it may be subject, we are not to understand that this is the work of an external preparer, to the operation of which the production of nature is passive, upon principles similar to those which render materials passive under the hands of a human workman. The natural production is always a cooperator in every change which it displays, whether we call it preparation or any thing else; and in the majority of cases it is the principal operator, or the one which has most influence in determining the character of the result. If it were not for this, all the species of natural productions which are near to each other in locality, and similarly exposed to the sun, the atmosphere, and other natural stimuli, would become like each other, not only in the times of their activity, but in all the particulars of their characters. 
If, for instance, the vegetable kingdom were passive to the operation of the sun and the season, in the same way as iron is passive in the liands of the blacksmith, then there would be no natural distinetion of spring plants, summer plants, antumn plants, and winter plants; neither would there be any of herb and slurub, of annual and peremnial; but the whole would be reduced to one dull uniformity; and the face of nature, which is now so pleasing in its diversity, would be so umbearable on account of its monotony, that no one conld endure the enmui of drawling out even one year ripon it.

It may be argned in opposition to this, that the blacksmith can, out of the same bar of iron, manufacture a very great variety of articles, such as a ploughshare, a reaping-hook, a horseshoe, a mail, a knife, and so on; and we readily admit that he may and dare not refuse to do so; but the maker has a separate forethought purpose in the making of each of those, and he follows up that purpose by a different mode of execution for each of them. But the sun, or the other general agency in the season, which acts upon the vegetable tribes, has no forethought purpose, and no difference in its mode of action. The sun, which withers the grass on the dry common and stimulates that of the carefully irrigated meadow to a more active growth, exerts the very same influence upon both, only they obey that influence differently; just as the labours of the blacksmith would be very different if he went about to make one nail out of a piece of iron, and another out of a brickbat. The different substances upon which it 
acts obey its action, or, morc corrcctly speaking, act along with it in very diffcrent ways; and the result is the production of all that beautiful variety which we see in nature. The sum, and those general influences of the atmosphere and the earth which the sun calls into activity, are the exterual causes of every change in the appearance of nature as the scasons perform their revolutions; but the obeying agencies which are in the plants themselves, and which, though they may be very greatly modified both by nature and by art, can never be so far changed as that one specics can be turned into another, - are the immediate and specific causes of all the individual productions and appearances; and whether in the grand stimulus of the beams of the sun, in the modifications of that influence by the daily rotation and anmual revolution of the earth, or in the minor obediences of the individual things upon the earth, we find that adaptation and cooperation to the performance of every single purpose in naturc, which shows that, notwithstanding the vast distance of the cclestial and the terrestrial portion, and the endless variety of principles which are called into action in the latter, thcre is a most perfect nicety pervading the whole.

In conscquence of the very great diversity of habit among the vegetable tribes, the preparation of the vegetable kingdom for the Wiuter, or for any other season, becomes a very vagne matter, and no single description can be so framed as to be expressive of any other than some small portion of it. Some plants are prepared for a total renewal of the generation, which 
shall take place in the spring of the ensuing year; though in others, which are strictly annual as well as these, the germination of the seeds is autummal, and the preparation for the Winter is in the young plant. Some again, without passing into seed in the whole plant, seed in part, and produce new plants at the roots, which come into flowering much sooner than those of the same species which are produced from the seed; and there are not a few anmuals, which make the Winter the middle of their year, producing nothing but roots and leaves in the part of it which precedes the Winter,-but treasuring up the result of that part of their labour in a bulb or tuber of some kind, which is exhausted by the process of flowering and fruiting in the next year; and the seeds, which are the result of this operation, are ready, against the time that the season comes round, to lun the same course; and so on, year after year,-always only annuals, but having one part of the annual growth before the Winter, and the other after.

Plants which have this habit of a pause in the Winter between what may be called an autumnal growth and a spring one, or which are susceptible of being so treated as to acquire it, are very convenient for the cultivator, and very obedient to lis art. A very large proportion of them are plants of wholesome and mutritious substance, and form an important part of the food of man and of those animals which he domesticates.

Of these the cabbage tribe, called Brassicacea (cabbage-like), and also Cruciferce (cross-bearing, from the four petals of the flowers being arranged in the form 
of a cross), are among the hest known of the plants which have this habit. 'They are very numerous, and many of them are so well known that they do not need any particular enumeration. We may inention, lowever, that of the common cabbage,"Brassica oleracea; there are six distinct varieties or sub-species, none of which appears to pass into any of the others by the ordinary modes of culture, though, when they are treated in different ways, they may be each broken into subvarieties almost without end. All these are probably originally the produce of the common wild sea colewort, B. sylvestris, (which is not the sea kale which grows in the sand, and which is so much esteemed in Britain as a culinary vegetable, when forced by artificial heat and blanched),--and they would probably all degenerate back to it if left in the state of nature for a sufficient number of years. Of the wild stock there is only one known species, of which there are no varieties: it is found upon the low grounds near the sea in the middle latitudes, in places where there is a considerable difference of seasons; and we may remark, that, in general, though there are exceptions, the plants of comntries with variable seasons are more plastic in the hands of the cultivator than those of countries where the seasons are less marked, or follow each other with less of variable weather between.

The five tribes of the cultivated ones, all of which form their accumulations of nutritious matter in different manners, or upon different parts of the plants, are the following: 1. Kale, Accphulu; 2. Savoys, Bullata; 3. Cabbages, Capitata; 4. Turmip-calbages, Caulorapa, 
ealled "Kolls," by the Gcrmans; and 5. Flower-eoles, Botrytis, called also eauliflowers and broecoli. These five tribes are hardy, or eapablc of enduring the Winter, very nearly in the order in whiel they liave been stated, thongh there are very different degrees of hardihood in the different varieties or sub-varicties of all the tribes.

There is one general habit whicl belongs to the whole of these plants, numcrous and varied as they are; and that is, that the accumulation of nutritive matter which they form is always deposited above the collet, or that part of the plant which is, in ordinary language, called the erown of the root, and is the division, or rather the union, between the root properly so called and the stem. This aceumulated matter is a sort of pith, and in whatever part of the plant it is collected it has in itself very little of an organie strueture, and bcars the samc relation to the regetable that fat does to the animal. In most, if not all of them, the collet is not confined to the mere upper part of the root, but rises on the stem so as to produce lateral buds in the axillie of the leaves, if the principal head is lopped off, or very much reduced in its dimcusions.

The Kalc are called Acephala, or headless, beeause the chicf aecumulation whieh they form is in the leaves, and in the centre of the stem within the fibrous part; and they never close and form a compact head. 'They are the most liardy of the whole, and the oncs which, by way of eminenee, are called "greens," though, in their young state, any of the others may be nsed for the same prirpose. If the crowns of their roots, at the lower 
part, are protected from the severity of the frost, the members of this tribe can endure very severe weather; and when the principal heads are cut at the proper time-which is matter of experience for the particular place-a succession of "sprouts" may be obtained from the lateral heads for a considerable length of time. There are eighteen or twenty named rarieties of them, and the local ones are absolutely innumerable.

The Savoys, - so called, as is understood, from the country which supplied them to the rest of Europe, and named Bulbata, because the dimples or honeycombings, with which the one side of the leaf is covered over, appear like knobs or studs, little balls, upon the other,-form their accumulation chiefly in the leaves, like the kale, but they have more tendency to accumulate into a close mass in the centre, and form a head, or rather perhaps a heart. They are hardy plants, though not quite so much so as the members of the preceding group. There is no wild plant known which has the peculiar characters of the savoys, or of any of the three groups which remain to be noticed. There are not so many varieties of them as there are of the kale; but still there are about a dozen of named ones beside those that are merely local. Both they and the former are in the best condition during the Winter months.

'The Cabbages, termed Capitata, becanse they form into heads or hearts by the close accumulation of the leaves into one mass, have many of the habits of the two preceding groups; only they have the leaves much plainer, and the accumulation in the part of the stem 
which is inchded among the thick leaves. The leaves are blanched in eonsequence of their closeness, and hence they are more succulent than those of the open ones. Some of them grow to a very large size; but they are coarse, and fit only for the food of domestic animals. They come to maturity at all seasons; but the ones which are in most estimation for the table, are in best condition during the summer. The named varieties of them are about the same in number as those of the savoys.

The Turnip-cabbages (of which Caulorapa is merely the Latin translation) have a very different habit from any of the three groups that have been mentioned. Their leaves remain wide apart from each other, have peduneles or footstalks of considerable length, aceumulate very little mutritious matter into their own substance, and never eollect, or "gather" as it is called, into a head. The aeeumulation is formed in the stem, and consists of the pith of that part of the plant. It is always above the eollet, though some of the varieties form it wholly or partly under ground, and others altogether on the surface; in which latter case, the upper part of the bulb is marked over with the bases of leaves. The varieties of these are comparatively few, not exeeeding three or four; and in Britain they are not mueh esteemed in an economical point of view. They are, however, held in mueh more estimation in Germany, where all the cabbage tribe enter mueh more largely into the food of the people than they do in Britain.

The Flower-eoles-cauliflowers and broeeoli, named 
Botrytis, because the part of them which is most estecmed for the table, eonsists of a eluster of small button-shaped buds, having some slight resemblanee to a bunel of grapes,-are, so to express it, the nobles of the family. They require the most eareful management, and are the most tender in their nature; but they far surpass even the best of the others as articles of food. Their habit in the aeeumulation of nutritious matter is also very different. They partially, though very partially, form it in the mid-ribs of the leaves toward the basal parts, but the most delieate is in the young flower-buds and the branching stems which earry these. 'They must be used in the carly stage of their flowering, long before any thing like the distinet parts of the individual flowers are in the least developed, otherwise they lose all the delieacy of their flavour. As they are held in much estimation, they are eultivated with assiduity, and a considerable number of varieties lave rewarded the skill of the eultivator. These, as usually named, are about as many as those of the eabbage, and they ean be brought forward at all seasons; so that, with proper management, there is only a very small part of the year during which one or another of them may not be supplied.

Though the various members of this family of plants, of which we have given a mere outline, are all artifieial ones, in those parts of their characters which give them their prineipal value to man, yet they, perhaps, as well as any others, serve to illustrate the mode in which a provision is made by a plant for the ocemrenee of a panse in its growth between the production of a root, a 
stem, and leaves, and the ultimate and most important of its labours - the production of flowers and seeds. The times of accumulation in these eultivated plants are distributed over the whole or the greater part of the year; and, therefore, they camnot strictly be called preparations of the plants for the Winter. But still, though the resulting effect on the appearance of the plant is changed by the skill of the enltivator, in time, in manner, and in extent, yet the essential habit of the plant can no more be ehanged for a new one by any labour of man, than one speeies of plant ean be changed to another by the same means; and thus all the varieties to which we have alluded are only modifications of the one habit which the wild plant has when cultivation has not affected it in one way or another. Even when in the natural state, there are differenees of habit in them; and these differenees sometimes break out when they are eultivated, although we are not, in all eases, able to explain the causes. At some times, and in some situations, the wild plant puts forth its flowering stem and rums to seed, without any marked aecumulation of matter in stem or leaf; and the same happens, though less frequently, with the eultivated ones. At other times there is an aeeumulation in the wild plant, though nerer to the same extent as in the eultivated one; and when there is an aeemmulation, there is also a pause, for which that aeeumulation is preparatory. Of the bulbing, or turnip-rooted cabbages, we nuay remark, in passing, that the speeies ealled the Swedish tunnip, and very extensively cultivated in many parts of Britain as food for cattle, is an exceed- 
ingly hardy one, very little injured by the severity of Winter, and, therefore, well adapted for the agriculture of the colder districts. It is far more hardy than the common turnip-not nearly so liable to the attacks of insects in the young state, or to be destroyed by the frost in severe Winters. This shows the greater security of a bulb formed above the collet in the stem, and one formed below it in the root; and there is a further difference between the members of the cruciferæ, which form their bulbs on opposite sides of this division of stem and root; those which have the bulb superior, or in the stem, retain their leaves more completely during the pause than those which have it inferior, or in the root; and the leaves which thus remain, as well as the bulb itself, may help to protect the collet from the frosts of Winter. The collet appears to be the most tender part of the stem of every plant, whether herbaceous or ligneous, and therefore attention should be paid to the protection of it by every one who is interested in the health and rigorous growth of all plants which are intended to live through the severity of the Winter, whether they come under the denomination of herbs, of shrubs, or of trees. At the same time, if the collet is a definite one, that is, if it is confined to a limited space, and the part of the plant from which the principal growth proceeds, it is of advantage that it should be freely exposed to the sum and the air during the season of growth.

Of the cruciferous plants which form their bulbs, or accumulations of mutritious matter under the collet, and thus have the bulb properly a root and not a stem, 
there are very many, some of which are cultivated for their bulbs, others for their leaves, and others, again, for their seeds; but the nost typical one, and the only one which it is necessary to mention for the purpose of illustrating the habit, is the turnip. As is the case with the cabbages, and, indeed, with all the bulbing crucifera, the accumulation in the turnip is in the central pulp, or pith, within both the integuments and the fibrous portion of that part in which it forms,though when turnips are grown in situations which are too hot for them, and soils which are too rank or retentive, they are apt to have fibrous matter dispersed through the bulbs, or to be "stringy," as it is called in common language. The bulb of the turnip, if it survives the Winter, and the plant is allowed to run its regular course, answers very nearly the same purpose as the accumulation of matter in the cabbage tribe, in whatever part of these it is found. It serves to nourish the flowering stem, and, by the growth of that, it is exhausted, so that no part of it remains after the seeds begin to ripen, but the shrivelled skin and the fibres.

It would far exceed our limits to detail all the various means by which the lierbaceous plants which have a pause in their annual growth, and thus lay up a store, in some way or other, for the Winter, accomplish their purpose; though they all have some resemblance to those which we have noticed, if not in the mamner, yet in the principle of their preparation. Even the seasonal trees which are deciduous, or shed their leaves in the autumn, follow nearly the same general law; 
only as their annual growth is from a number of points, greater in proportion as the plant is of larger size, and more of a branching habit, there is a separate preparation at each of them, in the form of a bud. Thus buds are always formed previous to, and preparatory for, the Winter, the formation of them being the last action of the tree for the year, and the one which, in the vegetable kingdom, more immediately links the autumn and the Winter together, and also connects with each other the growth of the two consecutive years.

In most trees, the growth and action of the roots are understood to be the portions of the annual action which first give place to seasonal repose; but in herbaceous plants, whose habit is to form regular bulbs, the case is different,-the bulb continuing to swell and consolidate, by drawing nourishment from the root fibres, not only after the leaves above ground have ceased to have any action, but after they are withered and gone. This is more remarkably the case in those plants which form superior bulbs, or bud-bulbs, on the upper side of the collet, as in the onion, the tulip, and the crocus, than in those which have bulbous roots below the collet, as in the turnip, the carrot, and the dahlia. 'The superior bulb, whatever may be its form, is always of the nature of a bud, of some kind or other ; and the chief difference between it and the bud of a tree is, that the bulb combines in its own structure all the three parts of stem, branch, and bud, and nothing originates from it in the season of growtl, but leaves and flowering stalks, the rudiments of which, and very often the less dereloped rudiments of several 
sucessional ones, being contained within the bud or bulb.

From this we can see why bulbs of this description are so much better adapted for dry and warm places, which have their only Winter an arid or tropical one, or have a considerable portion of their summer, according to the calendar, resembling a Winter of this kind. The superior bulb, partaking of the nature of a stem, or, indeed, of the whole upper part of a plant above the collet and roots, continues to receive nourishment, and, therefore, to grow long after the drought has put an end to all surface vegetation. This is the case, in an especial manner, when the whole bulb is lodged in the ground; only, in order that such a bulb may have scope to grow, the ground must not be of too binding a nature-must not consolidate like a brick in the drought; because, against this, when the sun has acted strongly upon it, the power of no vegetable can exert itself so as to produce much increase of volume. But soils-they are chiefly clay soils-which are of this binding nature, absorb moisture during the rains to a much greater extent, and are more intimately incorporated with them than soils which are free; and they loold that moisture with far more pertinacity during the drought. This, by the way, is the reason why they are popularly called retentive soils. Examples of them, as contrasted with soils of a more light and fiee character, may be found in any country, and in none, perlaps, more strikingly than in the valley of the Thames and its affluents. In some places the soil there is, to a great depth, a very tenacious clay, in others it is gravel 
or sand, and in others, again, it is chalk, up to very near the surface. The roads over these are the places where the different states, at some depth, in the dry season, are most easily seen; and the contrasts which they present are abundantly striking. The roads over all these soils are equally dry on the surface; and if the materials used for "pitching," or " metalling" the carriage-way are the same in them all, the chance is that the surface-dust on the road over the clay shall be the most light, loose, and troublesome. When, however, they are broken up, the states of the under parts are found to be very different. The sand, to any depth that may be examined, is comparatively dry, and the gravel and chalk are nearly the same, only with differences arising from the various admixture of clay in the gravel, and the number of perpendicular fissures in the chalk; but the clay is very different; and while the surface is quite dry, the interior, at the depth of only a foot or two, is worked into a sort of mortar or sludgy mire, by the kneading given to it by the carriages, as they alternately press down and release the surface, rendered flexible by its own tenacity, and the yielding nature of the sludgy substratum. Roads upon a bottom of this kind are, by the way, exceedingly deceptive, and there is a great waste of the power of traction upon them, which superficial observers are in nowise aware of. The surface may appear to be smooth and good; but it is flexible, and thus, though the wheels make no rut, the carriage always meets with the same resistance as it would do in being drawn up hill. Now, it will readily be understood that, 
though the length of a hill fatigues by its continued opposition, it has nothing to do with the absolute resistance against which the carriage has to be drawn at each individual point. The length of road with which the wheel is "coming" in contact, is all that the wheel has momentarily to contend with, and it alters not the individual effect that may be necessary, whether the length of the steep opposed to it is an inch or a mile. The yielding of the surface of those quagmire roads opposes an ascent to the wheels, so that upon a perfect level, or even upon a declivity, the pull may be all along equal to what is necessary to ascend a comparatively steep lill on a road which does not give way in this manner. The friction, and, consequently, the resistance to be orercome, is even greater than that on a firm road, the ascent of which is all along equal to that which arises from the depression of the elastic surface at the place where the wheels are passing, because a larger portion of the circumference of the wheel is in contact with the ground.

These remarks, it must be admitted, have no very obvious connexion with the preparation of the vegetable tribes for the Winter; but we often obtain more valuable and satisfactory knowledge from those bare analogies than we do from the parts of a subject itself, inasmuch as being more unexpected, they are more striking; and this is very much the case in the instance of which we have given some details. If the water remain so pertinaciously during the heat of summer beneath a dry road, where the evaporation from the surface may be considered a maximum, much more 
must it so remain where the surface is covered with vegetation, or with withered leaves, or dry vegetable matters of any kind, which are worse conductors, both of heat and of evaporation, than vegetables in the green and growing state; and as the surface at so small an elevation above the sludgy bottom is so consolidated as that it supports the pressure of a heavy carriage, much more must it resist the expanding of the bulb of a plant. But bulbs on the upper side of the collet, partaking as they do of the nature of stems, do not come to their proper maturity if they are buried so deeply in the ground as that the air, and in some degree the light, have not access to them. Any one may see this in a tulip, or any other bulb which has been left in the ground and buried too deeply there. The bulb and the leaves that spring from it are white and sickly, unable to bear the weather, and rarely capable of producing any flower; or if one is produced, it is of no beauty or value, and not capable of producing its seeds.

Hence, in the clayey and retentive soils of countries which have the Winter of a tropical character, or part of the summer answering to the same, the bulbs are for the most part of the above-ground character, and thus they consolidate and ripen in the atmosphere; while the root-fibres continue to supply them with nourishment from the retentive soil below, long after the loam soils in similar places are completely dried up to the same depth. 'These above-ground accumnlations, which the plants prepare against the ardour of the tropical Winters, are not, however, properly speaking, buds, 
they are stem-tubers, and answer nearly the same purpose above ground which the tubers of the potato answer below.

The plants which have this habit of forming large stem-tubers, on or near the surface of the ground, are, for the most part, natives of climates which are very hot and very seasonal; and thus they are good iliustrations of the mode in which perennial vegetables with annual stems prepare themselves for the extreme of the tropical Winter: many of them are also very interesting plants in themselves, and highly serviceable as wholesome food for the inhabitants of those countries in which they abound. They are plants of more simple structure than our cabbages, turnips, and potatoes, and in the botanical arrangements they belong to the extensive and splendid division of the vegetable kingdom, which includes the palms, bananas, aloes, lilies, rushes, orchideous plants, and a vast variety of others. In their aspect and in their flowers, they are perlaps the most splendid, and, at the same time, the most singular of all vegetables; and though many of them contain very acrid and even poisonous principles when in the raw state, these can generally be separated by boiling, or sometimes by simple maceration in cold water for a sufficient length of time, and then they yield an alimentary substance, which is of the most placid and light, and also of the most nourishing description. Very many of the people in the dry districts which border on the great deserts in Africa and the west of Asia, subsist, in great part, upon the fruit of the date palm; the banana furnishes more human food, from the same 
breadth of ground, than any other known regetable; and the great American aloe furnishes the people of the table-land of Mexico with the chief part of their vegetable drink, which, like our products of malt, may be made either a wholesome and refreshing beverage for those who labour hard, under exposure to the buming sun, in a country where pure water is not easy to be had, and where the drinking of it is not safe when obtained, or an ardent and intoxicating spirit. Even the roots of our common rush, which flourishes in the coldest parts of the couritry, contain a considerable quantity of pulpy matter, which is wholesome, and by no means unpalatable. Our orchideous plants, which of course belong to this division of the regetable kingdom, are not numerous, and they are humble plants as compared with those of the tropical countries; but the tubers of some of them, as of the great or male orchis, when duly prepared, furnish a light and pleasant kind of food. We may add, that as these plants follow next in order of simplicity to the grasses, they are also the next to them in importance as food for the human race; and that they form appropriate substitntes in those places which are too warm for the culture of the ordinary grain plants, and too dry for Indian corn or rice. Our object, however, is not to describe these or any other of the grand divisions of the vegetable kingdom, or to enumerate their uses to man, but merely to take them as illustrative of the preparation of regetables for the tropical Winter.

In passing, we may, however, remark, that from the great number of these plants, and the diversities of 
their aspect and character, one or another of them is, in the climates which are warm enough for them, adapted to almost every variety of situation that can be named, from the marsh and the moist forest of perpetnal verdure, to the scenes of extreme drought, upon which the tropical Winter tells with the most withering influence. Their roots are fitted to and found in all situations-in water, in moor, imbedded in ordinary monld, on the surface of the earth, and in the air, without any connexion with the ground, or any medium through which they can be nomished but the atmosphere aromind them. These last are supported, that is, kept from creeping prone upon the earth by the trees to which they cling; but though they are thus epiphytal, or upon trees, they are not parasites, deriving their nourishment from their supporters, but wholly dependent for that upon the free air which plays around their elegant foliage, and their most beautiful and fragrant blossoms; for, in both these respects, some of them have no equals in the whole vegetable world.

The plants which are most appropriate for our present purpose, are those which are called Taccince, from Tacca,-a plant of the east of Asia, the Asiatic isles, and those of the South Sea, for which there is not any descriptive English name. In all these comntries the grain plants which form the bread of man in Europe, and the other cold and temperate parts of the world, are more difficult of growth than they are with us; and in the isles they were wholly unknown when these isles were first visited by Europeans. But in the different species of Tacca, the people found good substitutes, 
growing naturally, and without any more trouble to them than that of gathering them when in the proper state, and preparing them for food. As is the case with the accumulated stores of nutritious matter in all vegetables, in what part soever they may be accumulated,whether in the root, the stem, the leaves, the buds, or the seed,-the proper season for the taccas is that of the annual pause of their growth, when the faculty of accumulation lias done the most that it can do for the year, and before the action of the next season has begun to deteriorate its quality or diminish its quantity. Even when in this state they are bitter and acrid, but when they are reduced to a pulp, and properly washed with water, the farina which remains is very mild, and highly mutritive and easy of digestion, and therefore admirably fitted for the inhabitants of countries, whose system is more feeble and relaxed, by the nature of the climate, than it is with us in the temperate and bracing atmosphere in which we live. The lower leaves of those plants, which are peculiarly succulent, more especially in their footstalks, are capable of being cleared of their bitterness and acridity by boiling, in which state they form very good substitutes for our greens and cabbages, which, being natives of temperate climates, are not found in a state of nature in those warmer regions of the globe.

Closely allied to the taccas in their habits, general adaptation to the seasons, and preparation for the torrid Winter, though differing in some respects, and indicating by their flowers, and also by the reticulation of the veins in their leaves, that they make a partial 
approach to those plants, which are called exogenous, or growing at the surface, to which class the "greater number of our native herbs and all our native trees belong, are the yams, dioscoracer. One of these, the common black briony, Tamus communis, is a native of Europe, growing in hedges, along which it climbs. The roots of this plant grow to a pretty large size, and accumulate a good deal of farinaceous or starchy matter; in their entire state, however, they have an unpleasant taste, and are probably not wholesome. But there seems little doubt that if the value when purified would repay the labour of the purification, the roots of these plants might be prepared as a wholesome article of food, in the same way as are the roots of the taccas, and those of other plants, which the natives of tropical countries use as substitutes for bread. The cereal grasses are, however, so much cultivated with us, and they so much engross the attention of the cultivators of the material of bread, that it would be in vain, and in all probability not very wise, to recommend the culture and preparation of such a root as that of the black briony;-and yet the great success which has attended the culture of the potato, the increase of population and industry which it has facilitated, and the extent to which it has assisted in preventing that famine which, before its introduction, used to be felt in some part of the country almost every year, render attention to those roots or lower stems of plants which collect great quantities of pulpy matter as preparatory for the season of their repose, of more importance than many are apt to suppose. 
Our briony is by 110 means a typieal plant in the section to which it belongs; for though it is met with in temperate countries, it is never found in very cold or exposed situations, or in those which are habitually marshy-the character of the tribe to which it belongs is tropical. There are two genera which may be considered as typical - the one, the more abundant and better known, and that from which the name is derived; and the other, more remarkable in its appearance, and more eompletely a plant of countries which are habitually burnt up and scorched in the dry season: these are the yam, properly so called, and the elephant's foot, or Hottentot's bread.

Of the Yam, there are sereral species, or varieties, which abound in most of the intertropical countries, where the situation is not too elevated, or too humid or dry; and they are eultivated with nearly the same assiduity as potatoes are with us. They are plants of vigorous growth, with elimbing stems, and rather handsome foliage; and the roots grow to a large size, so that a single one often weighs a quarter of a liundred weight, or more. They require a little more labour in dressing than our potatoes, as they contain a juice so very acrid, that it aets umpleasantly on the skin; but this can be easily removed, and then the substance of the roots beeomes a very excellent artiele of food, and, from the productiveness of the plants, a rery cheap one. When thoroughly cleared of its acrid juice and properly dried, the root of the yam-which is, indeed, the part to which the name "yam" is given-is more meally than the average of our potatoes; and thus, 
while it answers quitc as well for eating or substance as the potato does, it is a much bettcr substitnte for the meal of grain in making bread, and for other purposes.

The Hottentot's bread is not so widely distributed or so much used as the yam, and we know it chiefly as a wild plant of the dry plains of Southern Africa, which are completely burnt up toward the latter part of the south-east monsoon in that country. The root of this plant is wholly upon the surface of the ground; and, during the dry season, no one who had not seen it at other times would have the slightest idea of its being a vegetable, or any part of a vegetable. What it resembles most nearly is onc of the tortoises, which have the different plates of the shell in the form of polygons, with angular grooves between; and cven the markings of colour upon it liave some resemblance to those upon the tortoise. Hence it is called Testudinaria, as the generic name, and Eliphantipes, or the elephant's foot, as the specific one. There is not a leaf or a bud, or the lcast vestige either of the one or the other about it, or any point from which such an appendage would be likcly to issuc. Its external rind is proof against the severest action of the drought, while the under part of it, lying closely upon the surface of the earth as it does, continues to receive the moisture which the action of the heat brings upward, long after the ground upon which it appears to lie, like a piece of stone, is dry and parched. When the rains set in, lowever, this apparently moist mass very speedily shows that it is instinct with very active life. It soon puts out long and climbing 
stems, with rery handsome reticulated and slightly three-lobed leaves, and abundance of small flowers; the amnual growth having much the appearance of an ornamental climbing plant, standing round the root, as a picce of stone, which merely supported the plant, but did not produce it. This singular plant is not, we believe, admitted into cultivation as an esculent, but when animal food is scarce witl the wandering natives of Southern Africa, as it is apt to be during the dry season, when the antelopes, quaggas, and other wild animals are forced to seek food in the upper country, they resort to this as to a meal prepared for them in the desert. The external part of it is hard and woody; but the pulp within is eatable, and might, perhaps, become not an umpalatable dish if it were properly prepared.

The plant now noticed may be regarded as showing the extreme of vegetable preparation in the bulbous or tuberous root for the sererity of the tropical Winter. Many of the crassulinæ, or plants, the main body of which consists of thick and succulent leaves or leaflife productions, have very nearly the same habit. The common houselcek, which flourishes on the tops of walls, or the roofs of houses, among stones, or in any very dry place, but will not thrive in rich and humid soil, is an example with which every body must be familiar.

In the dry places of warm countries, those plants are very numerous, some of them bear fine flowers and pleasant fruit; and though they flower only at particular seasons, and some of them only after very long intervals, drought and heat, which would very soon wholly destroy even the hardiest plants with which we 
are familiar in temperate climates, have very little effect on those parts of them which answer to the stems and leaves of our common herbaceous plants.

The general habit of those crassulaceous, or thick and succulent leaved plants, which flourish in the most dry situations, and are but little affected by the ntmost ardour of the tropical Winter, is to derive the greatest part of their nourishment from the atmosphere, and to be but little dependent on root or on the earth for any thing farther than a mere resting-place. Their epidermis is remarkably close and tough, and generally, though not always, glossy; they give out very little moisture by evaporation; and they must take in a great deal by absorption at the general surface, as they are almost invariably and at all times very juicy within, and yet do not take up water in substance and give it out again in part in the same way as is done by the common plants, which are unable, in any parts of their structure, to endure the same extremity of drought.

In them we have one extreme of the regetable creation in its adaptation to climate, and its preparation for the peculiar Winter of that climate. For their own preservation as individuals, they may be said to be always in a state of preparation for the heat and drought, though of course they must grow most rapidly, and come most readily and freely into flower, when the atmosphere is most loaded with those substances which they absorb, and of which we may suppose that water is the chief. As the whole structme and physiology of these plants adapt them for the extreme of drought we might be prepared for the conclusion that muc 
humidity settling about them is their greatest enemy, because a plant cannot be adapted to one kind of circumstances, and also to the very opposite kind. The fact completely bears out this conclusion; for if an unskilful cultivator by any cliance gets hold of one of these plants, and endeavours to nurse it in what he considers to be a kindly manner, that is, by planting it in rich mould, and supplying it frequently and copiously with water, the plant is sure to canker, and die, and rot; whereas if it is treated with neglect, thrown, for instance, on a dry shelf and left there, the chance is that it will not only live but grow vigorously, and put out its flowers in their full beauty. So necessary is it for us to know the natural habits of the plants of peculiar climates and localities, if we wish to cultivate them successfully by artificial means.

In this manner is the vegetation at the warm extreme of the quadrant adapted to its locality, and prepared for those changes of season which it has to endure; and when we consider that the other, or cold Winter end of the quadrant, is the opposite of the warm one, in respect of the general character of the seasons, and of the Winter in an especial manner, the conclusion almost necessarily is, that the vegetation there must, both in its general nature and in its preparation for the Winter, be adapted to the opposite principle or agency :- that the good and the bad, or the favourable and the un. favourable to the vegetation at the one extremity of the quadrant, must cliange places at the other extremity, so that the bad at the one may be the good at the other, and the good the bad. 
Is it eold-the absenee of heat, to which the polar vegetation must be adapted, as the opposite of that to which vegetation is adapted at the equator? No; for though cold is an element of the polar Winter, as heat is an element of the tropical one, neither the one nor the other is the only element. It is not the heat at the equator whieh makes the warm time of the year the Winter in many situations there; for in those plaees where the supply of humidity is equal to the degree of heat, the Winter of the dry regions is the very intensity of the summer, - a season of vegetable aetivity unknowil and unequalled under any other eircumstanees. It is true that the progress of vegetation does not show itself so eonspieuonsly in the humid distriets of perpetual growth as it does upon those plaees whieh have been parched and naked during the drought, when the rains eome upon them; but there are various and obvious reasons why it should not be so apparent. 'The vegetation on the humid places is abundant at all seasons; and it is of such gigantie eharaeter, and so thiekly serried, that the addition to it during the hot season eamnot be fully estimated, or even seen, except very imperfectly; and the contrast with the dry and barren plains, is one of the most striking that can well be-that between perfeet barremness and abundant vegetation. There is another reason: as the plants on the humid platees in the equatorial regions have no Winter of repose, they ean have no spring of awakening. Of this, we have illustrative evidence in the spring of the temperate latitudes, where the spring is always marked in its 
character, and rapid in its progress, in proportion as the Winter is long, severe, and unbroken in its dominion. Where the Winter is short, and mild, and undivided, the spring comes on so gradually, apparently with such feeble power, and subject to so many checks and reverses, that we cannot notice its progress, except at the end of considerable intervals of time; while, in countries farther to the north, and in them in proportion to the length and confirmed character of the Winter, the spring comes on with such daily strides, that its course is run in a week or two, and that without. any reverse.

Another thing-the ever-growing vegetation of the moist places does not need, and, therefore, does not make, those preparations that are regularly made where there is a confirmed Winter and Winter's pause. Buds, bulbs, tubers, and other vegetable stores against a season of vigorous action, consequent upon repose, are not wanted, and, therefore, they are not formed. Man often accumulates what is useless to him, and occasionally what is injurious, from the mere love of accumulating; but nature never makes any accumulation for which there is not a use. In places of continual growth, every germ and growing part of a vegetable, whatever it may be, continues from its first starting, till it has run its appointed course; and so there is not even a bud there but such as are in active growth. The vegetation of such places, in short, has not to prepare either for summer or for Winter, as contrasted seasons ; for it feels neither the one nor the other.

Yet, again, the heat is never so intense upon these 
places of perpetual verdure as it is upon the dry ones, which feel the burning and parching effects of the. tropical Winter, The sumbeams do not reach the ground in any quantity, or with much effect, because of the dense canopy of foliage with which the trees are crowned and tangled; and although the light of the sun is very bright in the open places, a perpetual twilight prevails in the shade of these vast forests. Then, wherever the sunbeams do penetrate, their heat is, in a great measure, exhausted by the evaporating of humidity; whereas, on the dry and naked ground, they tell with great force, of which there is very little evaporation to blunt the intensity; and where moisture comes to be applied to the ground in this greatly heated state, the energy of vegetable action is forced to a degree much exceeding what would be displayed, if the ground were not previously brought to so high a temperature. It is true, that this intense forcing of the vegetation when the rain sets in upon the heated plains, very soon begins to abate; and it is well that it does so, for the strength of no vegetable could bear a continuance of it. In this we have a beatiful example of that beneficent law by means of which the antidote in nature always comes, not only along with, but in the very same power, or instrument, with the bane. The heat of the parched ground, which tends to force the vegetation so much, tends equally to evaporate the rain as it falls, and this, again, tends to reduce the temperature with corresponding rapidity. When plants are furnished with a store, this store enables them to meet the great stimulus to which they are subject 
with much less labour than they would do, had they to assimilate directly out of the elements the whole of the matter necessary for the great enlargement of the new parts, which takes place in the early stage of their growth; and, by the time that this store is exhausted, and they are thrown upon their own resources for this additional matter, the stimuli have abated, and the growth has become less rapid.

'This is a very beautiful part of the system of nature's working, and one which, in itself, if well considered, would be adequate demonstration of the wisdom and goodness of Him by whom the system of nature was begun, and according to the good counsel of whose will it is carried on. But it is as general as it is beautiful; and we find it in operation, although in a more limited degree, at every place on the earth to which we can direct our attention. To revert, in illustration, to the bulbous plants, and also to those which form large buds, or other stores, before the time of their anmual pause, may suffice to convince us of this. All the plants which bulb before the Winter are, unless they are kept back by being taken out of the ground, early flowerers, and the trees which form the most perfect buds in the autumm, are the first to come into leaf or flower in the spring; and they are, of course, also the first to run their career, and to prepare for the season which is to follow.

Many useful conclusions might be drawn from these general remarks, if our limits would permit us to draw them; and, among others, that it is not the heat, but the absence of humidity to act along with that heat, 
which is the cause of the scorching Winter of the tropical climates. But the polar Winter is the opposite of the tropical one; and therefore the cause of the one must also be the opposite of the cause of the other. In the tropical countries, it is an excess of heat, with a deficiency of humidity; and in the polar latitudes, it is an excess of humidity and a deficiency of heat. The tropical plants are adapted to the excess of heat; and therefore we might reason by anlogy-and the fact proves the correctness of the reasoning-that the polar vegetation must be adapted to an excess of humidity.

There is one point of resemblance between a very considerable portion of the native vegetation, both of the equatorial and of the polar countries, though meither can, in strict language, be said to be the most appropriate to the state of things there. The continual regetation, which knows no Winter, is the appropriate vegetation of tropical countries; and that is adapted to the circumstances of the locality, on the supposition that the supply of heat and that of moisture are always in nearly the same ratio to each other; and, consequently, needs no extraordinary preparation at one time more than at allother. The appropriate vegetation of the tropical climates is, therefore, that to which there can, from the ordinary action of the sun, be no excess of heat, if there is the requisite degree of humidity to act along with it.

In like manner, the appropriate vegetation in the regions of the poles, or in those regions as near to them as there can be any thing to which the name of vegetation can witl propriety be given, must be that 
which never can have too much humidity, if there is an adequate degree of heat along with it-that is, if the temperature is not lower than the freezing point of water, below which the fluids of plants are fixed and consolidated, and, therefore, they cannot grow. In both situations, plants which are not thus adapted to that which is the leading character of each, are really out of their proper element; and the various accumulations of matter, and other preparations for seasons which they make, are really adaptations for one climate, of those species which are, in their general nature, better adapted for another.

The characteristic and appropriate, and also the most prevalent vegetation of these high latitudes, which may be said to occupy the extreme of climate toward the poles, consists chiefly of the lichens and the mosses, - plants which are as little dependerit upon the soil or the surface which affords them a resting-place, and therefore as much dependent on the atmosphere in which they grow, as those plants which hold on their way without obvious preparation for seasons, in the tropical climates.

The lichens are plants of the rock, the upland, and the boles of trees and other surfaces; never making their appearance except in situations where the atmosphere is damp, at least for some portion of the year, and more exclusively dependent on the atmosphere for their supply of nourishment than perhaps any other family of plants. They come upon the bare rocks and other surfaces, where there is not previously a single particle of soil; and if the places upon which they come 
are different from this, they in no wise diminish the quantity of soil that may be there. In their nature, the lichens are very simple plants, and they appear to be as quiet in their action. That they elaborate vegetable jelly, originally and primarily, out of the atmosphere, or the substances which the atmosphere contains, without any assistance from a previous vegetation, is true; but how and by what means they do this, is another and a more difficult matter. 'They appear, as has been said, only where the atmosphere is moist, and yet they do not seem to have any very strong attraction for humidity, so as to retain it in the dry time of the year. When the weather is dry upon these mountain tops, and other places which are covered by them, they crackle under the foot, and are easily broken or rednced to powder; while they have more toughness and coherence when they are moist. In many respects, however, they appear to be equally secure, if not equally passive, in all states of the weather; so that, though a moist atmosphere is obviously the most congenial to them, they do not sufier either from the extreme of drought, or from that of frost.

The mosses are different, though they are also plants of the colder climates, but not exclusively confined to them. In all situations they are very retentive of moisture, and in the cold latitudes they hold it in opposition to the utmost influence of the atmosphere. In most of the species they are so exceedingly hardy, that few contingencies are able to destroy their vitality. In the drought they get brown and sickly, but they do not die, like plants of a more highly developed organization; for after a moss has been kept in a perfectly dry state 
for some time, it will again recover its greenness, if furnished with a sufficient supply of water.

We cannot, on account of the very limited space to which we are of necessity restricted, enter into any description of the various tribes of the mosses, or the circumstances under which they appear, or the situations in which they flourish the best. We can only spare room to remark, that they are ministers of good or of evil, according to the situations in which they establish themselves. They are bad conductors of heat, and, therefore, whenever they are so abundant as to form an entire covering for the surface, they are calculated alike to mitigate the heat of the long summer day, and the cold of the long Winter night, in the high latitudes. They are but little affected by the vicissitudes of the seasons, themselves, and therefore the roots of other and more valuable plants which are under a covering of them, are not liable to be much injured by seasonal changes. But, on the other hand, the cold damp which the mosses retain, is far from being favourable to the roots or the growth of any very valuable kind of regetation; and when they come in thick array, they almost uniformly come in the character of spoilers. When the mosses appear in numbers upon a lawn or a meadow, even in the most favourable situation for kindly herbage, they very speedily consume the grass; and when they once have gotten the mastery, the decomposition of them at the bottom, which groes on while they continue growing at the top, in time covers the whole surface witl peat-mould; and the retention of moisture is such, that the very climate is altered by them. 
'They are most prone to establish themselves in situations where water partially or seasonally stagnates to a limited deptlı; and when they are once established, they go on in converting the place into a perpetual mire. They retain the moisture, from their strong attraction for it, and also from their constant decaying at the roots while they are growing at the surface, until they form a stratum of their own earth, of very considerable thickness-not less than a hundred feet, in some instances; and, as this accumulation of moss or peat-earth is very retentive of moisture, it becomes, in most instances, a means of deteriorating the neighbouring surfaces and soils. If the subsoil is porous, or if there is a natural drainage, from slope or any thing else, so that the moss does not accumulate, but is dried. and its growth arrested, in part of the summer, then the mischief of which it is productive is not so great; and there are then, and, indeed, under most circumstances, some countervailing advantages that result from it. When there is merely a mossy turf on the surface, which becomes green in the autumnal rains, and continues to grow during the Winter, it acts as a preserving mantle, by retaining the heat in the earth; but if there is as much humidity among the roots as will enable it to grow in the summer also - which it will do, as it consists of plants of moisture and cold, which depend not on the sun for their summer-it prevents the summer heat from penetrating the earth; and thus though, under all circumstances, continually-growing mosses tend to equalize the temperature of the seasons, yet, if in large masses, they 
reduce the avcrage temperature of the year, and thereby injurc the climate. 'They load the air in their vicinity with humidity; and the result is, the formation of thick dews and fogs, and also white frosts later in the spring, and hoar frosts earlier in the auturm, than would be the ease if the moss was not there. The difference of climate which peat-bogs-which are, of eourse, aecumulations of moss-occasion, is mueh greater than they who have not attended to such matters would be apt to suppose. 'The author knows of a district, not very far from the sea in longitudinal distance, and not very much above the sea level, where the better varieties of oats coula scareely be ripencd before the autumnal frosts; but the peat-bogs have been drained, and in great part eleared; and now wheat is sown and comes to vely great perfeetion, while the quantity of rain and snow in the Winter is very much diminished; and though the summer is probably not so hot as it was then, it is more showery, and favomable for all the more uscful kinds of vegetables, and, by conscquenee, for domestic animals and for man. The place has, in firct, undergonc the same kind of change as though it had becn lifted to full two or three degrees nearer the equator. 'This fact, which is one of simple but direct pcrsonal observation, spcaks volumes ori the subject of peat-bogs, and of those mosses of which the substance of the bog is composed. If any country bccomes, to a considerable cxtent, covered by a polar vegetation, we may rest assured that, to the same extent, the climate will assume a polar character. But a character of this kind indueed upon lower latitudes, by what means 
soever it may be induced, is the least favourable for the cultivator that can well be named. It brings the bad of the polar seasons, without the countervailing good along with it. The moss may bring the fogs, the alternating frosts, and the other unpleasant attributes of the polar climates; but it will not bring the long days of the polar summer, or the settled serenity of the polar Winter.

What the cultivator requires is a greater uniformity of the seasons, - the summers less dry and burning, and the Winters less cold; and, as the necessary consequence of this, both the spring and the autumn less precarious. The humid atmosphere from the bog is equally unfavourable to ripening in the autumn, and to the principle of fertility in flowering plants at all seasons of the year. This is exemplified in the case of the potato in Ireland: the vicinity of the bog, and even the bog itself by a very little management, may be made to yield a good potato-crop for one year; but the tubers of that year, if planted the next, yield a much inferior crop, and sometimes fail altogether. It cannot be said that any change produced on the ground by the first crop is the cause of this; for the failure is the same if the second planting is made in new ground. If those who profess to have the welfare of countries most at heart, shall ever find leisure to ascertain by wnat means that welfare may most extensively and certainly be promoted, such subjects as the one now hinted at will necessarily occupy no small portion of their attention. But mankind are more occupied in wrangling with each other, - which the experience of ages shows 
can be productive of little good, though of much evilthan in studying and labouring to overcome those physical disadvantages, the removal of which would be advantageous to all. It is by doing this that private men, witl their own private interest as their chief ol only object, enrich the country even more than they enrich themselves; and it seems passing strange that those who take to the improvement of the country as a regular trade will not do the same. In most countries, if one tenth of the eloquence, the ingenuity, the time, and the expense, which have been consumed in settling whether the offices of public trust and emolument should be filled by $\mathrm{A}$ or by $\mathrm{B}$,- - both of whom are perhaps equally qualified, or disqualified, as may happen, for the discharge of the duties of those offices, - liad been bestowed upon subjects of practical usefulness, the world would have been all the richer, the wiser, and the happier. Mankind are somewhat like dogs: they will fight and worry for the bone which one dog possesses, though each might hunt out a bone for himself, in half the time, and withont any snarling or bites given or received. Nature prevents this pugnacity of temper among the canine race, for in the wild state they hunt in packs, in concert and amity with each other; and if men were to be guided as much by that reason which nature teaches, as dogs are by their natural instincts in the field, it might probably take off a little of the edge of their pugnacity.-But this is foreign to our main subject.

The mosses are not a primary vegetation like the lichens; they do not come to clothe the bare rocks and 
prepare a soil in which other plants may take root and flourish;- they come as destroyers, or to bury or consume that which has been destroyed by other causes. There is a rule,-rather an out-of-the-way one at first sight, it must be admitted,-which is yet better calculated to guide us to the general uses of plants in the economy of nature, than rules which have more of the poinp and circumstance of philosophy in them. It is this: If vegetation is consumed upon the surface of the ground, either by fire or by the rotting influence of humidity, the vegetation which the rains cause to grow upon the embers or the decaying vegetation, are always of a secondary kind-destroyers of an antecedent vegetation, or batteners upon its remains. If the place and the season are warm, fungi are the first vegetation; and if they are cold, the mosses. 'This is a matter of which any one who chooses to observe can easily convince himself. The site of a gipsy fire in the green lane,-the place where weeds or brushwood have been burnt, - - and every other situation where there is a remain of vegetable combustion, always shows fungi of some species or other after the midsummer or earlier autumnal rains. It is the same with a fallen tree which has been allowed to lie till the under part begins to rot,-with the lower part of a stack of wood similarly situated,-and even with a dead limb upon a living tree. So also in more cold and upland situations, burnt surfaces are very speedily covered with mosses; and some of tlose mosses present beautiful miniatures of forests. Upon fallen trees in similar situations the mosses are also sure to come, and that in much greater abundance than on the 
situations of former fires; and the mosses there may or may not be preceded by fungi, according to circumstances.

There is thus a correspondence of office in the fungus and the moss, though the plants are otherwise as different as the places where, and the degrees of temperature under which, they appear. The fungi are things of a day, and their remains very speedily perish, so that they cannot be traced. The mosses are perennial in their duration, and the deposits which their remains form can with difficulty be destroyed by any known species of natural action. When a peat bog rises so high as to have a surface-drainage sufficient to prevent the stagnation of the rain upon it, very few plants make their appearance; and the few that do come slowly appear to catch the soil from what is swept over the surface by the winds, until they have become so abundant as to produce by their anmual decomposition a new soil for themselves. In warm situations where the surrounding surface is rich, this may proceed with considerable rapidity, so that in sheltered valleys there are often meadows of rich grass over the peat; but in high, cold, and damp places, the moss assumes much of the character of a final vegetation, for it leaves the surface in black sterility after itself has ceased to grow.

The mosses do not appear to have, even in the decay of their under portions, any power of actually decomposing the ligneous parts of any trees or shrubs, though they disintegrate all the mild-juiced ones,-as may be seen in the birches, alders, and hazels which are embedded in the bogs. But although they reduce the 
wood of the hazel to a pulpy substance, they do not alter the shell of the nut any farther than by blackening it. They however reduce the kernel to a pulp; and of all plants and trees whereof they conserve the remains, they never leave a part which under any circumstances could germinate. They are thus final destroyers of all the other vegetation upon which they come in the abundance of their array, though they in some instances embalm the dead. In the great bogs of the British islands, those embalmings are most conspicuous in the oak and the pine. The formel appears to be preserved by means of the tamin and the astringent principle which it contains, and the latter by means of its resin; for the sap-wood and also the young twigs of both are reduced to pulp, and the heart-wood of the oak which remains is nearly as black as ebony. The destruction, from the accumulation of moss, and the long continuance of the peat into which it passes, is complete in so far as the herbaceous vegetation and even the vegetable mould are concerned. The hard testa of some of the smaller seeds, indeed, resist its action, much in the same way as the shells of the hazel nuts. In peat-bogs which we have seen cut through to the bottom, for a depth of at least forty feet, the substratum immediately under the peat consisted of pure white silicious sand, in a state of very minute division, and under that another of equally pure clay, quite impervious to water in the greater part of its extent. The same, we believe, is the case with the great turf bogs in Ireland: the substratum immediately under the bogs often consists of gravel, not water-rounded, as 
though it had been rolled for a time in every sort of flood before it was deposited there, but in angular fragments, such as we may suppose to have been produced by the fracture of larger masses of stone by the frosts of many Winters. But whether the stratum immediately under the peat or turf consists of this kind of gravel, or of sand in a state of more minute division, there is always a portion of clay under it; and the remains of pine trees and other substances which there has not been the means of decomposing, do not rest immediately upon the sand or gravel, but have always some of the peat or bog-earth under them. This clearly shows that the mosses, of which this bog-earth is composed, ate up, in some way or other, the richer soil which had existed prior to them, and which nourished the trees of which they contain the remains; and not only this, but that in the conversion of the vegetable soil, as we may call it, into moss, all the vegetable part of it has been appropriated by the mosses, and assimilated into their substance; while the silicious and argillaceous earths mixed with it have been precipitated ; the argil, or clay, taking the lowest situation, - as it invariably does when clay and silicious sand, both in a state of minute division, are left to arrange themselves according to their own natural tendencies.

The coating of fine and pure clay, which in most instances forms the very lowest of what may be called the accumulated strata of these bogs, contributes not a little to their growth and permanence, by forming a water-proof lining to the place on which the bog rests. In this way it divides the waters, that is, it prevents 
the rain which falls upon the bog above it from percolating into the earth; and it also prevents the water which may come into the lower portion of the earth, by other channels, from finding its exit in springs at the place which the bog occupies. The pressure of the bog itself contributes to the producing of the latter of these effects; and hence, though the surface of one of these bogs may be at all seasons so much charged with humidity as to be a quagmire or a marsh, there is never nuch water discharged from it by springs and rivulets, as compared with an equal extent of surface, lying in a similar manner, upon which there is no accumulation of decayed mosses; and the small quantity of water which is discharged in this way, is so impregnated with mossy particles, that it is equally unfavourable for kindly vegetation on the banks of the rivulets which it forms, and for the health and wholesome quality of fish in their waters. This last is well exemplified in the common trout, which are always few in number, dark in hue, and inferior in flesh and flavour, in these mossy streams, to what they are in those whose courses do not lie through moss of any kind.

The effect of this is a wintry state of the climate at all seasons of the year; for the rain which falls, not having the usual exit through the earth which it finds in countries where there are springs, is constantly either ascending or descending through the atmosphere; and both operations are sources of cold. When this accumulation of moss-earth is broken, and especially when it is removed to a considerable extent, the clay stratum, no longer strengthened by the pressure of the moss 
over it, gives way; springs of the purest water make their appearance, and the climate and vegetation are both greatly improved. But these mossy accumulations, though they are both unsightly and unprofitable in temperate countries, are highly valuable in many places of those near and within the polar circle. The accumulation of moss which goes on there, from its growth under the snow of Winter, is a preparation for the fertility of the summer, as important as any which takes place in climates more advantageously situated ıpon the globe. In the summer, when the sun is constantly above the horizon, or only below it for a very short time, the inland places of these polar regions, which are not in the immediate vicinity of many mountains, would be as completely parched as the plains under the equator are in the dry season; and the parching would be a far more serious matter in the polar climate than it is in the tropical one; for as the Winter there is a time of total stagnation to every species of regetable upon which either men or animals can subsist, if the summer were one of burning dronght, the whole year would be one season of complete barrenness; but the moss, which arrests the water, and gives it out only by evaporation, and that gradually, prevents the burning up of the surface by the action of the summer sun, unremitting though it be; and this, the Winter growth of those cold, and at that time snow-clad countries, enables them not only to support those children of wild nature which are permanently resident in them, but, during the summer, countless thousands which winter in warmer climates. 
Thus when we come to take a minute and careful examination of them, we find that all the scasons of the year, even in the utmost of their extremes, work for the good of the system; and that the physical properties are so adapted to each other, as that there is a mutual advantage reciprocating from the equator to the pole, in the distribution of which the atmosphere is the principal agent. The zone which happens to be parched with drought for the time is the means of a constant ascent of the atmosphere there; and that zone or portion which has the deptl of the cold Winter is equally efficient in causing a desccnt of the atmosphere toward the surface of the earth. But the state of things upon the globe is-either from astronomical causes, in respect of the position of the earth's axis of rotation with respect to a line supposed to be drawn from the centre of the earth to that of the sun, or from local causes arising from the character of the earth's surface-always such, that there is the extreme of the hot Winter in one region and that of the cold in another; and thus the circulation is always carried on by the atmosphere, from the opposite action of these impelling it in different directions, and thus effecting a constant circulation, which tells upon every part of the earth in proportion to its character.

If we took nothing into the account but the simple astronomical positions, we should be apt to suppose that the times of the equinoxes would be periods of equilibrium and pause. To a certain extent this is the case, in so far as the general currents of the atmosphere are concerned; but the extent of it is far more limited than 
we should be apt to suppose; and the physical times of its occurrence, as dependent on the obedience of the earth and the atmosphere to the action of the sun, do not coincide with the astronomical ones as resulting from the position of the earth's axis with regard to that luminary. The character of summer influence in that hemisphere which the sun lias apparently quitted, by means of the apparent motion in declination, has by no means ceased at the time of the equinox; and neither lias the Winter influence, in that hemisphere from which the sun has been apparently absent, and is about again to return. This retardation of the maximum of the effect produced beyond the producing cause, both in respect of heat and of cold, is different in its length in the different latitudes, and also in different places, according to their physical structure and local situation; and in consequence of this, all the four seasons of the year, as we understand them in their effects, are in continual occurrence every day throughout the year, though each is of course in a different place:-the season opening at one, in its full at another, and closing at a third, are of constant occurrence; and they call and answer to each other, through the medium of the atmosphere, in such a manner, that their very diversity is the cause of the activity, the life, and the ralue of the whole.

Thus, while in every season we view the system of nature, we find such mutual dependence and assistance to each other in all the parts of it, that there is no single work of man which shows with half the force and truth that it is the production of one author; and yet when 
we take the several parts in their details, we find that each of them is so admirably fitted for its purpose, that less than infinite wisdom and power could not have originated even the most local and the most minute.

The minor adaptations, such as that of the individual plant to its soil and its climate, and the complete perfection with which each of them works in concert with all else in its locality, are themes upon which we can dwell with pleasure: bnt when we come to discover that the burning sand of the equatorial desert, and the unthawed ice of the pole, work in concert for the advantage of every intermediate region of the earth; and that, if either of these extremes were to cease, the beauty and the usefulness of all that is intermediate would cease along with it; and also that, in countries which have extremes of seasons, if the one were to fail, so would the other,-we catch a shadowy glimpse of an extent of knowledge, and a power of working, at which all our feelings give way to the most adoring astonishment, and to the feeling that "we also are His offspring;" and that He has not endowed us with the power of knowing thus far, without making the principle of knowledge in our nature one of eternal growtl, whose extent and pleasure shall know no end. 


\section{CHAP'TER VI.}

PREPARATION OF ANIMATED NATURE FOR WINTER.

Animated nature works less to the seasons, or, which in observation amounts nearly to the same thing, the seasonal influences tell less generally upon it, than they do upon vegetable natnre. The reasons why this should be the case, may be readily and at once understood, by any one who reflects but for a moment on the physiological difference between animals and vegetables; though their differences must be estimated on the averages of the two kingdoms, and not on the confines, where, as both seem to approach the nature of dead matter, they also seem to approach each other.

Taken on the average, the animals have resources against the vicissitudes of the seasons which no regetable possesses. They can, for instance, betake themselves to places of shelter and safety when the state of the atmosphere is unfavourable to them; and where the seasons are strongly marked, there are some of them that ean change their habitations, even to a full quadrant of the earth's circumference, or more than six thousand 
miles, when the country which they quit is no longer able to afford them that kind of protection and nourishment which their nature requires. Vegetables, on the other hand, must remain in their places, and abide all the changes of the year, as those come round, without any means of preparation, except such as can be exerted without any change of place.

When we speak of adaptation, or preparation, in any animal or any plant, in reference to all the varying characters of the year in a seasonal country, we must be understood as making allusion only to such as are in the developed state throughout the whole year; for the egg of the animal, and the seed of the plant, may be, in all the annual ones, regarded as in nearly the same passive state during the season of repose; though even among those seasonal ones there is a wonderful difference between the resource of the parent animal in the depositing of the egg, and that of the plant in discharging its seeds. There are, no doubt, very curious structures and adaptations of seeds, by means of which they are carried to those places which are proper for their germination; but in all of them the winds, the waters, or something else than the parent plant, is always the agent by which the change of place is effected. Not so with the annuals among the animal races; for among insects, which, if not the only annual animals with which we are familiar in these latitudes, are the ones which are the most conspicuously so, we find more curious instances of resource displayed by the females in finding proper places for their eggs, and depositing them there, than are displayed in any other part of the living 
world. Very many of them appear to have no otlee purpose, while in their last or winged state, than this securing of a future generation. That it shall eat, is the chief, we may indeed say, the only use of an individual animal in wild nature; for animals having no knowledge to acquire, and no mental desires to gratify, have no speculation or contemplation. The pachydermatous animal which wallows in the foulest mire, has just as much enjoyment of that, as the sheep has of the flowery meadow, or the wild deer of the wind-charmed hill; and the butterfly which hovers over the fairest and sweetest flowers of the parterre, has not more enjoyment of them than the mud-flies have of the most putrid and loathsome ditch.

Many of the insects, the annual ones especially, have eaten all that they require, and thus performed their duty to the rest of nature, before they are transformed into the winged state; so that, in that state, they have nothing to do, but to sport, to make a succession sure, and to die. This perfect absolvement of the winged insect from labour and dependence on the earth, together with the fact that it passes through a death-like repose before it comes to this state, was probably the reason why they, who were prone to clothe every thought in a poetic dress, gave the same name to a butterfly and to the soul-both implying " of the wind," or " a breatll," - and breathing being the only vital function which many insects perform in their winged state. When the male insects, which are in many instances feeble compared to the female, have performed their part of this labour, they almost instantly die, 
just as the anthers and petals of a flower are cast off when the fertility of the seed is securcd; and they do this even in species of which the females live through the Winter, and do not deposit their eggs and found their colonies till the spring; which is the case with many of the wild bees. These females have a very laborious task to perform, as they have to prepare cells, deposit eggs, and nurse the young to activity, before they can have any assistance in thcir labours. The repose of the Winter is of course necessary to prepare these most industrious insects for the labours of the spring; and their repose during that time may be wcll allowed them, as their services arc required in the general economy of nature, only during the flowery time of the year.

The labours of those females which merely deposit their eggs,-commit them to the keeping of nature,-and die, are not so severe as those of the races which survive the Winter, and nurse and feed their offspring in the early part of the year; but still they are considcrable, and they are often highly curious, and done with a precision in the work, and a perfection in the performancc of it, to which there is nothing at all comparable in the most ingenious labours of the most dexterous and persevering of the human race. There is probably no living creature which casts its offspring wholly upon the world, in the same manner that the majority of plants do their seeds. The oviparous cartilaginous fishes - the sharks and rays, indeed, do not fasten thcir ecrgs to any fixed substance, but the eggs are furnished with tendrils or claspers, by means of which they can 
attach themselves to plants, and other moorings; and the animals always come into the vicinity of such objects, there to deposit their eggs. The ostrich in the dry desert leaves her eggs to the action of the sun during the day, and so, in great part, do many of the swift-footed birds which breed on our sandy banks and downs near the sea; but when cold or rain comes, the female returns to her charge. The greater number of the oviparous reptiles bury their eggs in the earth, or deposit them in the waters; but whether this is done in the one or in the other, a fit place is cliosen; and, in several instances, the mother remains near the place, and watches.

The insects which are strictly annual perish soon after the eggs are deposited; but still these are deposited with as much attention to the fitness of the place, as they are in the cases of those which form nests or cells, and feed the young while they are in the larva state. Some species, and those very minute ones, place their eggs upon the roots of vegetables, in such a manner as that the head of the young one, when it comes into life and activity, is placed in sucl a situation as that it shall, without previous motion, be able to begin eating that part of the young plant which is its most appropriate food. In not a few instances, those eggs are deposited in the bodies of living animals; and many of the insect mothers capture a number of other insects, and deposit them in holes, as a store of provision for the young; but those which have artificial larders of animal food prepared for them in this manner, rarely pass the Winter in the places where the eggs and stores 
are deposited. Annual ones without number are attached to the twigs of trees, or deposited in the buds or the bark, though we are not aware that any annual insect deposits its eggs in or upon a decidnous leaf, which is to fall to the ground in the autumn. Of such plants as have leaves of this kind, the insects select the permanent parts, as the young when hatched in the ensuing season are then ready to feed upon the leaves. Instances of the placing of the egg where it shall be secure, and the young one can obtain a supply of food the instant that food becomes necessary, are so many, that the mere catalogue of them would fill a large volume; but the slight allusions which have been made, will serve to show that there is, in the case of those animals which perish previous to the Winter, with the exception of the egg, a degree of what we are in the habit of calling care for the safety and welfare of the future progeny, to which there is notling at all comparable in the vegetable world; and if this is found to lold as a universal or general practice among those animals which are annual, in the securing of their offspring, we may be prepared to expect some care, at least, displayed by every perennial animal for its own personal protection during the Winter.

But here we must be careful not to fall into those errors with which this part of the subject is beset-the more so that they are deceiving, curious, and wear not a little of the semblance of truth. The preparations of the animal for the Winter, or for any other season of repose, whether they consist in the depositing of the egg in an advantageous situation, or in any thing else, 
such as the migration of the animal, its hybernation, the acquiring of a Winter covering different from what it has in the summer, are no more the result of any thing like knowledge or forethought on the part of the animal, than the shedding of leaves, the hybernating of buds, or the retreat of herbaceous plants into their bulbs or other roots; though, according to our common way of viewing matters, and speaking of them, the actions and preparations of the animal are said to be voluntary, and those of the plant wholly the results of external causes acting upon it.

This, however, is merely the result of our erroneous way of viewing these different parts of nature, and speaking of them. The animals have locomotion, circulation, breathing, and various other functions of animal life analogous to our own; and as we are very often not capable of drawing the line of distinction between those senses which bring us our information with regard to the external world, and that immaterial and inmortal principle within us, which alone can reason from experience, and form forethought plans, anticipating certain lesults, we are very apt to suppose that the animals proceed upon the same principles as we do; and this is the grand error which we commit with reference both to ourselves and to them.

Now, a very little reflection, if we would give ourselves the trouble of it, would suffice to set us right in this matter: the animals never require any teaching, even in the school of experience, in order to enable them to perform in the most perfect manner, and withont the slightest mistake or blunder, the very most of 
these observations, which, according to our ordinary modes of speaking, show such wisdom of purpose. 'The annual insect, which deposits her eggs in the most appropriate nidus, with such care and attention, can have no schooling in the matter from her parent, because long before she quickens in the egg, that parent is dead and dissolved, leaving not a trace of her individual existence. As little can she profit by her own experience, for the act is a single one, never performed a second time; and thus, even conceding to her all the reason and understanding that the wisest of the human race could possess, there are really no means by which she could bring them to bear upon the operations in question. They are simply the results of a natural law, in the operation of which the insect has no more plan or purpose than water has plan or purpose when it is congealed into ice in the Winter, or melted into a liquid in the summer; and what is true of the insect in these her most curious operations, is also true of every operation which is, or which can be, "performed by any being not endowed with an immortal spirit, and the faculty of receiving instruction, and proceeding by experience, which that spirit alone can impart.

Hence, how much soever the preparation of animals for the Winter may differ from that of vegetables in appearance and degree, and how apt soever we may be to regard the one as active and voluntary, and the other as passive, and wholly the result of external circumstances, they are, in truth, both exactly the same in kind and in principle. In none of them is there any thing which can be called voluntary, either in the 
creature which is adapted to the season, or in the season which is adapted to the creature. If we will call the one the changed, and the other the changer, still the action is reciprocal; and there must be a disposition or faculty to be clianged, on the one hand, before there can be any exercise of the faculty which we say changes it, on the other. Accordingly, there are some species which will be so adapted as that they will live at all seasons, and in almost any situation, while there are others that can hardly bear the slightest change. These differences of natural rapacity are found as much among animals as among plants, if not more; and it is a pleasing consideration to us, that those which have the greatest range of adaptation, are the most valuable to 11 , in an economical point of view, whether they are animals or vegetables. The ox, the sheep, and the horse can, in one or another of these varieties, adapt themselves to every climate which human beings can, with any thing like comfort, inhabit; while the elephant and the camel are confined within, comparatively, narrow limits, and even within these they are not relatively so useful as the others.

The fallacy-and it is a fallacy into which many, even of those who are well-meaning and far from ignorant, are apt to be betrayed - that animals of any class or any character, have, in and of themselves, a power of making their owl adaptations to the Winter, or to any other season, or any circumstance-how perfectly soever they may be adapted to any or to all of these, really explains itself when we come to scrutinize it closely; for there are results arrived at by these 
animals, at which not one of them could possibly arrive by the exercise of reason, even if we were to concede to them wisclom far exceeding the wisdom of Solomon; and some of these are very closely connected with their adaptations to the seasons. Of these we may select two well authenticated ones, which, together, may be held as conclusive of the fact. In the first place, several of those migrant birds, which come to the northern latitudes in the summer, and quit them in the Winter for warmer latitudes, have two broods of young during the time of their residence in their northern haunts. The young of the second brood are not always so far advanced as to be able to depart at the time of the general migration; but, though some of the very late ones remain and perish if the Winter is more than usually severe, there are others which find their way to the southern countries, as far as the equator and beyond it, even after all the old ones are gone; and we know of no exercise of reason by which such a result could be brought about. Again, it is well ascertained that some birds, though they may take an aërial journey of four thousand miles in the interior, and which cannot possibly have landmarks to guide them, return to the very same nesting places year after year, without the least deviation or error: as, for instance, the same honse martens have been ascertained to resort to the same identical window for many successive years; and there is no doubt that the case is the same with many other birds.

These long migrations of the feathered race may be reckoned among the most extraordinary adaptations of 
animals to the seasons; and if they are not only not performed according to any plan or purpose on the part of the birds themselves, but are such that no plan or purpose, even of man, could perform them, much nore must we allow that the simpler ones come under the same law, and that the creatures for whose benefit they occur, have no project of their own in the originating of them.

The experience of no finite being can be perfect; as there is no possibility of a finite being knowing of how many of the circumstances of any one case it may be ignorant, and whether these of which it is ignorant, may not be the very ones upon which the whole case turns. Many successes, and no failures, give a presumption or probability that the most important elements of the case are known; but no number of instances short of absolute infinity, which cannot of course be arrived at in measured time, however long, can amount to an absolute certainty; as, for instance, though we regard the rising of the sum as an event of which we have not the slightest doubt, yet it would be too much for any human being to assume that the sun shall rise a million of years hence in the same way that it does now. Yet this rising of the sun is a matter which depends wholly upon those physical laws which have been given to nations by the great Author of nature; and therefore our uncertainty with regard to it depends not upon those motions of the earth, which are the immediate causes of the event, but upon the imperfect conception which we have of them, and which throws the uncertainty as much on the one side as on the other, 
and renders the negative just as indeterminate to us as the positive.

In the adaptation of the animal to the season, there is never any failure; and hence we must conclude that it is regulated upon principles far more stable and certain than any whicl can have their foundation in finite reason; that, in truth, they must be part of that loly and immutable law by which the whole of physical nature is so obviously regulated. It is true that we cannot analyze the occurrence, so as to point out what is due to the prepared or adapted animal, and what to the preparing or adapting season. We know them only in the effects of their joint working; and as both are indispensable to that which appears to us, we have no possible means of dividing the result between them, so as to be able to say, that the one is more eminently the object, and the other the agent.

With these considerations to keep us in the right path, we are, in so far, prepared to consider the preparations of the animated races for the Winter. The Winter is varied, and so are the creatures which are prepared for it; and therefore the subject is one of details much more than of general principles. The scorching Winter of the tropical countries is the very opposite of the cold Winter of the polar ones; and, therefore, they requirc adaptations of an opposite character; and in the case of those animals which have the power of seasonally passing from the one region to the other, they act much in the same way as they do in the case of the transferable atmosphere, of which the two keep up a regular circulation.

But the varieties of animals, in their adaptations to Y : 
plaees and to cireumstanees, are so many, that it is quite impossible to bring them within the scope of any one general principle. The seasons in the waters and upon the land are very different in the strength of the eontrast whieh they form with eaeh other. In the waters, unless when they are frozen, the seasonal differenees are very limited, and their inhabitants require very little preparation for Winter or for any other season. The migrations of the fishes are never, to any eonsiderable extent, elimatal or seasonal ones, they are always physiologieal, and eonnected with the breeding of the animals - not with the weather. Many of them resort to the streams, the estriaries, and the rivers, in the fall, and some as late as mid-winter, for the purpose of depositing their spawn; so that the Winter is the season when many of them are to be had in greatest abundanee, and in the best eondition. The different raees do, indeed, alternate with each other, and by this means there are always young or fry upon the eoasts and banks, which furnish an abundant supply of food for sueh more advaneed ones as eome there for the purpose of nature; as the fishes, in very many of their speeies, depend on the young of other speeies for their principal supply of food. Thus the most elaraeteristic inlabitants of the sea, those which range in the extent of its waters, go on, season after season, and year after year, very mueh in the same manner; and at the depth of a very few fathoms below the surface, it is probable that the water has the same temperature all the year round, and summer and Winter are altogether unknown.

In the watcrs near the shores, and especially in those 
which alternately cbb and flow upon the beaches, the ease is different, being seasonal to some extent, varying with the latitude and the set of the tides and currents; but even there the seasonal influenee is small, compared with what it is upon the land; and as this lessened seasonal influence does not depend upon the action of the sea, which is in itself perfeetly equal upon land and sea, but upon the resistance of the water, the seasons of the sun happen later, aeeording to the ealendar, than those on the land, and thins the real harvest of the sea is thrown baek into the Winter montlss; and if the latitude is not very high, and the Winter long, the influcnee of the one year begins to be felt in the sea, before that of the preceding year has ceased.

This fact of a table being spread in the sea and along its shores, for the support of no ineonsiderable portion of the land animals, especially those in the ligh latitudes, at that time of the year when the land is not only barren of food, but when it is so mantled up in the snow of the Winter as to be inaceessible, is one of the most striking adaptations in nature; and, like all the others, it depends upon the most simple eauses,- the different obedienee which the water yields to the action of the sun, eompared with that of the land.

Before the different action of the atmosphere upon the land and the water was so well understood as it is now, there was not a little perplexity in accounting for some phenomena, which now appear to be very simple. We say the action of the atmosphere, though that is only the medium, the sm being the agent; but still the modifying influenee of the atmosphere is so great, 
that the resulting influence upon the earth or the waters, whether it be that the atmosphere has the higher temperature, and the influence is what we call a heating one, or that the atmosphere is the colder, and the influence a cooling one; in either case, the atmosphere conduces so much to the result, that we arc strictly correct when we say that the seasonal influence, whether of Winter, of summer, or of any thing intermediate, is atmospheric. We can form no adequate conception of what would be the effect of the rays of the sun, if they came directly to the earth, without that division and deflection into different directions, which they receive in the atmosphere, to a degree of minuteness, bordering almost upon infinitude. But were it not for the extreme dilatation and deflection, and diminution of velocity, which the solar action undergoes in passing through this medium, it is by no means improbable that not a plant could grow or an animal live on any part of the earth's surface. The moon is an example of an atmosphereless planet; and in so far as we can judge of the moon, from its appearance, as seen through the best telescopes, there is not a single growing or living thing upon the surface of that luminary. For these reasons, we may regard solar action and atmospheric action, in as far as heat and light are concerncd, as being onc and the same in their infunence, whether upon the solid earth or the waters, upou both of which, when the state and tcmperature of the air are the same, the joint influence of the sum and the atmosphere must come with the same intensity. 
But the land and the water receive and obey this influence very differently; and this is the cause why their seasons are different, and also why the seasons upon the coast lands are different from those upon inland places. Those differences are general, or belong to those agencies by which every thing that grows or lives is affected, and therefore the consideration of them is essential to the right understanding of every part of the working of the system of nature down to the most minute individual being.

In their obedience to the general action, the land and the water have some analogy to the vegetable and the animal kingdoms in their obedience to the seasons of the year. The vegetable abides the season in its place, and so does the solid earth abide the atmospheric influence. The animal is put in motion by the seasons, and the atmosphere has a similar effect upon the waters.

The motion immediately imparted to water by the influence of the atmosphere, supposing that water to be at rest, or not impelled literally by any current, is a motion in the direction of the perpendicular; and it is occasioned by the volume and consequently the weight of the water, changing with changes of temperature. 'These changes are of but limited extont, and they are brought about very slowly; but their progress is powerful beyond almost any mechanical resistance which we can assign, and they are productive of some very important results, more especially in the economy of the Winter. The absolute quantity of the water is, of course, not altered by those changes of volume and temperature, for these merely reciprocate, 
the increase of the one being within certain limits, proportional to the decrease of the other.

But watcr lias a peculiar property in the relation of the changes of its density by temperature, and it is this which is the foundation of those results to which we liave alluded as being of considerable importance in the economy of Winter. Water has a maximum, or greatest density, at the temperature of about thirty-nine degrees of the common thermometer, under the mean pressure of the atmosphere, which is about seven degrees above the freezing point under the same pressure. In cooling water from a ligher temperature its bulk diminishes, and the weight of an equal bulk increases, till the thermometer descends to $39^{\circ}$, or more correctly in our latitudes to $39^{\circ} 2^{\prime}$; but as the temperature shown by a thermometer is merely relative, not absolute, the fraction of a degree may for common purposes be disregarded. After this temperature of maximum density is arrived at, the water again begins to expand, and continues to do so as the temperature is lowered; and when it reaches the point of congelation and crystallizes into ice, there is a momentary change of temperature, cffected with great and irresistible force.

It is this power of expansion, after the temperature is below $39^{\circ}$, which makes the water of so much efficiency and ralue as a Winter agent. Its expansion is very limited, and very slow, excepting at the time when it shoots into crystals of ice. It is like a finely tapering wedge inserted between the particles of the soil, and into the fissures of the rocks, but, like all 
wedges that are finely tapering, it is a most powerfin one. Even though the cold does not descend so low as the freezing point, the expanding water breaks the clods, not in that rough way which would be done by the stroke of a hammer or any other mechanical instrument, but by acting through the mass and separating it particle from particle. If frost should come and penetrate to any considerable depth, the work of disintegration-one which is peculiarly favourable to the future growth of plants-is of course more completely performed, and the result is correspondingly advantageous; but, whether there is actual frost or not, a temperature below $39^{\circ}$ continued for such a length of time as that it shall penetrate the earth to the full depth to which the soil is available for the purposes of cultivation, is of great service in promoting the fertility of the land. Therefore, where the soil is stiff, and apt to harden into clods, the best preparation which the cultivator can make for the Winter, is to ridge up, or rough-plough, or dig the land so as to give it the greatest exposure possible both to the rain and to the action of the atmosphere.

The same loosening takes place by cold in the wild and uncultivated districts as in the arable lands; and where the soil is of a mossy nature, and, as such, takes in a great deal of humidity, the effect is so considerable, that after a frost the soil retains the height to which it lias been raised; while the stones-those of such small size as to have been raised by the expansion-sink down again in the thaw, and each appears as if lodged in a pit; and in some parts of the country where the soil is 
poor, the climate cold, and the stones often seen in this way when the frost goes off, the stones are accused of raising up the soil,-a species of depredation which they certainly do not commit, whatever effect their own disintegration may have upon it. This may seem a very simple operation; but it really has a great deal of influence in the growth of that vegetation with which countries that have the summer and the Winter in nearly equal balance, are so much more perennially clothed than those which have more of the extreme of either.

The effect of the expansion of water when freezing, in cleaving the rocks, and sometimes entire mountains, are far more striking; and in elevated places which have the Winter severe, we seldom see a bold precipice without the accompaniment of a mass of its own ruins at its base. This happens especially in the case of the clay-stone porphyries, of which great part of the summits, even of very lofty mountains, is formed. Ben Nevis, in the heart of the Scottish highlands, is a remarkable instance of this. Its summit is so lofty that there is scarcely a lichen upon it, and there are comparatively few nights in the course of the year in which the temperature does not sink as low as the freezing point. But from its situation, the current of the Atlantic, which is our warmest current of air, comes upon it with unabated influence; and consequently there is perhaps more freezing and thawing upon the top of Ben Nevis than there is upon that of any other mountain in the British islands, or probably in any part of Europe. The result is, that a vast quantity of the rock has been 
broken into angular fragments, which occupy a surface of acres on some parts of the upper slopes, and having a thickness of a good many feet; and those bects of broken stone are so loose, and lie so much on the slope, that any one attempting to walk on them is carried down-hill, to the imminent danger both of his flesh and his bones. The exposed parts undergo new divisions and are reduced into smaller masses in the course of every season. Nor is there any doubt that, in the lapse of years, the portion at the surface will be reduced to a powder, which, washed into the interstices of that below, will form a soil analogous to what we meet with in the angular gravels, of which there are such beds in most mountainous countries, and also in the angular breccias, which are merely such beds hardened into stone; and for the formation of which one could not account by the action of water, or motion, whether of waves and tides as in the sea, of river-currents, or of the more violent action of inundations and floods. In this way the peculiar adaptation of water to the Winter operates in converting the mountain rocks into a soil fit for vegetation, and sending the fragments down to places where a vegetation of some species or other will grow, and yet farther ameliorating the soil, by what it absorbs from the atmosphere in its growth, and deposits upon the earth in its decay.

If the operation were to go on to the full power of the Winter cold, upon the lofty summits and in the high latitudes, the process of division and disintegration would be so rapid that no species of vegetation could work up to it; and the result would be the conversion 
of the whole surface into sand as barren as that of the burning deserts of the tropical climates, and far more unsightly and dismal. But here the water interposes in one state to check and restrain the power of destruction which it exerts in another. The cap of snow remains perennial on the lofty summit; and the snowy mantle is thrown over the shoulders of the mountain and the face of the polar land, very soon after the Winter's cold begins to set in. This is another, and very striking instance, of that power of compensation in nature which brings the antidote in the very same agent as the bane.

But this, though a very important work of the Winter, and one which in so far makes the earth its own cultivator in those places which man cannot conveniently or profitably cultivate, is not the one which makes the principal contrast between the times of the seasons in the water and on the land, and so renders the shores and their vicinity prepared places for many of the animals during the severity of the season. It has been said, and we believe that there is some truth in the saying, that the more powerful of the ravenous beasts do not attack sleeping prey, just as the cat springs only upon the "stirring mouse;" and in like manner, those animals which have the requisite power of locomotion are drawn away from that nature which Winters and summers on the same spot, during the time that it is enjoying its repose. On the shores of the sea this depth of repose is never felt; and the time of the year at which there is the nearest approach to it is the latter part of the spring and the very early part of the 
summer, when the Winter loards of the sea begin to withdraw into the deeper water, in which most of the finny tribes acquire their chief tone and vigour, and before the breeds of the season have barely made their appearance; and that this approximation to Winter in the sea should occur after the spring has returned and food begins to be plentiful on the land, is another instance of the admirable working of the parts of the system of nature for each other. 'The slow effect of the seasonal influence upon the sea, compared with what it is on the land, is the chief cause of that difference of seasonal period which makes them reciprocate so advantageously; and therefore the cause and manner of the delay are well worthy of observation.

The chief cause of this difference is the motion upward or downward, which changes of temperature occasion in the water. Of the causes of such changes, as they may operate at the bottom of the sea, or in the body of its waters, we know little or nothing, and therefore we must confine our remarks to the action of the atmosphere, which, tlough it extends to some depth downward into the volume of the water, may yet be, for the sake of simplicity, considered as a surface action.

Now, the surface of the sea is open to our observation, so that we can ascertain its temperature, and compare it with that of the superincumbent air on the adjoining land. The temperature of the unfrozen sea is never much lower than the freezing point, and not in many places lower than $39^{\circ}$, or the point of maximum density; and generally speaking it is more than this, the average of the whole sea throughout the year being 
estimated at more than $50_{0}$, " about $52^{\circ}$ indeed; but as this estimate does rot take in the temperature at the south pole, which must be lower than at the north one, because the polar Winter is longer and more shut up in the south than in the north, it is too high. At every temperatme above $39^{\circ}$, cold applied to the surface of the sea causes the upper film to sink down and expose a new surface. It moves downward the instant that the cold affects it; and being in very small quantity it moves very slowly; and as the pressure increases with the depth, it meets with an increasing resistance as it descends. 'Thus it must stop altogether at some depth; but what that depth is, is not a general problem, but one depending chiefly upon the circumstances of the particular case, and therefore it does not belong to popular description. In very shallow waters, the whole is very speedily cooled down to $39^{\circ}$; and as all further cooling tends to render the water more buoyant, the surface is very soon frozen, as we find it to be in the foot-prints and shallow pools, with only a few hours of frost. Bnt when the depth is considerable, and the surface considerably above $39^{\circ}$ when the cold sets in, the process of bringing the water to a stationary condition, so that the cold may reduce it below $39^{\circ}$, is very slow, as the portions in which it descends are so thin, that there are probabiy thousands, or even millions of them in the incl.. Thus, unless where the water is both shallow and stagnant, where the surface is always below $39^{\circ}$, or where there is a nucleus of former ice to begin the fonndation, the sea never freezes. It is nuch the same with very decp lakes, even those which are sitnated 
in rather high latitudes; and there are examples of the same, even in the artificial ponds and ditches to which people resort in fiosty weather for the exercise of skating. If there is a spring in the bottom of the pond, especially one which has a deep-seated source, that spring seuds up warmer water to the surface, and keeps an opening after the rest of the surface is covered with ice; and if this is also covered at last, and especially if snow falls upon and conceals it, it becomes highly dangerous. A deep pit in the bottom produces the same kind of effect, though not to the same degree; but upon this account it is only the more dangerous, as it is sooner frozen over, and thus it is deceptive when the whole ice is more thin and elastic, and therefore more apt to give way where weakest. Care should be taken that those ponds to which city skaters, who seldom have much information upon natural suljects, are admitted, have the bottom level and without holes, and if the deptli of water were six inches instead of six feet, skaiting might be had more frequently and with perfect safety.

Such is the cause of that delay in the Winter on the sea and its shores, which makes it continue to be a source of plenty to many land animals when the supply upon the land fails; and the next point is to inquire which animals are adapted to profit by this supply. Generally speaking they must be animal feeders, or capable of subsisting, in part at least, upon animal substances; for there are not many of the vegetable productions of the sea upon which land animals are fond of feeding, even when they are famished by hunger.

$$
\text { z } 3
$$


In some parts of the north, however, the sea weeds are cut and gathered as food for pigs, and the cows are driven as regularly to the shores in the Winter as they are to the meadows in summer. Generally speaking, however, the herbivorous mammalia do not resort absolutely to the beach in Winter, unless for the purpose of collecting those remains of land vegetation which the tide may have left deposited there.

'The birds, and especially the running birds, which feed upon small invertebrated animals, such as mollusca, worms, and the larra of ground insects, are the chief resorters to the shores of the sea during the severity of the Winter; while the different species of ducks collect on the waters, though in the estuaries of the rivers, and especially where the adjoining land is fenny, and the bottom composed of mud, rather than the open seas or the ligh shores. We cannot say that the Winter absolutely draws the birds to those places, or that the birds come to them because they know that there is food to be obtained there. Their general movement is in the direction of the warmer air, just as their retreat frum the shores appears to be in the direction of that which is colder. The circumstances which cooperate with this instinct of the birds to move toward the warm air in the Winter, and toward the cold air in the summer, differ with the nature of their immediate haunts, and that of the food on which they subsist; and the physiological causes of the two morements are different. In Winter, or autumn, or whatever season the birds move to the south, their sole occupation till the Winter is over is the finding of their food, and otherwise taking 
care of themselves individually. But in the early part of the season, when they move toward the north, they are impelled by the pairing impulse, which heats and excites their system, and, as it were, drives them toward the colder locality for relief. This additional excitement of the system in birds, preparatory to the grand seasonal labour of rearing their broods, is very essential for enabling them to endure that labour, which is great in many species, and absolutely extreme in some. It is, indeed, a store of vigour through the year, and sustains them until the time of the great autumnal moult, when they are again reduced to their individual characters, and have nothing but their personal wants to supply, until more genial climates, or the renovating influence of a new season, slaall again arouse them to a repetition of the same labour.

This seasonal preparation of the birds is one of the most interesting subjects in the whole economy of living. nature. There are many circumstances which vary it, arising both from the birds themselves, and from climatal and other local causes, so that no general description can be expressive of every particular case; but the nature and object of the impulse are the same in all, and the differences are only in degree. Some birds do not move from the same haunt summer or Winter, except to seek food in one part of their range when that in another part is exhausted; and others dash along upon rapid wing, almost from the equator to the pole; and between these there is every variety. Some birds pair for life, and appear to have what we call an attachment to each other, independently of all reference to 
pairing and rearing a brood; in others, the malc is totally indifferent to the femalc during the time of her incubation, and instcad of taking any sharc in the rearing of the young, he is apt to destroy them if they come in his way; and between these two limits again the gradations are very many.

In general, therc is least excitement and disposition to range, or make any kind of display previous to the rearing of the broods, in thosc birds which are attached to each other for life; and those males which are the most indifferent to the young, make usually the greatest display, though thcy are not necessarily the ones which range to the greatest distances; for, the distance to which a bird ranges on its migrations, appcars to depend fully as much on the nature of its food as on any other circumstance. Indced, before we can arrive at any rery clear and satisfactory conclusions upon this interesting subject, thcre are many clements to be taken into account-far too many for entering into an incidental notice.

The impulse which the birds receive preparatory for their grand seasonal labour, leares, in most instances, a considerable surplus above what that labour naturally requircs. In the carly part of the season, this impulsc is most conspicuous in the male birds; and it is to it that we arc indebted for those varied songs which make the fields and groves so sonorous in the vernal scason and during part of the summer, and which in some of the species are partially rencwed in the autumm. Birds which pair for life have little or none of this seasonal roice; and the voices of such as inhabit the extensive and deep forests hare, in general, but littlc music in 
them; and if they are not harsh and screaming, they are melancholy and monotonous.

But the surplus energy arising from the vernal impulse extends till the year is far gone, and probably it is not wholly exhausted when the new impulse is given. In this latter part of the season it appears to be about equally strong in the male and the female. It carries them through the monlt; and strengthens them for their journey, if migrants, or fortifies them against the Winter, if they are not. Eren the Winter migrants, unless when they appear to be driven by the violence of storms, contrary to their natural impulse, are in better condition than at any other time; and if they are exhausted by a forced flight of considerable lengtl, they very speedily regain their flesh when they come to a locality where they can procure food at an ordinary expenditure of their energy.

There is something resembling this observable among the mammalia, although their seasonal affections, either one way or another, are by no means so remarkable as those of the birds. This is most conspicuous in the vegetable feeders; though it is no doubt aided by the more substantial nature of their autumnal and Winter food, as long as the Winter keeps open, to that which they have in the summer. Completely ripened stems, even when they have the appearance of being withered, contain much more of substantial nourishment than the green matter upon which those animals chiefly subsist during the summer months. This in part, no doubt, occasions that superior condition in which the herbivorous mammalia are found during the latter part of 
the autumn and the early Winter. But there is also a diminished waste of the vital energy of the animals at this season; and there is also that portion of the physiological impulse to which allusion has already been made. In those species which liave a long gestation, and in which the pairing is over before the Winter sets in, the impulse given by the remainder of the energy is chiefly in the males, and it is more decidedly in them in proportion as the pairing time is later in the season,as for instance, it is more decided in deer than in the ox tribe. In the animals of short gestation, which pair in the spring, such as the common hare, the strengthening for the Winter is more equal to the male and the female; but even in them there is a predominance on the part of the former.

In the mammalia, and also in those birds which seek the sane situations in the Winter as in the summer, there is a preparation in the covering as well as in the condition of the animal. The succession fur or hair, and the succession feathers, come on earlier according as the animal is more exposed; and the old covering grows to a greater length and remains longer. Mammalia are susceptible of mucl more change in this way than birds, because they have not the same facilities of changing their residences; and it is probable that the two kinds of hair which appear upon many of the alpine and cold-climate animals, are really caused by a continuation of the same influence of cold which alters the covering of those which are removed from warmer climates to winter in those colder ones. In extreme cases both manmalia and birds change their colours as 
preparatory for the Winter, and some of them become entirely white, except a speck or two which remain true to the summer colour, as if in evidence of the identity of the species. Some hybernate, or pass the Winter in a dormant state; though, in temperate latitudes, the mammalia which do this are but few, and of peculiar characters; and there are naturally no hybernating birds. Of reptiles, by far the greater number pass the Winter in a dormant state; and in the case of some, such as the common toad, dormancy is the rule of life, and activity only the exception. In proportion as this dormancy is more congenial to the character of the animal, less preparation seems necessary for entering upon it; and all action, and consequently all waste of the system, are more complctely suspended during its continuance. Where it is less continued and complete, the animal is prepared for it by the waste of the system diminishing sooner than the disposition to feed, in consequence of which the animals get very fat before they become inactive; and this fat serves them with what nourishment their system may require, until they are again able to come abroad and find food for themselves. The predatory mammalia, as they are subjected to nearly the same vicissitudes as those animals which constitute their prey, follow nearly the same law in their preparations for the $W$ inter. The chief difference is, that they have proportionally warmer and lighter coverings, which they receive, as their living food requires more labour in procuring than the regetable food of the others, which of course needs neither stratagem nor chase in its capture. 
T'o return to the birds. - The insectivorous birds are the first to depart from the colder latitndes and the colder climates. They obviously retire chiefly on account of the failure of their food, as they take their departure pretty much in the same order that their favourite food fails. The first to be gone are those which are most exclusively insectivorous, and prefer the soft caterpillars of lepidopterous insects, which are chiefly found on the leaves of deciduous trees, and disappear as those leaves become hard. Among these are to be found the sweetest of our seasonal songsters, the chief part of which are mute or gone soon after the midsummer rains; so that their Winter with us is the very beginning of autumn. Those which feed upon the winged insects of the year, come later and tarry longer than such of the former ones as come in numbers and spread themselves extensively over the country. Their winged food comes later than the caterpillars; and the winged insects have to make provision for the continuance of their race after the caterpillars lave disappeared. But they are generally gone before the harvest is over, especially in the late districts. The birds which feed upon small animals in the marshy places, and disperse themselves over the lowland fens and the humid wastes of the nplands, remain still later on their then summer pastures, because their food is not so seasonal as that which is found on the leaves of the trees or upon the wing in the air. They appear to be more influenced in the time of their departure by the severity of the weather, which sends much of their food to such a depth in the ground as that they cannot 
reach it, than by its actual destruction for the season. Some of them linger till they are driven by the storms; and in this they are followed or accompanied by the swimming birds of the fresh waters or the estuarics. All of them have upon the average a more polar locality than the insectivorous birds of the summer; and though they swarm in the north in the breeding season, there are many of them that never come so far south as Britain, except as very rare stragglers.

The omnivorous birds, and those which feed much or chiefly upon the seeds of vegetables, are not so migratory as any of the others; but the greater number of them flock in the Winter, and occupy a much smaller breadth of the country than they do in the summer. They come to the corn-fields and other open places, which are then strewed pretty thickly with the seeds both of cultivated and wild plants; and when the weather is severe, or the snow lies thick upon the ground, they approach the habitations of man, the banks of the open streams, and the shores of the sea. Unless the weather is more than usually severe, they remain in good condition all this time, arial are ready to begin their songs with the opening of the spring, or even in the Winter, when the days are warm and sunny. 


\section{CONCLUSION.}

WE have now brought our labours on the four seasons of the year to a close; and when we refleet on the wonderful revealments made in the eauses of the snccession of each revolution in them, we feel that, with some love of the subjeet, and a very firm convietion of the usefulness and pleasure of the study of it, we have by no means done justice, either to the principles or the details. It is a subject, indeed, of which no one book-not all the books that could be written, could give an adequate aeeount. It is not even desirable that there should be sueh a book; and thus the utter impossibility of produeing one is really an advantage, instead of being the reverse. "The Book of the Seasons," how irreverently or arrogantly some, in the plenitude of the many folds of "mantle-muffled pride," may appropriate the title, is not a volume to be written by human hand. It is "graven with an iron pen and lead in the roek for ever." The lines thereof have gone forth to all lands, in language intelligible to people of every tongue and language, and in every age of the world; and round the mighty globe of the earth, those lines will be apparent and impressive, until the 
command shall go forth to the air, the earth, and the sea, and all that in them is, that for them "Time is no longer," and they must go into the utter darkness of that oblivion from which there is no natural return.

For any one human being to attempt, or even to profess, to furnish an interpretation of the great book of nature, - to translate into the puny language of a child of the dust, a thing "crushed before the moth," - that which stands written by the finger and in the character of the Almighty himself, would be surpassing arrogance. It would be this in its coexistence, and even in the least active state and the most narrow view of that coexistence, for one day, one hour, or even one moment. It is in every department of natmre, and in every tenant of - all those departments; and it needs no aid of human speech. As well might man attempt to set forth the power of the lightning in the touch of his hand, or illustrate the hmrricane in the breath of his nostrils, as to unfold the system and explain the operations of nature, in any thing that he conld say or write: for, the countless millions of tints, and tones, and tastes, and odours, and tonches, and indescribable influences to which no man can give names, but whose impression every man feels, wherein nature addresses itself to every sense and mode of sensation, and to each of them singly, and all of them jointly, in the lapse of every momerit, and throughont all the moments of unnumbered ages, are far beyond human powers.

The shortest walk - the mere circumstance of coming into the open air, at any time or in any situation, is suficient to afford to every mind which is imbued 
with any thing like a true feeling of contemplation, ample store whereon to meditate for months-for a lifetime, however long. Away, then, with the pretence of those who proffer to school us in the knowledge of nature, and let us resort to the fountain-head.

When Alexander of Macedon, who, in many respects, deserved his cognomen of "the Great" more than almost any human invader and conqueror to whom allusion could be made, visited the Cynic Diogenes, and proffered to give him whatever he might ask or desire, "Stand from between me and the sun, and do not take from me that which you cannot restore," said the Sage; and much in the same terms may we address those who, in the slender pretence of their small philosophy, and still smaller taste, would stand between us and the inspiring radiance and cheering warmth which beam upon us from all nature around.

In these four volumes on the seasons, as well as in the four preceding ones on the Heavens, Air, Earth, and Sea, which relate to the coexistent states of nature much in the same way that the present ones relate to its annual successions, my object has not been so much to furnish a gnide as to give an invitation; and to express the pleasure which I should feel to be the wayfaring companion of every one, who goes forth with willing heart and well-prepared frame, to traverse the lovely reahms of nature, and take note of the many sources and subjects of delight which are to be met with there. The highways of nature are ready prepared, open and inviting, and easy withal; and all that seenls to be wanting is the setting-up of a few finger- 
posts, to wile the unwary away from the by-paths which lead to nothing of interest, and to beacon them to those in which instruction and cnjoyment can be found, far more than adequate to the compensating of so easy and so pleasant a labour.

To those who are entering "pon the observation and study of nature, not as a trade, but as a source of refreshment in the time of active occupation, and as a retreat to which they may retire and recover their tone whon the current of the world sets against them, the chief danger is,--that they may be betrayed into some of the narrow considerations by which mere merchandise is made of that which is fitted and intended for the general cnlargement of the mind; and the glorious system of nature, in the freshness and vigour of its own activity, is neglected for the sake of gathering a fow cast-off trifles which may be arranged in drawers, and the museum which God himself has founded and funished with such ample stores, and such certain means of maintaining the whole, is mimicked in the paltry contents of a cabinet.

In this, as in most matters, - and the danger that it may be the case in this is greater than in most others, - the desire of mere possession very generally destroys the whole of the pleasure which would be otherwise obtained, and obtained without money and without price. Even in those matters which, according to law and the usage of society, are, or can be made property, and secured, as the cant phrase has it, "while grass grows or water runs," by entail-notching to prevent sliding off; or any other of those exquisitely hudicrous A A 3 
means, by which mankind, finding that they cannot convert three score and ten years into an immortality, attempt to secure countless generations against the consequences of those aches which grieve their own bones, - even in them the legal proprietor does not hold the title of the pleasure and enjoyment. Cares and anxieties beset him on every side, so that the little tent of a gipsy, with the light-lieartedness of that singular and unhousable Nommade, would often be paradise compared to what is felt in his gilded chamber, and under his canopy of the most costly stuffs-the down all too hard for his dainty bones-by the encumbered legal possessor of wealth which he never could have won.

But if this is true in those cases in which there are all the rights of legitimacy, and all the sanctions of law, so that no vulgar step shall intrude, how much more must it be the case in the wide and glorious field of nature, which is free alike to every man. The most successful conqueror,- he who spoils the greatest number of his fellow-men of their goods, and bereaves them of their lives, and for so doing has his likeness in most appropriate stone set up within the church, and his bloodstained banner displayed over the altar,--even he cannot extend his subjugating arms to the more exalted glories of nature, or the more mighty laws which the system obeys. The mightiest monarch that ever trod the earth, aud in so doing trampled on the dust of his fathers, was never able to forbid the fall of a single raindrop, or command the seasons to alter one iota of their course; and all the laws of nature are immeasurably above his edicts. He is also drawn away from these 
things; and, if the veil could be removed, the probability is, that the most envied of the human race would be found to be the most wretched. There is no savour to their pottage, no raciness in their cup. They can command all that they know; and, in consequence of this, desire sickens, hope withers, life becomes extinct, the successor is the idol, and their very memory is blotted out.

These circumstances are mentioned, from no desire to lessen the esteem in which the parties alluded to are held by the majority of the world; for they have their uses-and no unimportant ones, in society,-and therefore they are more worthy of the consideration and support of generous and right feeling men, than of contumely of any other description, for if they have their peculiar honours they pay for them at a rate, of the extent of which they are, in all probability, but little aware. And it may be well for them that they are not, for if they were to know it to its full extent, their condition would be altogether insupportable.

The chief object which we have had in view is the illustration of the fact, that the world of possession, and the world of knowledge and consequent enjoyment, are very different matters. The first belongs to a comparatively limited portion of mankind-at least as forming their distinctive and most valuable, or at all events, most valued characteristic, upon which their status in the world mainly depends. The second is free to all, so that all may enjoy the pleasure of it, without money and without price, if they will only prepare themselves for so doing, or to speak more correctly, will not spoil 
the preparation which is natural to them. It has this farther recommendation to the great body of mankind, that it is much better suited to the industrious than to the idle-to those who labour than to those who have nothing to do. By the one class it can be enjoyed at any time; and therefore, according to a very general law, or at least practice, of human nature, it is enjoyed at no time: to the other class it is always new, in those little snatches of time which they can devote to it; and, as there is but little in very many of the pursuits of man, to give the mind a fair share of occupation along with the body, and farther, as the unoccupied mind is always in danger of wandering into vanity or vice, and reaching upon the body and paralyzing the hand of labour, it is desirable that every one should have some mental resource to keep the mind in order and the body in tone, even when the wheels of routine business are trundling most swiftly.

But in order to render the great system of things a constant pleasure and ever ready retreat for us, as its whole structure, as well as our own, shows to have been the beneficent purpose of the great Author of both, it is necessary that our attention should be directed to it as a living and a working structure, and not merely as a collection of individual parts. Active nature is the proper study for active men, and the details of its still life are fitter for the dull and the idle. A ware of this fact, I have endeavoured so to frame the hints in this volume and its three co-annuals, as to draw the attention of the reader far more to agencies and modes of action than to the details of the materials which form the instru- 
ments in the action, or description of the phenomena or the productions which form the result.

Throughout the whole of the series, I have never omitted to point the attention to the grand truth of what is incorrectly called Natural Theology - the feeling of an ever-present, all-wise, and Almiglity God, to whom, as the maker and governor of the system, every part of it has a strong and obvious tendency to draw us near. But I have endeavoured to express those hints in terms so very general, as to avoid all clashing with any of those points of dispute, upon which men come so sturdily to issue in religious matters, and in which they cannot be all in the right, and probably the far greater number are in the wrong. In such parts of the volumes, my province and my endeavour have been, to show that the sincere in heart and the willing in mind may receive the advantages - the theological as well as the physical advantages, which resnlt from a knowledge of the great principles of nature, with actual profit, whatever may be their differences in the details of their creeds-details which, possibly, some of their own number do not very clearly understand. This may not flatter any party; but it appeared to me as the best that could be adopted for offending none; and besides, as the one which is really the most useful in itself.

To prefer either of the two modes of studying the works and the workings of nature, - that is, studying them in their coexistence in space and in their snccession in time, would not be easy, and it is not necessary, as both of them are highly desirable, well calculated for promoting activity, virtue, and intelli- 
gence, and for preventing or restraining indolence, vice, and ignorance. To a certain extent, too, they come equally within the scope of every body's observation, although in this respect the advantage appears to lie on the side of the successional view of the matter. The localities of observation are much confined to many of the human race; and the productions of nature as coexistent in any one state as on the average of their characters without reference to time, are soon either exhausted, or they become so familiar as to cease to be objects of excitement; and if the party wishes to pursue the subject farther, this can be done only through the medium of books, the connexion between what is stated in which and real nature in any one limited place, is neither so close nor so inviting as might be desirable.

But, by means of the seasonal changes which, at most times and in most situations, go on regularly, or at all events progressively from day to day, the face of nature is new to us every morning, not only when we are in the country and have a wide and varied horizon, but even when we are in the lieart of a city, and must confine our notice of terrestrial nature to the cage-bird in the room and the flower-pot in the window, with the cat on the hearth-rug for our barometer,-the electric sparks from her back answering to "set fair," and "set frost," and the ablution of her countenance with her paw, to " much rain." and "very stormy," with perhaps nearly as much accuracy as the marks on the scale of the instrument; for very often that philosophy which is held in such wondering esteem by the workd, does not consist 
so much in knowing more of matters than other people do, as in having a more incomprehensible way of speaking about them ;-any puddle looks deep, if muddy.

When we add the consideration of locality on the surface of the earth to that of succession .in time, and also bear in mind how the hemispheres reciprocate with each other in the different seasons, our field for contemplation becomes greatly extended and varied; but as these variations all depend on one set of causes, or rather upon a single compound cause-the position of the earth's surface with relation to the sun, the explanation of the one of them suggests, and in so far supplies, that of the other; and thus, although the seasons are, upon any one day of the year which we can name or select as a standard, very much diversified in any one locality, still they are parts of one great whole; and the one cannot be fully understood without a reference to the other.

It is farther to be borne in mind, that although we are in the habit of speaking of the beginning and the end of the year, and calling the first of January its first day, and the thirty-first of December its last, yet that, in so doing, we speak according to an artificial calendar of our own establishing, and not according to any thing in nature, either celestial or terrestrial, $\rightarrow$ which answers to these two days; the year is a constant circle, always begimming in some of its phenomena, and ending in others, but never coming to a pause, or being without all the varieties of the alternating seasons, at one place upon the globe, or another. Thus, though, in our gratitude for the stores with which the season 
rewards our labours, we say that the year, at a particular season, is crowned with the bounty of God; yet, in truth, it wears that all-radiant and joy-dispensing crown at all seasons and in every clime.

THE FND. 





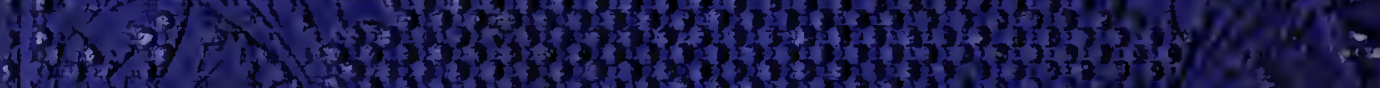

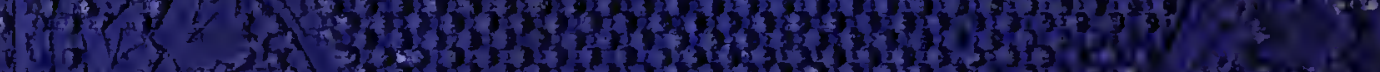

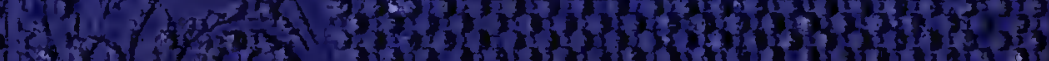

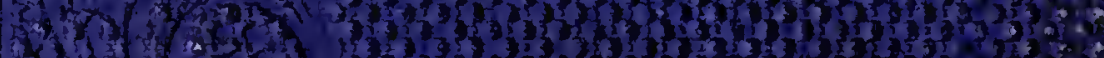

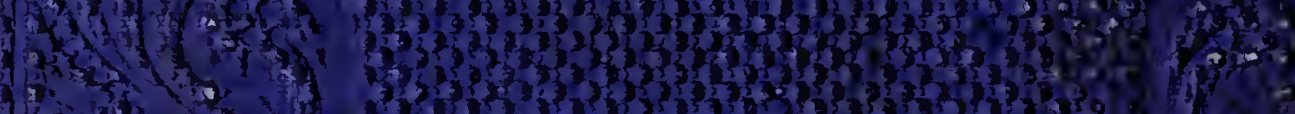

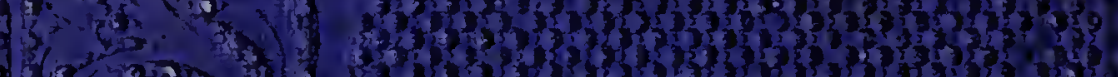

(3)

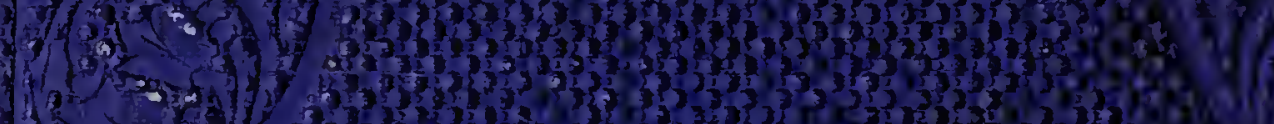

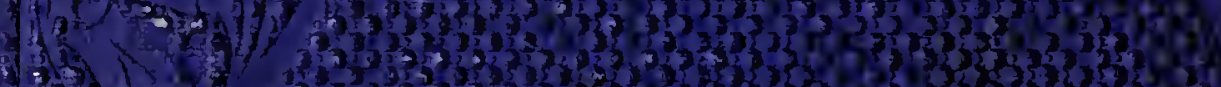

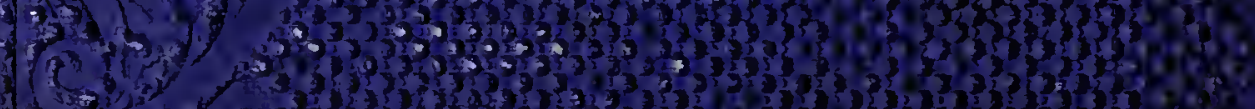

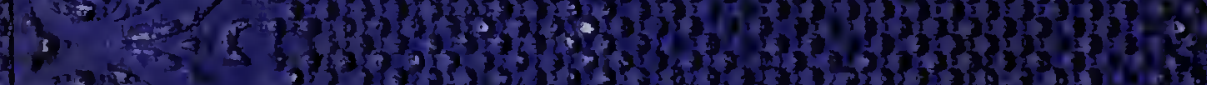

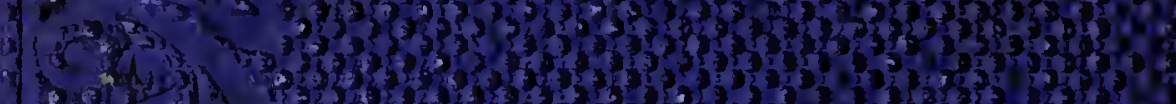

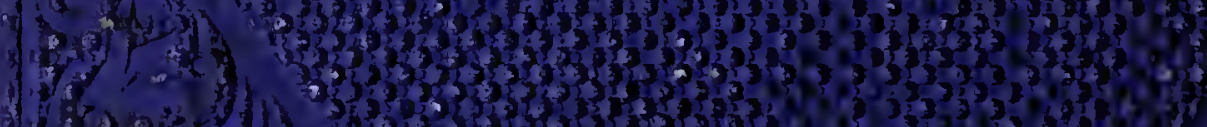

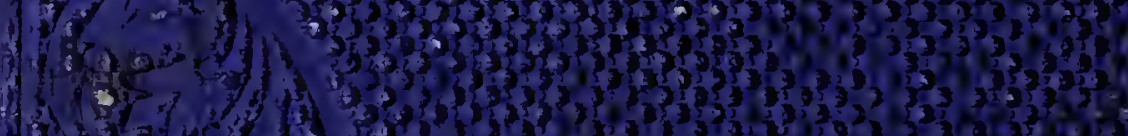
A. 1 is
is:
ats 3 ?

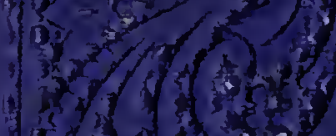

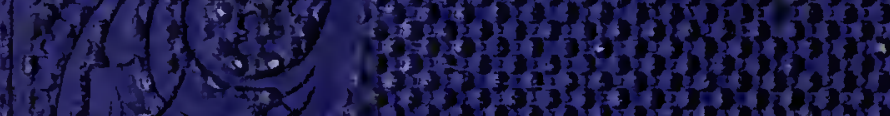

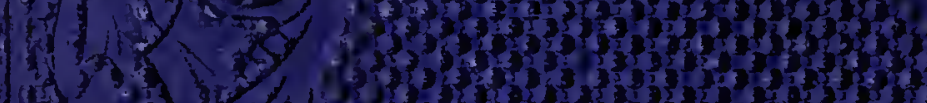

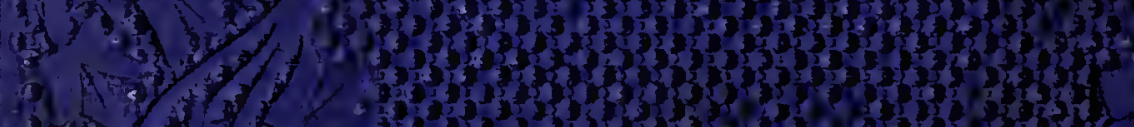

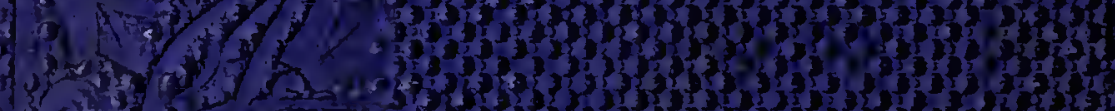

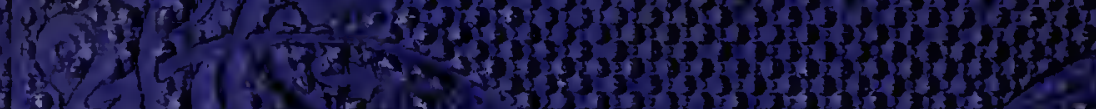

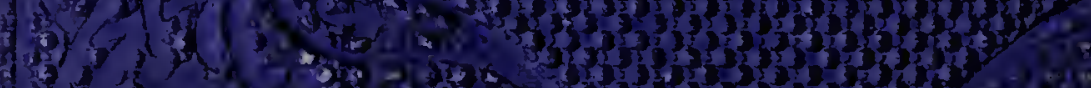

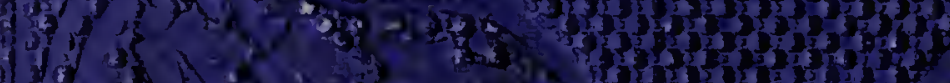

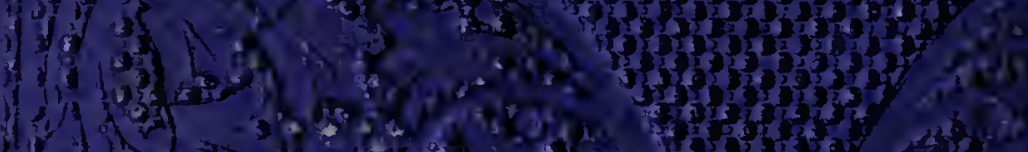

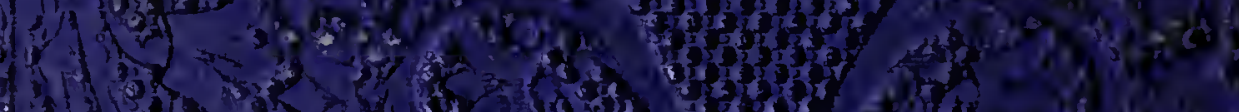

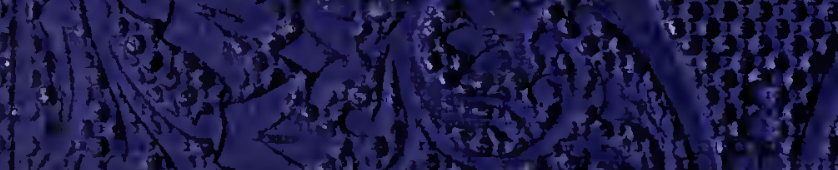

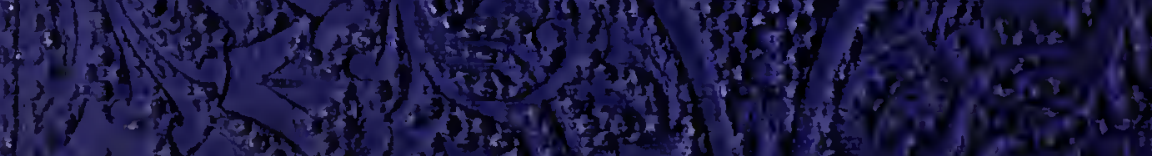

(1)

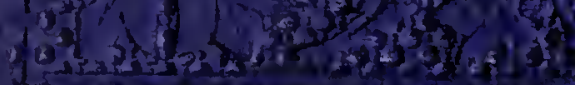

